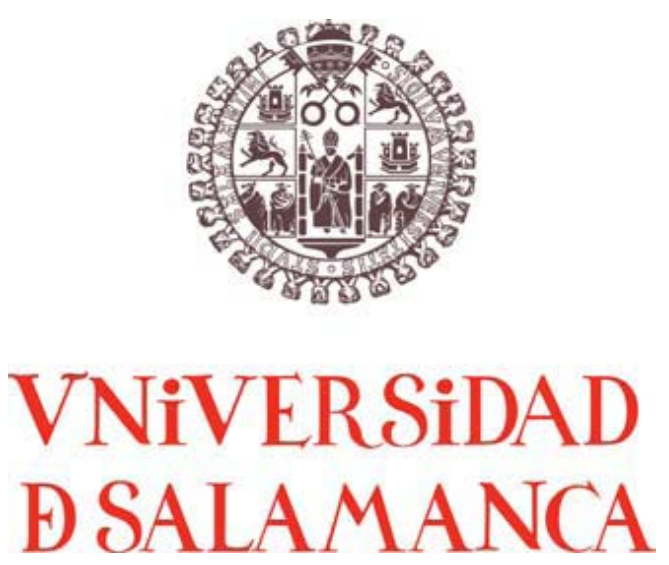

Departamento de Geología

\title{
Registro del plancton silíceo y calcáreo en trampas de sedimento del Mediterráneo Occidental durante el período 1993-2006
}

Andrés Salvador Rigual Hernández

Tesis doctoral

Salamanca, Enero del 2011 



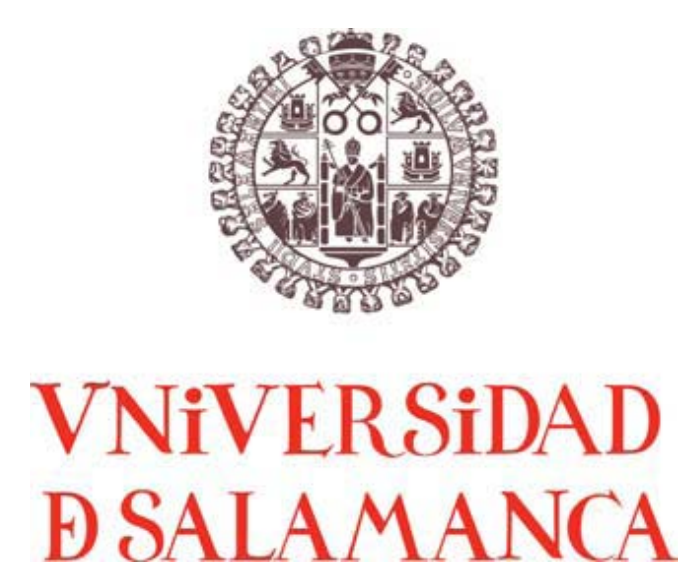

Departamento de Geología

\begin{abstract}
Registro del plancton silíceo y calcáreo en trampas de sedimento del Mediterráneo Occidental durante el período 1993-2006
\end{abstract}

Memoria presentada por Andrés Salvador Rigual Hernández para optar al grado de Doctor en Ciencias Geológicas por la Universidad de Salamanca

Directores de la Tesis:

Dra. María Ángeles Bárcena Pernía

Profesora titular del Departamento de Geología (Paleontología)

Facultad de Ciencias

Universidad de Salamanca

Dr. Francisco Javier Sierro Sánchez

Catedrático del Departamento de Geología (Paleontología)

Facultad de Ciencias

Universidad de Salamanca

Dr. José Abel Flores Villarejo

Catedrático del Departamento de Geología (Paleontología)

Facultad de Ciencias

Universidad de Salamanca 

Dra. Dña. María Ángeles Bárcena Pernía, Dr. D. Francisco Javier Sierro y Dr. D. José Abel Flores Villarejo, profesores del Área de Paleontología en el Departamento de Geología de la Facultad de Ciencias (Universidad de Salamanca)

CERTIFICAN que:

Andrés Salvador Rigual Hernández ha realizado en el Departamento de Geología de la Universidad de Salamanca y bajo nuestra supervisión, el trabajo:

"Registro del plancton silíceo y calcáreo en trampas de sedimento del Mediterráneo Occidental durante el período 1993-2006”

Y para que conste, firmamos el presente certificado en Salamanca, en Enero de 2009

Los directores:

María Ángeles

Bárcena Pernía

El doctorando
Francisco Javier

Sierro Sánchez
José Abel

Flores Villarejo

Andrés Salvador Rigual Hernández 
La realización de esta Tesis ha sido posible gracias a la concesión de la beca predoctoral AP2006- 01992 del programa Nacional de Formación de Profesorado Universitario (FPU) del Ministerio de Educación y Ciencia, y a la financiación obtenida por los proyectos GRACCIE (CONSOLIDER-INGENIO CSD 2007-00067), CGL 2006-10593, CGL 2008-05560 and CGL 2009-08651 del Ministerio de Ciencia y Tecnología y GR34 de la Junta de Castilla y León. Adicionalmente se ha obtenido financiación de la Universidad de Salamanca a través del Programa de Difusión de Resultados de la Agencia de Investigación. 




\section{RESUMEN}

Las diatomeas y los silicoflagelados son organismos unicelulares que conforman la mayor parte del fitoplancton silíceo marino. Mientras que las diatomeas son uno de los grupos de fitoplancton más abundantes y están consideradas como uno de los principales productores primarios del océano, los silicoflagelados son un grupo minoritario que sólo alcanza altas concentraciones en aguas estuarinas y costeras. Las diatomeas juegan un importante papel en los ciclos biogeoquímicos del carbono y de la sílice debido a su capacidad fotosintetizadora, su exoesqueleto silíceo y su capacidad de agregación y rápido hundimiento. Por su parte, los foraminíferos planctónicos son organismos unicelulares que forman parte de las comunidades de zooplancton en el medio marino y que presentan la capacidad de sintetizar conchas calcíticas susceptibles de fosilizar. La abundancia y distribución de las asociaciones de foraminíferos actuales, así como la composición química de su concha, están íntimamente relacionadas con las condiciones ambientales de las masas de agua donde habitan.

Los esqueletos silíceos y calcáreos de estos tres grupos de organismos planctónicos han sido ampliamente utilizados para llevar a cabo reconstrucciones paleoclimáticas y paleoceanográficas a través del registro fósil. Sin embargo, para alcanzar conclusiones fiables a través de estos marcadores, es necesario el conocimiento de la ecología de sus representantes actuales. En este sentido las trampas de sedimento son una herramienta útil que nos permite monitorizar los flujos de plancton en océano abierto durante largos períodos de tiempo, proporcionándonos una valiosa información sobre los ciclos de productividad superficial, disolución, descomposición y transporte sedimentario.

El Mediterráneo ha sido objeto de numerosos estudios sobre la composición y dinámica de las asociaciones de fito- y zooplancton, no obstante, la mayor parte de estos trabajos se ha basado en el estudio de muestras de la columna de agua y su duración raras veces ha sido plurianual. Con esta tesis se pretende mejorar el conocimiento sobre algunos de los principales grupos plancton silíceo y calcáreo del Mediterráneo a través del estudio de varios registros procedentes de trampas de sedimento dispuestas en el Mediterráneo Occidental. Las trampas estudiadas en este trabajo han sido desplegadas en algunas de las zonas más productivas del Mediterráneo, tales como mar de Alborán (dos registros de un año de duración), margen continental catalán (un registro de un año de duración) y golfo de León (dos registros de 12 años de duración). Las trampas de Alborán y del margen continental catalán fueron únicamente empleados para el estudio de silicoflagelados, mientras que para el golfo de León se han estudiado los flujos de diatomeas, silicoflagelados y foraminíferos planctónicos. Gracias a los dos registros de excepcional duración del golfo de León se ha podido abordar el estudio de la variabilidad interanual de estos grupos de microplancton y su relación con fenómenos climáticos de periodicidad plurianual como la Oscilación del Atlántico Norte (NAO) y El Niño Southern Oscillation (ENSO), así como con fenómenos estocásticos tales como la ola de calor sobre Europa de 2003.

El primer trabajo presentado en esta tesis tiene como objetivo principal describir la composición 
de las asociaciones de los flujos diatomeas en el Mediterráneo Noroccidental, así como sus patrones generales de distribución estacional. Para ello se calculó un año medio a partir de los doce años de registro disponibles de la trampa de sedimento de Planier, situada en el extremo noreste del golfo de León. Fueron identificados un total de 126 taxones que presentaron sus máximos flujos en diferentes momentos del ciclo anual en función de sus características morfológicas y fisiológicas. De forma general, tras la mezcla invernal primero se desarrollaron diatomeas oportunistas, de pequeño tamaño y rápido crecimiento que fueron reemplazadas de forma gradual por taxones más grandes, de crecimiento más lento y mejor adaptados a condiciones de estratificación (ejemplo, Skeletonema-Chaetoceros-Rhizosolenia). Asimismo, los principales taxones identificados en este estudio se ilustran en 13 láminas de fotografías de microscopía óptica y electrónica.

Un segundo estudio de este manuscrito es el del análisis de la variabilidad estacional e interanual de los flujos de diatomeas, cocolitos y de material en la estación de Planier en el golfo de León. El bloom primaveral de diatomeas parece desarrollarse con especial intensidad los años de fuerte mezcla invernal y baja intensidad de vientos al comienzo de la primavera. Los flujos de cocolitos mostraron un patrón interanual más estable que las diatomeas y presentaron sus flujos máximos los años de poca productividad de diatomeas, lo que sugiere una posible competición entre los dos grupos de fitoplancton. No se encontró una relación directa entre los flujos de fitoplancton y la NAO, sin embargo, el evento ENSO de 1997-98 y la ola de calor de 2003, tuvieron repercusiones en la composición y desarrollo del bloom de primavera de 1998 y 2004, respectivamente. Además, en un anexo al final esta sección, se discute el posible papel del fitoplancton en la sedimentación del material particulado de la columna de agua durante el inicio de la primavera.

En lo referente a los silicoflagelados, fueron estudiadas un total de 337 muestras procedentes de cinco trampas de sedimento dispuestas a lo largo de un transecto Norte-Sur del Mediterráneo Occidental. El principal objetivo de este estudio fue el de analizar la variabilidad estacional, interanual y geográfica de los flujos de silicoflagelados en estas áreas del Mediterráneo Occidental. En general, los flujos máximos de silicoflagelados ocurrieron en la transición invierno-primavera coincidiendo con el periodo de máxima productividad primaria, mientras que los flujos mínimos fueron registrados durante el verano, coincidiendo con el periodo de mayor estratificación y menor concentración de clorofila- $a$. No se encontró ninguna relación directa entre el comportamiento de la NAO y los flujos de silicoflagelados, sin embargo, las condiciones ambientales anómalas generadas por el evento ENSO 1997-98 y la ola de calor de 2003 posiblemente determinaron los bajos flujos de silicoflagelados registrados durante las primaveras de 1998 y 2004. Se identificaron tres especies de silicoflagelados: Dictyocha fibula, dominante en todos los registros (>80\%); Dictyocha speculum, sólo está presente en los registros procedentes del golfo de León, lo que sugiere una afinidad por aguas relativamente frías; y Octactis octonaria cuya distribución está restringida al mar de Alborán donde las temperaturas alcanzan los valores más elevados de las cinco áreas de estudio. 
El último apartado de esta tesis está dedicado al estudio de los foraminíferos planctónicos. Para ello se analizaron 266 muestras procedentes de las trampas de sedimento del golfo de León y un total de 13 muestras de sedimento superficial recogidas en diferentes zonas del margen continental. Fueron identificadas un total de 11 especies de foraminíferos planctónicos, sin embargo, sólo cuatro dominaron las asociaciones: Globigerina bulloides, Neogloboquadrina pachyderma (dex.), Globorotalia inflata y Globorotalia truncatulinoides. Los flujos máximos anuales de foraminíferos ocurrieron durante el bloom de primavera y los mínimos durante el verano. Al igual que con el resto de grupos de plancton estudiados, no se observó una clara relación de los flujos de foraminíferos con el estado de la NAO, sin embargo, durante la primavera de 1998 se registraron flujos bajos de foraminíferos en las dos estaciones probablemente causados por las condiciones generadas por el evento ENSO 1997-98. En lo referente a la distribución de las asociaciones de foraminíferos en el sedimento superficial, G. bulloides fue la especie dominante en las zonas con mayor aporte de nutrientes mientras que $N$. pachyderma dominó en el resto.

\section{Palabras clave}

Diatomeas, silicoflagelados, foraminíferos planctónicos, cocolitóforos, trampas de sedimento, coretops, Sea-WIFS, SST, Mediterráneo Noroccidental, golfo de León, técnicas de preparación de muestras, análisis factorial, análisis espectral, NAO, ENSO, ola de calor de 2003. 



\section{ABSTRACT}

Diatoms and silicoflagellates are unicelular organisms that make up most of the marine siliceous phytoplankton. While diatoms are one of the most abundant phytoplankton group, regarded as one of the most important primary producers within the ocean, silicoflagellates are a minor group that only reaches high concentrations in estuarine and coastal waters. Diatoms play an important role in the silica and carbon cycles owing to its ability to photosynthesize, its silica skeleton and its capacity to form mass aggregates which rapidly sink to the seabed. On the other hand, planktonic foraminifera are unicellular organisms that form part of the marine zooplankton communities and have the ability to synthesize shells of calcite that can be preserved in the sediment. The abundance and composition of the modern day foraminiferal assemblages, as well as the chemical composition of their shell are intimately related to the environmental conditions of the water masses where they live.

The fossil record of the siliceous and calcareous skeletons of these three groups of planktonic organisms has been widely used to make paleoclimatic and paleoceanographic reconstructions. However, In order to correctly interpret the meaning of this fossil record, it is fundamental to understand the ecology of the living representatives of these planktonic groups. In this sense, sediment traps are a useful tool that allows us to monitorize the plankton fluxes in open ocean areas during long time periods, providing valuable information about the superficial productivity cycles, dissolution, decomposition and sediment transport.

The Mediterranean has been object of several studies about the composition and dynamics of the phyto- and zoo- plankton assemblages, nonetheless, most of these works are based on samples from the water column and rarely cover periods longer than one year.

In this $\mathrm{PhD}$ thesis, we attempt to improve the knowledge about some of the most important siliceous and calcareous plankton groups of the Mediterranean through the study of several sediment trap records from different areas of the Western Mediterranean. The sediment traps analyzed in this work have been deployed in some of the most productive regions of the Mediterranean, such as the Alboran Sea (two one-year records), the Catalan continental margin (a one-year record), and Gulf of Lions (two 12-year record). The sediment traps from the Alboran Sea and the Catalan continental margin were only used for the silicoflagellate analysis, while for the Gulf of Lions records, diatoms, silicoflagellates and planktonic foraminifera were studied. The two exceptional long records of the Gulf of Lions permitted the study of the interannual variability of these microplankton groups and its relationship with climatic phenomena with a longer-than-one-year periodicity such as the North Atlantic Oscillation (NAO), El Niño Southern Oscillation (ENSO) and stochastic events such as the 2003 heat wave over Europe. The main objective of the first section presented in this thesis was to describe the composition of the diatom sinking assemblages in the Northwestern Mediterranean, as well as their general distribution patterns. To do so, an average year was compiled from the 12-year-long sediment trap records of the Planier site, in northeastern part of the Gulf of Lions.

The annual diatom assemblage was composed of 126 taxa that exhibit a wide range of 
morphological and physiological characteristics, allowing them to thrive in different moments of the annual cycle of the water column. As a general trend, after the winter mixing, small, fast-growing and opportunistic diatoms appear in the water column that later-on are gradually replaced by larger and slower-growing diatoms that are better adapted to stratified waters and oligotrophic conditions (e.g. Skeletonema-Chaetoceros-Rhizosolenia). In addition, the main diatom species are presented in 13 plates of SEM and LM photographs.

A second study presented in this manuscript is the analysis of the seasonal and interannual variability of the fluxes of diatoms, coccoliths and bulk compounds in the Planier station in the Gulf of Lions.

The intensity of the annual diatom spring blooms seems to be enhanced those years with strong winter mixing and low wind stress during the beginning of the spring. Coccolith fluxes showed a more stable interannual pattern than diatoms, often exhibiting maximum values during years of low diatom productivity, suggesting a possible competition between the two groups. No straightforward relationship was found between the North Atlantic Oscillation (NAO) and phytoplankton skeleton fluxes. Nevertheless, other phenomena such as the 1997-98 El Niño Event and the 2003 summer heat wave over the Western Mediterranean had remarkable consequences on the composition and timing of the phytoplankton spring bloom. Addtionally, the biological control of the sedimentation during the beginning of spring is discussed.

Regarding silicoflagellates, a total of 337 samples collected from five sediment traps deployed along a North-South transect of the Western Mediterranean Sea were studied. The main objective of this study was to analyze the seasonal to interannual variability and geographic distribution of the silicoflagellate fluxes in the Western Mediterranean.

As a general trend, maximum fluxes of silicoflagellates occurred during the winter-spring transition, coinciding with the period of maximum primary productivity, while minimum fluxes were recorded during summer, that are characterized by a-strong stratification and low productivity. No clear relationship between the NAO and the silicoflagellate fluxes was found, however, the anomalous conditions elicited by the 1997-98 El Niño Event and the 2003 summer heat wave probably caused the low silicoflagellate fluxes during spring 1998 and 2004, respectively.

Three silicoflagellate species were identified: Dictyocha fibula that is the dominant species at all sites (>80\%); Dictyocha speculum, that is only recorded in the Gulf of Lions, which suggests an affinity for relatively cold waters; and Octactis octonaria which distribution is restricted to the Alboran Sea where temperatures are the highest of all studied sites.

The last section of this thesis is dedicated to the study of the planktonic foraminifera of the Northwestern Basin. A total of 266 (sediment trap) samples collected by the sediment traps of the Gulf of Lions and 13 surface sediment samples recovered from different areas of the continental margin were analyzed. Eleven planktonic foraminifera species were identified, nevertheless just four species are dominant in the assemblages: Globigerina bulloides, Neogloboquadrina 
pachyderma (dex.), Globorotalia inflata and Globorotalia truncatulinoides. Total foraminifer flux maxima occurred during the spring bloom and minima during summer. No relationship was found between the NAO (North Atlantic Oscillation) and the planktonic foraminifer fluxes in the sediment trap records, however, the low planktonic foraminifer fluxes recorded during the spring 1998 probably are related to the anomalous environmental conditions triggered by the 1997-98 El Niño Event. Furthermore, discrepancies between sediment traps and sediment samples and the application of these results in further paleoceanographic reconstructions are discussed.

\section{Key words}

Diatoms, silicoflagellates, planktonic foraminifera, coccoliths, sediment traps, core tops, SeaWIFS, SST, Western Mediterranean, Gulf of Lions, simple preparation techniques, NAO, ENSO, 2003 summer heat wave. 



\section{AGRADECIMIENTOS}

En primer lugar, me gustaría agradecer a los profesores María Ángeles Bárcena, Francisco Javier Sierro y José Abel Flores Villarejo haberme brindado la oportunidad de formar parte del Grupo de Geociencias Oceánicas de la Universidad de Salamanca y realizar la tesis bajo su supervisión. Muchas gracias Lines por toda tu ayuda y apoyo a lo largo de estos años y por haberte dejado convencer cuando te pedía que me dejases ir de estancia. También quiero agradecer a Paco todo el tiempo que me ha dedicado para discutir mis resultados, para responder mis preguntas y por darme ánimos cuando se complicaba alguna publicación. Quiero dar las gracias a Abel por haber diseñado un proyecto de tesis a mi medida y $\tan$ interesante, por encontrar siempre tiempo para responder mis dudas y por motivarme en mi investigación. Por supuesto no quiero olvidarme de Elena, la nueva profe, que me ha ayudado siempre que se lo he pedido, especialmente en mi contribución al proyecto SVAIS.

I would like to address special thanks to Richard Jordan, for his good cares during my stay in Yamagata, all his help and good advices every time I needed them.

I would also like to thank Serge Heussner for the confidence he put in me to study his valuable samples and his help while writing my manuscripts. Nicole, for her help during the sampling process and all the problems involved. Thanks a lot to Anna for introducing me in the world of sediment traps and for her support in Perpignan. Also to Xavier Durrieu de Madron for his kidness and his classes about the Gulf of Lions.

I would like to thank Anne de Vernal for offering me the possibility to work with the GEOTOP research team and receiving me in Montreal. Also to Maryse Henry, for teaching me the dinocyst taxonomy and how to play with the fluorhidric acid. And to Sophie y Sergio for welcoming me in the department. Thanks to W.G. Deuser, for his advice and the original papers he kindly sent me.

Thanks to the people of the RCOM center, for introducing me into the field of oceanography during my short stay in Bremen.

Quiero agradecer a mis padres, a mi hermano y a toda mi familia el apoyo incondicional que siempre me han brindado para seguir adelante con mis estudios y con cualquier tipo de problema. También quisiera agradecer a Mieke estar siempre conmigo y ayudarme en todo lo posible. Sin vosotros no hubiera sido capaz de acabar esta tesis.

También quiero dar las gracias a todos mis compañeros del área sin los cuales el trabajo hubiera sido mucho más duro: a Mariem, la aventurera de los polos, siempre me has ayudado por mucho trabajo que tuvieses, a Margarita por alegrar siempre nuestro despacho con su buen humor, a Deb por todos los momentos divertidos que nos ha hecho pasar, a Aleix por ayudarme con los análisis estadísticos y por ser un buen compañero de juerga, a Iván por su ayuda con mi muestreo en Perpignan y su buen humor. Y a todos los demás (Eloy, Montse, Alejandra, Gastby,...) por haberme ayudado de un modo u otro en mi trabajo y por haber contribuido a crear un entorno de trabajo agradable que seguro echaré de menos en el futuro. También quiero agradecer a José Ignacio y a Chuchi por el buen ambiente que crean en el microlaboratorio y su compañía durante la "artesanal" preparación de mis muestras. No quiero olvidarme de los compañeros de otras áreas como Antonio (el isótopo) y Diego (estrati) con los que he pasado buenos momentos. 
Por supuesto quiero dar las gracias a todos mis amigos con los que he compartido la maravillosa y divertida mansión Pastores 17 sin los cuales los años de doctorado hubieran sido aburridos: Manu, Alex, Diego, Pelos, Quique, Félix, Isaac, Pablo "bird is the word", Gonzalo, Markus, Valentine, Marek,...y Pilar que es una más en nuestra casa. Por supuesto a todos mis buenos amigos del Hernán: Fernando, Raquel, Kenet, Edu, Pepe, María, Bea, Antonio y todos los demás que no son menos importantes por no haber sido nombrados. Y mis buenos amigos de la carrera Hugo, Charly, Sheila, Anita y toda nuestra clase, gracias a los cuales desearía que biología hubiese durado muchos más años. También a mis amigos de Palencia de toda la vida, que por mucho tiempo que estuviese fuera siempre me han recibido con los brazos abiertos: Jesús y el campamento Kikari, Conde, Oscar, Narcispoup, Borch, Pelef, Ángel, José,...

Por último y no por ello más importante a todo el mundo con los que he compartido esos buenos ratos en Salas Bajas jugando al baloncesto, a los Legends y a mi entrenador Juan Carlos por enseñarme que el esfuerzo tiene recompensa.

Muchas gracias a todos 
The Mediterranean, or at least its pelagic zone, would be like a marine version of the Amazon forest.

Ramón Margalef, 1995 



\section{Índice}

1.1 PRESENTACIÓN Y JUSTIFICACIÓN DE LA TESIS

1.1.1 Introducción

1.1.2 Marco particular

1.1.3 Trampas de sedimento

1.1.4 Presentación de la tesis

1.2. OBJETIVOS

1.2.1 Objetivos generales

1.2.2 Objetivos particulares

1.2.3 Artículos que constituyen esta tesis

CAPÍTULO 2: CIRCULACIÓN ATMOSFÉRICA Y OCEÁNICA

2.1 EL MAR MEDITERRÁNEO

2.1.1 Fisiografía

2.1.2 Meteorología y climatología

2.1.3 Hidrodinámica

2.1.4 Productividad en el mediterráneo 20

2.2 EL MAR DE ALBORÁN

2.2.1 Fisiografía e hidrodinámica

2.2.2 Productividad en el mar de Alborán $\quad 22$

2.3 EL MAR CATALANO-BALEAR

2.3.1 Fisiografía e hidrodinámica 23

2.3.2 Productividad en el mar Catalano-Balear 24

2.4 EL GOLFO DE LEÓN 24

2.4.1 Fisiografía 24

2.4.2 Meteorología $\quad 25$

2.4.3 Hidrodinámica $\quad 26$

2.4.4 Formación de aguas profundas 30

2.4.5 Productividad del golfo de León $\quad 32$

2.5 DINÁMICA DE LA NAO 36

2.5.1 El caso particular del Mediterráneo Noroccidental 38

2.6 DINÁMICA DEL ENSO 40

2.6.1 El evento El Niño 1997-98 y su efecto sobre el mediterráneo occidental 43

CAPÍTULO 3: MATERIAL Y MÉTODOS

3.1
TRAMPAS DE SEDIMENTO

3.1.1 Definición $\quad 47$

3.1.2 Estructura de la línea de muestreo (mooring) $\quad 47$

3.2 DESCRIPCIÓN DEL EXPERIMENTO 49

3.2.1 Golfo de León $\quad 49$

3.2.2 Margen continental Catalán $\quad 51$

3.2.3 Mar de Alborán $\quad 51$

3.2.3 Material analizado $\quad 52$

3.2.4 Core tops

3.3 PROCESAMIENTO DE LAS MUESTRAS $\quad 53$

3.3.1 Consideraciones preliminares 53 
3.3.2 Procesamiento de las muestras 54

3.3.3 Técnicas de preparación de muestras en lámina delgada para su estudio en 57 microscopia óptica

3.4 CONSIDERACIONES DEL RECUENTO 57

3.4.1 Analisis de foraminíferos $\quad 57$

3.4.2 Analisis de diatomeas y silicoflagelados (fracción $<63 \mu \mathrm{m}$ ) 58

3.4.3 Microscopía electrónica $\quad 58$

3.5 BASES DE DATOS COMPLEMENTARIAS 58

3.5.1 Datos biogeoquímicos 58

3.5.2 Concentración de clorofila $\quad 59$

$\begin{array}{ll}\text { 3.5.3 Variables ambientales } & 59\end{array}$

$\begin{array}{ll}\text { 3.6 TRATAMIENTO DE LOS DATOS } & 60\end{array}$

$\begin{array}{ll}\text { 3.6.1 Contribución relativa } & 60\end{array}$

3.6.2 Cálculo del flujo de microfósiles $\quad 60$

3.6.3 Índices de diversidad $\quad 61$

3.6.4 Análisis de componentes principales 61

CAPÍTULO 4: ECOLOGÍA DE LAS DIATOMEAS Y SILICOFLAGELADOS

4.1 ECOLOGÍA DE LAS DIATOMEAS $\quad 65$

4.1.1 Introducción $\quad 65$

$\begin{array}{ll}\text { 4.1.2 Las diatomeas y ciclo de la sílice } & 68\end{array}$

4.1.3 Principales grupos ecológicos $\quad 69$

4.1.4 Consideraciones ecológicas de las principales especies del golfo de León 72

4.1.5 La sucesión ecológica en el Mediterráneo $\quad 75$

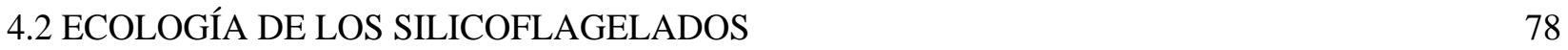

$\begin{array}{ll}\text { 4.2.1 Introducción } & 78\end{array}$

$\begin{array}{ll}\text { 4.2.2 Taxonomía } & 78\end{array}$

4.2.3 Ecología de las especies de silicoflagelados del mediterráneo occidental 80

CAPÍTULO 5: ECOLOGÍA DE LOS FORAMINÍFEROS PLANCTÓNICOS 81

$\begin{array}{ll}5.1 \text { INTRODUCCIÓN } & 83\end{array}$

5.2 DISTRIBUCIÓN VERTICAL, HORIZONTAL Y ESTACIONAL $\quad 84$

5.3 CARACTERÍSTICAS ECOLÓGICAS DE LAS ESPECIES

5.4 ECOLOGÍA GENERAL DE LOS FORAMINÍFEROS EN EL GOLFO DE LEÓN 91

CAPÍTULO 6: ANNUAL SUCCESSION OF DIATOM ASSEMBLAGES

IN THE NORTHWESTERN MEDITERRANEAN SEA BASED ON

\begin{tabular}{ll} 
A 12-YEAR-LONG SEDIMENT TRAP RECORD & 93 \\
\hline
\end{tabular}

6.1 INTRODUCTION $\quad 96$

6.2 STUDY AREA $\quad 96$

6.3 MATERIALS AND METHODS $\quad 97$

$\begin{array}{ll}\text { 6.3.1 General processing } & 97\end{array}$

6.3.2 Siliceous microplankton sample preparation and analysis 98

6.3.3 Sea surface temperature and chlorophylla data sets 98

$\begin{array}{ll}\text { 6.3.4 Diatom valve fluxes and diversity index calculation } & 98\end{array}$

$\begin{array}{ll}6.4 \text { RESULTS } & 99\end{array}$

6.5 DISCUSION 101

$\begin{array}{ll}\text { 6.5.1 General considerations } & 101\end{array}$

6.5.2 Diatom succession in the Gulf of Lions 101 
6.5.3 Benthic and fresh water diatoms 106

$\begin{array}{ll}\text { 6.6 CONCLUSIONS } & 107\end{array}$

6.7 APPENDIX A. TAXONOMIC APPENDIX. 107

6.8 PLATES 111

CAPÍTULO 7: SEASONAL AND INTERANNUAL VARIABILITY OF DIATOM

AND COCCOLITH FLUXES IN THE NORTHWESTERN MEDITERRANEAN:

A 12-YR SEDIMENT TRAP RECORD.

125

$\begin{array}{ll}7.1 \text { INTRODUCTION } & 128\end{array}$

7.2 REGIONAL SETTING $\quad 129$

7.3 MATERIAL AND METHODS 129

$\begin{array}{ll}\text { 7.3.1 Field experiment } & 129\end{array}$

7.3.2 General processing of the sediment traps 130

7.3.3 Specific treatment for siliceous microplankton and calcareous nannoplankton $\quad 130$

7.3.4 Additional data sets on environmental variables 131

7.3.5 Principal Component Analysis (diatoms) 133

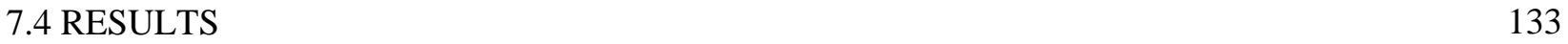

7.4.1 Total particle flux 133

7.4.2 Correlation analysis 133

7.4.3 Seasonal to interannual variations in total diatom and coccolith fluxes. 134

7.4.4 Principal Components Analysis (PCA) 135

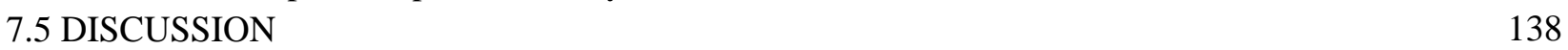

7.5.1 Sources and preservation of trap-collected phytoplankton in the Planier Canyon $\quad 138$

$\begin{array}{ll}\text { 7.5.2 Seasonal siliceous and calcareous phytoplankton flux variability } & 141\end{array}$

7.5.3 Wind-driven interannual fluctuations of the diatom and coccolith fluxes 143

7.5.4 Impact of NAO and ENSO variability on phytoplankton skeletons fluxes 145

$\begin{array}{ll}7.6 \text { CONCLUSIONS } & 147\end{array}$

$\begin{array}{ll}7.7 \text { OTHER CONSIDERATIONS } & 149\end{array}$

CAPÍTULO 8: SEASONAL TO INTERANNUAL VARIABILITY AND

GEOGRAPHIC DISTRIBUTION OF THE SILICOFLAGELLATE FLUXES

IN THE WESTERN MEDITERRANEAN.

8.1 INTRODUCTION 156

8.2 OCEANOGRAPHIC SETTING 157

8.2.1 Gulf of Lions 158

$\begin{array}{ll}\text { 8.2.2 Catalan margin } & 159\end{array}$

$\begin{array}{ll}\text { 8.2.3 Alboran Sea } & 159\end{array}$

8.3 MATERIAL AND METHODS 160

$\begin{array}{ll}\text { 8.3.1 Field experiments } & 160\end{array}$

8.3.2 General processing of the sediment traps 163

8.3.3 Specific treatment for siliceous microplankton 163

8.3.4 Environmental variables 163

8.4 RESULTS 163

8.4.1 General considerations 163

8.4.2 Gulf of Lions 164

8.4.3 Catalan Margin $\quad 164$

$\begin{array}{ll}\text { 8.4.4 Alboran Sea } & 165\end{array}$

8.5 DISCUSION 166

8.5.1 Biological and physical processes controlling the seasonal changes of the 
$\begin{array}{ll}\text { silicoflagellate fluxes } & 166\end{array}$

8.5.2 Impact of NAO and ENSO variability on silicoflagellate fluxes 168

8.5.3 Geographic distribution of the Western Mediterranean silicoflagellates $\quad 170$

8.6 CONCLUSIONS 172

CAPÍTULO 9: SEASONAL AND INTERANNUAL CHANGES OF PLANKTONIC

FORAMINIFER FLUXES IN THE GULF OF LIONS (NW MEDITERRANEAN)

AND THEIR IMPLICATIONS FOR PALEOCEANOGRAPHIC STUDIES:

TWO 12-YEAR SEDIMENT TRAP RECORDS.

$\begin{array}{ll}9.1 \text { INTRODUCTION } & 180\end{array}$

9.2 OCEANOGRAPHIC SETTING 181

9.3 MATERIAL AND METHODS 182

9.3.1 Field experiment 182

9.3.2 Core tops 182

9.3.3 General processing of the sediment trap and core top samples 182

9.3.4 Satellite imagery, meteorological and oceanographic data 185

$\begin{array}{ll}\text { 9.3.5 Spectral analysis } & 186\end{array}$

9.4. RESULTS 186

9.4.1 Total planktonic foraminiferal flux 186

$\begin{array}{ll}\text { 9.4.2 Foraminiferal assemblages } & 186\end{array}$

$\begin{array}{ll}\text { 9.4.3 Core tops } & 187\end{array}$

9.5 DISCUSSION 189

9.5.1 Sources and preservation of trap-collected planktonic foraminifers 189

$\begin{array}{ll}\text { 9.5.2 Seasonal and geographical flux variability } & 189\end{array}$

9.5.3 Interannual planktonic foraminifer fluctuations 190

9.5.4 Foraminifer faunal composition in the sediment trap records 192

9.5.5 Sediment traps versus sediments: implications for paleorecontructions 195

$\begin{array}{ll}9.6 \text { CONCLUSIONS } & 197\end{array}$

$\begin{array}{ll}\text { CONCLUSIONES } & 199\end{array}$

APÉNDICE

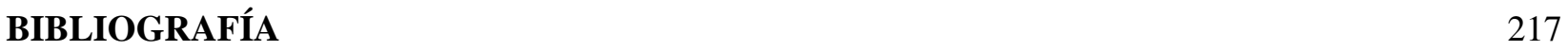


Capítulo 1

Introducción 



\subsection{PRESENTACIÓN Y JUSTIFICACIÓN DE LA TESIS}

\subsubsection{INTRODUCCIÓN}

En la actualidad se debaten ampliamente los cambios climáticos predichos en los últimos informes del Panel Internacional sobre el Cambio Climático (IPCC; 2001 y 2007), que se fundamentan en las posibles consecuencias del aumento de los gases de efecto invernadero en nuestro planeta y los efectos que éste pueda tener sobre la población mundial. Se prevé una variación de la temperatura media global entre los 1.4 y $5.8^{\circ} \mathrm{C}$, en función de la población y la emisión del $\mathrm{CO}_{2}$ y partículas sólidas a la atmósfera. Igualmente los cambios en el nivel del mar, así como en el régimen pluviométrico, tendrán una repercusión importante en el planeta.

Los pronósticos emitidos por el IPCC para el área mediterránea son bastante alarmantes, especialmente debido a su condición de zona fronteriza entre el clima desértico del norte de África y el templado y húmedo de la Europa atlántica y central. Además de esto, durante la última década han tenido lugar modificaciones importantes, con periodos de sequía prolongada en el sur y lluvias persistentes en Europa central. Estas predicciones son el resultado de un amplio debate dentro de la comunidad científica basado en la extrapolación de los modelos climáticos elaborados para el Holoceno, partiendo de la suposición de un clima fuertemente estable que presentará una cierta deriva a partir de las condiciones actuales. En efecto, durante el Holoceno el clima de nuestro planeta se ha caracterizado por una relativa estabilidad, tal como se refleja, en la composición isotópica $\delta^{18} \mathrm{O}$ de los hielos de Groenlandia (Fig. 1), en contraposición con la variabilidad climática registrada para los periodos glaciares.

En este sentido, desde los años 90, el Grupo de Geociencias Oceánicas (GGO) de la Universidad de Salamanca en colaboración con otros grupos de investigación han puesto de manifiesto oscilaciones climáticas identificadas como ciclos Dansgaard-Oeschger (D-O) muy relevantes en el Mediterráneo Occidental, afectando a la entrada de agua superficial atlántica, a la temperatura superfi cial de las aguas, y a las comunidades planctónicas, tanto en el mar de Alborán como en la región del golfo de León (Cacho et al., 1999; Bárcena et al., 2001; Sánchez-Goñi et al., 2002; Colmenero-Hidalgo et al., 2004). Los cambios abruptos D-O no sólo han sido relevantes a nivel de la hidrodinámica de las aguas mediterráneo-atlánticas sino que también se han manifestado como variaciones abruptas en el clima de la Península Ibérica (Sánchez-Goñi et al., 2002).

Pese a la relativa estabilidad del Holoceno, éste es un periodo que se caracteriza por rápidas fluctuaciones climáticas reconocidas en ambos hemisferios, tanto en registros continentales como marinos (Domack and Mayewsky, 1999; Hodell et al., 2001). El registro interhemisférico de eventos neoglaciales apunta hacia patrones astronómicos como responsables de estos cambios climáticos, que serían los responsables de conexiones entre el sistema atmósfera-hidrosferacriosfera. Muchos son ya los estudios que han propuesto la actividad solar y la variación en el número e intensidad de las manchas solares, con un ritmo de 250 años, como los responsables de estas oscilaciones climáticas (Leventer et al., 1996). La actividad eruptiva solar influye de manera determinante en el clima global, de tal modo que una mayor actividad solar implica una 
mayor velocidad en los vientos solares y ondas de choque que actúan como escudo protector magnético contra los rayos cósmicos. Así, una mayor actividad solar conduce a un incremento en las temperaturas, mientras que mínimos de actividad lleva a periodos más fríos. Esta actividad eruptiva del sol presenta variaciones cíclicas conocidas como ciclos Schawe (11 años) que se modulan generando ciclos mayores (Hale, 20-30 años y Gleissberg, 80-90 años) (Leventer et al., 1996). Igualmente hay que resaltar las implicaciones globales que fenómenos como el Niño puedan tener en la región del Mediterráneo occidental. En este sentido, Bárcena et al. (2004) y Hernández-Almeida et al. (2011) estudiaron una serie de trampas de sedimento del mar de Alborán para determinar la influencia estacional de los cambios oceanográficos. El periodo de muestreo coincidió con el evento El Niño más intenso del siglo XX (McPhaden, 1999), este fenómeno afectó a los patrones oceánicos del mar de Alborán, destacando una temperatura de las aguas superficiales anormalmente alta durante el otoño de 1997 (de más de $3^{\circ} \mathrm{C}$ por encima de su $\mathrm{T}^{\mathrm{a}}$ media) (García-Gorriz and Carr, 2001). Cuando se compararon los flujos anuales de las comunidades planctónicas recuperadas en las trampas con los sedimentos superficiales se observaron diferencias significativas entre ambas. Así pues, lo que se registró en las trampas de sedimento fue el resultado de una estacionalidad anómala inducida por el Evento El Niño, que se manifestó en una señal excepcional.

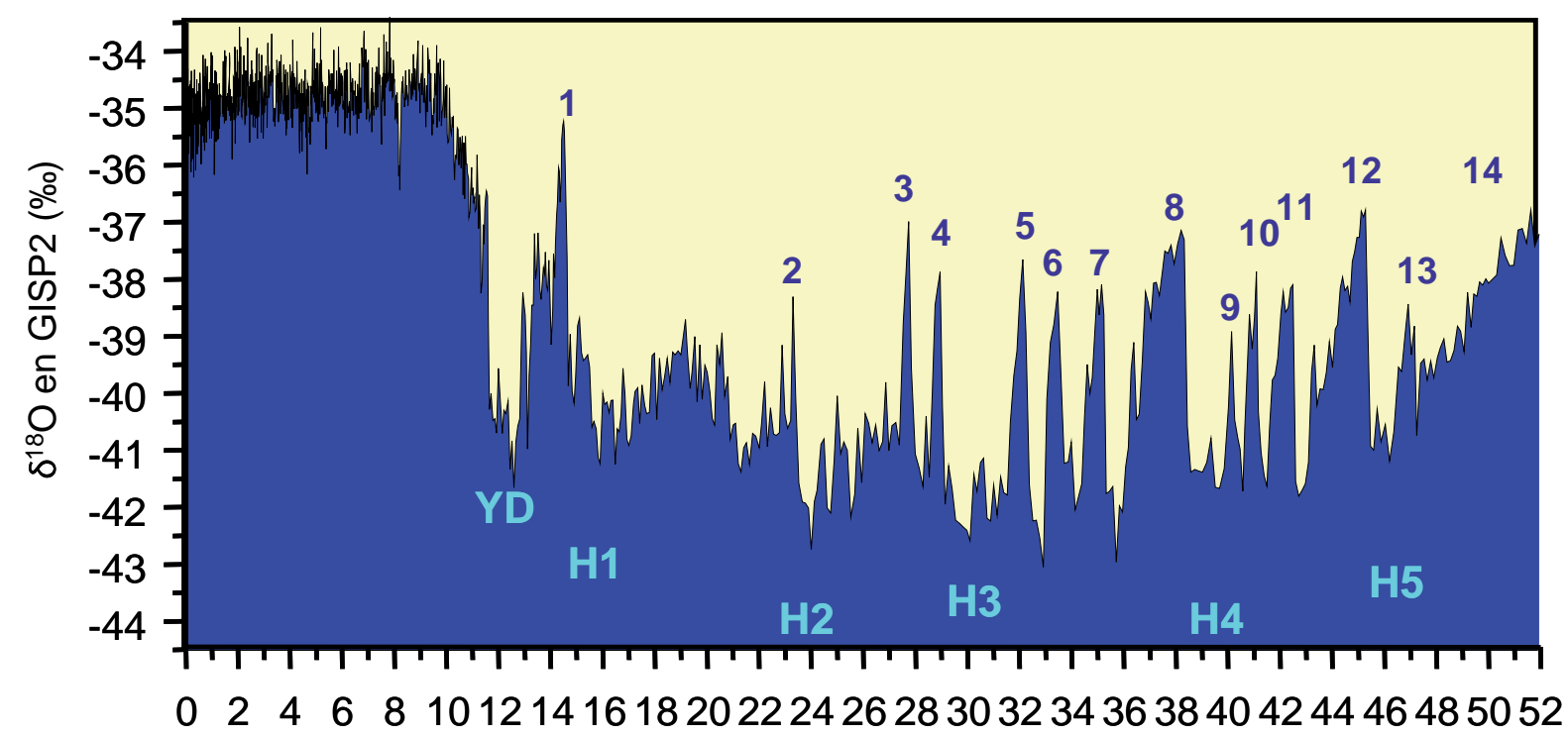

Figura 1. Registro $\delta 180$ de los hielos de Groenlandia (GRIP). Se observa el fuerte contraste entre la relativa estabilidad de la señal en el Holoceno y sus variaciones abruptas durante los estadios isotópicos 2, 3 y 4. Modificado de http://www.geo.arizona.edu/palynology/geos462/ 07nonmarin.html

Por ello es muy importante avanzar en la comprensión de los fenómenos que las generan. La necesidad de obtener resultados que puedan predecir dichos fenómenos es tanto más urgente cuanto en la actualidad nuestra civilización está introduciendo grandes cantidades de gases que tienen efecto invernadero y por tanto constituyen otra causa de variación de las condiciones climáticas. 


\subsubsection{MARCO PARTICULAR}

Lo expuesto anteriormente pone de manifiesto la necesidad del empleo de herramientas de reproductivilidad de ambientes y escenarios que posibiliten una aplicación actualista de los ambientes pretéritos. Así, las herramientas biológicas que por su composición mineralógica se preservan en los sedimentos son una herramienta fundamental sobre la que se sustentan los estudios paleoclimáticos. Su desarrollo es producto de la interacción de factores, tales como variaciones en la temperatura, características químicas del agua (incluyendo salinidad y disponibilidad y calidad de nutrientes), etc., que a su vez están afectados por la dinámica atmosférica, oceánica y climática globales. Aspectos como la estacionalidad, ritmos de producción y volúmenes de producción (y preservación), en relación a la variabilidad anteriormente expuesta, deben ser tenidos en cuenta a la hora de aplicar modelos. Una de las herramientas más empleadas para la reproducción de ambientes y escenarios son las trampas de sedimento, el análisis de la evolución del flujo de partículas sedimentarias, junto con datos físico-químicos de la columna de agua a distintas profundidades (salinidad, temperatura, intensidad y dirección de corrientes, contenido en nutrientes, etc.), atmosféricos y meteorológicos permiten una visión integrada de los procesos actuales que se manifestarán en la columna sedimentaria.

El GGO lleva desarrollando, en colaboración con otros grupos españoles y europeos, el análisis de material recuperado en trampas de sedimento en el Mar de Alborán que están dando unos resultados de incalculable valor en el calibrado de la señal biótica en la columna sedimentaria. Con el desarrollo de diversos proyectos financiados por la UE en el golfo de León (PROMESS, EUROSTRATAFORM, HERMES,...) y otros dentro del programa nacional del MEC y la Junta de Castilla y León, se planteó la necesidad de iniciar una campaña de recalibrado de la señal biótica actual en esa región esencial en lo referente a la dinámica general del Mediterráneo Occidental.

Gracias a esto, actualmente el GGO dispone de material recuperado en diversas campañas desarrolladas durante 12 años en el Golfo de León (1993-2006).

\subsubsection{TRAMPAS DE SEDIMENTO}

Las trampas de sedimento han supuesto un importante avance en la investigación del transporte vertical de las partículas sedimentarias. Desde finales de la década de los 90, los trabajos con trampas de sedimento se han venido multiplicando (Treppke et al., 1996; Romero et al., 1999; Fabres et al., 2002; Bárcena et al., 2004; Sanchez-Vidal et al., 2004). La información obtenida gracias a la utilización de estas herramientas ha supuesto un gran desarrollo en el conocimiento de los mecanismos de producción biológica en las áreas pelágicas. Además ponen de manifiesto la influencia de un transporte lateral de materia procedente de otras áreas. Destacan la importancia del flujo de ópalo biogénico y carbono orgánico como indicadores de la productividad primaria superficial, y como ésta puede ser o no estacional y/o episódica, a la vez que se puede relacionar con los patrones hidrográficos del área de estudio. Estos datos son determinantes para posteriores investigaciones de paleoproductividad y paleoceanografía. 
La composición taxonómica de la asociación de organismos planctónicos es fundamental para cualquier reconstrucción paleoambiental, pero previamente se han de tener garantías de la reproductivilidad de la asociación fósil. Para ello es necesario examinar toda la secuencia desde la producción en la superficie de la columna de agua, el proceso de transporte vertical, y su almacenamiento en los sedimentos, en escalas temporales lo más cortas posibles. En otras palabras, se hace necesario un análisis detallado a lo largo de todo el proceso de muerte, sedimentación y enterramiento, así como de los procesos físicoquímicos que están actuando sobre los primeros estadios diagenéticos. Por otro lado, el uso de estas técnicas nos permite estudiar temas clave de mayor actualidad como es la dinámica de la exportación de material biogénico de la capa fótica; estas investigaciones, a su vez, están íntimamente ligadas a proyecciones del impacto de efecto invernadero, acumulación de $\mathrm{CO}_{2}$ en la atmósfera, deterioro de la capa de ozono, etc. (Berger et al., 1989).

A pesar de presentar ciertas restricciones (Heussner et al., 1990), que deben tenerse siempre en cuenta, las trampas de sedimento están consideradas como los mejores instrumentos oceanográficos para el estudio cualitativo y cuantitativo de la variación espacial y temporal de los flujos de partículas.

\subsubsection{PRESENTACIÓN DE LA TESIS}

Esta tesis Doctoral opta al grado de "Doctor Europeus" y por lo tanto contiene capítulos escritos en castellano e inglés. Se compone de tres partes fundamentales. Una primera sección, del capítulo 1 al 5 , en la que se describe la circulación oceánica y atmosférica de la zona de estudio, los materiales y métodos empleados y un resumen de la ecología de las diatomeas, silicoflagelados y foraminíferos planctónicos. De esta sección cabe destacar el método mejorado que se ha empleado para el procesamiento de muestras de trampas de sedimento para el estudio de microfósiles silíceos y calcáreos. La segunda sección, del capítulo 6 al 9, es la parte central de la tesis y se compone de cuatro artículos escritos en inglés, cada una correspondiente a un aspecto diferente de la ecología del plancton en el Mediterráneo. Estos artículos se encuentran en diferentes etapas del proceso de publicación. Los capítulos 6 y 7 están dedicados al estudio de las asociaciones de diatomeas registradas en la trampa de Planier en el golfo de León, considerada como la estación con menor influencia de la plataforma de las dos estudiadas en este trabajo. El capítulo 6 se centra en la sucesión y composición taxonómica de las asociaciones de diatomeas del golfo de León. En este artículo se describe la sucesión estacional de las diatomeas en el golfo de León a través de un año medio modelo calculado a partir de los doce años de registro y se presentan 13 láminas con fotografías de microscopía electrónica y óptica de los principales taxones identificados. El capítulo 7, se centra en la variabilidad interanual de los flujos de diatomeas, cocolitos y de los principales componentes del flujo total. En este artículo se discute la relación del viento con el desarrollo y composición del bloom primavera, la relación de los flujos de diatomeas y cocolitos con fenómenos como la NAO y ENSO y el posible 
control biológico de la sedimentación del material en suspensión en la columna de agua. En el capítulo 8 se describe la variabilidad estacional, interanual y geográfica de los flujos de silicoflagelados en el Mediterráneo Occidental. Para este estudio fueron analizadas muestras provenientes de cinco trampas de sedimento dispuestas a lo largo de un transecto Norte-Sur del golfo de León hasta el mar de Alborán. Los datos obtenidos en esta investigación han aportado nueva información sobre diversos aspectos de la ecología de los silicoflagelados en el Mediterráneo tales como las condiciones óptimas para su desarrollo, la respuesta de este grupo a los aportes fluviales, la distribución biogeográfica de las asociaciones de silicoflagelados y la relación de los flujos de este grupo con fenómenos climáticos tales como la NAO, ENSO y la ola de calor de 2003. El capítulo 9 está dedicado al estudio de los flujos de foraminíferos planctónicos registrados por las dos trampas de sedimento situadas en el golfo de León. En este apartado se describe la composición de las asociaciones de foraminíferos planctónicos, su variabilidad y distribución estacional e interanual y se discute la influencia del Ródano sobre los flujos de una de las trampas. Además, se presentan una serie de muestras de sedimento superficial recogidas de diversos puntos del fondo del golfo con el objetivo de comparar las asociaciones de foraminíferos del sedimento con las registradas por las trampas. Debido al formato por artículos de este trabajo no todos los resultados obtenidos a lo largo de mi trabajo de investigación han podido ser presentados en este manuscrito. Cabe destacar dos bloques importantes de datos no incluidos que serán publicados con posterioridad: los datos de recuentos de diatomeas de una de las trampas de sedimento del golfo de León (Lacaze Duthiers) y los datos de recuentos de dinoquistes de dos testigos de sedimento del sur de las Islas Svalvard. Este último trabajo se realizó como una colaboración en el proyecto de investigación español SVAIS, independiente de mi trabajo de tesis. Al final del manuscrito de tesis se incluye una publicación en la que se incluyen algunos datos preliminares de esta investigación. 



\subsection{OBJETIVOS}

El presente estudio se enmarca dentro de varios programas de investigación europeos (Euromarge-NB, MTP II-MATER, EUROSTRATAFORM y HERMES) y franceses (PNEC) cuyos principales objetivos son (1) describir la variabilidad espacial, estacional e interanual de la intensidad y composición de los flujos de partículas en los márgenes continentales europeos y (2) analizar el papel de los diferentes factores que controlan el intercambio de partículas en el margen continental.

\subsubsection{Objetivos generales}

Por su parte, para este estudio se plantean unos objetivos generales abordados desde una perspectiva micropaleontológica:

- Obtener un registro espacio-temporal del plancton calcáreo y silíceo del Mediterráneo Occidental que permita inferir variaciones pretéritas registradas en el registro sedimentario.

- Relacionar las variaciones del registro de comunidades planctónicas con los cambios estacionales e interanuales de las condiciones oceánicas en el área.

\subsubsection{Objetivos particulares}

Los objetivos generales se desglosan en los siguientes objetivos particulares:

1. Desarrollar una técnica para el procesamiento óptimo de muestras procedentes de trampas de sedimento para el posterior estudio de microfósiles calcáreos y silíceos.

2. Caracterizar los procesos que controlan la productividad superficial en las áreas de estudio.

3. Identificar y catalogar las principales especies de diatomeas y foraminíferos del golfo de León, así como las asociaciones de silicoflagelados en tres áreas del Mediterráneo Occidental (golfo de León, margen continental Catalán y mar de Alborán).

4. Ilustrar las principales especies de diatomeas del golfo de León y de silicoflagelados del Mediterráneo-Ooccidental a través de fotografías de microscopía óptica y electrónica.

5. Describir los patrones generales de distribución estacional y los periodos de máxima productividad de los principales taxones de diatomeas y foraminíferos planctónicos en el golfo de León y de silicoflagelados en el Mediterráneo Occidental.

6. Determinar la influencia del aporte fluvial sobre la abundancia y composición de los flujos de silicoflagelados y foraminíferos planctónicos. 
7. Caracterizar las variaciones interanuales de los flujos de diatomeas, silicoflagelados y foraminíferos planctónicos en el Golfo de León e identificar los mecanismos que controlan su variabilidad.

8. Determinar el papel que juega la productividad biológica sobre la sedimentación de material particulado en suspensión de la columna de agua.

\subsubsection{Artículos que constituyen esta tesis}

- Rigual-Hernández, A.S., Jordan, R. W., Bárcena, M.A., Sierro, F.J., Flores, J.A. and Heussner, S. Annual succession of diatom assemblages in the northwestern Mediterranean Sea based on a 12-year-long sediment trap record. (Para ser enviado a Micropaleontology; to be submitted to Micropaleontology).

- Rigual-Hernández, A.S., Bárcena, M.A., Sierro, F.J., Jordan, R.W., Flores, J.A., Sebastian Meier, K.J., Beaufort, L. and Heussner, S.. Seasonal and interannual variability of diatom and coccolith fluxes in the northwestern Mediterranean: a 12-yr sediment trap record. (Marine Micropaleontology, en revision; Marine Micropaleontology, under review).

- Rigual-Hernández, A.S., Bárcena, M.A., Sierro, F.J., Flores, J.A., Hernández-Almeida, I., Sanchez-Vidal, A., Palanques, A. and Heussner, S. Seasonal to interannual variability and geographic distribution of the silicoflagellate fluxes in the Western Mediterranean. (Marine Micropaleontology 77, 46-57. 2010).

- Rigual-Hernández, A.S., Sierro, F.J, Bárcena, M.A., Flores, J.A. and Heussner, S. Seasonal and interannual changes of planktonic foraminifer fluxes in the Gulf of Lions (NW Mediterranean) and their implications for paleoceanographic studies: Two 12-year sediment trap records. (Para ser enviado; to be submitted).

- Elena Colmenero Hidalgo, Andrés S. Rigual Hernández, Renata G. Lucchi, Ma Ángeles Bárcena, Francisco J. Sierro, José-Abel Flores, Anne de Vernal y Angelo Camerlenghi. Análisis de un nuevo registro micropaleontológico en el margen meridional del archipiélago de las Svalbard (océano Ártico): resultados preliminares e implicaciones paleoceanográficas. (Geogaceta, 46, 2009). 


\section{Capítulo 2}

Circulación atmosférica y oceánica

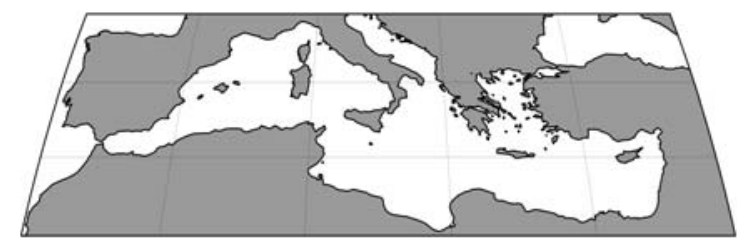





\subsection{EL MAR MEDITERRÁNEO}

\subsubsection{Fisiografía}

El mar Mediterráneo es una cuenca semicerrada que se extiende entre $\operatorname{los} 30^{\circ}-45^{\circ} \mathrm{N}$ y $\operatorname{los} 5^{\circ}-35^{\circ} \mathrm{O}$ y que se encuentra rodeada por Europa (Norte), África (Sur) y Asia (Este) (Fig. 1). Cubre aproximadamente un área de 2.5 millones de $\mathrm{km}^{2}$ y está conectado con (1) el océano Atlántico a través del estrecho de Gibraltar, (2) con el mar Negro por medio de los estrechos del Bósforo y Dardanelos y el pequeño mar de Mármara y (3) con el mar Rojo, a través de la conexión artificial del canal de Suez. El Mediterráneo está dividido en dos cuencas, la Occidental y la Oriental separadas por el estrecho de Sicilia, de aproximadamente $330 \mathrm{~m}$ de profundidad. Estas dos cuencas, están divididas a su vez en otras subcuencas más pequeñas conectadas por estrechos poco profundos que controlan la entrada y salida de las aguas (Fig. 1).

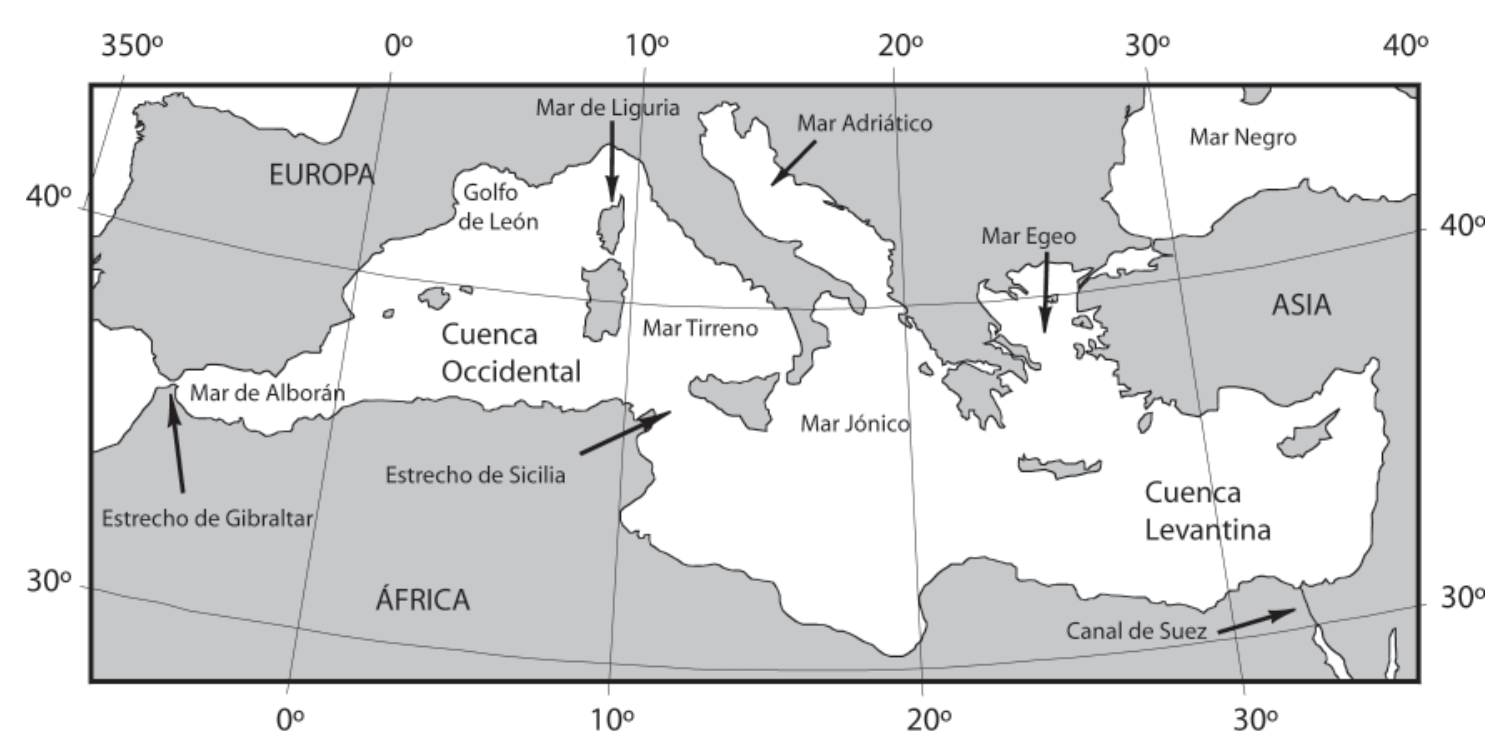

Figura 1. Mapa del mar Mediterráneo. Modificado de Drakopoulos y Lascaratos (1999).

\subsubsection{Meteorología y climatología}

La región mediterránea se encuentra situada entre dos zonas climáticas: la templada mediterránea al norte y la semidesértica al sur y al este, ambas caracterizadas por una pluviosidad entre escasa y moderada. Esta peculiar situación geográfica, convierte al Mediterráneo en una zona especialmente sensible a cambios climáticos. El patrón climático actual de la zona mediterránea está fuertemente influenciado por la posición de la Zona de Convergencia Intertropical o ZCIT. La ZCIT es un cinturón de bajas presiones que ciñe el globo terrestre en la región ecuatorial y que está formado por la confluencia de masas de aire cálido y húmedo de latitudes al norte y sur del Ecuador (Fig. 2) (Cramp y O’Sullivan, 1999). La estacionalidad de los vientos asociados a la ZCIT determina en gran medida la meteorología y movimiento de las masas de agua superficiales del Mediterráneo. De este modo, durante los meses de verano 
el sistema climático mediterráneo se caracteriza por un sistema de altas presiones muy estable, originando condiciones cálidas y secas, mientras que durante el invierno, este sistema de altas presiones desaparece gradualmente debido al desplazamiento de la ZCIT hacia el Sur dando paso a unas condiciones más frías y húmedas (Fig. 2) (Cramp y O’Sullivan, 1999).
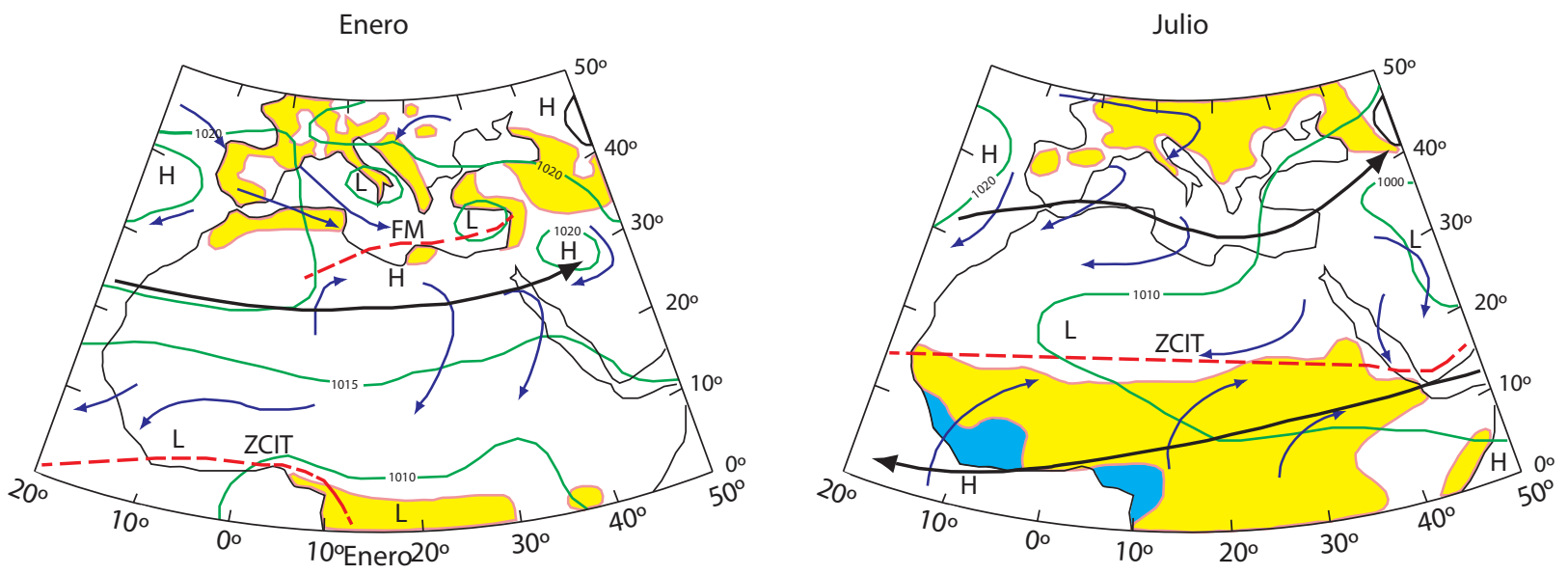

Precipitaciones mensuales $(\mathrm{mm})$

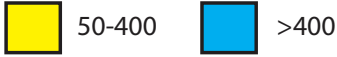

Figura 2. Distribución de presión superficial, vientos y niveles de precipitación del Mediterráneo y Norte de África durante Enero y Julio. Señaladas la distribución media de las corrientes de chorro Subtropicales del Este (flechas negras grandes), junto con la zona de convergencia intertropical (ZCIT o ITCZ) y el Frente Mediterráneo (MF). H señala áreas de alta presión y L de baja presión. Modificado de Cramp y O'Sullivan (1999).

Durante el invierno, en toda la Cuenca Mediterránea soplan vientos de origen continental provenientes del Noroeste. Entre estos vientos, caben destacan el Mistral y la Tramontana provenientes de Francia y que afectan principalmente a la zona del golfo de León. Estos vientos invernales hacen circular masas de aire frío y seco sobre el Mediterráneo causando una gran evaporación y enfriamiento de las aguas superficiales (Pinardi y Masetti, 2000). Los vientos invernales originan a su paso giros ciclónicos y anticiclónicos (Fig. 3). A finales del verano, en la cuenca Levantina, aparecen los vientos alisios o etesios provenientes del Norte que soplan principalmente sobre el mar Egeo (Pinardi y Masetti, 2000). 


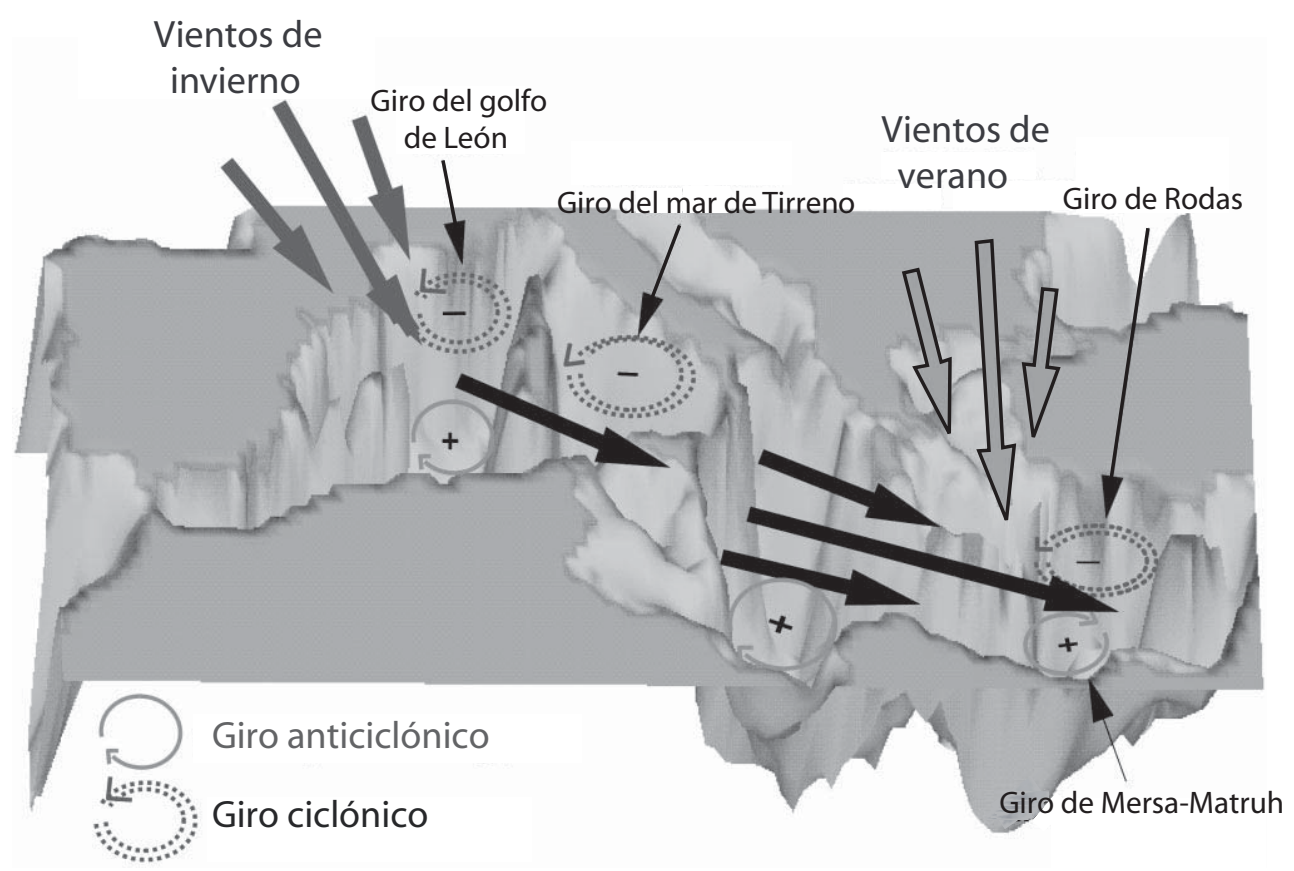

Figura 3. Esquema de la circulación del viento en invierno y verano. Las flechas grises representan la dirección del viento y las flechas negras representan la fuerza ejercida por el viento sobre las capas superficiales de agua durante el invierno y los giros (ciclónicos y anticiclónicos) que generan. Modificado de Pinardi y Masetti (2000).

\subsubsection{Hidrodinámica}

El mar Mediterráneo posee un sistema de circulación termohalino dirigido por las variaciones estacionales en la salinidad y temperatura de las aguas superficiales (Wüst, 1961). Además, el Mediterráneo se comporta como una cuenca de concentración debido a que presenta un balance hídrico global negativo. Es decir, la pérdida de agua por evaporación es mayor que la cantidad de agua que llega por medio de las precipitaciones y el aporte fluvial (Béthoux, 1979) (Fig. 4). En la cuenca oriental la evaporación excede la precipitación, lo que provoca la formación de aguas más salinas, densas y cálidas (Cramp y O’Sullivan, 1999), como veremos más adelante (Fig. 4). Por otro lado, su única conexión con el océano abierto es el estrecho de Gibraltar (14 km de ancho y $330 \mathrm{~m}$ de profundidad), lo que determina en gran medida este balance hídrico negativo. Finalmente, el aporte fluvial no juega un papel relevante en el balance hídrico global de la cuenca Mediterránea. No obstante, el caudal aportado por los ríos puede tener repercusiones en la hidrodinámica a nivel local, principalmente en las desembocaduras de los ríos mediterráneos más caudalosos (Durrieu de Madron et al., 2005) tales como el Ebro, Ródano, Po, Danubio y Nilo (Ludwig et al., 2009).

El balance hídrico negativo del Mediterráneo conlleva dos consecuencias directas: (1) la formación estacional (principalmente en invierno) de masas de aguas salinas y densas que se hunden en determinados puntos del Mediterráneo (cuenca Levantina, mar Egeo, mar Adriático 
y golfo de León) (Pinardi y Masetti, 2000); y (2) la formación de un gradiente de densidad entre el Atlántico y el Mediterráneo, lo que provoca la entrada de aguas atlánticas superficiales - ligeras, poco salinas y pobres en nutrientes- a través de la superficie del estrecho de Gibraltar y la salida de aguas mediterráneas -más densas, salinas y relativamente ricas en nutrientespor el fondo del Estrecho. Este tipo de circulación se conoce como antiesturina y determina, en gran medida, el carácter oligotrófico de la cuenca mediterránea (Béthoux, 1979). Este tipo de gradiente también ocurre entre las cuencas Occidental y Oriental (Millot, 1999; Pinardi y Masetti, 2000).

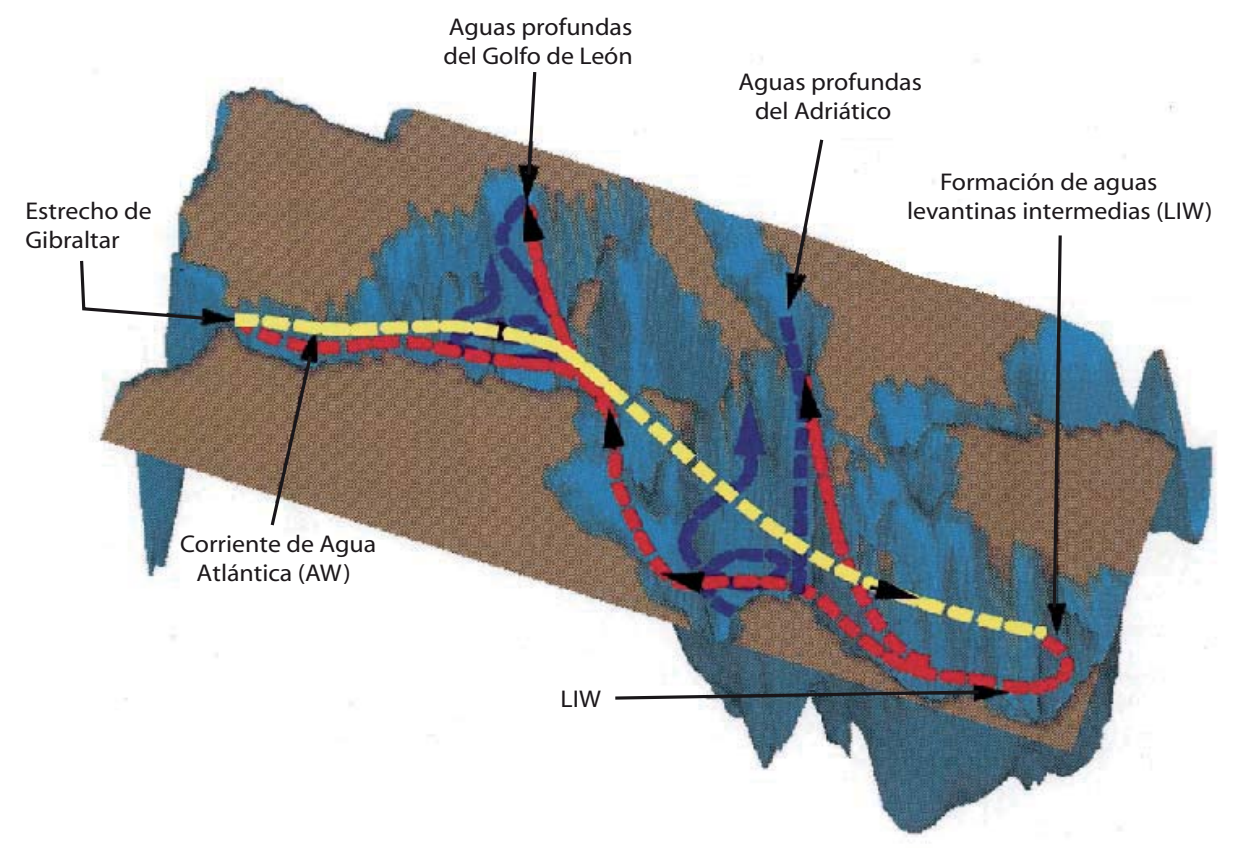

Figura 4. Esquema de la circulación termohalina en el Mediterráneo. El amarillo indica la corriente AW que es superficial. El rojo indica circulación de la LIW a profundidades intermedias. El azul indica las aguas profundas. Modificado de (Pinardi y Masetti, 2000).

Antes de explicar en detalle la circulación del Mediterráneo es importante definir las diferentes masas de agua que podemos encontrar en él:

- Agua Atlántica o Atlantic Waters (AW). Estas aguas de origen atlántico entran a través de la zona superficial del estrecho de Gibraltar (100-200 m de profundidad) (Lacombe et al., 1972)(Fig. 5). A su paso por el mar de Alborán son modificadas en dos giros anticiclónicos al mezclarse con el Agua Intermedia Levantina (Levantine Intermediate Waters - LIW). Estas aguas atlánticas mezcladas con las mediterráneas se denominan Agua Atlántica Modificada o Modified Atlantic Waters (MAW) (Millot, 1999) (Fig. 5). La MAW ocupa los primeros 100-200 m de la columna de agua y circula hacia el Este en dirección a la cuenca Levantina. A medida que la MAW penetra en el Mediterráneo, su temperatura y salinidad aumentan de forma 
gradual debido a la evaporación y mezcla pasando de una salinidad de 36.5 psu en Gibraltar a cerca de 39 psu en el Mediterráneo Oriental (Fig. 5) (Cramp y O'Sullivan, 1999; Millot, 1999).

- Agua Intermedia Levantina o Levantine Intermediate Waters (LIW). Esta masa de agua se forma a partir de la MAW en el Mediterráneo Oriental. Las aguas superficiales (MAW) aumentan su densidad por la elevada evaporación de cuenca Levantina y se hunden hasta encontrar masas de agua de su misma densidad (Millot, 1999). La LIW circula a una profundidad entre los 200 y los $600 \mathrm{~m}$ de profundidad (Astraldi et al., 2002) y su salinidad oscila entre 38,7-39 psu (Cramp y O’Sullivan, 1999; Millot, 1999). Esta masa de agua sigue modificándose en la cuenca Noroccidental donde recibe el nombre de Agua Mediterránea Intermedia o Mediterranean Intermediate Waters (MIW).

- Agua Mediterránea Intermedia de invierno o Winter Mediterranean Intermediate Waters (WIW). Esta masa de agua intermedia se forma en el Mediterráneo Noroccidental todos los años durante el invierno, (Salat y Font, 1987; Millot, 1999). Se forma por enfriamiento y evaporación de la MAW durante el invierno desencadenado por los fuertes y persistentes vientos que soplan en esa zona durante la época invernal (Fig. 3) (Millot, 1990, 1999).

- Aguas Profundas del Mediterráneo Oriental y Occidental o Eastern Mediterranean Deep Water-EMDW y Western Mediterranean Deep Water $(W M D W)$ (Fig. 4). Estas dos masas de agua se forman únicamente en áreas del Norte del Mediterráneo como el golfo de León o el mar Adriático y mar Egeo (Millot, 1999; Pinardi y Masetti, 2000) (Fig. 5). Durante el invierno, fuertes y persistentes vientos de Noroeste (Fig. 3) soplan sobre el Mediterráneo provocando un aumento de densidad de las capas superficiales de la columna de agua por la elevada evaporación y enfriamiento. La salinidad de la EMDW es de 38,65 - 38,7 psu mientras que la de la WMDW es de 38.44-38.46 psu (Millot, 1999). Además de estas masas existe otra masa de agua densa en el Mediterráneo Occidental llamada Agua Densa del Tirreno o Tyrrhenian Dense Water (TDW). Esta masa de agua se forma al mezclarse EMDW que pasa a través del estrecho de Sicilia con las existentes en el mar Tirreno y las que provienen de la cuenca argelina.

- Corriente de Salida del Mediterráneo o Modified Outflow Water (MOW). A1 llegar al estrecho de Gibraltar la WMDW y la LIW se ven forzadas a ascender por la batimetría (Fig. 5) y pasan a formar la MOW (Millot, 1999). 


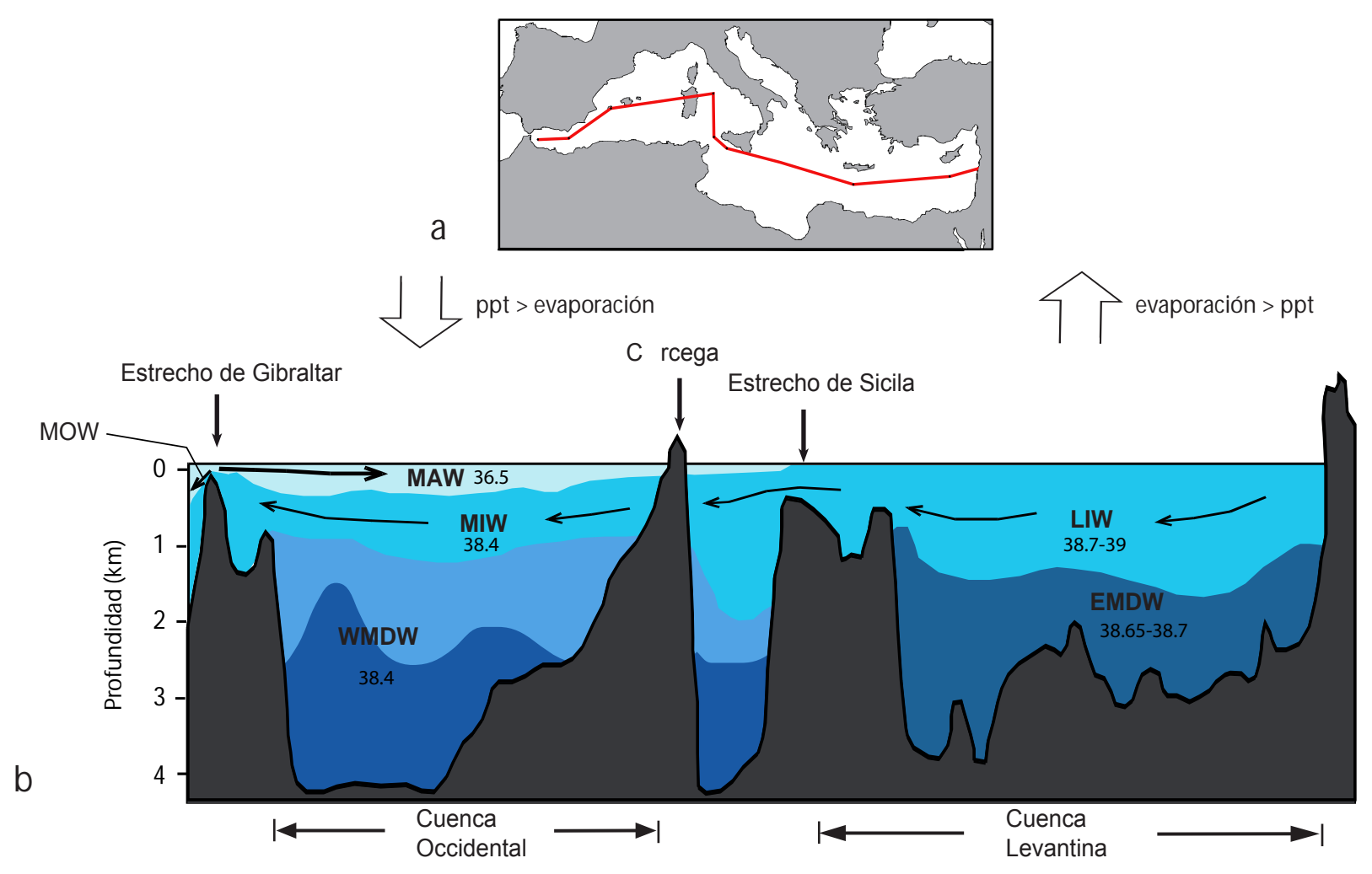

Figura 5. a. Transecto del Mediterráneo (rojo). b. Diagrama esquemático de la circulación actual de la cuenca mediterránea durante el verano siguiendo el transecto a. WMDW: aguas profundas del Mediterráneo Occidental; EMDW: aguas profundas del Mediterráneo oriental; LIW: aguas intermedias levantinas; MIW: aguas mediterráneas intermedias; MAW: aguas atlánticas modificadas; MOW: aguas de salida del Mediterráneo. En cada masa de agua se especifica su salinidad en psu. Modificado de Cramp y O’Sullivan (1999).

Las aguas superficiales de Mediterráneo describen un gran giro ciclónico que engloba todo el Mediterráneo y otro giro, también ciclónico, que describen las aguas de la cuenca Occidental (Fig. 4 y 6). La circulación superficial al Sur de las cuencas Occidental y Oriental está dominada por "corrientes de chorro", mientras que su parte Norte está dominada por giros ciclónicos (Fig.6) (Pinardi y Masetti, 2000). Además de estas corrientes principales, existen pequeñas células anticiclónicas distribuidas en distintos puntos de la cuenca Mediterránea (Fig. 6). Las AW entran por la superficie del estrecho de Gibraltar y van siendo modificadas en su camino hacia el Mediterráneo Oriental. La elevada tasa de evaporación en la cuenca Levantina provoca el aumento de densidad de las masas de agua superficiales y la formación de la LIW. Una vez formada, la LIW, se dirige a la cuenca Occidental a través del estrecho de Sicilia (Fig. 4). Por este estrecho no sólo pasan MAW y LIW, sino también, por la zona más profunda pasa una masa de agua fría y densa que es una mezcla de las aguas profundas generadas en el mar Adriático y en el mar Egeo (EMDW) (Millot, 1999). Las aguas profundas se mezclan con las aguas del Mediterráneo Occidental formando la TDW dando la vuelta al Mediterráneo 
Occidental bajo la LIW, sin mezclarse con ella, hasta salir por el estrecho de Gibraltar como parte de las aguas intermedias (Millot, 1999). Por último tenemos la formación de aguas profundas en el mar Egeo, mar Adriático y golfo de León (Pinardi y Masetti, 2000) que juega un papel clave en la circulación termohalina del Mediterráneo. La formación de aguas profundas presenta una gran variabilidad tanto estacional como anual que está principalmente relacionada con las variaciones en la intensidad de los vientos (Pinardi y Masetti, 2000). En función de la fuerza de los vientos, las aguas pueden hundirse hasta las zonas más profundas de las cuencas o quedarse en capas intermedias de la columna. De este modo, las aguas intermedias se forman todos los años mientras que las profundas son episódicas (Millot, 1999). Finalmente, la WMDW y la LIW salen al Atlánticoa través del estrecho de Gibraltar (Fig. 5), pasando a formar la MOW (Millot, 1999) que pierde gradualmente su salinidad y densidad características debido a su mezcla con las aguas atlánticas (O’Neill-Baringer y Price, 1999).

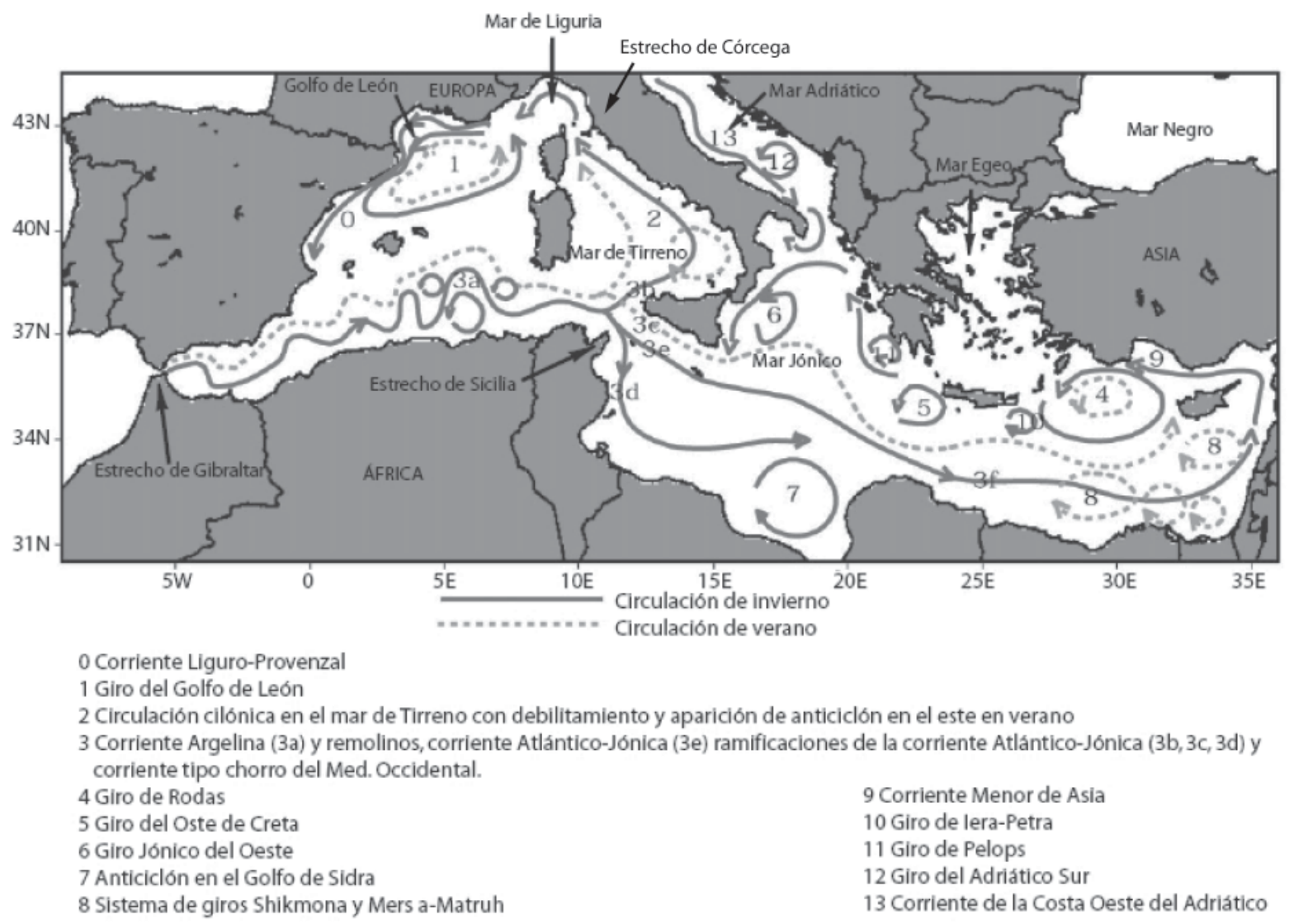

Figura 6. Mapa del mar Mediterráneo en el que se muestran las principales corrientes y giros, así como su variabilidad estacional. Modificado de Pinardi y Masetti (2000). 


\subsubsection{Productividad en el Mediterráneo}

Considerado globalmente, el Mediterráneo es un mar oligotrófico (Estrada, 1996), ya que la mayor parte de los nutrientes se encuentran por debajo de la zona fótica y la fuerte haloclina no permite que las aguas se mezclen (Pujol y Vergnaud- Grazzini, 1995). Esta haloclina es estacional y en invierno las masas de agua superficiales aumentan su densidad y se produce mezcla en la columna y el enriquecimiento de la zona fótica. El fósforo es el nutriente más frecuentemente limitante en el Mediterráneo (Margalef, 1963), aunque seguido de cerca por el nitrógeno (Estrada, 1996). Debido a la escasez de nutrientes la productividad primaria en el Mediterráneo presenta valores relativamente bajos $\left(<0.2 \mu \mathrm{g}_{\text {chla }} \mathrm{l}^{-1}\right)$ presentando un ligero incremento a finales del invierno (Siokou-Frangou et al., 2010). El intercambio de aguas a través del estrecho de Gibraltar es uno de los principales causantes de la oligotrofia del Mediterráneo que pierde aguas profundas relativamente ricas en nutrientes mientras que recibe aguas superficiales atlánticas oligotróficas. Sin embargo, a pesar de su pequeña extensión el Mediterráneo presenta una gran heterogeneidad. En este sentido, la cuenca Levantina es la menos productiva mientras que la Occidental presenta algunas zonas de alta productividad como es el caso del mar de Alborán o el Mediterráneo Noroccidental. Este último presenta los valores de productividad primaria más elevados de todo el Mediterráneo llegando a alcanzar concentraciones de hasta $3 \mu \mathrm{g}$ chl $a \mathrm{l}^{-1}$ durante la transición invierno-primavera (Siokou-Frangou et al., 2010). Los principales mecanismos de enriquecimiento de estas zonas más productivas son la intensa mezcla invernal, el afloramiento de aguas profundas inducido por el viento y el aporte fluvial.

Las imágenes de clorofila $a$ obtenidas vía satélite muestran tres importantes características de la cuenca Mediterránea: (1) un gradiente decreciente de productividad del oeste hacia el este (D’Ortenzio y Ribera d'Alcalá, 2009); (2) ciclos estacionales de productividad revelando, generalmente, máximos en invierno y primavera y mínimos en verano; (3) marcadas variaciones interanuales en la productividad primaria incluso en aguas muy oligotróficas como es el caso de la Cuenca Levantina (Vidussi et al., 2000).

\subsection{EL MAR DE ALBORÁN}

\subsubsection{Fisiografía e hidrodinámica}

El mar de Alborán conecta el Mediterráneo con el océano Atlántico a través del estrecho de Gibraltar, constituyendo la cuenca más occidental del Mediterráneo. La cuenca del mar de Alborán presenta una compleja topografía de la que cabe destacar una alineación volcánica en el centro de la cuenca que divide al mar de Alborán en dos subcuencas: la Oriental y la Occidental (Fig. 7). 


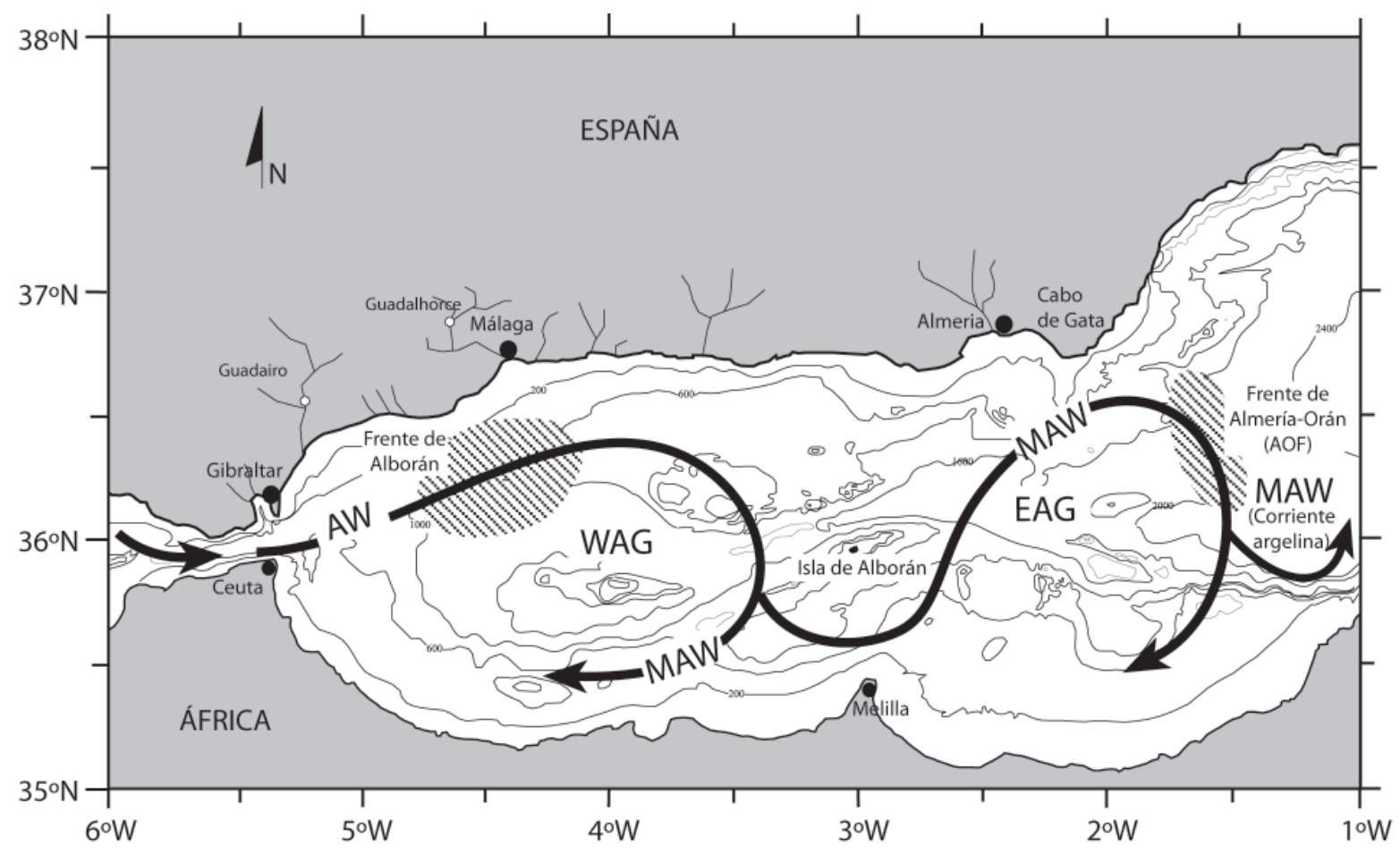

Figura 7: Mapa batimétrico del mar de Alborán en el que se indica la circulación de las principales corrientes oceánicas superficiales (AW y MAW). Las dos áreas de puntos señaladas al norte del Giro Occidental (WAG) y al este del Giro Oriental (EAG) representan zonas de upwelling. Modificado de Bárcena et al. (2004).

Las condiciones atmosféricas del Mar de Alborán están controladas en gran medida por el anticiclón de las Azores e influyen directamente sobre la circulación oceánica general (Parrilla y Kinder, 1987). Los vientos dominantes sobre la zona son los ponientes (del oeste) y los levantes (del este), sin embargo, también soplan vientos de componente Norte y Sur. La formación de vientos del Oeste ocurre durante una situación de bajas presiones en el Norte y Noroeste de la Península Ibérica. Estos vientos favorecen el upwelling de aguas en la costa española. Por otro lado, los levantes aparecen asociados a una situación de altas presiones al Norte de la Península y suelen ir acompañados de nubes y precipitaciones.

La circulación oceánica en esta parte del Mediterráneo se encuentra fuertemente controlada por el intercambio de agua con el Atlántico (Vergnaud-Grazzini et al., 1989; Pierre, 1999). Las aguas atlánticas penetran en el Mediterráneo por las capas más superficiales de la columna de agua a través del estrecho de Gibraltar formando una corriente de baja salinidad. Esta corriente es modificada a medida que se adentra en el Mediterráneo debido a su mezcla gradual con las aguas mediterráneas formando la denominada MAW (Bormans et al., 1986) que ocupa los primeros 150-200 m de profundidad (Parrilla y Kinder, 1987; Tintoré et al., 1988). El inicio de esta mezcla ocurre en el mar de Alborán cuando la corriente de entrada describe dos grandes giros anticiclónicos situados aproximadamente en las subcuencas occidental y oriental 
de Alborán y denominados Giro de Alborán Occidental (Western Alboran Gyre, WAG) y Giro de Alborán Oriental (Eastern Alboran Gyre, EAW) (Parrilla y Kinder, 1987; Heburn y La Violette, 1990) (Fig. 7). Estos giros presentan una gran variabilidad con un fuerte componente estacional, llegando en ocasiones a desaparecer (Heburn y La Violette, 1990). Sin embargo, es importante señalar que el giro Occidental es mucho más estable que el Oriental (Heburn y La Violette, 1990). A pesar de que se han realizado diversas modelizaciones de circulación oceánica del mar de Alborán (Heburn y La Violette, 1990; Stanev y Friedrich, 1991) las causas de la variabilidad de los giros aún no están bien definidas. El flujo de la corriente genera células de upwelling de aguas más profundas en la parte norte del giro Occidental y en el borde oriental del mar de Alborán (Perkins et al., 1990; Tintoré et al., 1991) (Fig. 7).

Por debajo de la masa superficial de aguas atlánticas modificadas se encuentra la MIW, aproximadamente entre los 200 y 600 m (Masqué et al., 2003). Esta masa de agua es el principal componente del flujo de salida de agua mediterránea. Finalmente, existe una tercera masa de agua situada por debajo de la MIW que se encuentra en contacto con el fondo de la cuenca, la WMDW. Esta masa de agua se forma en el golfo de León durante los inviernos (Millot, 1990). Tanto la MIW como la WMDW circulan en sentido opuesto a las aguas superficiales (MAW) en dirección al Estrecho por donde salen formando la MOW (Bormans et al., 1986).

\subsubsection{Productividad en el mar de Alborán}

El mar de Alborán es una de las zonas más productivas del Mediterráneo principalmente debido al aporte de nutrientes de las aguas atlánticas (AW) y a los afloramientos o upwellings generados por los dos giros anticiclónicos (Estrada, 1996) (Fig. 7). En la zona septentrional del WAG tiene lugar un upwelling de aguas frías y salinas, denominado Frente de Alborán (Fig. 7) (Minas et al., 1991), que es resultado de la inestabilidad creada por el contacto de la AW, la LIW y la topografía del fondo (Perkins et al., 1990). Debido a la mezcla y aporte de nutrientes de origen atlántico, en esta zona tiene lugar una elevada productividad primaria (Bárcena y Abrantes, 1998). La fuerza de los vientos afecta a su intensidad (Pujol y VergnaudGrazzini, 1995). Así, durante el verano ésta disminuye considerablemente debido a la fuerte estratificación de las aguas.

En lo referente al EAG, encontramos otra zona de elevada productividad biológica en su zona oriental conocida por el frente de Almería-Orán (Fig. 7) (Viúdez et al., 1998). Cerca del Cabo de Gata se produce la convergencia de las aguas procedentes del WAG y las mediterráneas que vienen bordeando la Península Ibérica en dirección sur, dando como resultado el frente de Almería-Orán. La mezcla generada por la convergencia de estas dos masas de agua junto al aporte de nutrientes y material biogénico procedente del WAG, determinan que el frente de Almería-Orán sea una zona de elevada productividad (Minas et al., 1991; García-Gorriz y Carr, 2001).

De acuerdo con García-Gorriz y Carr (2001), la evolución anual de la productividad primaria en el mar de Alborán se puede dividir en cuatro fases: (1) régimen de bloom, de 
Noviembre a Marzo, caracterizado por unas temperaturas superficiales $\leq 17^{\circ} \mathrm{C}$; (2) régimen sin bloom, de Mayo a Septiembre caracterizado por unas temperaturas superficiales $\geq 19.5^{\circ} \mathrm{C}$; (3) un periodo de transición de Abril-Mayo, coincidiendo con el inicio de la estratificación; (4) y un segundo periodo de transición de Octubre-Noviembre, coincidiendo con la máxima variabilidad de intensidad de vientos y rotura de la estratificación de la columna de agua.

\subsection{EL MAR CATALANO-BALEAR}

\subsubsection{Fisiografía e hidrodinámica}

El mar Catalano-Balear se encuentra en el Mediterráneo Noroccidental y está delimitado al norte y al oeste por las costas de la Península Ibérica (Fig. 8). El mar Catalano-Balear se encuentra conectado con el sur a través de un paso de escasa profundidad entre la Península y las Islas Baleares lo que limita el intercambio de agua a las masas más superficiales. La circulación oceánica en esta parte del Mediterráneo está controlada por la corriente del Norte (NC) que fluye desde el golfo de León hacia el sur dirigida por el talud continental (Fig. 8). La velocidad media de esta corriente es de unos $30 \mathrm{~cm} / \mathrm{s}$ pudiendo llegar a alcanzar $40 \mathrm{~cm} / \mathrm{s}$ durante el invierno y presenta un flujo total de aproximadamente $1 \mathrm{~Sv}$ (Castellón et al., 1991).

La NC interacciona con los cañones submarinos del talud lo que provoca la formación de remolinos que modifican el sentido de la corriente induciendo la formación de flujos secundarios hacia la plataforma y hacia el centro de la cuenca. Estas turbulencias facilitan la mezcla entre las distintas masas de agua (La Violette et al., 1990a; Tintoré et al., 1990). Al llegar a la altura de las islas Baleares, la NC se bifurca, parte continúa su camino hacia el sur en dirección del mar de Alborán y otra parte se desvía hacia el norte de las Baleares (Fig. 8). La ramificación de la NC que sigue hacia el sur se vuelve a dividir al llegar al mar de Alborán, parte se dirige hacia el este formando parte de la MAW y fluyendo a lo largo de las costas del norte de África y parte se une a las aguas que salen por el estrecho de Gibraltar (Millot, 1999).

Por debajo de las aguas superficiales en el mar Catalano-Balear encontramos las aguas intermedias de invierno (WIW). Esta masa de agua se forma todos los años durante el invierno por la evaporación y enfriamiento de las capas de agua más superficiales (Millot, 1999). Por debajo de la WIW se sitúan otras dos masas de agua la LIW y la WMDW.

La interacción de la NC con el talud y la diferencia de densidad entre las distintas masas de agua causan la aparición de dos frentes, uno en el margen continental catalán y otro al norte de las islas Baleares (Font et al., 1988). El frente Catalán se extiende desde el golfo de León hasta el delta del Ebro y separa las aguas costeras de la plataforma, relativamente poco salinas (salinidad $<37,5 \%$ ), de las masas de agua oceánicas, más salinas ( $>38 \%$ ). El frente Catalán presenta una importante variabilidad estacional principalmente debida a la variabilidad de la $\mathrm{NC}$ que, durante el invierno, es especialmente intensa (Béthoux et al., 1988). Por otro lado, el frente Balear se forma por la interacción de las masas de agua de la NC y el margen continental de las Islas Baleares. 


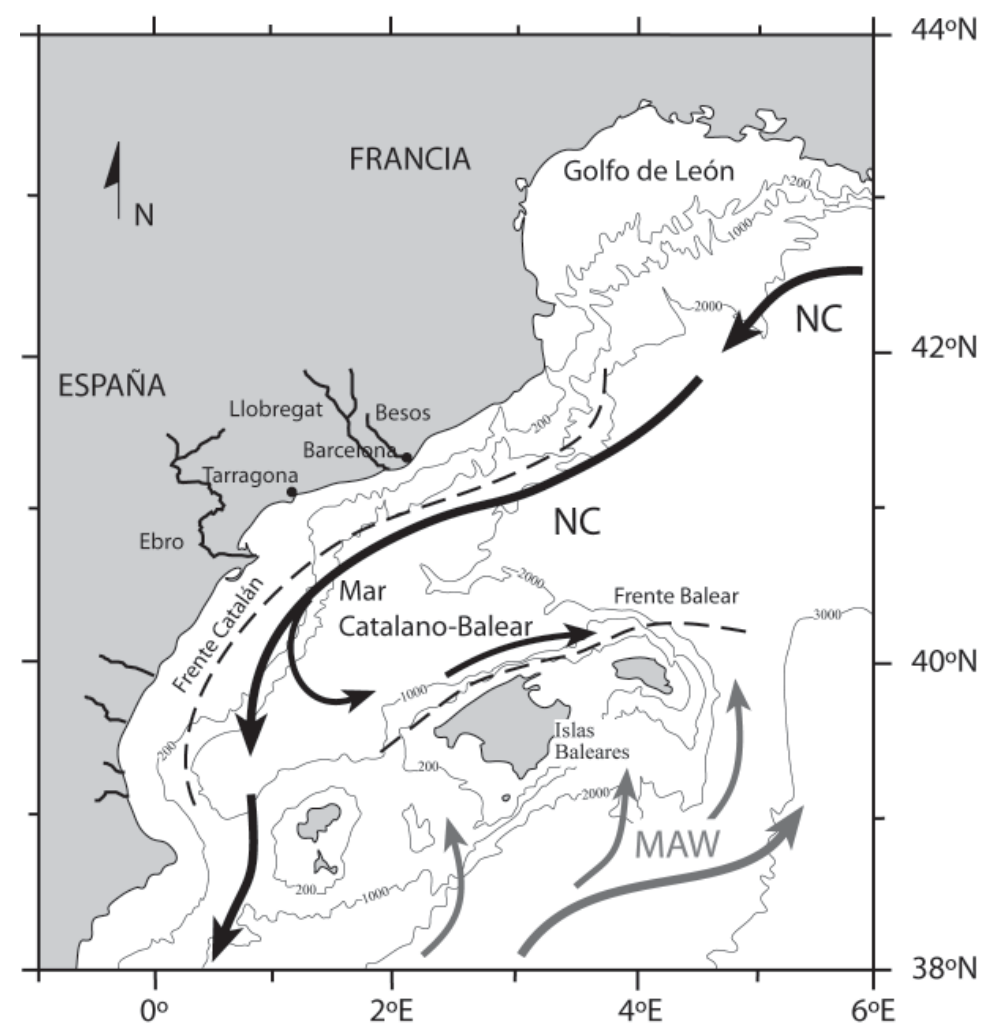

Figura 8. Mapa batimétrico del Mar Catalano-Balear en el que se indica con flechas la circulación de las principales corrientes oceánicas y con líneas discontinuas los frentes Catalán y Balear. Modificado de La Violette (1990a) y ColmeneroHidalgo (2004).

\subsubsection{Productividad en el mar Catalano-Balear}

El mar Catalano-Balear puede considerarse como una zona relativamente fértil dentro del Mediterráneo. Los principales mecanismos de enriquecimiento de la zona fótica en esta zona son similares a los del golfo de León: (1) la variabilidad de la NC que induce el intercambio de material particulado entre la plataforma continental y el océano abierto, (2) los frentes Catalán y Balear (3) la mezcla invernal de la columna de agua y (4) la descarga fluvial (Ebro, Llobregat, Besós, etc.) (Estrada, 1996).

\subsection{EL GOLFO DE LEÓN}

\subsubsection{Fisiografía}

El golfo de León se encuentra situado en el Mediterráneo Noroccidental (Fig. 1). Su plataforma continental tiene forma de media luna alcanzando, en algunos puntos, una anchura de hasta 70 km (Fig. 9). Estas dimensiones son bastante inusuales para el Mediterráneo y se deben a una intensa progradación durante el Plio-Cuaternario bajo la influencia de una gran cantidad de sedimento aportado por el río Ródano (Lofi et al., 2003). El talud continental del golfo de León presenta una intrincada red de cañones submarinos (Fig. 9) que funcionan como conductos de transporte de sedimento desde la plataforma hacia el fondo de la cuenca. 


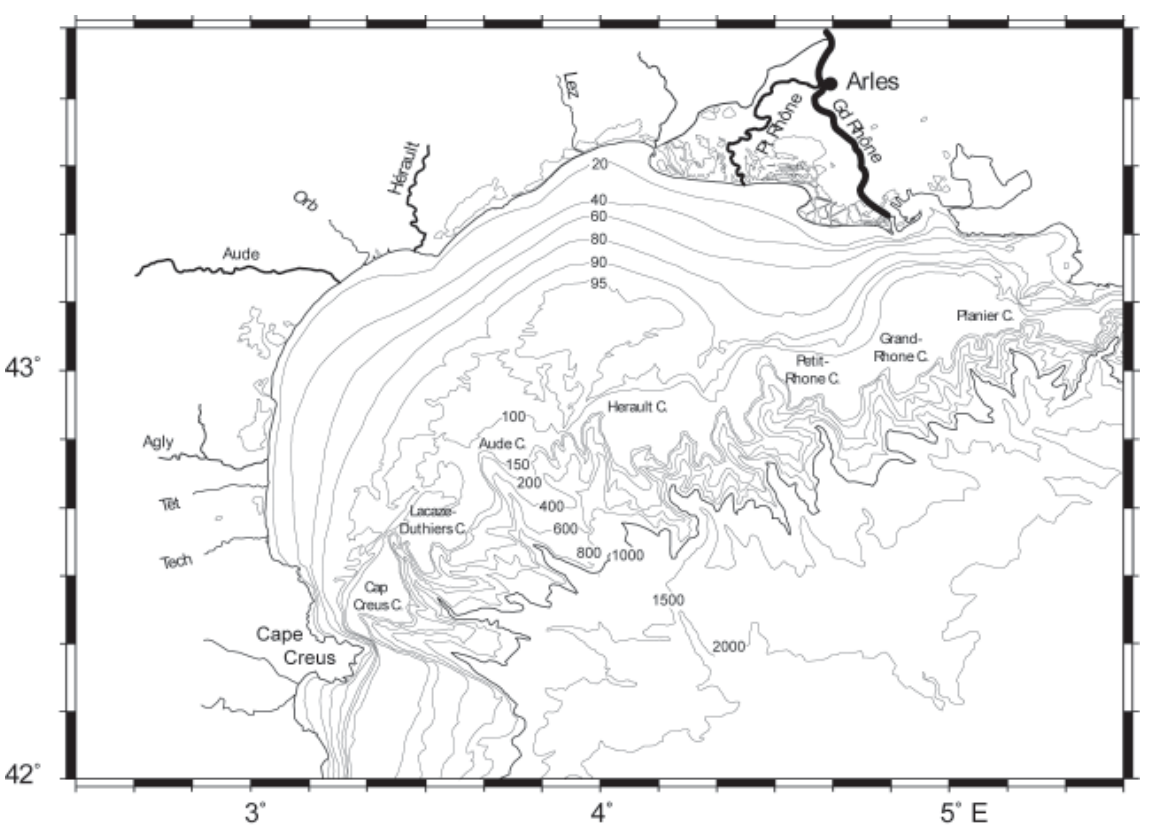

Figura9: Mapabatimétrico del golfo de León.

Las aguas de la plataforma reciben aportes de material particulado de diverso origen (Heussner et al., 2006):

- Material de origen fluvial. Más de diez ríos desembocan en el golfo de León (Fig. 9), sin embargo, el río Ródano es la principal fuente agua dulce y partículas terrígenas $(>80 \%)$ (Aloïsi et al., 1977).

- Material atmosférico proveniente del Sáhara principalmente.

- Material de la propia producción biológica. Sobre todo el margen continental del golfo de León existe una capa nefeloide de superficie que llega hasta los 30-90 m de profundidad y es principalmente debida a la producción planctónica (Loeillet y Leveau, 1985; Durrieu de Madron et al., 1990; Monaco et al., 1990).

- Material resuspendido a partir de sedimento recién depositado

Debido al predominio de los aportes fluviales, las concentraciones de partículas presentan una fuerte variabilidad estacional e interanual (Heussner et al., 2006).

\subsubsection{Meteorología}

En el golfo de León dos patrones de vientos determinan en gran medida la dinámica atmosférica y oceánica:

- Vientos del Noroeste (Fig. 10). Dos grupos de fuertes vientos continentales provenientes del Noroeste soplan sobre el golfo de León: el Mistral y la Tramontana. La dirección de estos vientos catabáticos (Ver Glosario) está determinada por la orografía circundante y por lo tanto siempre afectan al golfo de León de la misma manera (Millot, 1990). El Macizo Central Francés y los Alpes hacen un "efecto embudo" canalizando los vientos que soplan sobre el valle del Ródano formando el denominado viento Mistral (Fig. 10). 
Una situación similar es la de la Tramontana que se forma entre los Pirineos y el Sur del Macizo Central Francés. Estos dos vientos soplan todo el año sobre el golfo de León pero son más fuertes en invierno cuando arrastran masas de aire frías de origen polar o continental (Millot, 1990).

- Vientos del Sureste (Fig. 10). Soplan desde otoño hasta primavera y, aunque son menos frecuentes que los vientos del Noroeste, pueden alcanzar velocidades de hasta $90 \mathrm{~km} /$ h. Son importantes en el transporte sedimentario porque generan grandes marejadas e intensas corrientes a lo largo de la costa. La circulación inducida por estos vientos tiene importantes consecuencias en el transporte de sedimento cerca de la costa (Millot, 1990).

\subsubsection{Hidrodinámica}

Desde un punto de vista hidrodinámico, el golfo de León puede considerarse como una región compleja debido a que una serie de fenómenos intensos y altamente variables interactúan en la zona. Entre ellos, los más importantes son la fuerte circulación general a lo largo de la costa, la formación de aguas densas, tanto sobre la plataforma como en océano abierto y la variación estacional de la estratificación de la columna de agua (Millot, 1990).

La circulación general en el golfo de León está dominada por la corriente del Norte (Northern Current-NC) o corriente Liguro-Provezal (Fig. 10). La NC se forma a partir de dos corrientes que fluyen a ambos lados de la isla de Córcega: la corriente de Liguria, al oeste de la isla y la corriente de Tirreno, al este de la isla. Estas dos corrientes se juntan en el norte de Córcega y fluyen a lo largo de las costas de Italia, Francia y España (Fig. 6). En el golfo de León la NC fluye hacia el Sudoeste dirigida por el talud hacia el mar Catalano Balear en sentido ciclónico. Ocupa unos 30-50 km de ancho y presenta a una importante variabilidad estacional, mostrando aproximadamente el doble de flujo en invierno que en verano, llegando a alcanzar los 1.5 a $2 \mathrm{~Sv}$ en inviernos largos y fríos (Béthoux et al., 1988). La velocidad de la $\mathrm{NC}$ es máxima cerca de la superficie $(\sim 0.5 \mathrm{~m} / \mathrm{s})$ y desciende casi linealmente con la profundidad siendo de unos pocos $\mathrm{cm} / \mathrm{s}$ a varios cientos de metros de profundidad (Lapouyade y Durrieu De Madron, 2001). Aunque el núcleo principal de la NC fluye a lo largo del talud continental, las capas más superficiales tienden a penetrar en la plataforma (Fig. 10). La mayor parte del agua que se encuentra sobre la plataforma continental es canalizada hacia el Suroeste obligada por la rama principal de la NC en el Este y por la propia costa en el Oeste. Al llegar al límite suroccidental del golfo de León, las dos ramas de la NC chocan contra el promontorio del cabo de Creus y la NC es desviada hacia el cañón más cercano, el cañón del cabo de Creus (Canals et al., 2006). 


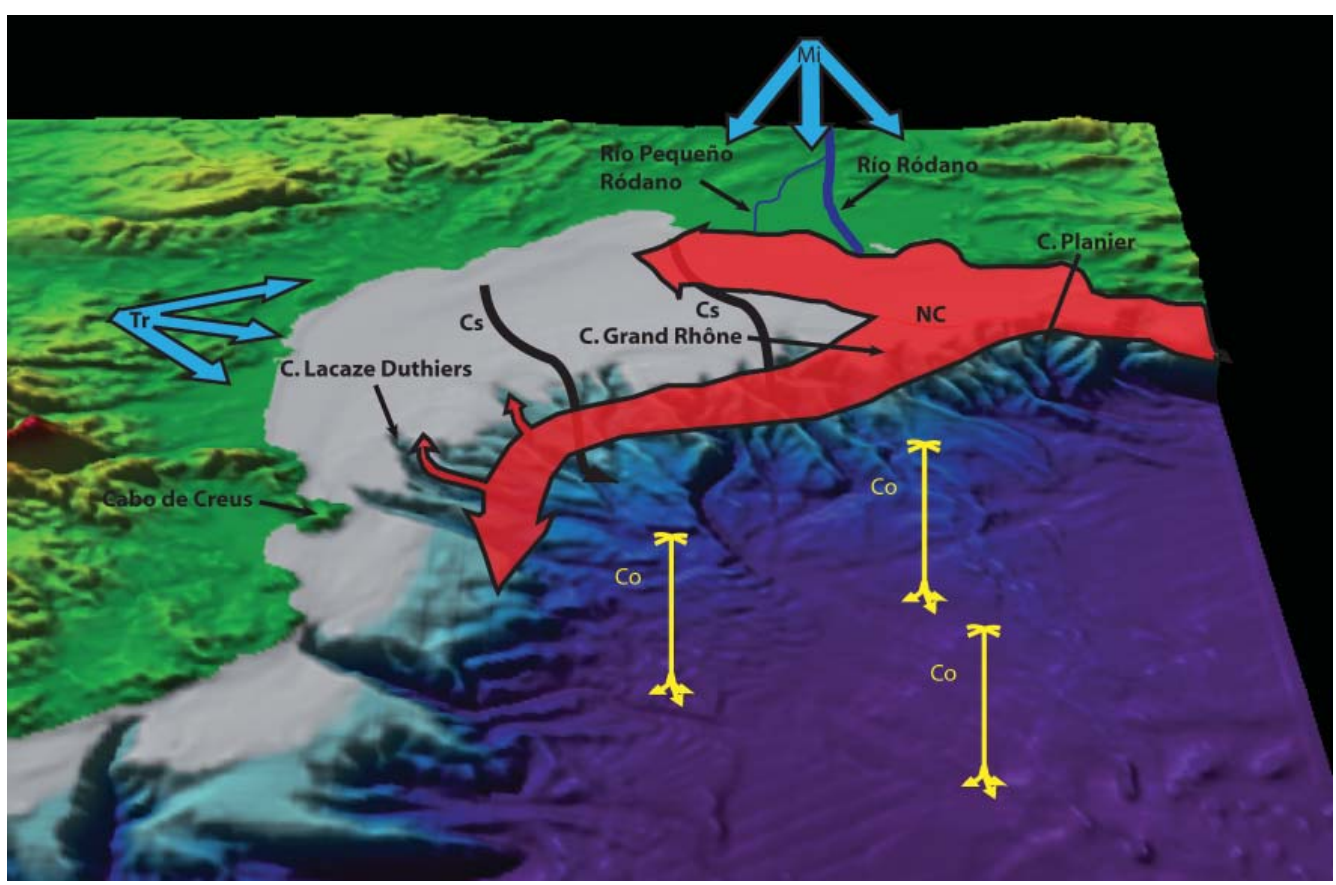

Figura 10. Vista tridimensional del golfo de León. a. Se representan los fenómenos inducidos por los vientos. (Mi, Mistral; T, Tramontana): las seis zonas de upwelling (1-6), la circulación horizontal en la superfi cie (fl echas rojas) y en el fondo (flechas negras). b. Señalada la circulación general en el Golfo. La NC (señalada con una flecha roja) de la que salen otras más pequeñas que son corrientes secundarias. Señaladas con Cs (en la plataforma) y Co (en océano abierto) los fenómenos de formación de aguas profundas. Modificado de Millot (1990) y de http://www.icm.csic.es/geo/gma/geo0es.htm.

La capa superficial de la NC está compuesta por agua de origen atlántico (Millot, 1990), es decir, MAW que ha completado su recorrido por el Mediterráneo Occidental a lo largo de los taludes de Argelia y del mar Tirreno (Millot, 1999). Por debajo de la MAW se encuentran otras tres capas: la WIW, la LIW y la WMDW que fluyen hacia el suroeste siguiendo las isobatas. El tamaño y dirección de estas masas de agua varía a lo largo del año debido a la estratificación estacional y al efecto del viento (Millot, 1999). Todos los años durante el invierno, los fríos, secos y persistentes vientos del Noroeste (Mistral y Tramontana) provocan el enfriamiento y evaporación de las masas de agua superficiales provocando el aumento de densidad de la MAW y su hundimiento formando las Aguas Intermedias de Invierno (WIW). Esta masa de agua se sitúa por debajo de la MAW y se caracteriza por presentar temperaturas de 12.5-13.08 ${ }^{\circ} \mathrm{C}$ y una salinidad de 38.1-38.3 psu. Durante algunos inviernos especialmente fríos en el golfo de León se forman masas de agua aún más densas que la WIW y LIW que se hunden hasta el fondo marino formando la WMDW (Millot, 1999). Esta masa de agua está caracterizada por una temperatura de $12.75-12.80^{\circ} \mathrm{C}$ y una salinidad de $38.44-38.46$ psu (Schott et al., 1994). En el apartado 2.4.4 de este capítulo trataremos más detalladamente de la formación de aguas profundas y sus repercusiones en la hidrología y transporte de sedimento.

A su paso por el golfo de León, la NC interacciona con la compleja morfología del talud 
provocando desviaciones de la corriente de fondo, corrientes dentro de los cañones (Fig. 10) (Millot, 1990) y el desarrollo de mucha actividad de remolinos. Estas turbulencias contribuyen al intercambio energético entre las distintas masas de agua mediante el hundimiento de aguas (intrusión termohalina) y al transporte de material particulado (La Violette et al., 1990b; Durrieu de Madron et al., 1999).

Los regímenes de vientos y de oleaje constituyen la fuerza que dirige la circulación local en el golfo de León. Los vientos Mistral y Tramontana originan surgencias y hundimientos de agua (Gaudin et al., 2006). Además de esto, estudios recientes han demostrado la importancia del impacto de eventos excepcionales como tormentas o intensos vientos fríos y secos sobre la hidrodinámica local del golfo de León (Estournel et al., 2003; Palanques et al., 2006).

La hidrodinámica del golfo de León también está marcada por el aporte de agua dulce del río Ródano (Fig. 10). Cerca de su desembocadura, la capa de agua dulce tiene varios metros de grosor y disminuye gradualmente mar adentro, llegando a medir unos pocos centímetros a varios kilómetros de distancia durante periodos tranquilos. Debido a que el golfo de León es una región de fuertes vientos, esta capa de agua dulce se mezcla fácilmente con las inferiores. Normalmente la pluma del río Ródano se desvía hacia el suroeste debido al Mistral y la circulación general. El flujo del río Ródano es de orden de $1000 \mathrm{~m}^{3} / \mathrm{s}$, que es aproximadamente 1000 veces menor que el flujo de la circulación general, lo que significa que el aporte de agua del Ródano a la circulación general es insignificante (Millot,1990).

Un buen ejemplo de la complejidad de la circulación en el golfo de León es el proporcionado por Estournel et al. (2003). En su trabajo, estos autores describen distintos patrones de circulación oceánica determinados por la dirección e intensidad de viento (Fig. 11). En este sentido, podemos definir cuatro situaciones generales de circulación durante el invierno:

1. Ausencia o baja intensidad de vientos (Fig. 11). La circulación general está dominada por la corriente del Norte. La formación de meandros favorece el intercambio de material entre la plataforma y el talud.

2. Prevalencia de vientos del Norte (Mistral) (Fig. 11). La circulación sobre la plataforma está dominada por un giro anticiclónico y reducido intercambio de material entre la plataforma y el talud.

3. Prevalencia de vientos del Noroeste (Tramontana) (Fig. 11). Circulación sobre la plataforma dominada por un giro ciclónico. Aumento del intercambio de material entre la plataforma y el talud (surgencia en la zona central de la plataforma y exportación de las aguas continentales hacia el Suroeste).

4. Vientos del Norte y Noroeste (Mistral y Tramontana, situación típica del invierno) (Fig. 11). Se forman dos giros en sentido opuesto sobre la plataforma, se reduce la zona de influencia de las aguas del Ródano, formación de aguas profundas y cascading (preferentemente en la zona suroccidental del Golfo). 

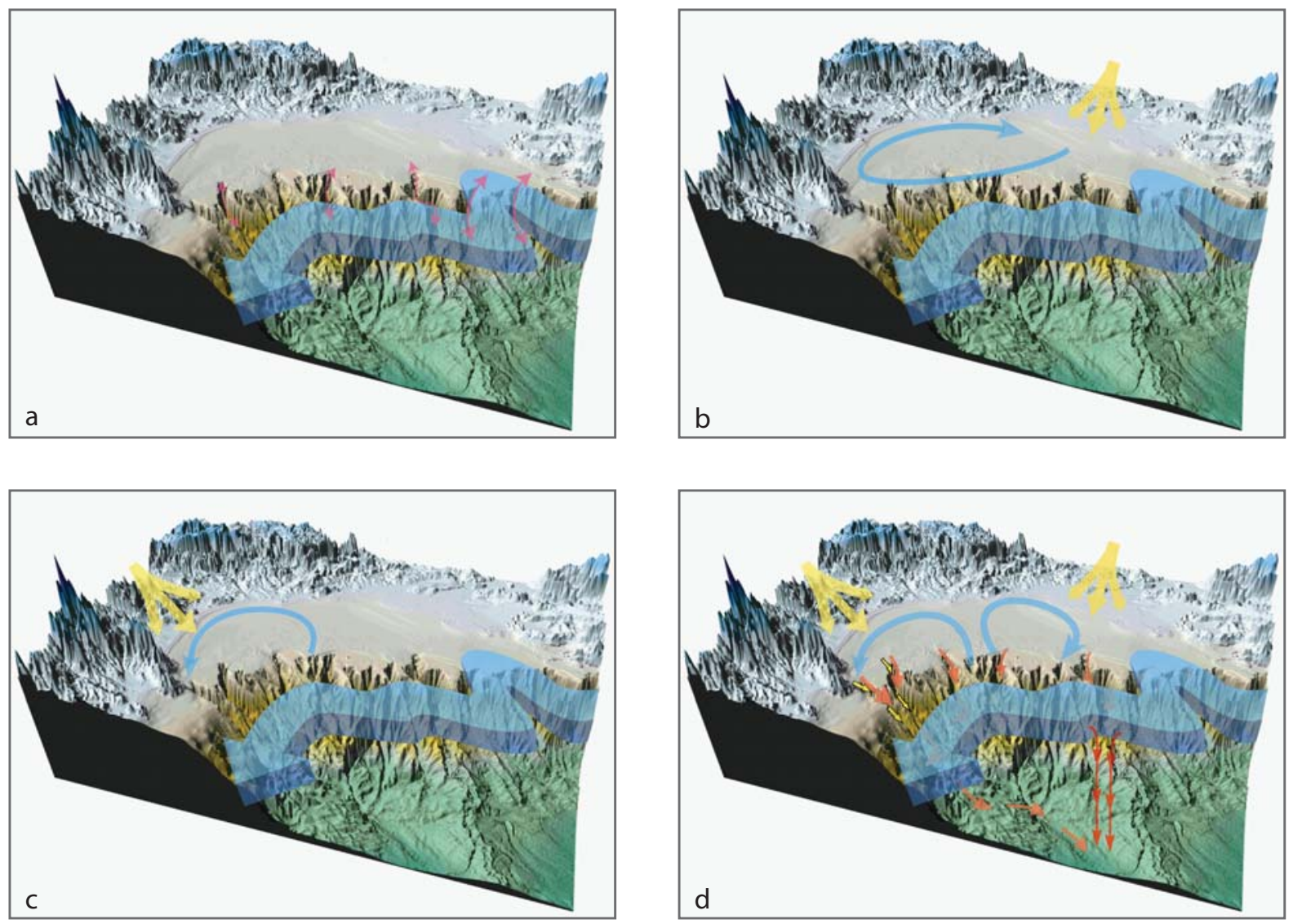

Figura 11: Circulación general del golfo de León durante cuatro situaciones meteorológicas diferentes. a. Baja intensidad de vientos. b. Prevalencia de vientos del norte (Mistral). c. Prevalencia de vientos del noroeste (Tramontana). d. Coexistencia de vientos del norte y noroeste (Mistral y Tramontana). Modificado de Durrieu de Madron et al. (2007).

Finalmente cabe destacar la relevancia del ciclo anual de la columna de agua sobre la hidrodinámica del golfo de León. Desde primavera hasta otoño se forma una termoclina que separa dos capas de agua: una profunda que presenta temperaturas de unos $13.5^{\circ} \mathrm{C}$ en la plataforma y otra en la zona superior de la columna de agua en la que la temperatura es de unos $20^{\circ} \mathrm{C}$, alcanzando máximos de $25^{\circ} \mathrm{C}$ en la superficie. La termoclina tiene un grosor aproximado de unos 10-20 m y se encuentra en la mitad de la columna en la plataforma continental y en el océano abierto a unas decenas de metros de profundidad. La termoclina, que es también picnoclina, es importante desde un punto de vista dinámico ya que permite que las dos capas de agua que separa "deslicen” entre sí comportándose como dos bloques independientes, reduciéndose la mezcla vertical. Durante el invierno esta estratificación desaparece casi por completo y la columna de agua se homogeniza especialmente en la región más externa del Golfo (Millot, 1990). 


\subsubsection{Formación de aguas profundas}

Dos factores determinan que el golfo de León sea una zona propensa para la formación de aguas profundas: (1) su situación geográfica, que le expone a fríos y secos vientos del Noroeste y (2) la cercanía a la superficie de las aguas profundas formadas años previos, lo que facilita la mezcla.

Durante el invierno los vientos Mistral y Tramontana soplan persistentemente y con intensidad sobre el golfo de León enfriando e incrementando la tasa de evaporación de las masas de agua superficiales lo que provoca un aumento de su densidad. Esta situación desencadena un complejo proceso de inestabilidad baroclínica, provocando un hundimiento de las capas de agua superficiales y una surgencia de las aguas intermedias levantinas (LIW). Durante inviernos especialmente fríos, las aguas más densas formadas en superficie llegan a alcanzar las capas más profundas de la columna de agua e incluso el fondo marino. En el golfo de León la formación de aguas profundas tiene lugar en dos zonas bien diferenciadas: mar adentro (más allá del talud) y sobre la plataforma continental (Fig. 10) (Millot, 1990). Mar adentro las masas de agua densa formadas en superficie se hunden a través de "chimeneas" de unos $10 \mathrm{~km}$ de diámetro con velocidades de hasta $10 \mathrm{~cm} \mathrm{~s}^{-1}$ (Demarco, 1985; Millot, 1990) (Fig. 10). Mientras que la formación de aguas profundas sobre la plataforma continental del golfo de León da lugar a un fenómeno conocido por Dense Shelf Water Cascading (DSWC) (Ivanov et al., 2004b). Dicho fenómeno consiste en la formación de aguas densas que llegan hasta el fondo de la plataforma y se deslizan por ella y por el talud continental hasta encontrar aguas de similar densidad. A su paso por el fondo arrastran y removilizan sedimento (Fig. 12) dando lugar a fenómenos mezcla, erosión y deposición de sedimentos así como formación de capas nefeloides intermedias y de fondo. Este fenómeno ocurre principalmente en latitudes altas aunque también ha sido observado en algunas zonas de latitudes medias sujetas a vientos fríos y secos como es el caso del golfo de León (Ivanov et al., 2004a).

El DSWC ocurre todos los años en el golfo de León, sin embargo, únicamente durante algunos inviernos anómalamente fríos y de intensos vientos, grandes volúmenes de agua son canalizados desde la plataforma hacia la cuenca profunda. Esta fue la situación de los años 1999, 2005 y 2006 (Fig. 13). Durante el invierno de 2005, Canals et al. (2006) llevaron a cabo una detallada monitorización de un evento de cascading en el golfo de León. Estos autores calcularon que aproximadamente $2 / 3$ del agua de la plataforma $\left(750 \mathrm{~km}^{3}\right)$ fue canalizada hasta la cuenca profunda principalmente a través del cañón del Cabo de Creus en un periodo de 40 días (Canals et al., 2006; Ulses et al., 2008). Además, estimaron que durante el evento de 2005, unas $0.6 \times 10^{6}$ de toneladas de Carbono orgánico fueron arrastrados al fondo marino. 


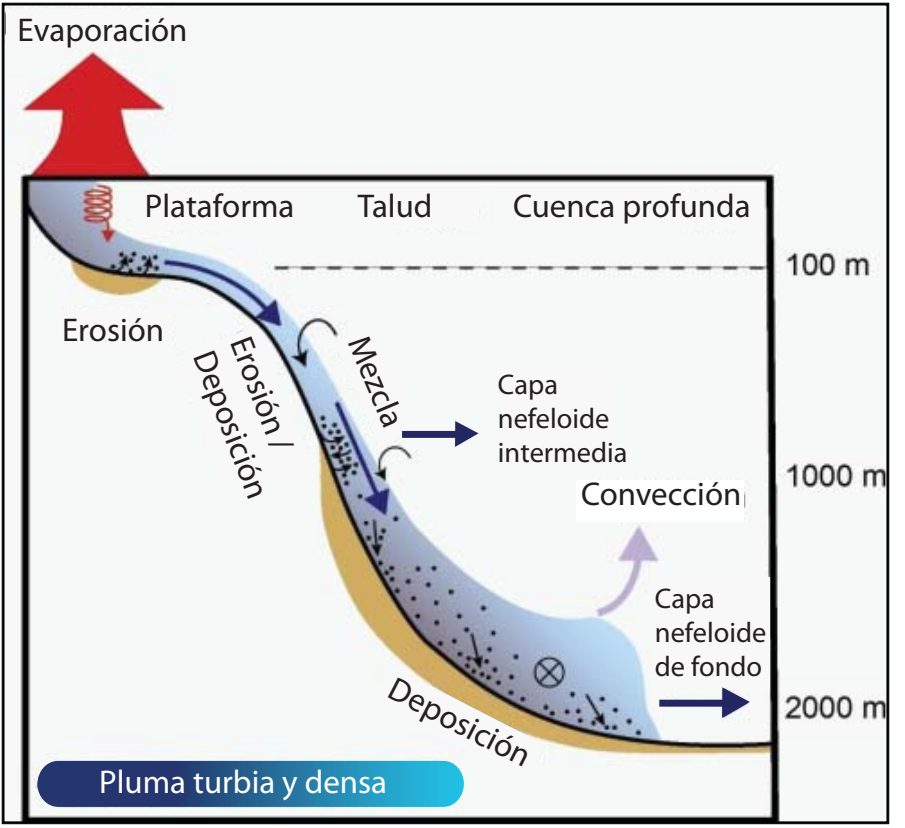

Figura 12. Corte del talud durante un evento de formación de Dense shelf water cascading. Debido al enfriamiento y evaporación se forman masas de agua densa sobre la plataforma que se hunden y erosionan el fondo removiizando sedimento y formando capas nefeloides. Modificado de Fohrmann et al. (1998).

Todos estos datos ponen de manifiesto la importancia DSWC en los márgenes continentales. DSWC tiene importantes repercusiones sobre la ventilación de las aguas intermedias y profundas, la modificación del fondo marino por la erosión y deposición de sedimentos y el transporte eficiente de contaminantes y materia orgánica acumulada en la plataforma hacia el talud y la cuenca profunda (Ulses et al., 2008). Especialmente relevante es su papel en el tranporte de carbono de la plataforma hacia el océano profundo. El carbono es secuestrado por las aguas más profundas y, por lo tanto, es difícil que vuelva a la atmósfera. Además, afecta directamente al funcionamiento de los ecosistemas de profundidad ya que les provee de una fuente extra de alimento (Canals et al., 2006).

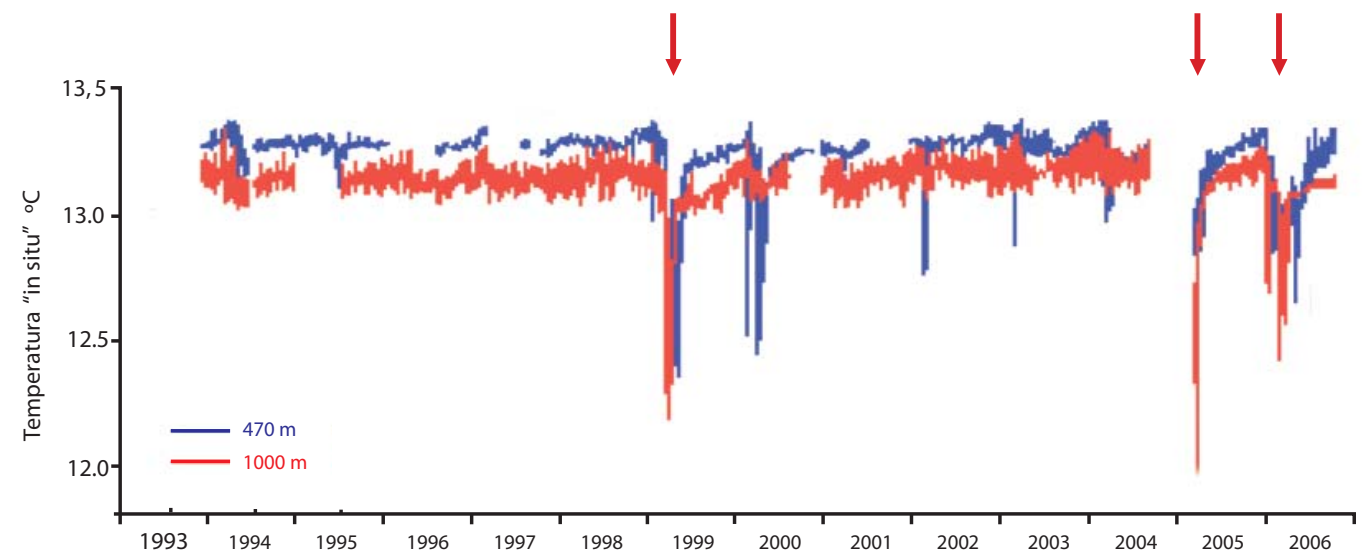

Figura 13: Temperatura del agua a 470 m y 1000m (fondo) en el cañón de Lacaze Duthiers. Cada año hay eventos de formación de aguas densas a $470 \mathrm{~m}$, mientras que a 1000 sólo algunos (flechas rojas). 
Según anticipan modelos climáticos del Mediterráneo, en las próximas décadas, la formación de aguas profundas en el golfo de León va a sufrir un descenso importante como consecuencia del cambio climático de la cuenca Mediterránea hacia condiciones más secas y cálidas. Esta disminución en la formación de aguas profundas no sólo va a ocurrir en el Mediterráneo sino también en latitudes como, por ejemplo, en las regiones Nórdicas y Árticas (Gregory et al., 2004). Regionalmente, estas alteraciones podrían afectar de forma significativa a la bomba de carbono de la plataforma y de los ecosistemas de profundidad, cuyo funcionamiento está íntimamente ligado a la DSWC. (Canals et al., 2006)

\subsubsection{Productividad del golfo de León}

Aunque el Mediterráneo presenta una marcada oligotrofía, el golfo de León es una de sus escasas zonas productivas (Estrada, 1996). Cada una de las masas de agua presentes en el golfo de León presentan diferente fertilidad y esto se debe principalmente a la hidrodinámica del Golfo. Una de las causas por las que esta región es particularmente productiva es debido a la mezcla vertical en invierno que lleva nitratos y otros nutrientes desde las capas inferiores de la columna de agua a la superficie. La formación de DSWC en la plataforma continental es generalmente sincrónica con altos niveles de productividad en las aguas superficiales (blooms de fitoplancton) (Canals et al., 2006). Además, la circulación de la NC genera un frente a lo largo del talud que provoca un aumento de la productividad en esa zona (Estrada, 1996; Durrieu de Madron et al., 1999). Finalmente, el aporte fluvial dominado principalmente por la desembocadura del río Ródano, enriquece las aguas del Golfo con nitratos y amonio (Lefèvre et al., 1997).

Según Lefèvre et al. (1997), el golfo de León puede dividirse en cuatro zonas o provincias en función de sus características hidrográficas, la descarga fluvial del Ródano y la distribución de productividad primaria (Fig. 14):

- Golfo de Marsella: sistema costero oligotrófico delimitado al norte por la costa, al oeste por la pluma y al sur por la NC.

- Desembocadura y pluma del río Ródano: zona de alto contenido en nutrientes con niveles constantes de clorofila $a$. Esta zona está limitada a un área de unos pocos $\mathrm{Km}^{2}$. La media de descarga de agua del río Ródano es de $1600 \mathrm{~m}^{3} \mathrm{~s}^{-1}$, 1000 veces menor que el flujo general producido en la circulación general de la NC.

- La zona de dilución: Zona de alta productividad situada al Oeste del Ródano. Está zona se encuentra bajo el efecto intermitente de la descarga del Ródano y está limitada al Este por la pluma, al oeste y norte por la línea de costa y al sur por la NC.

- La zona del Sur: separada del resto de zonas por la NC que muestra una zona de productividad en el frente de contacto con esta corriente. 


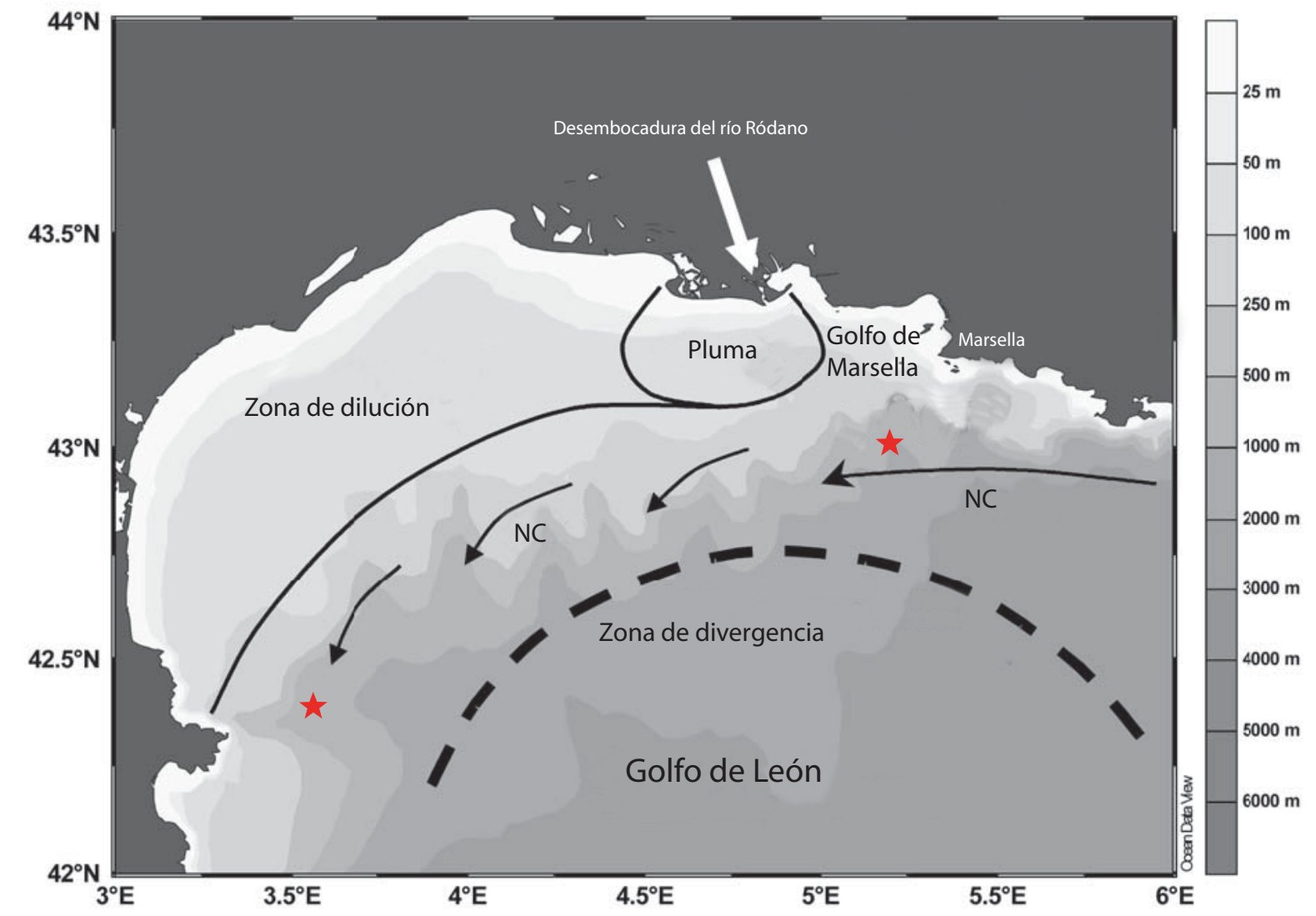

Figura 14. Mapa del golfo de León con las cuatro áreas productivas principales y con la situación de las trampas de sedimento (estrellas). Modificado de Lefèvre et al. (1997).

A partir de los datos obtenidos de imágenes satélite (Fig. 15) y estudios previos realizados en el golfo de León (Bustillos-Guzmán et al., 1995; Lefevre et al., 1997; Marty et al., 2002) se puede definir, de una forma general, la evolución anual de la estructura columna de agua así como el ciclo de productividad primaria en el golfo de León. Así, se pueden diferenciar cuatro fases:

- Fase de semimezcla 1 (SM1): Tiene lugar durante el periodo otoño-invierno. Durante este periodo la duración de los días y la radiación solar se reducen provocando un enfriamiento del agua superficial. Este enfriamiento va acompañado de un aumento de la densidad de la zona superior de la columna de agua que igualan su densidad con la masas de agua subsuperficiales con mayor concentración de nutrientes. Todo ello favorece la mezcla de aguas y, por lo tanto, la fertilización de la zona fótica. En este momento, las condiciones de luz, turbulencia y concentración de nutrientes en la zona fótica son las adecuadas (Leblanc et al., 2003) para el fitoplancton viéndose reflejado en un aumento de la concentración de clorofila $a$ (Fig.15).

- Fase de mezcla (M): Esta fase tiene lugar durante el invierno. El enfriamiento de las masas de agua superficiales continúa debido a una progresiva disminución de la radiación 
solar y de la temperatura del aire así como la acción de los vientos Mistral y Tramontana. Este cambio en el sistema provoca la surgencia de aguas profundas ricas en nutrientes. Durante este periodo aumenta la productividad primaria (Fig. 15), sin embargo, el crecimiento del fitoplancton se ve limitado por las fuertes condiciones de mezcla y la falta de luminosidad.

- Fase de semimezcla 2 (SM2): Este periodo coincide, aproximadamente, con la primavera. El aumento de la radiación solar y la duración de los días y el debilitamiento de los vientos desencadenan el inicio de la estratificación de la columna de agua. Estos factores junto con la elevada concentración de nutrientes (remanentes del invierno) proporcionan al fitoplancton las condiciones óptimas para su desarrollo. El desarrollo masivo de fitoplancton durante esta etapa es conocido por bloom primaveral (Fig. 15). La máxima concentración de clorofila en el golfo de León, así como, en el resto del Mediterráneo suele ocurrir durante la transición invierno-primavera (Febrero-Marzo) (Siokou-Frangou et al., 2010).

- Fase de estratificación (E): Durante el final de la primavera y el verano la capa superficial de la columna de agua es estable y está caracterizada por una picnoclina bien definida que constituye una fuerte barrera para el abastecimiento de nutrientes de la zona fótica. A pesar de que las condiciones de luz son óptimas, la escasez de nutrientes impide el desarrollo de fitoplancton en las capas superiores de la columna de agua (Fig. 15). No obstante, eventos puntuales de vientos pueden romper la estratificación y permitir el aporte de nutrientes a la zona fótica que pueden modificar la dinámica de la asociación de fitoplancton y tener implicaciones en la cadena trófica (Bustillos-Guzmán et al., 1995; Vidussi et al., 2000; Leblanc et al., 2003). Debido a la situación geográfica del golfo de León, es una de las zonas del Mediterráneo más sensibles a romper dicha estratificación, ya que las temperaturas no alcanzan valores tan elevados como en otras zonas y por lo tanto, la estratificación es menos marcada. 

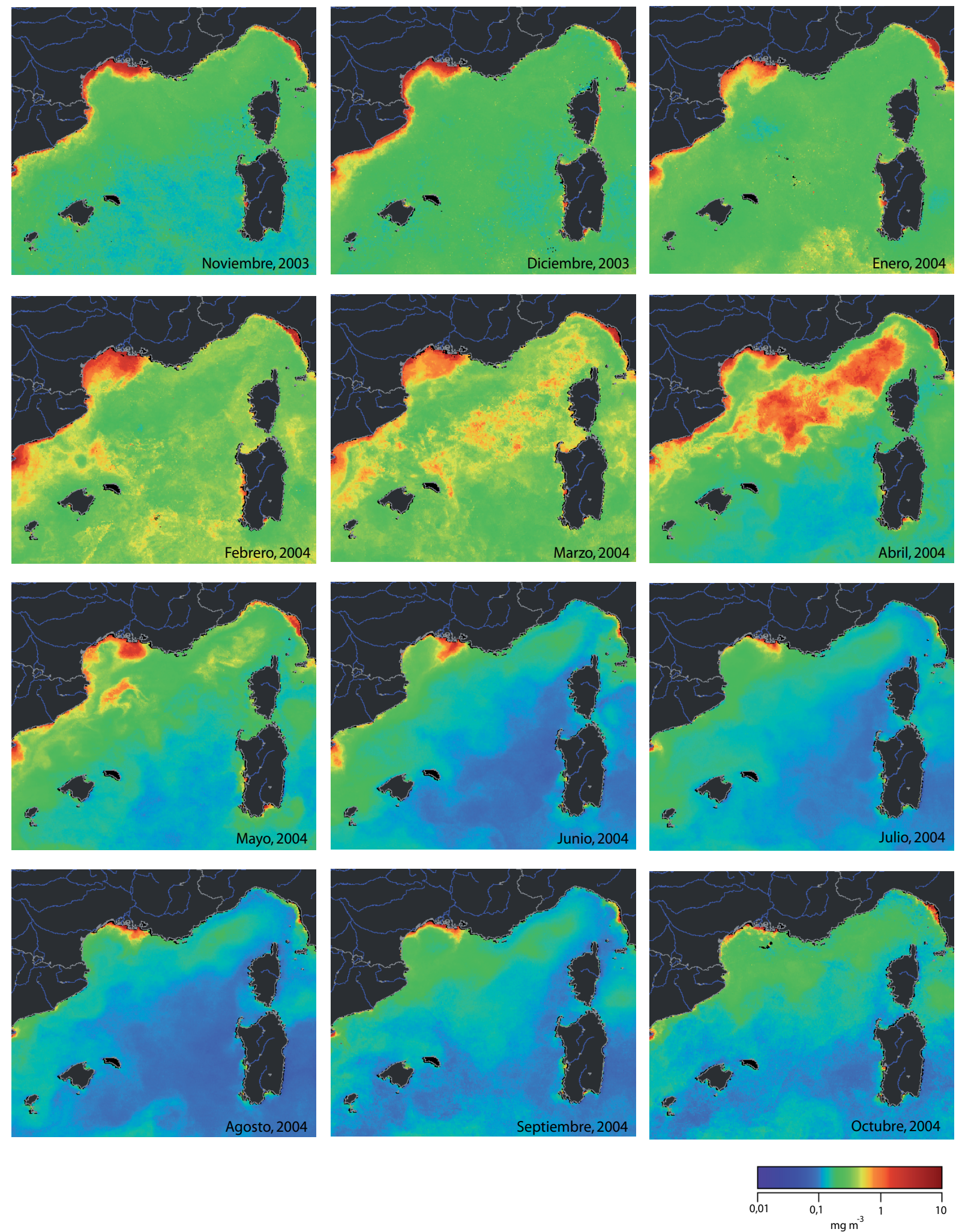

Figura 15: Imágenes del satélite Sea-WIFS. Cada fi gura representa la media mensual de producción de clorofila- $a$ correspondiente al periodo Nov/2003 - Oct/2005.La leyenda señala los colores que corresponden con las diferentes concentraciones de clorofila $a$. Imágenes tomadas de la base de datos del programa europeo Ocean Colours: http://marine.jrc.cec.eu.int/data_portal/oc_portal/main.php 


\subsection{DINÁMICA DE LA NAO}

La Oscilación del Atlántico Norte (North Atlantic Oscillation - NAO) es el patrón de variabilidad atmosférica más importante en las latitudes medias y altas del Hemisferio Norte. La NAO puede definirse como la diferencia de presión a nivel del mar entre el sistema de bajas presiones sobre Islandia (Borrasca de Islandia) y el sistema de altas presiones sobre Portugal (Anticiclón de las Azores). Estos dos centros de presiones permanentes controlan la dirección y fuerza de los vientos del Oeste que soplan sobre el continente Europeo (Fig. 16). La fuerza de estos dos sistemas es más pronunciada durante el invierno boreal (Noviembre-Abril), varía de año en año y es medida por índice de la NAO que expresa las anomalías de presión entre Lisboa (Portugal) y Stykkisholmur (Islandia) (Hurrell, 1995). Durante los meses de invierno, la variación de la NAO explica aproximadamente un tercio de la varianza interanual de temperaturas en el hemisferio Norte (Hurrell et al., 2001).
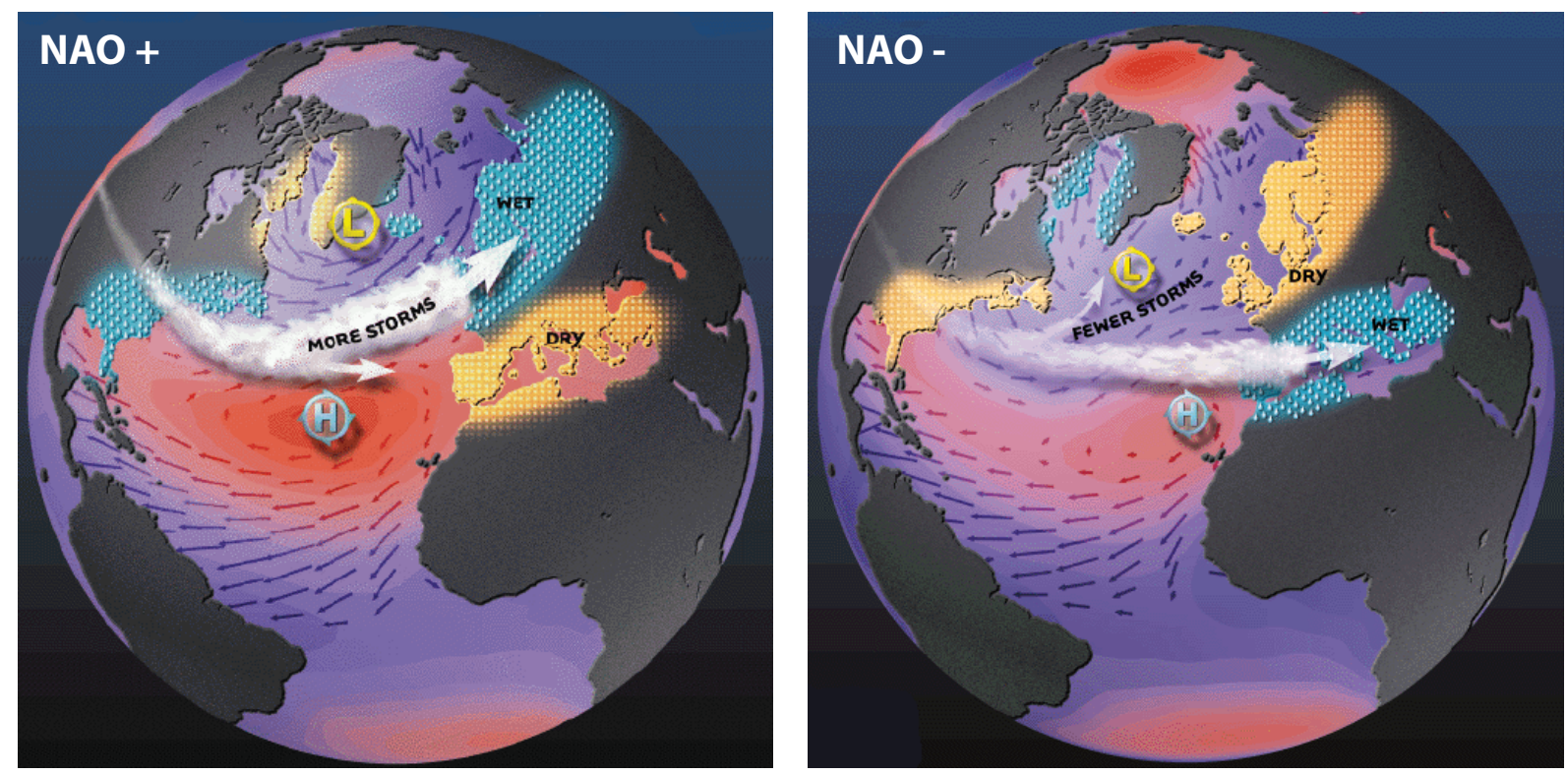

Figura 16. Mapa del oceáno Atlántico mostrando las dos fases de la Oscilación del Atlántico Norte (NAO). También están representadas el anticiclón de la Azores, la borrasca de Islandia y los vientos del Oeste. Modificado de http://www.ldeo.columbia.edu/res/pi/NAO/

Durante la fase positiva de la NAO el anticiclón de las Azores es especialmente fuerte mientras que la borrasca de Islandia presenta presiones más bajas de lo normal. Este incremento en la diferencia de presión provoca un aumento de las tormentas que atraviesan el Atlántico y una desviación de estas hacia el norte de Europa (Fig. 16). El resultado de esta situación son inviernos cálidos y húmedos en el norte del continente europeo y fríos y secos en Groenlandia, sur de Europa y Mediterráneo (Hurrell, 1995). En cambio, valores negativos de la NAO se deben a un debilitamiento del anticiclón de las Azores y del centro de bajas presiones de Islandia. La 
reducción del gradiente de presión resulta en un debilitamiento y disminución de las tormentas que cruzan el Atlántico (Fig. 16). Esta situación genera inviernos suaves y húmedos en gran parte del Mediterráneo y fríos en el norte de Europa (Fig. 16).

La NAO fue uno de los primeros patrones meteorológicos descritos en el mundo. Las primeras referencias a este fenómeno se remontan a varios siglos de antigüedad, cuando marineros escandinavos relacionaron las condiciones del Atlántico Norte con las variaciones en el clima de las diferentes masas terrestres de alrededor, como Dinamarca y Groenlandia (Stephenson et al., 2003).

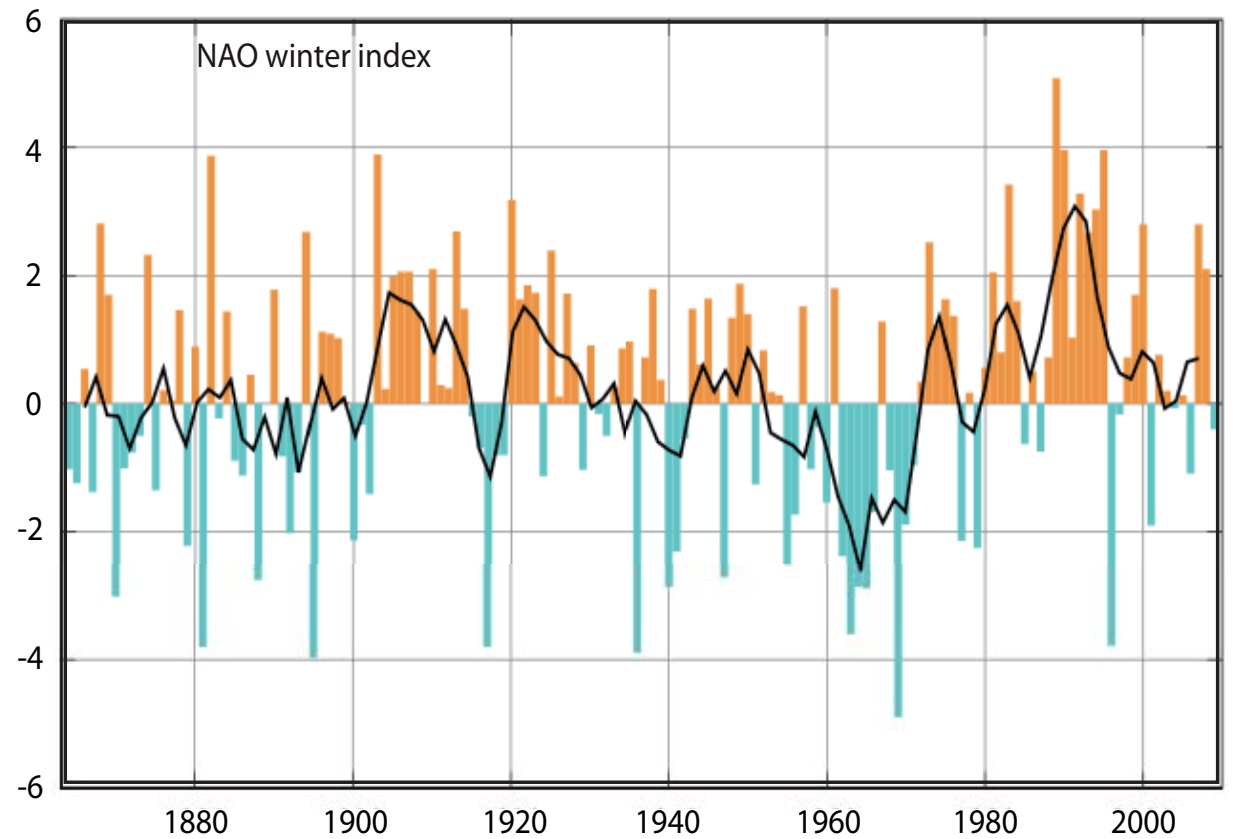

Figura 17: Índice de la NAO basado en la diferencia en la presión atmosférica a nivel del mar normalizada entre Lisboa (Portugal) y Stykkisholmur/Reykjavik (Islandia) desde 1864, con la media en color negro (5 años moving average). Modificado de http://upload.wikimedia.org/wikipedia/commons /8/87/Winter-NAO-Index.svg.

En los últimos años, se ha renovado el interés por este fenómeno debido a su relación con el cambio climático global. Las variaciones en la NAO producen importantes cambios en la velocidad y dirección del viento en el Atlántico, lo que repercute en el transporte de masas de aire y tormentas entre el océano y los continentes adyacentes. Las oscilaciones en la NAO generan cambios en la temperatura de la superficie del océano, en las corrientes oceánicas y en la cobertura de hielo del océano de las regiones árticas y subárticas. Estas fluctuaciones climáticas tienen importantes repercusiones económicas ya que afectan, entre otros, a la agricultura, pesquerías y demanda energética (Hurrell et al., 2003).

En la actualidad, las temperaturas del Hemisferio Norte son las más cálidas del último milenio (Mann et al., 1999; Jones et al., 2001). Este aumento ha sido especialmente elevado 
durante los últimos cuarenta años $\left(\sim 0.15^{\circ} \mathrm{C} \mathrm{década}^{-1}\right)$ (Hansen et al., 2002). Una parte importante de este incremento está relacionado con un cambio en el comportamiento de la NAO en los últimos años (Hurrell, 1996; Thompson y Wallace, 2000) (Fig. 17). Aproximadamente entre los años sesenta y ochenta prevaleció la fase negativa de la NAO y a partir de los ochenta ocurrió un cambio de fase, pasando a dominar valores positivos (Fig. 18), lo que probablemente estimuló el incremento de temperaturas.

La intensidad de la mezcla invernal de la columna de agua en algunas zonas del Mar del Labrador y de los mares de Groenlandia, Islandia y Noruega también está relacionada con el estado de la NAO. Sin embargo, esta relación no es directa ya que otros fenómenos atmosféricos juegan también un importante papel interaccionando con la NAO (Hurrell et al., 2003). Estos cambios afectan a la circulación termohalina del Atlántico y por lo tanto, a la cantidad de calor transportado por la circulación oceánica y las temperaturas de la superficie de la columna de agua.

La NAO también tiene importantes repercusiones sobre los ecosistemas terrestres y marinos. Así por ejemplo, actualmente en algunas partes de Europa muchas especies de plantas florecen antes y durante más tiempo debido a la tendencia de los inviernos a ser más húmedos y cálidos. También, se ha relacionado el estado de la NAO con el crecimiento, desarrollo, fertilidad y tendencias demográficas de muchos animales terrestres (Mysterud et al., 2003). Así mismo, se ha demostrado la influencia de la NAO sobre la hidrología, química y biología de los ecosistemas marinos (Drinkwater et al., 2003) y de agua dulce (Straile et al., 2003). Un buen ejemplo del efecto de la NAO sobre el fitoplancton es el proporcionado por Irigoen et al. (2000), que describieron como en el canal de la Mancha la proporción de diatomeas durante el bloom de primavera estaba correlacionada con el índice de la NAO.

\subsubsection{El caso particular del Mediterráneo Noroccidental}

Las condiciones atmosféricas de la cuenca Noroccidental del Mediterráneo (golfo de León y cuenca Liguro-Provenzal) están determinadas en gran medida por la NAO, es decir, por la alternancia de masas de aire cálido y húmedo procedentes del Atlántico y masas de aire frío y seco de las regiones árticas (Meteorological Office, 1962). Además, es importante señalar que el efecto de la NAO sobre la cuenca Noroccidental y los Alpes es diferente al resto de la cuenca Mediterránea. En este sentido, valores negativos de la NAO están asociados con la llegada de vientos fríos y secos sobre el Mediterráneo Noroccidental (Fig. 18), provocando inviernos inusualmente fríos. Un índice de la NAO positivo indica un cambio de la trayectoria de los vientos del Oeste (Fig. 18) resultando en inviernos suaves y lluviosos y en una disminución de la pérdida de calor en la cuenca Noroccidental (Wanner et al., 1997). 


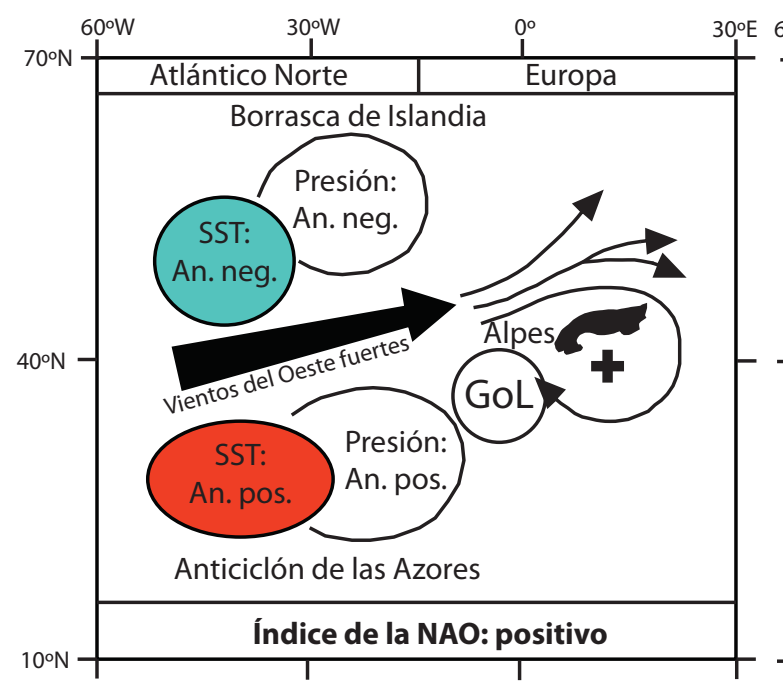

a

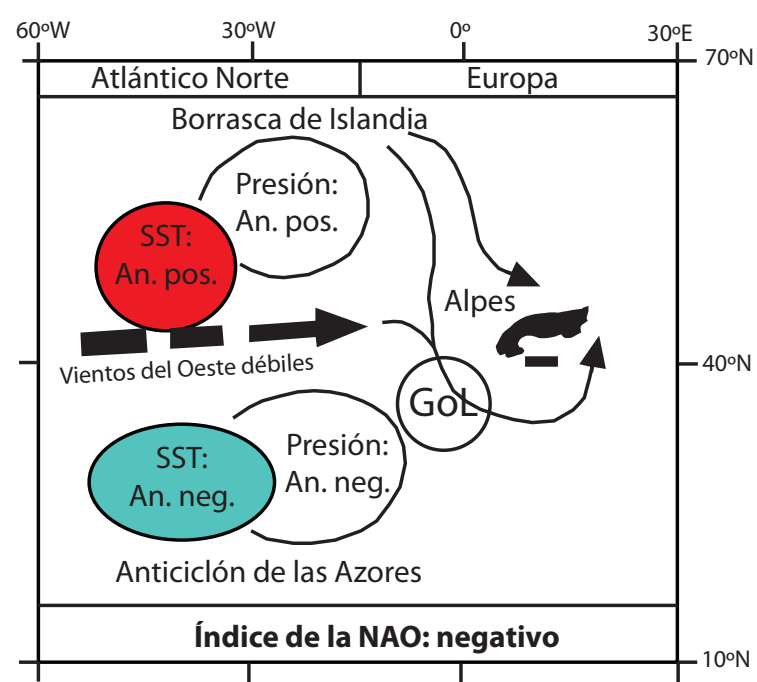

b

Figura 18: Representación esquemática de las anomalías de temperatura de la superficie del océano y de la presión atmosférica en el océano Atlántico durante las dos fases de la Oscilación del Atlántico Norte (NAO). También están representadas la influencia sobre los vientos y la tendencia de presión en los Alpes y Cuenca Noroccidental del Mediterráneo (signos más y menos). An. pos.: anomalía positiva / An. neg.: anomalía negativa; GoL: golfo de León. Modificado de Wanner (1997).

Como ya hemos mencionado en la sección 2.4.3, la corriente del Norte se forma a partir de la corriente de Liguria y la corriente de Tirreno que fluyen al oeste y este de la isla de Córcega respectivamente (Fig. 6). La corriente de Tirreno atraviesa el estrecho de Córcega (430 $\mathrm{m}$ de profundidad) que conecta el mar Tirreno con mar de Liguria. La corriente de Tirreno presenta una clara variabilidad interanual que parece estar relacionada con el estado de la NAO (Vignudelli et al., 1999). Inviernos anómalamente fríos y secos resultan en una mayor evaporación y pérdida de calor en la cuenca Noroccidental lo que provoca un aumento en la mezcla de columna de agua e intensifica el transporte de la corriente de Tirreno a través del canal de Córcega. Mientras que inviernos más suaves y húmedos producen el efecto inverso, disminuyendo la mezcla y el transporte a través del estrecho de Córcega (Vignudelli et al., 1999). La intensidad de la corriente de Tirreno tiene un efecto directo sobre la corriente del Norte (NC) que presenta una clara variabilidad interanual (Béthoux et al., 1982; Astraldi y Gasparini, 1992)

Gómez y Gorsky (2003) señalaron la posible relación entre la variabilidad de la NC con la intensidad del bloom de primavera en el mar de Liguria basándose en datos históricos (Tabla 1). Según estos autores, durante los años de elevado flujo de agua a través del estrecho de Córcega (y valores bajos o negativos del índice de la NAO) se desarrolla un intenso bloom durante la primavera, mientras que los años de circulación baja (índice de la NAO positivo) la intensidad del bloom de primavera es bajo. Además señalan que durante los años más productivos el bloom de primavera se desarrolla antes (Marzo) mientras que durante los menos productivos se retrasa (Mayo). 


\begin{tabular}{cccc}
\hline Año & Flujo & NAO & Bloom \\
\hline 1962 & - & $-2,38$ & Alto \\
1963 & - & $-3,60$ & Alto \\
1985 & 2 & $-0,63$ & Alto \\
1986 & 1,6 & 0,50 & Alto \\
1987 & 1,3 & $-0,75$ & Alto \\
1988 & 0,9 & 0,72 & Bajo \\
1989 & - & 5,08 & Bajo \\
1990 & - & 3,96 & Bajo \\
1991 & 0,6 & 1,03 & Bajo \\
1992 & 0,4 & 3,28 & Bajo \\
1993 & 0,2 & 2,67 & - \\
1994 & 0,8 & 3,03 & - \\
1998 & 1 & 0,72 & Bajo \\
1999 & - & 1,70 & Bajo \\
\hline
\end{tabular}

Tabla 1. Intensidad del bloom o eclosión de primavera en la Bahía de Villefranche basada en datos históricos (Gómez y Gorsky, 2003)(evaluada como alta o baja) comparada con el caudal de invierno (Sverdrups) a través del canal de Córcega (Astraldi et al., 1995; Vignudelli et al., 2000) y con el índice de invierno de la NAO (Hurrell, 1995). Modificado de Gómez and Gorsky (2003).

\subsection{DINÁMICA DEL ENSO}

El Niño - Oscilación del Sur (El Niño - Southern Oscillation) es un fenómeno climático que ocurre a lo largo del Pacífico Tropical y que consiste en un cambio de los patrones de movimiento de las corrientes oceánicas y masas de aire en la zona intertropical. Este fenómeno presenta una periodicidad irregular que varía entre tres y siete años (media cinco años) y controla el sistema climático tropical influyendo fuertemente en la dinámica atmosférica y oceánica del océano Pacífico subtropical (Philander, 1990).

En condiciones normales o “condiciones neutras” del ENSO (Fig. 19), el océano Pacífico tropical está caracterizado por aguas superficiales cálidas en el oeste $\left(29-30^{\circ} \mathrm{C}\right)$ y mucho más frías en el este $\left(22-24^{\circ} \mathrm{C}\right)$. La masa de agua más cálida del oeste se llama a menudo warm pool (Webster y Palmer, 1997). El warm pool es bastante profunda y presenta una termoclina situada entre los 100 y los 200 metros de profundidad. En cambio en la zona oriental del Pacífico las aguas superficiales son más frías como resultado del afloramiento de aguas profundas y frías. Esta diferencia de temperatura entre los dos extremos del océano Pacífico genera un gradiente de temperatura, que provoca a su vez, un gradiente de presiones atmosféricas, siendo estas más elevadas en el este. Los vientos de superficie siguen ese gradiente, dando lugar a los vientos alisios (Fig. 19). 


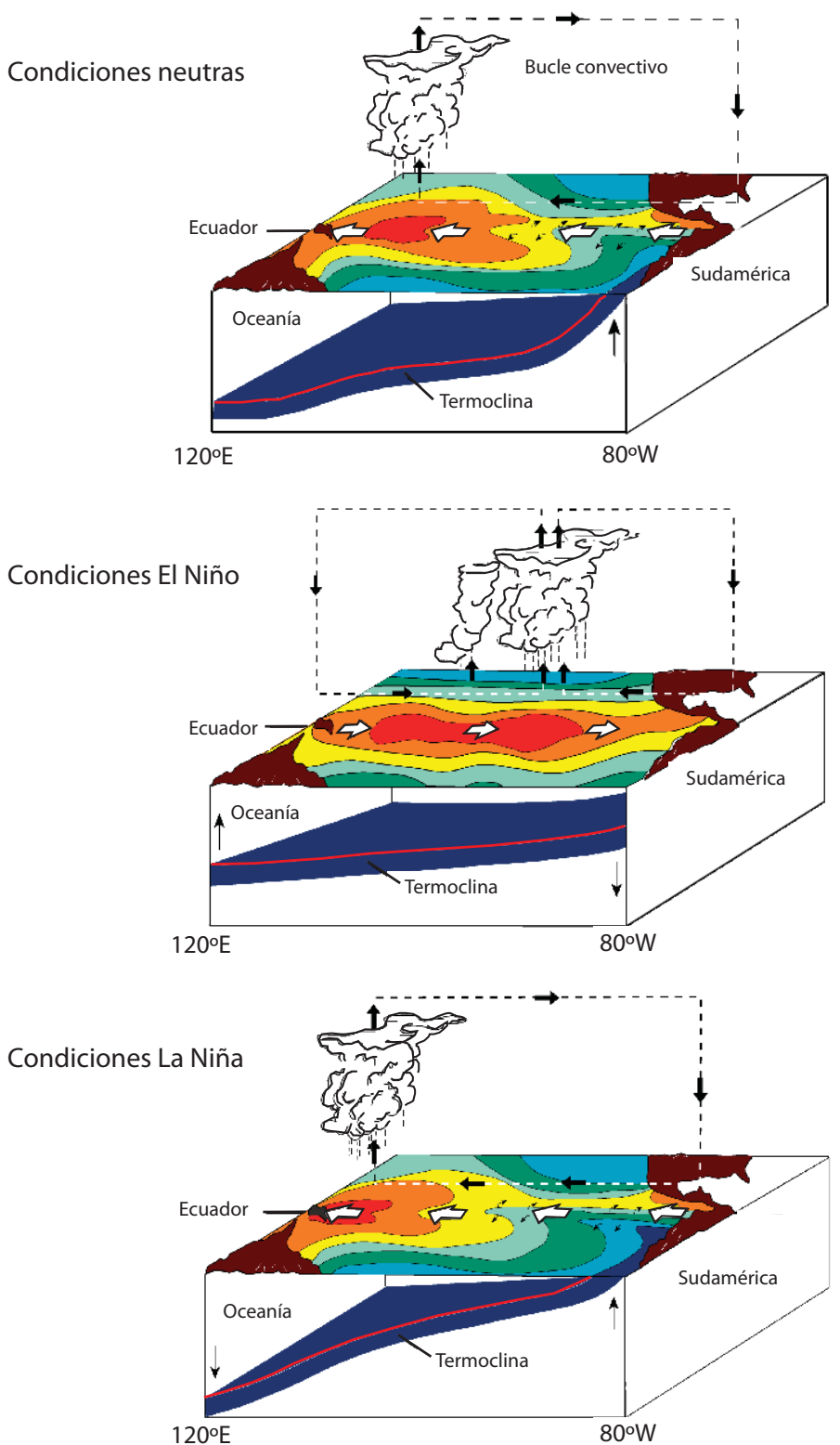

Figura 19: a. Condiciones normales en el océano Pacífico. Los vientos alisios llevan aguas cálidas hacia el Oeste, mientras que aguas frías afloran en las costas de Sudamérica. b. Condiciones El Niño. La masa de agua cálida del oeste se extiende hacia Sudamérica. La surgencia de aguas frías se frena aumentando el calentamiento. c. Condiciones La Niña. La masa de agua cálida está más hacia el Oeste que habitualmente. Modificado de http://www.pmel.noaa.gov/tao/proj_ over/diagrams/ index.html.

Periódicamente, y por causas que aún no están claras, las "condiciones neutras" cambian y se produce un calentamiento a lo largo de toda la cuenca del Pacífico tropical durante un periodo de tiempo que puede superar un año (Webster y Palmer, 1997). La expansión de las aguas calientes del Pacífico Occidental hacia el Este provoca el bloqueo progresivo del afloramiento de aguas profundas en las costas de Sudamérica, con el consiguiente hundimiento de la termoclina (Fig. 19). El bloqueo del afloramiento reduce el gradiente longitudinal de temperatura, lo que a su vez provoca una disminución del gradiente barométrico en la atmósfera, y una disminución de los vientos alisios (Fig. 19). Estos episodios de sobrecalentamiento del Pacífico ecuatorial se conocen científicamente como El Niño.

Normalmente, después de aproximadamente un año de un evento de El Niño tiene lugar una situación contrapuesta a las condiciones de sobrecalentamiento conocida por La Niña. Durante La Niña se produce un enfriamiento relativo de las aguas cálidas del este del océano 
Pacífico, lo que provoca una expansión de las aguas frías de la costa sudamericana hacia el Este (Fig. 19). Esto provoca un aumento del gradiente longitudinal de temperatura de la superficie del mar y un incremento en la intensidad de los vientos alisios (Fig. 19).

Uno de los índices que se emplean para caracterizar el ENSO es el de la Anomalía de Temperatura del Agua Superficial del Mar (Sea Surface Temperature, SST) en la zona comprendida entre las longitudes de $90^{\circ} \mathrm{W}$ y $150^{\circ} \mathrm{W}$ y las latitudes $5^{\circ} \mathrm{S}$ y $5^{\circ} \mathrm{N}$. Esta zona se conoce como la Zona de El Niño. Las anomalías positivas de SST hacen referencia a El Niño y las negativas a La Niña. Para que una anomalía sea considerada como Niño o Niña tiene que observarse que durante más de cinco meses la anomalía de temperatura es superior a la desviación típica del valor promedio en condiciones neutras. Por otro lado, la Oscilación del Sur se define como la diferencia normalizada entre la presión atmosférica a nivel del mar de la ciudad de Darwin (Australia) y la ciudad de Tahití (Polinesia Francesa). En este caso, las anomalías negativas indican condiciones El Niño, mientras que las positivas indican condiciones La Niña. Ambos índices muestran que a pesar de tener un origen diferente (atmosférico y oceánico), registran el mismo fenómeno. Para poder monitorizar este fenómeno se desarrolló un índice conocido por Índice Multivariable ENSO (Multivariate ENSO Index, MEI) (Fig. 20) que tiene en cuenta las seis principales variables que afectan al fenómeno ENSO en el Pacífico Tropical. Las variables que se emplean para calcular este índice son las siguientes: presión a nivel del mar, dirección e intensidad del viento, temperatura superficial del océano, temperatura del aire a nivel del mar y cantidad total de nubes. Valores negativos del MEI representan la fase fría del ENSO, i.e., La Niña, mientras que valores positivos representan la fase cálida del ENSO, i.e., El Niño.

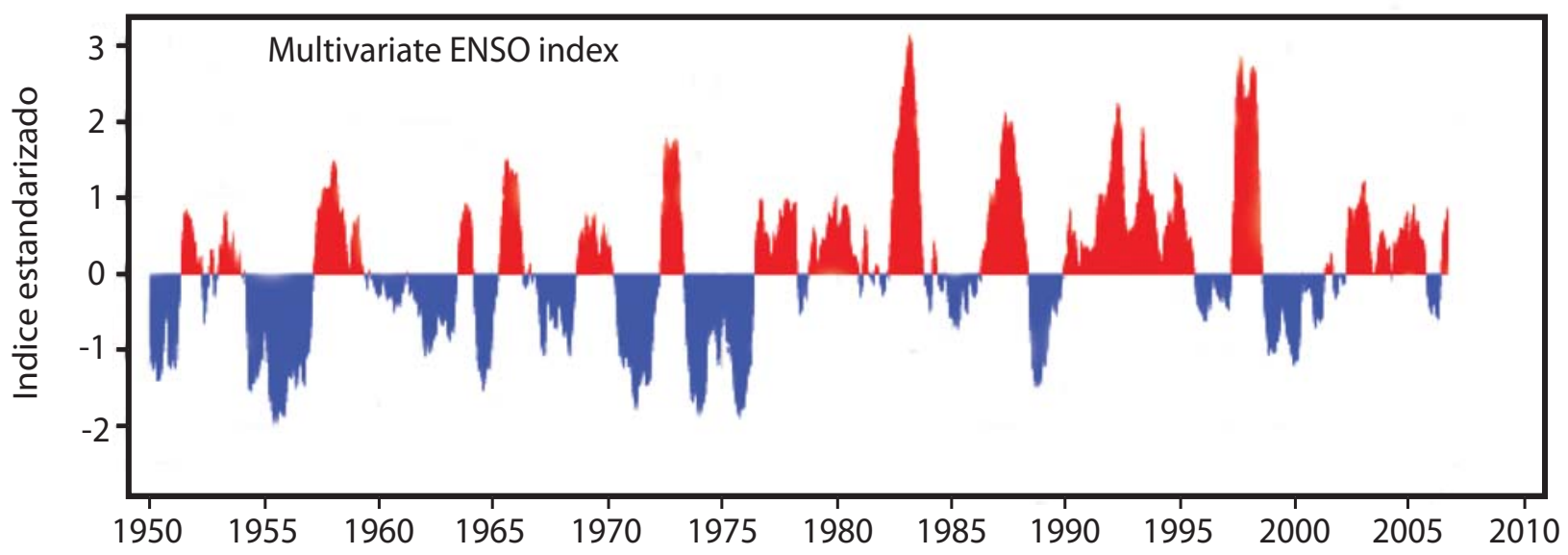

Figura 20: Índice Multivariable ENSO (Multivariate ENSO Index, MEI) desde 1950 hasta la actualidad. Valores positivos indican la fase de El Niño mientras que valores negativos indican la fase de La Niña. Modificado de http://www.esrl.noaa.gov/psd/people/klaus.wolter/MEI/. 


\subsubsection{El evento El Niño 1997-98 y su efecto sobre el Mediterráneo Occidental}

El ENSO es el patrón dominante en el sistema climático tropical influyendo en la circulación atmosférica y oceánica del océano Pacífico. Eventos extremos del ENSO pueden llegar a modificar el clima Atlántico y Europeo (Wanner et al., 1997). En este sentido, Fraedrich and Müller (1992) y Fraedrich (1994) mostraron que eventos cálidos del ENSO (El Niño) pueden provocar cambios en la dirección de los vientos del oeste que soplan sobre el continente europeo influyendo en sus patrones meteorológicos. Sin embargo, aún no se conocen bien los efectos de estos eventos extremos sobre nuestra zona de estudio, i.e. Mediterráneo Noroccidental (Wanner et al., 1997).

Durante el periodo 1997-98 tuvo lugar el evento El Niño más fuerte nunca registrado (Fig. 20). Según McPhaden (1999) este fenómeno tuvo importantes repercusiones climáticas en todo el mundo, como por ejemplo un aumento de la temperatura media global de unas décimas de grado Celsius debido a la pérdida de calor del Pacífico tropical hacia la atmósfera. En el Mediterráneo Occidental diversos estudios registraron condiciones anómalas durante este periodo. En este sentido, en su trabajo en el mar de Alborán, García-Gorriz y Carr (2001) describieron SST anómalamente altas y una fuerte estratificación durante el verano y otoño de 1997 así como un debilitamiento de los vientos durante el otoño. Estas condiciones dificultaron la mezcla de la columna de agua y el consecuente aporte de nutrientes a la zona fótica durante el invierno, lo que tuvo importantes repercusiones sobre las poblaciones de fitoplancton (Bárcena et al., 2004; Mercado et al., 2005; Mercado et al., 2007; Hernández-Almeida et al., 2010). Entre ellas, cabe destacar el debilitamiento y retraso del bloom de primavera.

En el Mediterráneo Noroccidental, Gómez y Gorsky (2003) registraron bajas abundancias de microplancton durante 1998, mientras que Marty et al. (2002) describieron una débil mezcla de la columna de agua durante el invierno 1997-98 y una baja abundancia de diatomeas durante la eclosión de primavera de 1998. 



\section{Capítulo 3}

Material y métodos

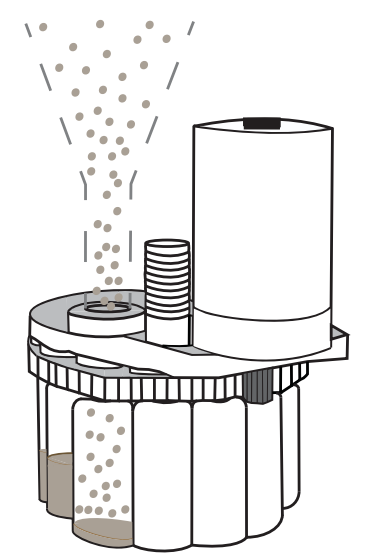





\subsection{TRAMPAS DE SEDIMENTO}

\subsubsection{Definición}

Las trampas de sedimento (Fig. 1) son herramientas oceanográficas cuya función es la de capturar el material particulado (de origen orgánico e inorgánico) que cae por la columna de agua. Consisten básicamente en un cono colector que converge hacia un plato rotatorio o carrusel provisto de una serie de frascos colectores. El carrusel se encuentra acoplado a un motor regulado por un circuito electrónico programable que avanza escalonadamente cambiando el recipiente colector en la base del cono a intervalos de tiempo preestablecidos (Fig. 1).

De este modo las trampas de sedimento permiten obtener un registro continuo del flujo de material hacia el fondo durante periodos de tiempo relativamente largos, siendo actualmente el único modo de medir el flujo de masas, composición, estacionalidad y variabilidad interanual del flujo de partículas en la columna de agua (Deuser, 1996; Usbeck et al., 2003).

\subsubsection{Estructura de la línea de muestreo (mooring)}

Un mooring o línea de muestreo consiste un conjunto de instrumentos conectados a un cable anclado temporalmente al fondo marino (Fig. 2). Los principales componentes de un mooring se detallan a continuación:

- Boyas: Se encuentran distribuidas a distintas profundidades del mooring (Fig. 2) y su función es la de mantenerlo en posición vertical. La verticalidad de la línea de muestro es de vital importancia ya que algunos de los instrumentos no funcionan correctamente a partir de cierto grado de inclinación.

- Trampas de sedimento: Colectores pasivos de las partículas que caen por la columna de agua (Fig. 1).

- Correntímetro: Instrumento que mide la intensidad y dirección de las corrientes (Fig. 2). Además de esta función, puede tener integrados diferentes sensores para medir otras variables oceanográficas, como la temperatura, presión, conductividad del agua (que permite conocer la salinidad) o la turbidez (concentración de materia en suspensión). Es posible programar el correntímetro para registrar todas estas medidas cada pocos minutos o incluso cada 30 segundos.

- Liberador acústico: Su función es la de liberar el mooring del anclaje para recuperar los instrumentos. Se activa enviando una señal acústica codificada desde el barco de mantenimiento (Fig.2).

- Peso muerto: Cadenas de aproximadamente 600-700 kg cuyo peso impide que el mooring se desplace de su posición inicial (Fig. 2). 

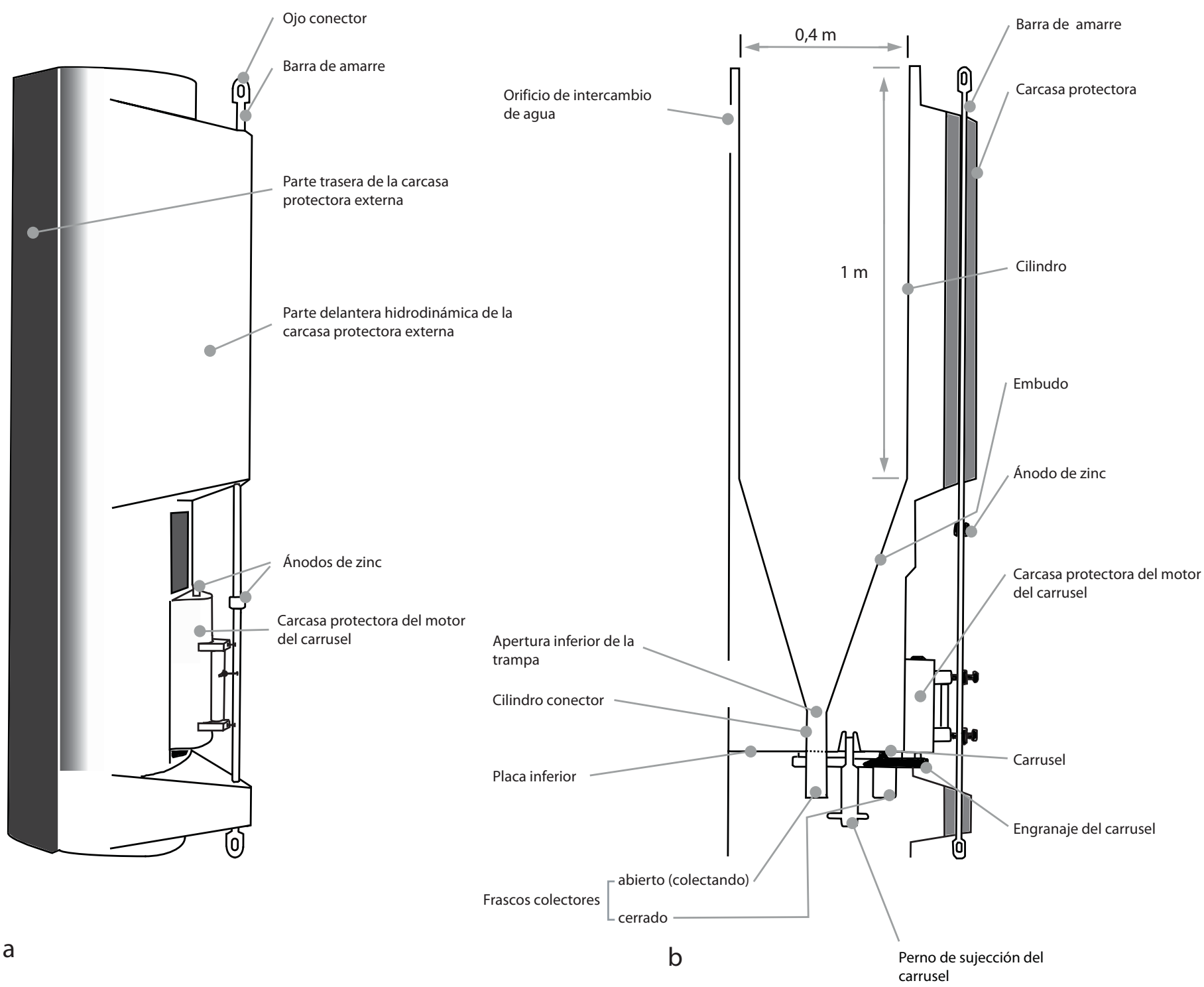

a

b carrusel

Figura 1. Estructura de una trampa de sedimento modelo PPS 3. a. Vista exterior. b. Corte de la trampa. c. Detalle del carrusel recogiendo material de la columna de agua (señalado con una flecha el sentido de giro). Modificado de

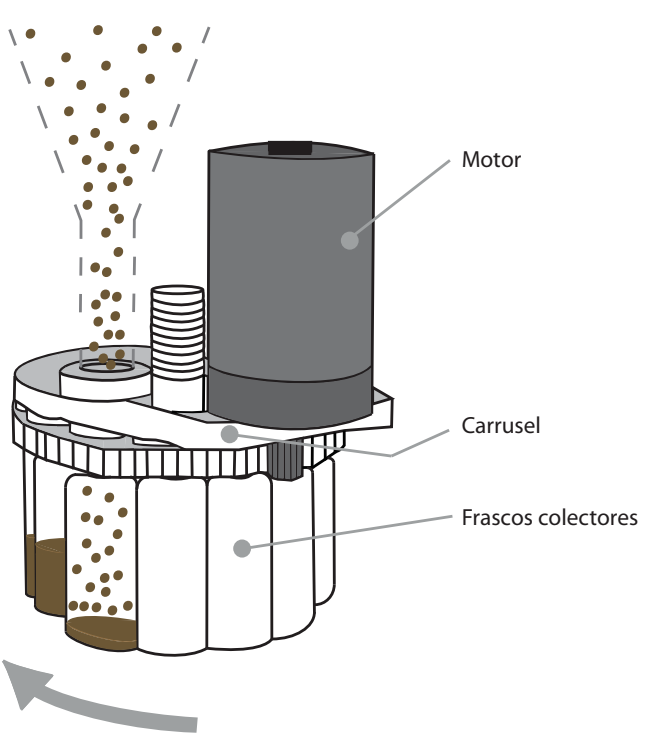
Heussner (1990) y de Martín (2007). 


\subsection{DESCRIPCIÓN DEL EXPERIMENTO}

El presente trabajo forma parte de tres experimentos independientes llevados a cabo en tres áreas del Mediterráneo Occidental: golfo de León, margen continental catalán y mar de Alborán. Los principales objetivos de estos proyectos son: (1) monitorizar el transporte de material particulado en la columna de agua por medio del registro en trampas de sedimento con el fin de describir la variabilidad espacial, estacional e interanual del flujo de partículas y (2) analizar el papel de las diferentes fuerzas que controlan el intercambio de partículas en las diferentes áreas de estudio. A continuación se detallan los tres experimentos:

\subsubsection{Golfo de León}

Los dos registros procedentes del golfo de León son los de mayor duración y en los que se ha centrado la mayor parte de este trabajo. Este experimento fue iniciado por Heussner et al. en 1993 y continua en la actualidad (Heussner et al., 2006). Basándonos en los periodos de muestreo, el trabajo puede dividirse en dos etapas:

1. durante la primera fase del experimento (1993 - 95) fueron colocados siete moorings o líneas de muestreo en tres zonas del golfo: tres en el cañón de Planier (Noreste), tres en el cañón de Lacaze-Duthiers (Suroeste) y otro aproximadamente en la zona central del golfo de León, en el cañón de Sète (Fig. 2).

2. para segunda fase del experimento (1995-2006) sólo dos de los siete moorings permanecieron en funcionamiento, los situados en el eje central de los cañones de Planier y Lacaze-Duthiers en la mitad del talud continental (Fig. 2).

Todos los moorings estaban equipados con dos trampas de sedimento: una situada a $30 \mathrm{mab}$ (meters above bottom - metros sobre el fondo) y la otra a 500 mab. Dos metros por debajo de cada una de ellas fueron colocados correntímetros Aanderaa (Fig. 2). El modelo de las trampas empleadas fue del tipo PPS3 Technicap de forma cilindrocónica con un diámetro de apertura de $0,4 \mathrm{~m}$ (con una relación de 2,5 altura/diámetro de la parte cilíndrica) y equipada con de 6 a 12 frascos de muestreo (Fig. 1). El intervalo de muestreo programado en las trampas fue de aproximadamente 14 días desde Octubre de 1993 hasta Enero de 1997 y a partir de ese momento (fin de la primera fase del experimento) fue de aproximadamente un mes hasta Marzo de 2006 (Heussner, 2006). En el presente trabajo se han estudiado las muestras procedentes de las dos trampas de sedimento situadas a 500 mab de los moorings de los cañones de Planier y Lacaze-Duthiers, situados a la entrada y a la salida del golfo de León, respectivamente (Fig. 2). La situación exacta de los dos moorings es de $43.02^{\circ} \mathrm{N}, 5.18^{\circ} \mathrm{E}$ para el situado en el cañón de Planier y de $42.41^{\circ} \mathrm{N}, 3.54^{\circ} \mathrm{E}$ para el del cañón de Lacaze-Duthiers.

Las trampas de sedimento requieren un mantenimiento cada cierto número de meses, para el caso que nos ocupa el mantenimiento fue semestral. Para ello los moorings son liberados uno a uno por medio de una señal acústica codificada y posteriormente son recogidos y revisados. Las piezas dañadas son cambiadas, los frascos colectores son reemplazados por unos nuevos, los datos de los correntímetros son descargados en un ordenador y los motores de la trampa 
y los instrumentos son programados de nuevo. El control de este experimento fue llevada a cabo por el CEFREM (CEntre de Formation et de Recherche sur l'Environnement Marin) adscrito a la Universidad de Perpignan gracias a la financiación de cuatro programas europeos consecutivos (Euromarge-NB, MTP II-MATER, EUROSTRATAFORM y HERMES) y el programa Francés PNEC (Programme National Environnement Côtier).

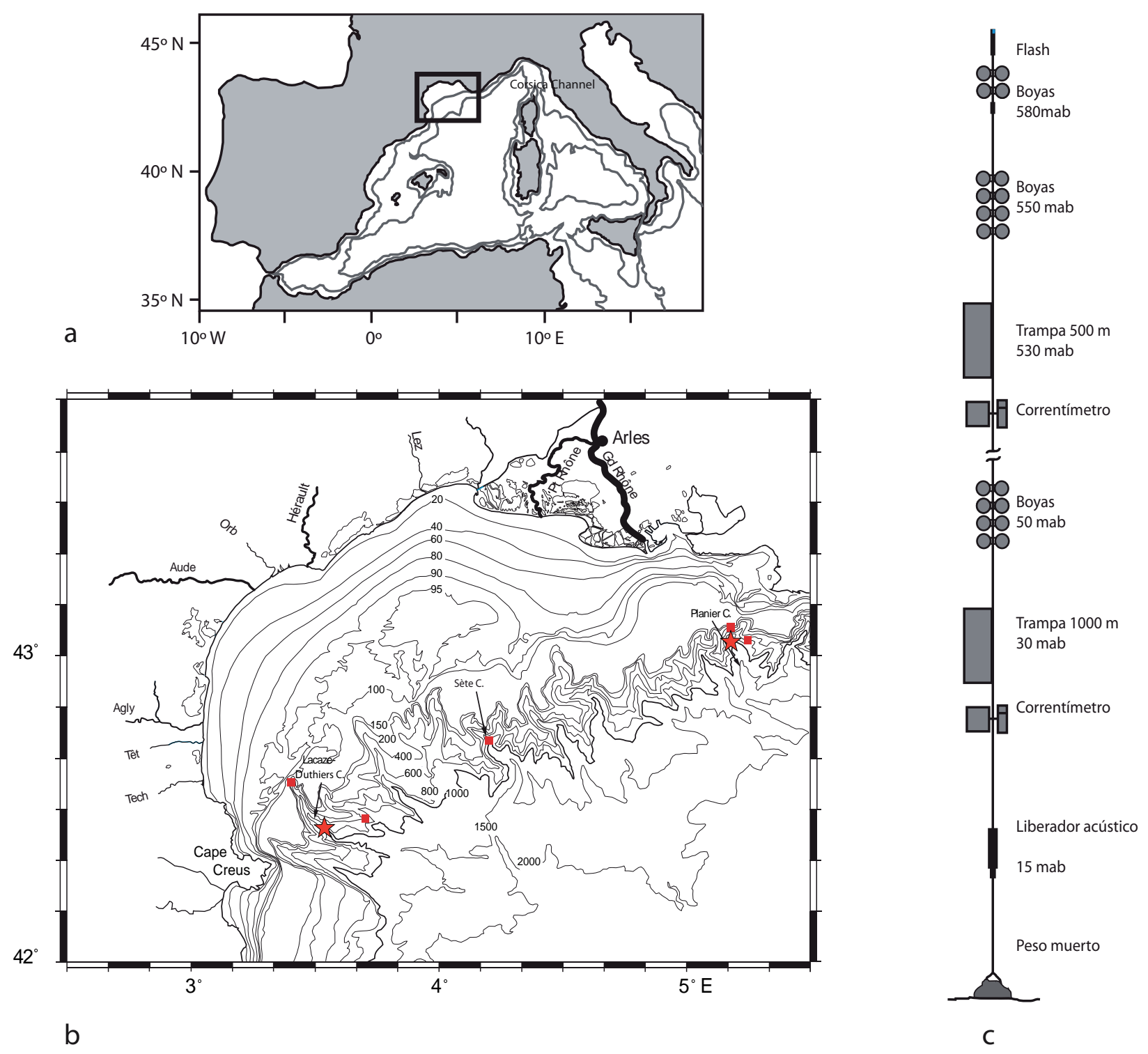

Figura 2: a. Situación del golfo de León en el Noroeste del Mediterráneo. b. Mapa batimétrico del golfo de León con la localización de los moorings en el cañón de Planier, de Sète y de Lacaze-Duthiers. Señalados con un cuadrado los moorings de la primera fase del experimento y con una estrella los de la segunda. 


\subsubsection{Margen continental Catalán}

La monitorización de los flujos de partículas en el margen continental de Barcelona (Fig. 3) fue llevada a cabo mediante del despliegue de tres moorings, con un total de cuatro trampas de sedimento, durante el periodo Abril 1993 - Mayo 1994 y con una resolución de muestreo de entre 15 y 16 días (Puig and Palanques, 1998). Sólo uno de los registros de las cuatro trampas desplegadas fue analizado para presente trabajo, la situada en el eje del cañón de Foix a 530 mab (Fig. 3) en una columna de agua de $680 \mathrm{~m}$. El modelo de las trampas fue el mismo que el empleado para el resto de zonas de estudio: PPS3 Technicap. El desarrollo de este experimento fue llevado a cabo por personal del Institut de Ciencies del Mar (CSIC) de Barcelona gracias a la financiación de los proyectos Euromarge-NB y CONCENTRA.

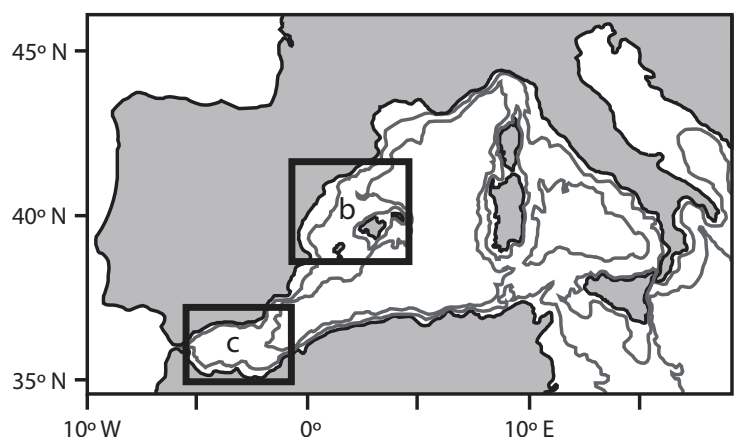

a

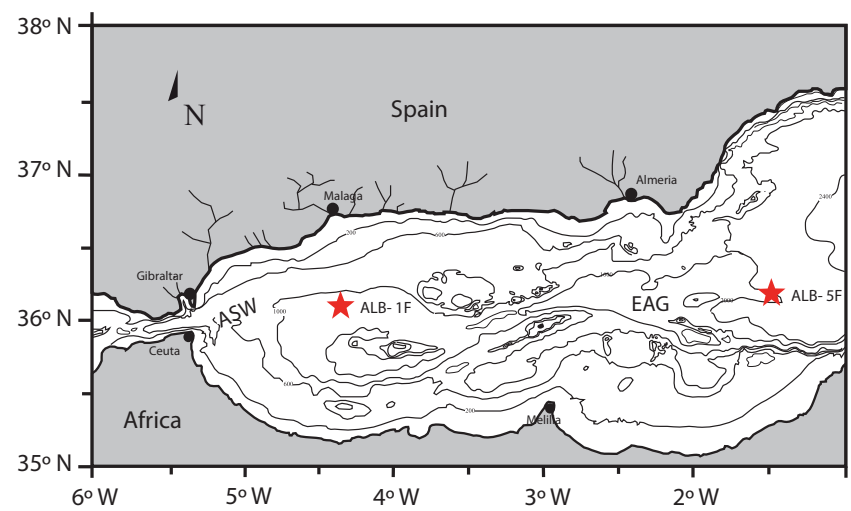

$\mathrm{C}$

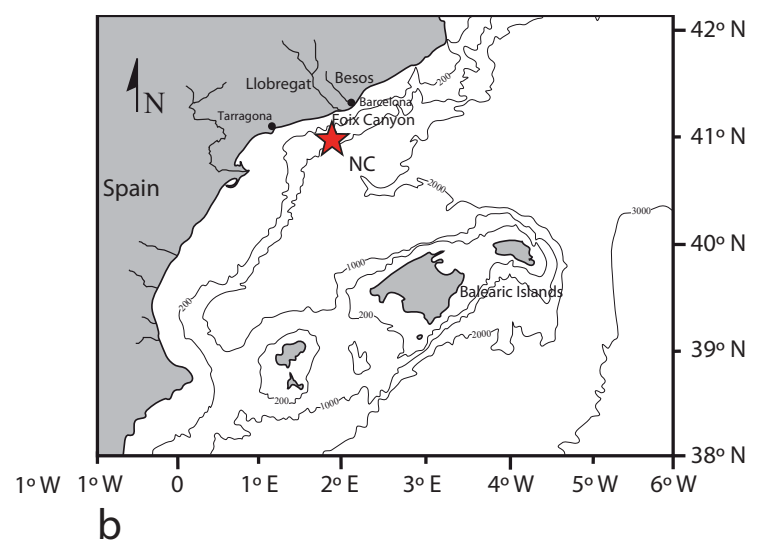

b

Figura 3: a. Situación del margen continental Catalán y mar de Alborán en el Mediterráneo Occidental. b. Mapa batimétrico del margen continental Catalán con la localización del mooring en el cañón de Foix (estrella roja). c. Mapa batimétrico del mar de Alborán con la localización de los dos moorings.

\subsubsection{Mar de Alborán}

En el margen continental español y norteafricano fueron desplegadas dos líneas de muestreo: ALB-1 $\left(36.02^{\circ} \mathrm{N}, 04.26^{\circ} \mathrm{W}\right)$ y ALB-5 $\left(36.23^{\circ} \mathrm{N}, 04.46^{\circ} \mathrm{W}\right)$ (Fig. 3). El mooring ALB-5 se situó en el AOF, en el borde sur-oriental del EAG (Fig. 3), a una profundidad de 2100 m. ALB-5 estaba equipado con tres trampas de sedimento dispuestas a 500, 1000 y 2070 
$\mathrm{m}$ de profundidad. Únicamente la trampa más cercana del fondo (ALB-5F), situada a $2070 \mathrm{~m}$ de profundidad (30 mab), fue empleada para el estudio micropaleontológico. Por otro lado, el mooring ALB-1 se dispuso en una zona bajo la influencia de la ASW y el WAG (Fig. 3) a una profundidad de $1004 \mathrm{~m}$. Este mooring fue equipado con dos trampas de sedimento situadas a 471 y 974 m de profundidad. Para el análisis micropaleontológico se analizaron las muestras recogidas por la trampa de fondo (ALB-1F, $974 \mathrm{~m}$ de profundidad y $30 \mathrm{mab}$ ). El tiempo de muestreo de ambos registros fue de 11 meses Julio 1997 - Mayo 1998 y se realizó durante tres periodos: (I) de Julio a Octubre de 1997, (II) de Noviembre de 1997 a Marzo de 1998 y (III) de Abril a Mayo de 1998. Los intervalos de muestreos fueron de diez días, excepto durante el tercer periodo que se redujo a intervalos de tres. El modelo de las trampas empleadas fue Technicap PPS3. Este experimento fue realizado en el marco del proyecto de investigación MTP-I-MATER.

\subsubsection{Material analizado}

Un total de 122 muestras procedentes de la estación de muestreo de Planier y 154 muestras de Lacaze-Duthiers fueron procesadas y analizadas para el estudio de microfósiles silíceos y calcáreos. Además de esto 21 muestras del registro del margen continental Catalán y 32 muestras de ALB 1F y 29 de ALB 5F del Mar de Alborán fueron analizadas para el estudio de silicoflagelados. El conjunto de muestras y grupos de fósiles estudiados en este trabajo se resumen en la Tabla 1.

\begin{tabular}{|c|c|c|c|c|c|}
\hline Trampa & Profundidad & Periodo & $\begin{array}{l}\text { Intervalo de } \\
\text { muestreo }\end{array}$ & $\begin{array}{l}\text { Número } \\
\text { de muestras }\end{array}$ & Grupos estudiados \\
\hline Planier & $500 \mathrm{~m}$ (500 mab) & Oct 1993 - Mar 2006 & 14 - 30 días & 122 & Diatomeas, silicoflagelados y foraminíferos \\
\hline Lacaze Duthiers & $500 \mathrm{~m}(500 \mathrm{mab})$ & Oct 1993 - Mar 2006 & 14 - 30 días & 154 & Diatomeas, silicoflagelados y foraminíferos \\
\hline Foix & 150 m (530 mab) & Abr 1993 - Abr 1994 & 15 - 16 días & 21 & Silicoflagelados \\
\hline ALB-5F & $2040 \mathrm{~m}$ (30 mab) & Jul 1997 - May 1998 & 3 - 10 días & 29 & Silicoflagelados \\
\hline ALB-1F & 974 m (30 mab) & Jul 1997 - May 1998 & 3 - 10 días & 32 & Silicoflagelados \\
\hline
\end{tabular}

Tabla 1: Resumen de las principales características de las muestras de trampas de sedimento analizadas.

\subsubsection{Core tops}

Con el objetivo de complementar la información de microfósiles silíceos y calcáreos aportada por las trampas de sedimento, para este trabajo se procesaron y analizaron dos muestras de sedimento superficial o core tops recogidas debajo de las trampas de Planier y Lacaze Duthiers, a unos $1000 \mathrm{~m}$ de profundidad aproximadamente. Además se recurrió a la base de datos de Kallel et al. (1997) para obtener datos de abundancias relativas de foraminíferos de otros 11 coretops recogidos en áreas clave del golfo de León (Ver Capítulo 9). 


\subsection{PROCESAMIENTO DE LAS MUESTRAS}

\subsubsection{Consideraciones preliminares}

El mantenimiento y tratamiento del material recuperado en la trampa de sedimento previo al estudio micropaleontológico requiere una serie de consideraciones anteriores a su estudio:

\section{Solución biocida de los tubos colectores.}

Los tubos colectores situados en la trampa de sedimento han sido rellenados previamente con una solución de formaldehído tamponada al $5 \%(\mathrm{v} / \mathrm{v})$ con agua de mar previamente filtrada (con una membrana con un tamaño de poro de $0,45 \mu \mathrm{m}$ ). Esta solución, más densa que el agua del entorno, actúa de biocida para prevenir la degradación, principalmente bacteriana, de las partículas atrapadas. Además, evita o retarda la degradación de los carbonatos y protege a la muestra de la alteración mecánica que puedan realizar organismos nadadores al entrar ocasionalmente en las trampas durante el muestreo (Lange y Boltovskoy, 1995).

\section{El problema de los nadadores.}

Los organismos vivos más importantes numéricamente en muestras de trampas de sedimento son bacterias y microalgas. Las bacterias son descomponedoras de la materia orgánica muerta y la acompañan en su camino de descenso a través de la columna de agua, por lo tanto se incluyen en el flujo pasivo. Los organismos fotosintetizadores también son considerados parte del flujo pasivo. Pequeños flagelados, ciliados, algunos radiolarios y foraminíferos se adhieren a partículas en descenso y se consideran parte de la comunidad descomponedora que consume bacterias, autótrofos y otros protozoos asociados, y por lo tanto también se los incluye en el flujo total. Algunos organismos de talla mayor, entre centenares de $\mu \mathrm{m}$ y algunos mm, como ciertos copépodos, acompañan la nieve marina y también pueden considerarse miembros de la cadena alimenticia descomponedora, y por lo tanto parte del flujo pasivo.

Por otro lado, hay organismos que se retienen en las trampas como resultado de su movimiento activo de natación (Harbison and Gilmer, 1986; Lee et al., 1988; Michaels et al., 1990). Estos organismos no forman parte del flujo unidireccional y pasivo. Frecuentemente son crustáceos, hidromedusas, pterópodos, sifonóforos, apendicularias, algunos copépodos, etc. Constituyen uno de los principales problemas de las trampas de sedimento y especialmente agudo en trampas instaladas en aguas costeras someras donde gran parte del material colectado está formado por nadadores. Estos nadadores sesgan las estimaciones de flujo del material particulado atrapado por lo que deben ser separados antes de proceder a análisis ulteriores.

Para las muestras analizadas en el presente trabajo, estos organismos nadadores han sido eliminados de la muestra original manualmente. Se trata de un procedimiento tedioso pero eficaz para el caso de organismos grandes (Lange and Boltovskoy, 1995). 


\subsubsection{Procesamiento de las muestras}

\section{Procesado inicial básico.}

Una descripción detallada del procesamiento de las muestras recogidas por las trampas de sedimento PPS3 para su almacenamiento puede encontrarse en Heussner et al. (1990). Las principales etapas de este procedimiento están resumidas a continuación:

Una vez recogidos los tubos colectores, fueron almacenados en oscuridad, a una temperatura de entre 2 y $4^{\circ} \mathrm{C}$ hasta que fueron procesados en el laboratorio (Heussner, 2006). Después de la decantación del sobrenadante, las muestras fueron tamizadas en húmedo a través de un tamiz de nylon con un tamaño de poro de $1 \mathrm{~mm}$ para atrapar a los nadadores más grandes. Los nadadores más pequeños se eliminaron con la ayuda de pinzas y de una lupa estereoscópica. La mayor parte de las muestras sólo presentaban unas pocas decenas de copépodos.

Las muestras originales fueron divididas en submuestras para posteriores análisis usando el método conocido por rotary splitting method (Heussner et al. 2006) y almacenadas en frascos de cristal en una cámara oscura, a una temperatura entre 2 y $4^{\circ} \mathrm{C}$. Las muestras fueron dividas en 8 o en 16 fracciones, dependiendo de los análisis programados para cada secuencia de muestras. Se calculó el flujo total masa a partir de cuatro submuestras siguiendo el procedimiento indicado en Heussner et al. (1999).

El procesamiento inicial de las muestras procedentes de las trampas del golfo de León, que comprende desde la recogida de las muestras hasta su fraccionamiento, fue llevado a cabo en el CEFREM (Centre de Formation et de Recherche sur l'Environnement Marin) en la Université de Perpignan (Francia). En lo referente a las muestras de las trampas recogidas en el Margen continental Catalán y Mar de Alborán fueron procesadas en el Institut de Ciències del Mar (ICM) de Barcelona y en la Universidad de Barcelona, respectivamente.

\section{Tratamiento micropaleontológico.}

La preparación de las muestras para el estudio micropaleontológico fue llevado a cabo en la Universidad de Salamanca. Tanto en el transporte como en su almacenamiento las muestras se mantuvieron en oscuridad y a una temperatura entre 2 y $4{ }^{\circ} \mathrm{C}$. La cantidad de muestra disponible ha sido variable comprendiendo fracciones entre $1 / 64$ y 3/4, siendo $1 / 8$ la más frecuente.

Las muestras fueron enrasadas con un tampón fosfato a $\mathrm{pH}$ neutro $(7,5)$ con el objetivo de evitar la disolución de los carbonatos y de la sílice y de no alterar posibles estudios isotópicos. Un litro de este tampón de $\mathrm{pH}$ de 7,5 contenía 11,6 g de $\mathrm{K}_{2} \mathrm{HPO}_{4}$ y 4,53 g de $\mathrm{KH}_{2} \mathrm{PO}_{4}$ y agua destilada.

Una vez enrasadas las muestras, $5 \mathrm{ml}$ fueron separados para posteriores estudios de algas cocolitoforales y almacenados de nuevo a $4^{\circ} \mathrm{C}$ en viales de cristal de $10 \mathrm{ml}$ de volumen.

Las muestras estudiadas presentaban algunas peculiaridades entre la que cabe destacar la presencia de una gran cantidad de sedimento y de algas talofitas (esto último sólo en algunas muestras). Estas peculiaridades impidieron el uso de los procedimientos estándares descritos en la bibliografía para el procesamiento de trampas de sedimento, ya que la formación de agregados 
algales y de sedimento fino provocaron problemas en el tamizado, así como la fractura de foraminíferos durante el proceso de secado.

Uno de los objetivos de este estudio fue el de desarrollar un método para el procesado de muestras de trampas de sedimento para el estudio micropaleontológico, de modo que la preservación de los organismos y la separación entre fracciones fuese óptima. Para ello, se llevó a cabo un estudio tanto bibliográfico como experimental para poder aislar los distintos grupos de microfósiles de interés. Se realizaron numerosos ensayos previos con material procedente de trampas del Mar de Alborán y del golfo de León con el fin de poner a punto un nuevo método para el procesado de microfósiles de trampas de sedimento. El nuevo método desarrollado se resume a continuación y en la Figura 4.

\section{- Procesado para el estudio de foraminíferos.}

Las muestras fueron tamizadas con tres tamaños de poro: 425,150 y $63 \mu \mathrm{m}$. Las fracciones mayores de 63, 150 y $425 \mu \mathrm{m}$ fueron destinadas al estudio de foraminíferos, mientras que la menor de $63 \mu \mathrm{m}$, se empleó para el estudio de diatomeas. El tamiz de $425 \mu \mathrm{m}$ sólo se utilizó en las muestras con elevada cantidad de material y de agregados algales con foraminíferos adheridos.

Para minimizar el riesgo de disolución y fragmentación de los foraminíferos no se empleó agua corriente a presión para tamizar las muestras como es habitual. En lugar de esto, se utilizó una solución tamponada de fosfato, la misma utilizada para enrasar las muestras.

Para tratar de preservar al máximo los foraminíferos más delicados, se eligió un procedimiento menos agresivo que el estándar. Dicho procedimiento consistió en sacar el material tamizado con ayuda de un frasco lavador y pasar dicho material por un embudo con un papel de filtro (Fig. 4). De este modo, se minimizó el contacto de los foraminíferos con otras soluciones diferentes de la preservadora en la que se encontraban almacenados además de evitar el estrés mecánico del chorro de agua sobre la muestra. Una vez seco el papel de filtro, los foraminíferos fueron separados con ayuda de un pincel (Fig. 4).

\section{- Procesado para el estudio de microfósiles silíceos.}

Una vez seca la fracción mayor de $150 \mu \mathrm{m}$ se volvió a tamizar con el tamiz de $63 \mu \mathrm{m}$ para optimizar la separación de fracciones (Fig. 4). La fracción de $425 \mu \mathrm{m}$ y la de $150 \mu \mathrm{m}$ se almacenaron juntas ya que el único objetivo de este doble tamizado fue el de eliminar los agregados algales y de sedimento. La fracción mayor de $63 \mu \mathrm{m}$ fue almacenada en otro vial aparte. En lo referente a la fracción menor de $63 \mu \mathrm{m}$, destinada al estudio de diatomeas, las muestras fueron tratadas con el procedimiento estándar para el procesamiento de microfósiles silíceos descrito por Bárcena and Abrantes (1998). Este procedimiento consiste, básicamente, en tratar a las muestras con agua oxigenada y con ácido clorhídrico en caliente, con el fin de eliminar la materia orgánica y los carbonatos (Fig. 4. El procedimiento ha sido ampliamente descrito en la literatura (Abrantes et al., 2005; Bárcena and Abrantes, 1998). 


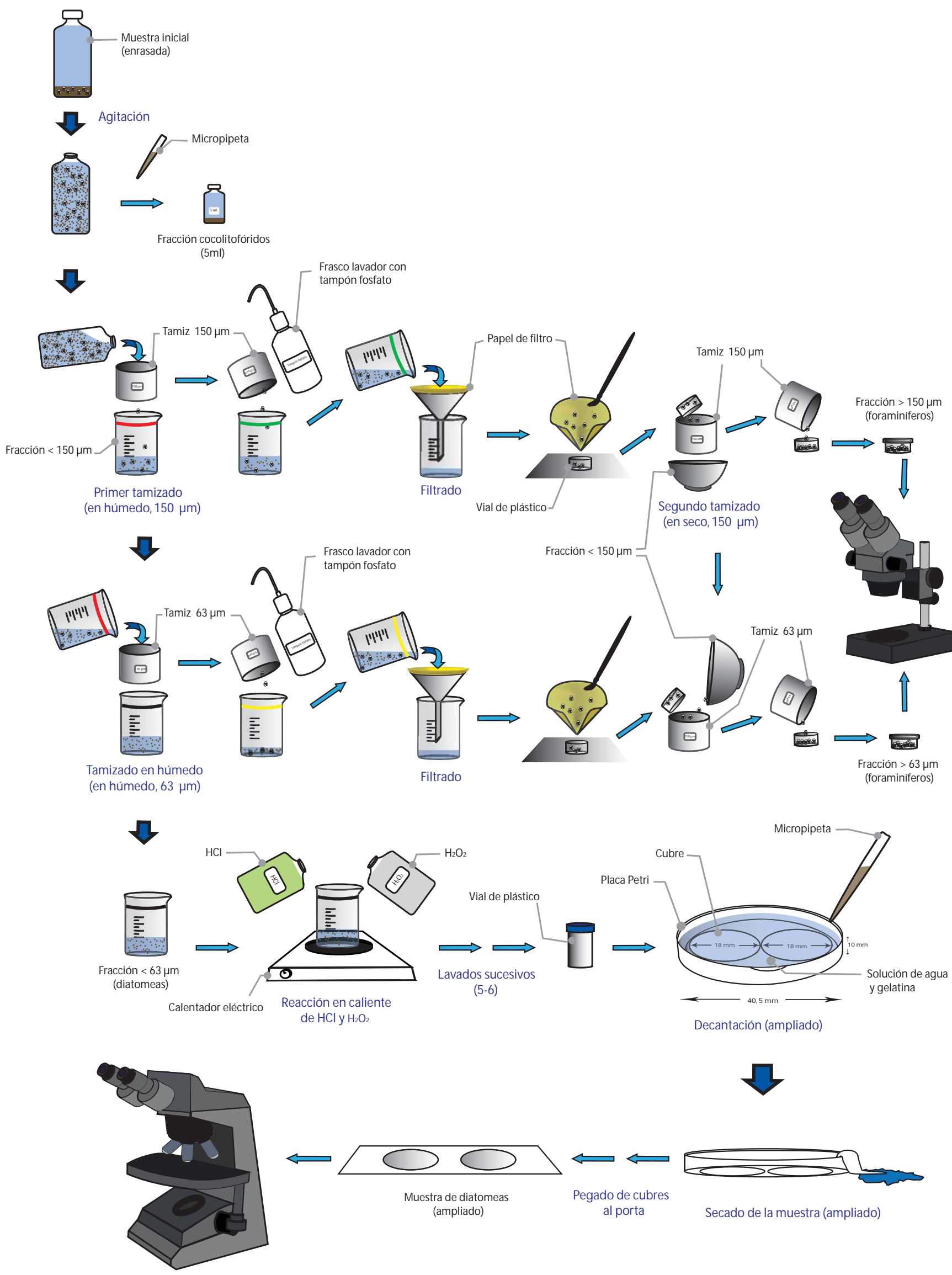

Figura 4: Esquema del procesamiento de muestras de trampas de sedimento para el estudio micropaleontológico. 


\subsubsection{Técnicas de preparación de muestras en lámina delgada para su estudio en microscopía óptica}

Para la preparación en lámina delgada de las muestras de microfósiles silíceos se llevó a cabo la técnica descrita por Flores y Sierro (1997) y Bárcena y Abrantes (1998). El objetivo de este tipo de preparación es el de conseguir una distribución homogénea y representativa sobre la lámina para poder obtener datos cuantitativos del número de microfósiles $\mathrm{m}^{-2}$ día $^{-1}$. A continuación se resumen los principales pasos (Fig. 4):

- Dentro de una placa Petri de $49 \mathrm{~mm}$ de diámetro se colocaron dos cubreobjetos circulares de $18 \mathrm{~mm}$ de diámetro.

- La placa Petri fue enrasada con una mezcla de agua tamponada y de gelatina $(0,08$ $\mathrm{g} / 1)$.

- Con la ayuda de una micropipeta automática se extrajo un volumen variable de muestra, entre 400 y $6000 \mu 1$, dependiendo de la concentración de microfósiles silíceos.

- Se realizó una distribución homogénea mediante un suave bombeo con la micropipeta.

-Se dejó reposar la placa Petri durante unas 12 horas para permitir una correcta decantación.

- Una vez decantada la suspensión de sedimento, se extrajo la mayor parte de la solución con tiras de papel secante por capilaridad (Fig. 4).

- Para el montaje de los cubreobjetos se empleó bálsamo Permount (IR: 1,525) a $80^{\circ} \mathrm{C}$.

\subsection{CONSIDERACIONES SOBRE EL RECUENTO}

Para poder realizar una reconstrucción de las comunidades de diatomeas, silicoflagelados y de foraminíferos es necesario contar un número mínimo de organismos para minimizar el error estadístico. El grado de confianza de los datos obtenidos a partir de los recuentos depende del número mínimo de individuos que se tome de partida. Para este trabajo se han seguido los criterios para el recuento indicados por Fatela y Taborda (2003).

\subsubsection{Analisis de foraminíferos}

Las fracciones $>150 \mu \mathrm{m}$ y $63-150 \mu \mathrm{m}$ fueron analizadas con ayuda de una lupa estereoscópica Leica de diferentes niveles de aumento (entre 15, 12x y 96x). Todos los foraminíferos encontrados en la fracción $>150 \mu \mathrm{m}$ fueron identificados hasta nivel de especie y contados en su totalidad. El número de foraminíferos en las muestras fue muy variable, entre 0 y 1946 individuos. Además de foraminíferos planctónicos, también fueron identificados y contados otros organismos tales como: foraminíferos bentónicos, radiolarios, gasterópodos, bivalvos, restos de artrópodos de pequeño tamaño, escamas de peces, etc.

Debido a la alta cantidad de material sedimentario presente en la fracción 63-150 $\mu \mathrm{m}$ y a que en la mayor parte de trabajos con foraminíferos actuales sólo se emplea la fracción $>150$ $\mu \mathrm{m}$ (e.g. Asahi and Takahashi, 2007; Bárcena et al., 2004; Pujol and Vergnaud Grazzini, 1995) 
la fracción $<63 \mu \mathrm{m}$ no se ha tenido en cuenta para este trabajo. No obstante fue almacenada para posibles estudios futuros.

\subsubsection{Analisis de diatomeas y silicoflagelados (fracción $<63 \mu \mathrm{m}$ )}

El recuento de diatomeas fue llevado a cabo en preparaciones en lámina delgada con la ayuda de un microscopio óptico Nikon eclipse 80i con contraste de fases a 1000 aumentos. Los individuos fueron identificados, siempre que fue posible, a nivel de especie y fueron contadas un mínimo de 400 valvas de diatomeas por placa no pertenecientes al género Chaetoceros RS (resting spore). Así, de acuerdo con Fatela y Taborda (2003), en un estudio de 400 de organismos todos los taxones con una abundancia mayor al 1\% han de quedar registrados con un margen de error del 5\%. Respecto a las consideraciones sobre el recuento de las valvas se han seguido las recomendaciones de Schrader y Gersonde (1978).

En lo referente al recuento de silicoflagelados, el estudio de las muestras fue prácticamente idéntico al de las diatomeas con la excepción de que fueron contados un mínimo de 100 esqueletos de silicoflagelados por placa.

Además de las diatomeas y silicoflagelados, fueron contados e identificados hasta el nivel taxonómico más preciso posible otros grupos de organismos silíceos como radiolarios, crisofitas y dinoflagelados silíceos, etc. al igual que espículas de esponja y ciertas formas aún no identificadas. Las diatomeas junto con los silicoflagelados representaron los grupos más abundantes de organismos silíceos en las muestras.

\subsubsection{Microscopía electrónica}

Debido a la gran diversidad de especies de diatomeas y a la difícil identificación de algunas de ellas, se ha recurrido a la microscopía electrónica de barrido para poder observar detalles que permitan una correcta identificación de las especies. La preparación de las muestras es similar a la preparación en lámina delgada, la única diferencia es que una vez que la muestra ha decantado sobre los cubres y estos se han secado se recubren con baño de oro o plomo para poder ser observados con el microscopio electrónico. Una descripción más detallada de este procedimiento puede encontrarse en Backman y Shackelton (1983) y Andruleit (1996).

\subsection{BASES DE DATOS COMPLEMENTARIAS}

\subsubsection{Datos biogeoquímicos}

Datos del flujo de masa total así como de sus principales componentes (litogénico, carbono orgánico, sílice y carbonato) para todo el periodo estudiado de las estaciones de Planier y Lacaze Duthiers han sido proporcionados por el CEFREM perteneciente a la Université de Perpignan. 


\subsubsection{Concentración de clorofila}

Sea-WIFS (Sea-viewing Wide Field-of-view Sensor) es un satélite de la NASA destinado al estudio oceanográfico que proporciona imágenes en color de los océanos del planeta (Fig. 5). Este satélite empezó a ser operativo el 18 de Septiembre de 1997. Por esta razón, en este estudio sólo se dispone de datos de concentración de clorofila a partir de dicha fecha. Todos los organismos fotosintetizadores del océano (plantas vasculares, algas y cianobacterias) contienen pigmentos para la absorción de distintas longitudes de onda de la luz. A pesar de presentar una diferente composición, todas tienen un pigmento en común indispensable para la fotosíntesis, la clorofila $a$. Gracias a la ubicuidad de la clorofila $a$ en todos los grupos de fitoplancton así como la capacidad de ésta de absorber un rango de longitud de onda específico, podemos relacionarla directamente con la productividad primaria (Vidussi et al. 2000).

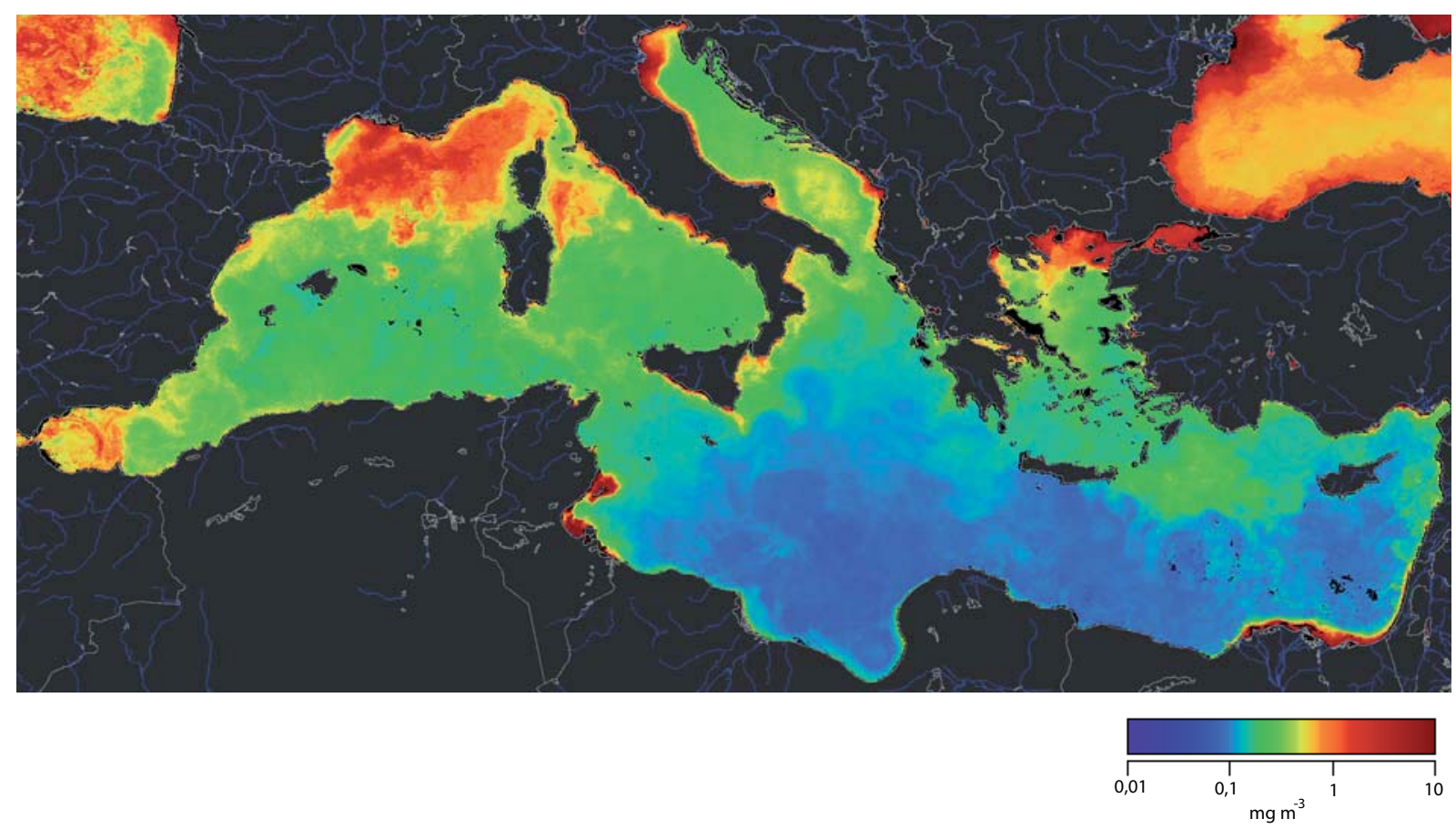

Figura 5: Imagen procesada del satélite Sea-WIFS mostrando media mensual de producción de clorofila $a$ del mes de Abril de 2006 en el mar Mediterráneo. La leyenda señala los colores que corresponden con las diferentes concentraciones de clorofila $a$. Imagen tomada de la base de datos del programa europeo Ocean Colours (http://oceancolour.jrc.ec.europa.eu/data_portal/oc_portal/main.php).

\subsubsection{Variables ambientales}

Gracias a la base de datos Optimum Interpolation Sea Surface Temperature Analysis (Reynolds et al., 2002) de la National Oceanic and Atmospheric Administration (NOAA) se obtuvieron datos semanales de temperatura superficial de la columna de agua para todas las zonas y periodos de tiempo abarcados en el presente trabajo de tesis. Por otro lado, la Agencia Española de Meteorología (AEMET) cedió datos diarios de radiación solar global de las estaciones meteorológicas españolas más cercanas al golfo de León (Gerona y Barcelona) de 
Agosto de 1996 hasta Marzo de 2005. Por último, datos de velocidad del viento y temperatura del aire medidos en la estación meteorológica del aeropuerto de Marsella se obtuvieron del sitio de internet Weather Underground Forecast desde Julio de 1996 a Marzo de 2006 con la excepción del año 2000 (Ver Capítulo 9).

\subsection{Tratamiento de los datos}

Para conocer los flujos y la contribución relativa de las asociaciones de microfósiles recogidos por las trampas de sedimento es necesario llevar a cabo una serie de cálculos a partir de los datos obtenidos en los recuentos. Estos cálculos se resumen a continuación.

\subsubsection{Contribución relativa}

La contribución relativa $(\mathrm{CR})$ de un taxón es el valor en tanto por ciento $(\%)$ de representación de ese taxón respecto al total de la asociación.

$$
\mathbf{C R}=\mathbf{n} \cdot \mathbf{1 0 0} / \mathbf{N}
$$

donde $\mathbf{C R}$ es la contribución relativa, $\mathbf{n}$ es el número de individuos observados de un taxón concreto y $\mathbf{N}$ es el número total de individuos considerados en el recuento.

\subsubsection{Cálculo del flujo de microfósiles}

El flujo de cada taxón, expresada en individuos $\mathrm{m}^{-2} \mathrm{~d}^{-1}$, es el número de individuos que caen a través de un metro cuadrado durante un día. El cálculo es diferente para preparaciones en lámina delgada que para las muestras mayores de $63 \mu \mathrm{m}$ :

\section{- Lámina delgada:}

$$
\text { Flujo }=(\mathbf{n} \cdot \mathrm{S} / \mathbf{s} \cdot \mathrm{V} / \mathbf{v}) / \mathbf{d} \cdot \mathbf{a} / \mathbf{A}
$$

donde Flujo es el número de individuos o partículas por unidad de superficie y día, $\mathbf{n}$ es el número individuos o partículas observados en la muestra, $\mathbf{S}$ la superficie de la placa Petri, $\mathbf{s}$ la superficie de la lámina en $\mathrm{mm}^{2}$ sometida a recuento, $\mathbf{V}$ el volumen de agua de la disolución inicial (35 ml.), v el volumen de muestra empleado para la preparación, $\mathbf{d}$ el número de días de muestreo, a el número de alícuotas subdivididas por la muestra y A es la superficie del embudo colector de la trampa de sedimento.

\section{- Muestras mayores de $63 \mu \mathrm{m}$ :}

$\mathbf{N}=\mathbf{n} / \mathbf{d} \cdot \mathbf{a} / \mathbf{A}$

donde $\mathbf{N}$ es el número de individuos por unidad o partículas de superficie y día, $\mathbf{n}$ es el número total de individuos o partículas por muestra, d es el número de días de muestreo, 
a es el número de alícuotas en el que subdividió la muestra y A es la superficie del embudo colector de la trampa de sedimento.

\subsection{3 Índices de diversidad}

Un índice de diversidad es un número con base a una función estadística con el que se pretende medir la biodiversidad de un ecosistema. La estimación de la diversidad se ha revelado como un buen auxiliar para el entendimiento del dinamismo de las comunidades por el hecho de dar una imagen de su estructura que permite determinar de una manera indirecta el funcionamiento y hasta el grado de eficiencia de ésta (Margalef, 1970). Para este trabajo se ha empleado el índice de biodiversidad de Shannon-Weaver $\left(H^{\prime}\right)$.

$$
H=\sum_{i=1}^{k} p_{i} \log _{2} p_{i}
$$

donde $\mathbf{p}_{\mathbf{i}}=\mathbf{n}_{\mathbf{i}} / \mathbf{N}$, siendo $\mathbf{n}_{\mathbf{i}}$ el número de individuos de cada especie y $\mathbf{N}$ el número total de individuos.

\subsubsection{Análisis de componentes principales}

El Análisis de Componentes Principales (ACP o PCA en inglés) es una técnica estadística de síntesis de la información, o reducción de la dimensión (número de variables). Es decir, ante un banco de datos con muchas variables, el objetivo será reducirlas a un menor número perdiendo la menor cantidad de información posible. Esta técnica fue empleada para el estudio de la variación de las asociaciones de diatomeas a lo largo del registro de la estación de Planier. Para hacer este análisis se utilizó el programa informático Statistica 7.0®. El tratamiento de los datos para el estudio de las variaciones de los flujos de diatomeas en la estación de Planier se detalla en el Capítulo 7. 



\section{Capítulo 4}

Ecología de las diatomeas y silicoflagelados

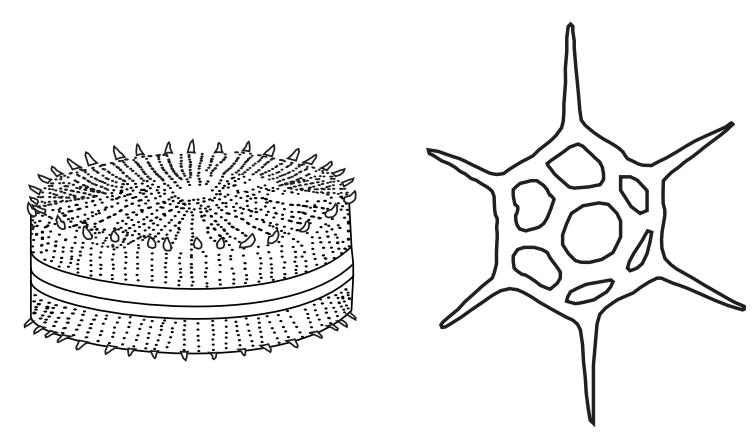





\subsection{ECOLOGÍA DE LAS DIATOMEAS}

\subsubsection{Introducción}

Las diatomeas son organismos unicelulares, diploides y autótrofos pertenecientes a la división Bacillariophyta (Round et al., 1990) y cuyo tamaño varía entre los $2 \mu \mathrm{m}$ y los $2 \mathrm{~mm}$. Después de las bacterias, son los organismos acuáticos más abundantes y uno de los principales productores primarios de los océanos (Liu et al., 2009). Las diatomeas presentan una enorme biodiversidad (ca. 200,000 especies; Crawford, 2006) y están distribuidas en todos los medios acuáticos, siendo abundantes en el fitobentos y fitoplancton tanto de aguas dulces como saladas (Round et al., 1990). Una característica única de este grupo de fitoplancton es la posesión un esqueleto de sílice situado por fuera de su membrana plasmática (frústulo) formado por dos valvas (hipo- y epivalva) (Fig. 1). La naturaleza silícea de este exoesqueleto permite que las diatomeas puedan ser incorporadas al sedimento y pasen a formar parte del registro fósil.

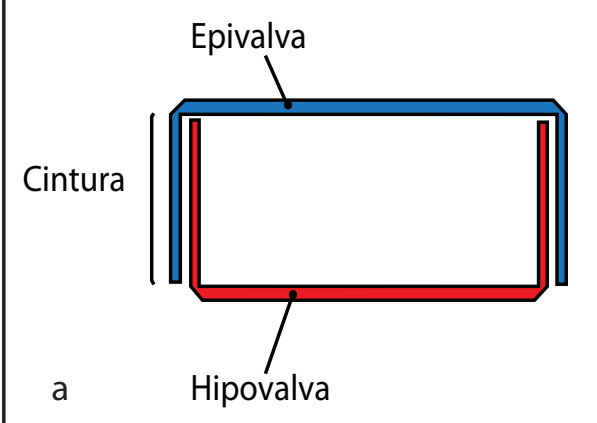

b

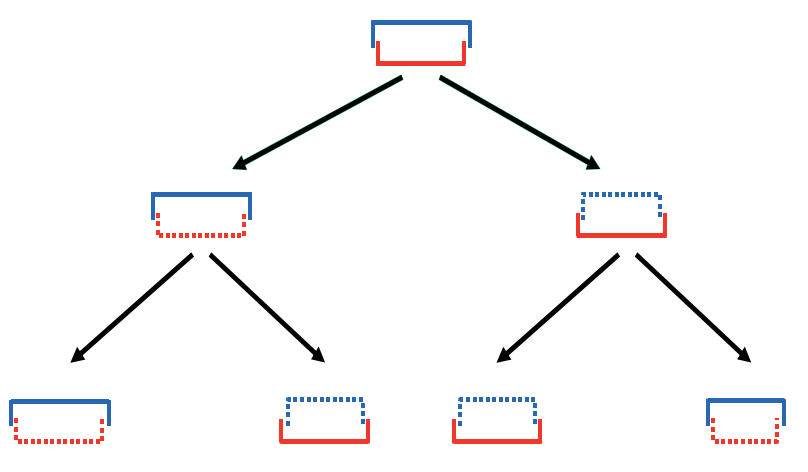

Figura 1: a. Esquema del frústulo de una diatomea. b. Esquema de la reproducción asexual de una diatomea. La célula parental aporta siempre la epivalva.

De forma general, las diatomeas pueden dividirse en dos grandes grupos morfológicos: pennales y centrales (Fig. 2). Las diatomeas pennales presentan frústulos alargados de simetría bilateral pudiendo presentar una fisura a lo largo de su eje longitudinal conocida como rafe, que se cree que está implicada en los movimientos realizados por la diatomea. Las diatomeas centrales presentan un frústulo con forma circular o elipsoidal, ornamentación de simetría radial y carecen de rafe. Sin embargo, una clasificación más correcta es la propuesta por Round et al. (1990) en la que separa a las diatomeas (división Bacillariophyta) en tres clases: clase Coscinodiscophyceae (diatomeas centrales, de simetría radial), clase Fragilarophyceae (diatomeas pennales sin rafe, de simetría bilateral) y clase Bacillariophyceae (diatomeas pennales con rafe, de simetría bilateral). Estos grupos no sólo se diferencian en su morfología sino también en su reproducción y ultraestructura. 

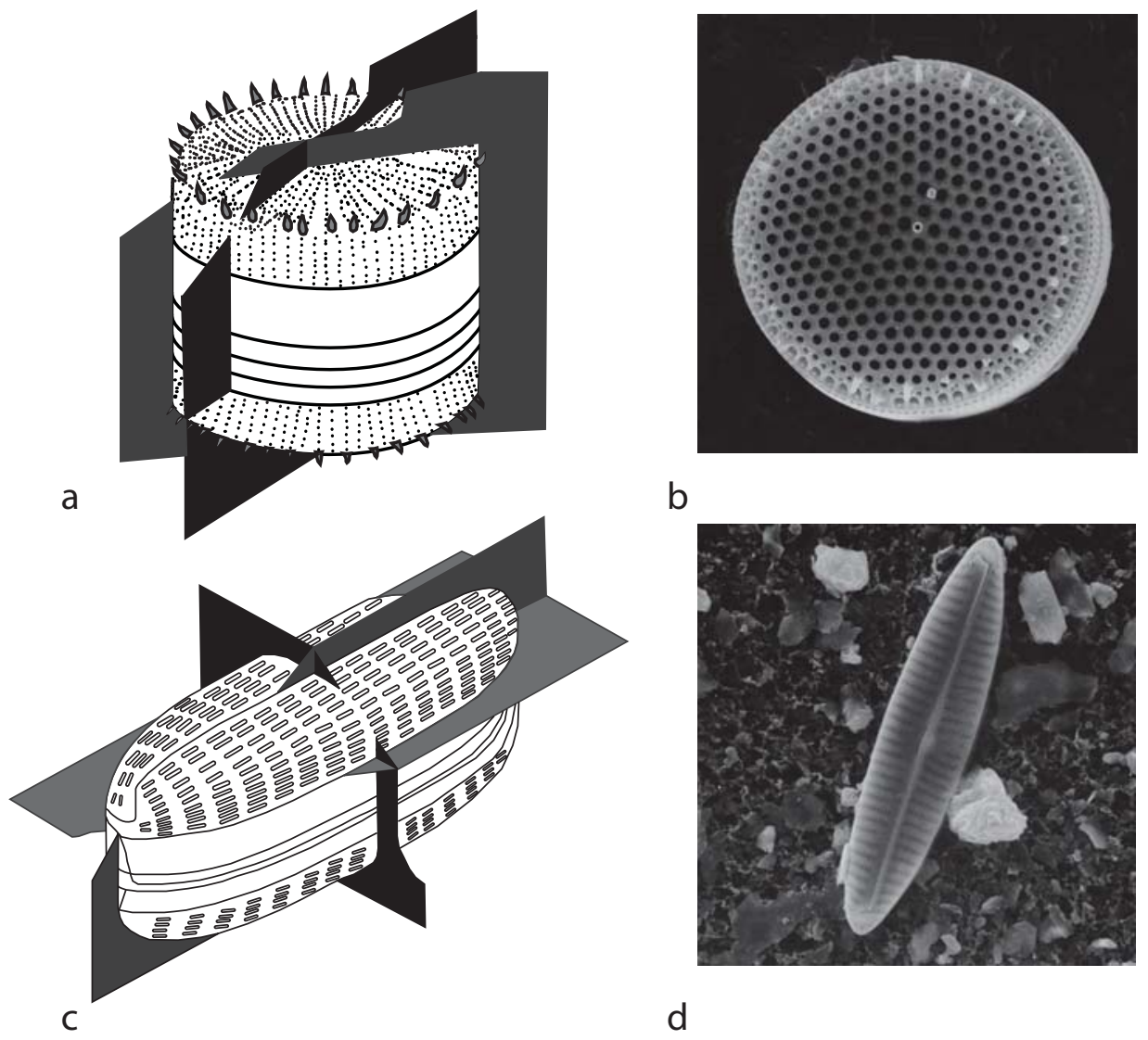

b

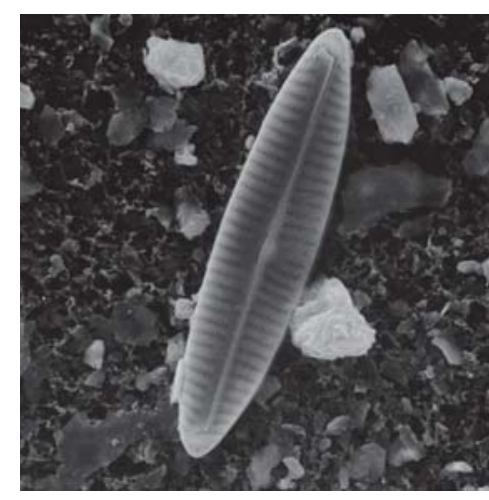

d

Figura 2: Esquema y ejemplos de simetría de una diatomea central y una diatomea pennal. a. Diatomea central (simetría radial). b. Ejemplo de diatomea central: Thalassiosira sp. c. Diatomea pennal (simetría bilateral). d. Ejemplo de diatomea pennal: Navicula sp.

El ciclo de vida de las diatomeas puede definirse como monogenético diploide y se divide en dos fases:

- Fase vegetativa (Fig. 1). Durante esta parte del ciclo las diatomeas se multiplican por reproducción asexual (división mitótica) (Fig. 1). Las células hijas conservan una de las valvas de la célula madre y la otra la sintetizan de novo como hipovalva. Por lo tanto, tras sucesivas divisiones un grupo de las células hijas disminuyen gradualmente sus dimensiones hasta alcanzar un tamaño crítico. En ese momento tiene lugar la reproducción sexual.

- Fase de reproducción sexual (Fig. 3), ocurre al alcanzar el tamaño crítico de la especie. Las diatomeas pennales presentan isogamia mientras que las centrales presentan oogamia (Fig. 3). Los dos gametos se fusionan dando lugar a una auxospora diploide a partir de la cual comienza un nuevo ciclo de reproducción asexual (Fig. 3). 
Figura 3: Reproducción sexual de una diatomea central. Oogamia: gametos flagelados y oosfera.

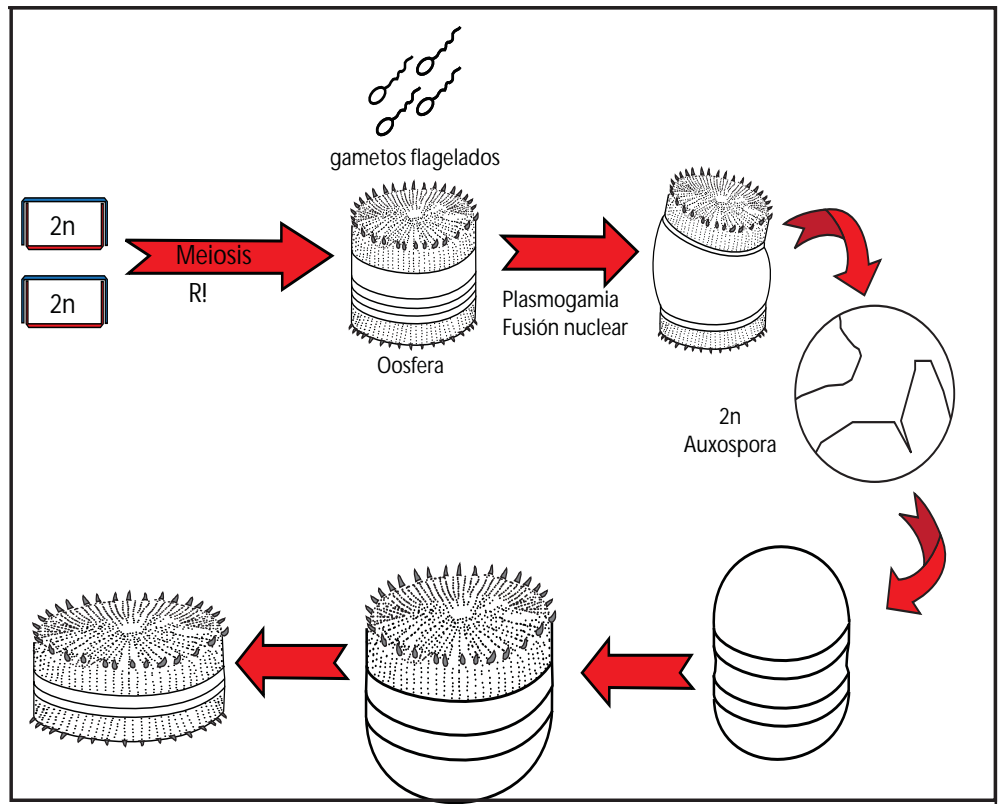

A parte de estas dos fases, algunas especies de diatomeas pueden formar, bajo condiciones ambientales desfavorables, quistes de resistencia conocidos por estatosporas. De este modo, pueden sobrevivir en estado latente a condiciones adversas durante largos periodos de tiempo. Un ejemplo de diatomea que sigue esta estrategia biológica es el de las especies pertenecientes subgénero Hyalochaete del género Chaetoceros (Fig. 4).

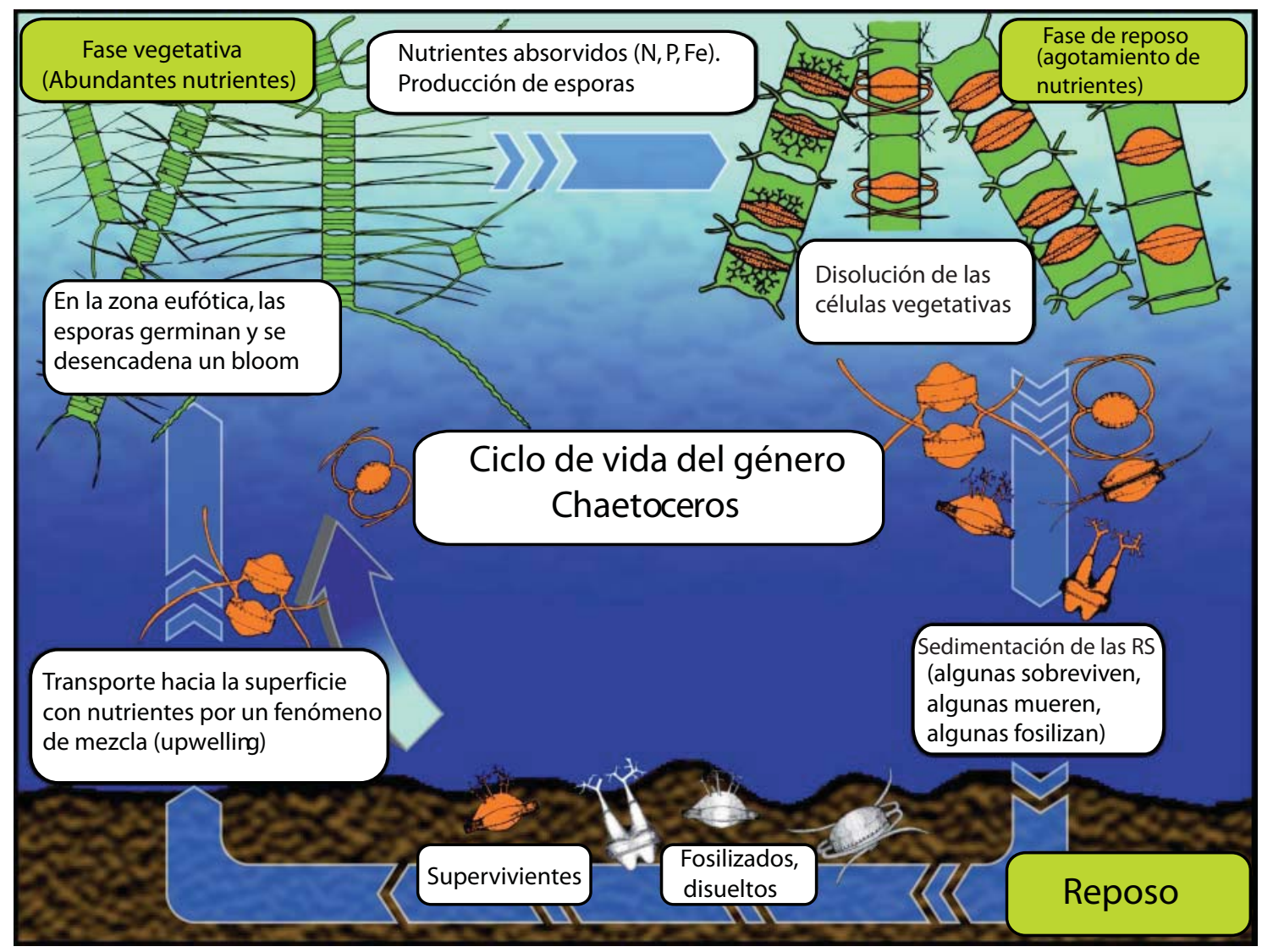

Figura 4: Ciclo de vida del género Chaetoceros. Modificado de Suto (2007). 


\subsubsection{Las diatomeas y el ciclo de la sílice}

Las diatomeas presentan una distribución cosmopolita en el medio marino, siendo especialmente abundantes en aquellas zonas del océano donde el aporte de sílice es importante tales como: zonas de upwelling, desembocaduras de ríos, divergencias ecuatoriales, blooms en océano abierto desencadenados por el viento, blooms de primavera en zonas templadas y cinturones polares y ecuatoriales (Nelson et al., 1995; Tréguer et al., 1995; Ragueneau et al., 2000). La contribución de las diatomeas a la productividad primaria global varía entre el 25$30 \%$ en áreas oligotróficas en océano abierto y $75 \%$ en áreas costeras eutróficas (upwellings costeros, divergencias ecuatoriales, frentes de hielo, desembocaduras de ríos, etc.) (Nelson et al., 1995).

El crecimiento poblacional de las diatomeas está a menudo limitado por la disponibilidad de sílice en el medio. Para poder desarrollarse las diatomeas requieren concentraciones de sílice superiores a $2 \mu \mathrm{M} / 1$ (Egge y Jacobsen, 1997) así como otros nutrientes (fosfatos, nitratos, etc.). En un ambiente oceánico la disponibilidad de sílice es muy baja y el desarrollo de las poblaciones depende del transporte a la superficie de aguas profundas ricas en nutrientes (Smetacek, 2000). Ante un aporte de nutrientes, algunas especies de diatomeas son capaces de multiplicarse a gran velocidad originando eclosiones masivas o blooms que llegan a agotar por completo la sílice del medio. Además de nutrientes, las diatomeas requieren unas condiciones ambientales específicas, entre las que cabe destacar una intensidad lumínica suficiente para llevar a cabo la fotosíntesis y un nivel de turbulencia medio-alto para no hundirse en la columna de agua.

Las diatomeas juegan un importante papel en los ciclos biogeoquímicos del ópalo y carbono orgánico debido a su capacidad para formar agregados y de hundirse rápidamente. Estudios en laboratorio han demostrado como un aporte moderado de $\mathrm{Si}(\mathrm{OH})_{4}$ al medio provoca una duplicación de la producción primaria (principalmente causada por las diatomeas) (Egge y Jacobsen, 1997) así como un aumento de la exportación de C hacia el fondo del 18\% (Wassmann et al., 1996). La participación de las diatomeas en los ciclos biogeoquímicos es especialmente importante en los márgenes continentales donde tienen lugar aproximadamente el $45 \%$ y el 32-39\% del hundimiento del carbono orgánico y el ópalo biogénico mundial, respectivamente (Hedges y Keil, 1995; Ragueneau et al., 2000).

Sin embargo, a pesar de la capacidad de las diatomeas para hundirse rápidamente, una importante cantidad de la sílice biogénica es reciclada en los primeros metros de la columna de agua (Fig. 5). En este sentido, aproximadamente el 50\% de la sílice producida por las diatomeas en la zona fótica global se disuelve en los primeros $100 \mathrm{~m}$ (Nelson et al., 1995), a 500 m sólo se preserva el 5\%, mientras que a 1000 m sólo se conserva un 1\% (Tréguer et al., 1995). Finalmente, las valvas de diatomeas depositadas en los primeros 2-4 cm de sedimento están sujetas a otros fenómenos de disolución (Van Bennekom et al., 1988), entre los que destaca la acción bacteriana (Smetacek, 1999a). 


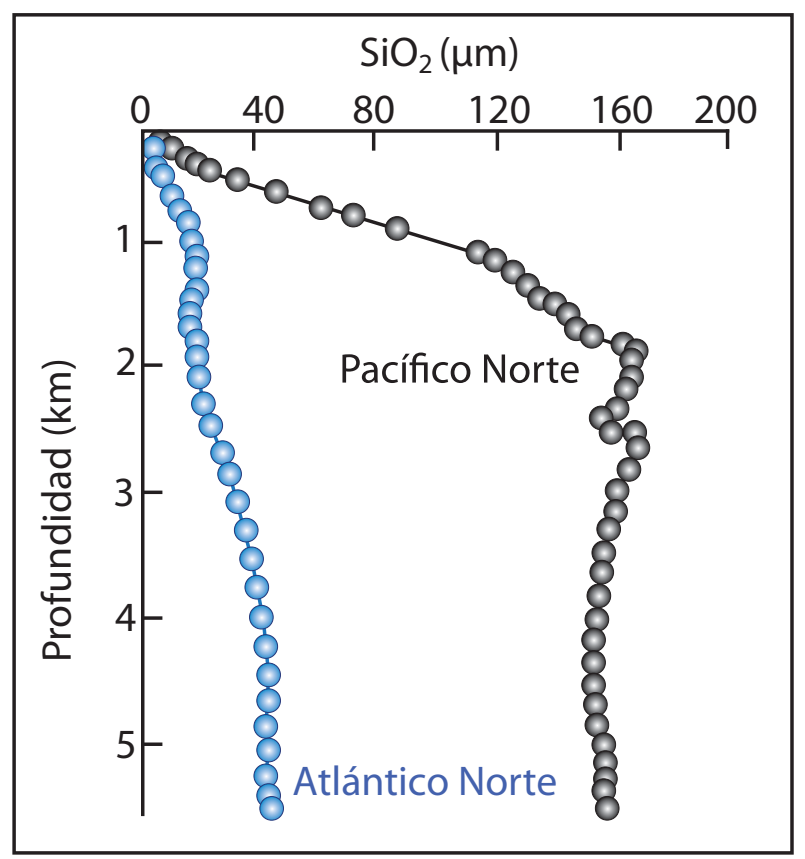

Figura 5: Variación vertical de la sílice en la columna de agua (Thurman y Burton, 2001).

\subsubsection{Principales grupos ecológicos}

En este apartado se agrupan los principales taxones identificados en este estudio en función de sus características ecológicas siguiendo las pautas descritas por Round et al. (1990) y Hasle and Sylvertsen (1997), así como las bases de datos World Register of Marine Species (WoRMS)(Appeltans et al., 2010) y AlgaeBase (Guiry y Guiry, 2010):

\section{Grupo de especies oceánicas}

Alveus marinus (Grunow, 1880) Kaczmarska y Fryxell, 1996

Asteromphalus flabellatus (Brévisson) Greville, 1859

Asteromphalus robustus Castracane, 1886

Asterolampra marylandica (Ehrenberg) Ehrenberg, 1844

Azpeitia sp. M. Peragallo en Tempére y Peragallo, 1912

Bacteriastrum delicatulum Cleve, 1897

Bacteriastrum hyalinum Lauder, 1864

Bacteriastrum sp. Shadbolt, 1854

Coscinodiscus marginatus Ehrenberg, 1841 (1843, 1844)

Coscinodiscus radiatus Ehrenberg, 1840

Coscinodiscus spp. Ehrenberg, 1839

Cyclotella ocellata Pantocsek, 1912

Hemidiscus cuneiformis Wallich, 1860

Leptocylindrus danicus Cleve, 1889

Nitzschia spp. Hassall, 1845

Nitzschia acicularis (Kützing) Smith, 1853

Nitzschia sicula Hassall, 1845

Nitzschia bifurcate Kaczmarska y Licea, 1986 
Nitzschia braarudii Hasle, 1960

Nitzschia bicapitata Cleve, 1900

Nitzschia panduriformis Gregory, 1857

Odontella mobiliensis (J.W.Bailey) Grunow, 1884

Odontella sp. Agardh, 1832

Pleurosigma directum Grunow, 1880

Pleurosigma normanii Ralfs, 1861

Pleurosigma sp. Smith, 1852

Rhizosolenia acicularis Sundström, 1986

Rhizosolenia bergonii Peragallo, 1892

Rhizosolenia setigera Brightwell 1858

Rhizosolenia spp. Brightwell, 1858

Roperia tesselata (Roper) Grunow ex Pelletan, 1883

Stellarima stellaris (Roper) Hasle y Sims, 1986

Thalassionema bacillaris (Heiden) Kolbe 1955

Thalassionema frauenfeldii (Grunow) Tempére y Peragallo ex Hallegraeff 1986

Thalassionema nitzschioides spp. (Grunow) Mereschkowsky 1902

Thalassionema nitzschioides var. capitulata (Castracane) Moreno-Ruiz 1995

Thalassionema nitzschioides var. lanceolata (Grunow) Peragallo y Peragallo 1901

Thalassionema nitzschioides var. parva Heiden y Kolbe 1928

Thalassiosira eccentrica (Ehrenberg) Cleve, 1903-1904

Thalassiosira endoseriata Hasle y Fryxell 1977

Thalassiosira gravida Cleve 1896

Thalassiosira lineata Jousé 1968

Thalassiosira symmetrica Fryxell y Hasle 1972

Thalassiosira oestrupii (Ostenfeld) Hasle 1972

Thalassiosira rotula Meunier 1910

Thalassiosira tenera Proshkina-Lavrenko 1961

Thalassiosira spp. Cleve, 1973

\section{Grupo de especies neríticas}

Actinocyclus curvatulus Janisch, 1874

Actinocyclus octonarius Ehrenberg, 1838

Actinocyclus sp. Ehrenberg, 1837

Actinoptychus sp. Ehrenberg, 1843

Cyclotella litoralis Lange y Syvertsen, 1989

Dimeregramma sp. Ralfs, 1861

Ditylum brightwellii (West) Grunow en Van Heurck, 1883

Grammatophora angulosa Ehrenberg, 1841

Grammatophora oceanica Ehrenberg, 1841

Grammatophora serpentina (Ralfs) Ehrenberg, 1844

Grammatophora sp. Ehrenberg, 1840

Licmophora sp. Agardh, 1827

Paralia sulcata (Ehrenberg) Cleve, 1873

Skeletonema grethae Zingone y Sarno, 2005

Trachyneis aspera Cleve, 1894

Triceratium sp. Ehrenberg, 1839

Toxarium undulatum Bailey, 1854

Toxarium sp. Bailey, 1854

Chaetoceros curvisetus Cleve, 1889 
Chaetoceros didymus Ehrenberg, 1845

Chaetoceros spp. Ehrenberg, 1844

\section{Grupo de especies bentónicas}

Aulacoseira granulata (Ehrenberg) Thwaites, 1848

Cyclotella atomus Hustedt, 1937

Cyclotella striata (Kützing) Grunow en Cleve y Grunow, 1880

Cyclotella meneghiniana Kützing, 1844

Cymbella sp. C.A. Agardh, 1830

Diatoma vulgare Bory de Saint-Vincent, 1824

Diatoma sp. Bory de St-Vincent, 1824

Hannaea sp. Patrick, 1966

Pseudostaurosira brevistriata (Grunow, 1885) Williams y Round, 1988 (1987)

Stephanodiscus astraea (Kützing) Grunow 1880

Synedra sp. (Ehrenberg) Königl, 1830

\section{Grupo de especies de agua dulce y/o salobre}

Aulacoseira granulata (Ehrenberg) Thwaites, 1848

Cyclotella striata (Kützing) Grunow in Cleve y Grunow, 1880

Cyclotella meneghiniana Kützing, 1844

Cymbella sp. C.A. Agardh, 1830 nom. cons.

Diatoma sp. Bory de St-Vincent, 1824

Hannaea sp. Patrick, 1966

Pseudostaurosira brevistriata (Grunow, 1885) Williams y Round, 1988 (1987)

Stephanodiscus astraea (Kützing) Grunow 1880

Synedra sp. (Ehrenberg) Königl, 1830

Grupo de esporas de resistencia del género Chaetoceros Ehrenberg, 1844

Chaetoceros affinis Lauder 1864

Chaetoceros diadema (Ehrenberg) Gran 1897

Chaetoceros lauderi Ralfs 1864

Chaetoceros lorenzianus Grunow 1863

Chaetoceros mitra (Bailey) Cleve 1896

Chaetoceros seychelarus Karsten 1907

Chaetoceros vanheurckii Gran 1897 


\subsubsection{Consideraciones ecológicas de las principales especies de diatomeas del golfo de León}

La presencia en el registro de determinadas asociaciones o de ciertos grupos de diatomeas pueden proporcionar información de las condiciones del medio, tales como condiciones de upwelling, aporte de nutrientes o aumento de la descarga fluvial. En este capítulo se detallan las principales características de los taxones clave encontrados en este estudio. Por otro lado, en el Capítulo 6 se pueden encontrar fotografías de microscopía óptica y electrónica de las especies de diatomeas más representativas del Golfo de León.

Género Skeletonema, Greville 1865

Los miembros de este género (Fig. 6) son organismos de pequeño tamaño (2- $21 \mu \mathrm{m}$ ) (Hasle y Sylvertsen, 1997), con una elevada tasa de reproducción y capaces de asociarse entre sí para formar cadenas. Las especies del género Skeletonema han sido descritas como pioneras u oportunistas ya que suelen aparecer en las primeras fases de un bloom, siendo en el Mediterráneo un importante componente de las asociaciones de primavera (Margalef, 1978). A diferencia de las especies costeras de Chaetoceros, Skeletonema costatum no forma esporas de resistencia cuando se agotan los nutrientes del medio (Smetacek, 1985). S. costatum sigue otra estrategia de supervivencia: las cadenas de pequeñas células se agregan entre sí por medio de sus proyecciones y a la síntesis de polímeros gelatinosos, desencadenando su rápido hundimiento. Estas diatomeas son capaces de resistir en aguas profundas durante largos periodos de tiempo. Cultivos en laboratorio han demostrado que células de Skeletonema costatum pueden sobrevivir en oscuridad a $2^{\circ} \mathrm{C}$ hasta seis meses (Smayda y Mitchell-Innes, 1974). Cuando la mezcla anual de la columna de agua vuelve a llevar nutrientes y células Skeletonema costatum a la zona fótica, estás salen de su latencia y comienzan a desarrollarse rápidamente.

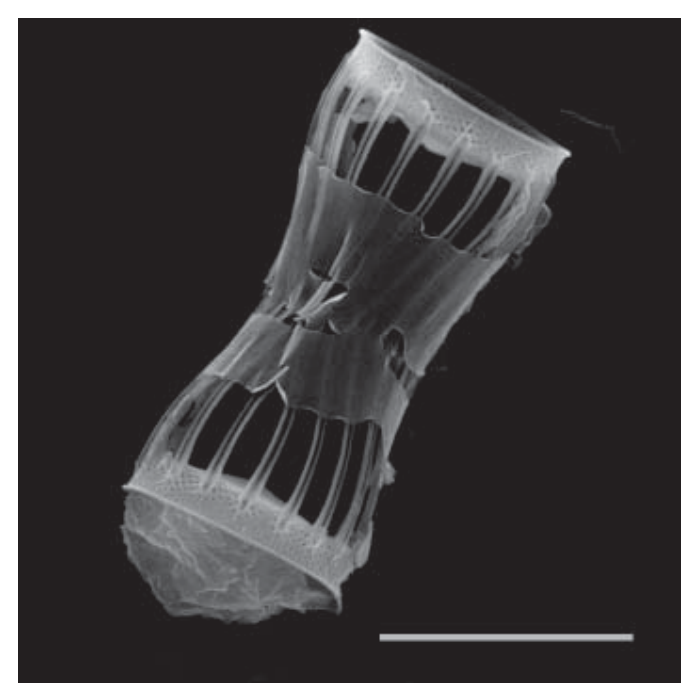

Figura 6. Sketonema grethae. SEM. Escala $5 \mu \mathrm{m}$.

Género Thalasionema, Grunow ex Mereschkowsky 1902

El género Thalassionema presenta una distribución cosmopolita en el medio marino con la excepción de las zonas polares (Hasle, 1969). La presencia de especies de este género ha sido relacionada con aumentos en el aporte fluvial (Alvarez et al., 2006) y su presencia junto 
con Chaetoceros RS ha sido asociada a condiciones de upwelling (Bao et al., 2000). Algunas especies de este género presentan valvas fuertemente silicificadas por lo que se preservan bien en el sedimento (Koning et al., 2001). En el Mediterráneo se encuentran varios representantes de este género entre los que destacan: Thalassionema frauenfeldii (Fig. 7) que es una de las especies de diatomeas más abundantes en el Mediterráneo Occidental y está presente en la columna de agua durante todo el año (Travers, 1971; Gómez y Gorsky, 2003) y T. nitzschioides también una especie abundante en el Mediterráneo y presenta diversas variedades (Hasle, 2001).

a
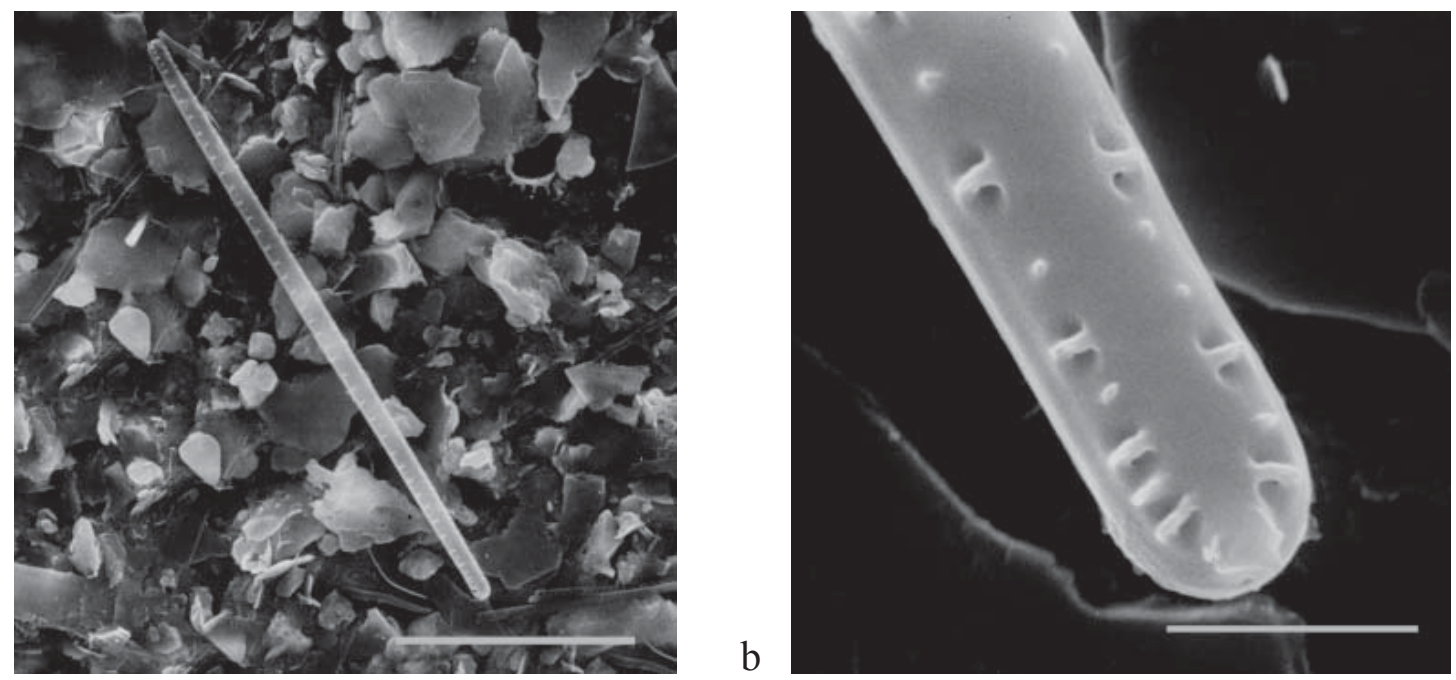

Figura 7. Thalassionema frauenfeldii. SEM. Escalas: a, $25 \mu \mathrm{m} . ; \mathrm{b} ; 2 \mu \mathrm{m}$..

Género Rhizosolenia, Brightwell, 1858

Las especies del género Rhizosolenia (Fig. 8) son características de aguas estratificadas y oligotróficas donde viven asociadas a la nutriclina en la parte inferior de la zona fótica. Presentan dos adaptaciones clave para sobrevivir en estas condiciones de baja luminosidad y fuerte estratificación: (1) pueden albergar cianobacterias endosimbiontes fijadoras de nitrógeno (Richelia intracellularis) que las proporcionan nutrientes y (2) son capaces de regular su flotabilidad entre las zonas profundas de la columna de agua ricas en nutrientes y la zona eufótica (Villareal et al., 1993; Moore y Villareal, 1996). Este género, junto con Stephanopyxis palmeriana, Thalassiothrix spp. y algunas especies del género Coscinodiscus pertenecen a un grupo ecológico conocido como "shade flora" o "diatomeas de sombra" (Sournia, 1982; Kemp et al., 2000). Las "diatomeas de sombra" viven asociadas al DCM (Deep Chlorophyll Maximum, ver Glosario) donde crecen con un ritmo lento, prolongando su vida durante los meses de estratificación de la columna de agua. Cuando se rompe la termoclina, generalmente por la mezcla del otoño-invierno, las diatomeas de este grupo mueren de forma masiva. A este fenómeno de muerte y hundimiento masivo se le conoce por fall dump (Kemp et al., 2000). 
En el Mediterráneo Oriental, se han descrito capas casi monoespecíficas del género Rhizosolenia asociadas a depósitos ricos en carbono orgánico (sapropeles, ver Glosario). De acuerdo con Rohling (1994) estas capas ricas en materia orgánica podrían ser un reflejo de unas condiciones de fuerte estratificación y elevado aporte de agua dulce (fluvial y/o por precipitación directa). Así, aguas estratificadas y pobres en nutrientes podrían llegar a producir depósitos sedimentarios de intensidad igual o superior a las floraciones de las condiciones eutróficas (Kemp et al., 2000).

Ditylum brithwellii , (West) Grunow en Van Heurck, 1883

Ditylum brightwellii (Fig. 8) es una diatomea planctónica característica de aguas costeras (Round et al., 1990) con valvas débilmente silicificadas y grandes vacuolas (Margalef, 1978; Smetacek, 1999b). Esta especie suele aparecer en las etapas finales de un bloom ya que están adaptadas a desarrollarse en condiciones de elevada radiación solar y bajas concentraciones de nutrientes (Smetacek, 1999b).

a
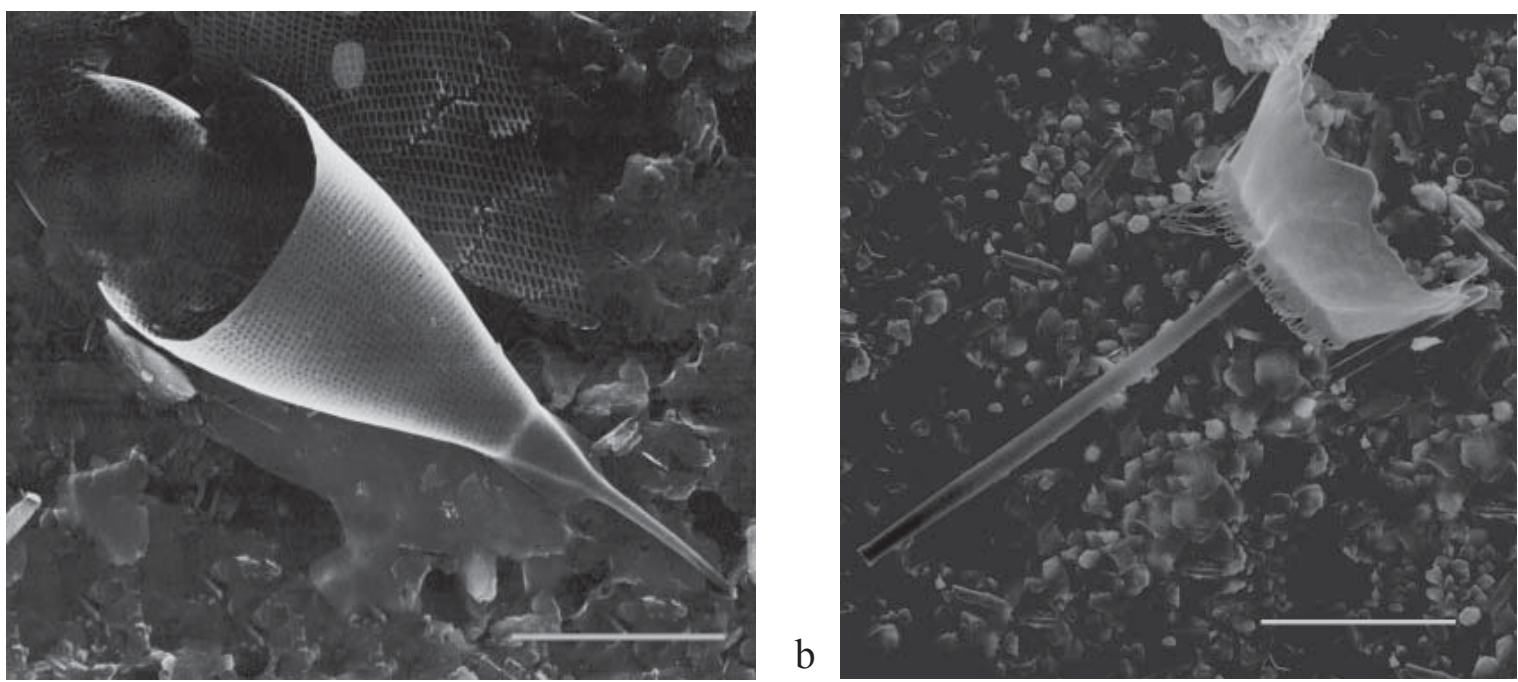

Figura 8. a. Rhizosolenia sp. b. Dytilum brithwellii. SEM. Escalas: a, $10 \mu \mathrm{m} ; \mathrm{b}, 25 \mu \mathrm{m}$.

Género Chaetoceros, Ehrenberg, 1844

Actualmente se conocen más de 400 especies del género Chaetoceros. Son abundantes en aguas costeras, sobre todo en regiones templadas y frías de ambos hemisferios (Hasle et al., 1969). Este grupo es uno de los principales contribuyentes en los upwelling costeros. Su contribución a la productividad primaria marina total es del 20-25\% (Suto, 2007). Las especies de este género están consideradas como oportunistas debido a su rápido desarrollo en un medio rico en nutrientes. Las formas vegetativas presentan paredes poco silicificadas, con proyecciones (setas) y llegan a formar largas cadenas. En condiciones de pocos nutrientes gran número de especies del subgénero nerítico Hyalochaete del género Chaetoceros (Fig. 9) forman esporas 
de resistencia o resting spores (RS) (Fig. 4 y 9). La formación de las esporas de resistencia se desencadena ante condiciones desfavorables como el agotamiento de nutrientes o de fósforo, cambios de $\mathrm{pH}$ o de salinidad y disminución de la luminosidad o de la temperatura. Sin embargo, el factor más importante para desencadenar la esporulación es el agotamiento de nitrógeno del medio. El tiempo de formación de las esporas es muy variable pudiendo durar de 6-48 horas a varias semanas (Suto, 2007). Estas esporas, que presentan una pared muy silicificada, se hunden una vez formadas y alcanzan el fondo marino donde permanecen hasta que ascienden a la superficie transportadas por corrientes ascendentes (Fig. 4). Ya en la superficie, bajo unas condiciones adecuadas, continúan su ciclo vital eclosionando y desarrollando su fase vegetativa. Los factores que determinan la eclosión de las Chaetoceros RS son la presencia de nutrientes y de luz. La germinación tiene lugar en uno o dos días. Estas características permiten a las esporas de resistencia sobrevivir a periodos largos con condiciones desfavorables durante los cuales las células vegetativas son incapaces de subsistir (McQuoid y Hobson, 1996; Suto, 2007). El género Chaetoceros (RS) ha sido descrito en estudios en trampas de sedimento asociado a condiciones de verano/otoño y de pocos nutrientes (Lopes et al., 2006). Además, la presencia de cuerpos vegetativos en trampas de sedimento o en el sedimento es un indicador de una escasa disolución en la columna de agua (Bao et al., 2000).
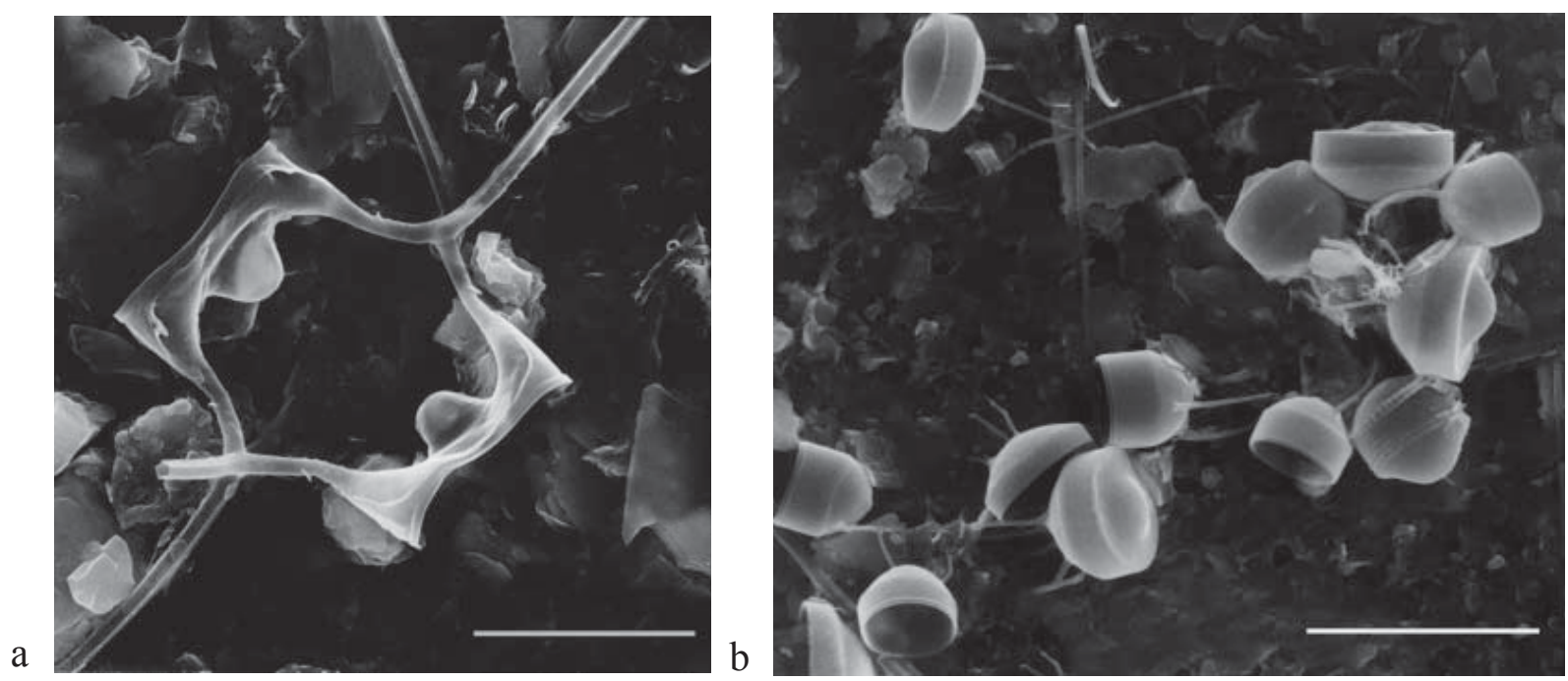

Figura 9. a. Chaetoceros didymus. b. Chaetoceros (RS) group. SEM. Escalas: a, $10 \mu \mathrm{m} ; \mathrm{b}, 20 \mu \mathrm{m}$.

\subsubsection{La sucesión ecológica en el Mediterráneo}

De forma general se puede definir sucesión ecológica como el reemplazo de algunos elementos del ecosistema por otros en el transcurso del tiempo. Margalef (1978) sugiere un modelo de sucesión ecológica del fitoplancton tras un evento de mezcla teniendo en cuenta la turbulencia de la columna de agua, la cantidad de nutrientes del medio y la velocidad de asimilación de nutrientes por los distintos grupos de organismos (Fig. 10). Según este modelo, 
tras un periodo de mezcla y aporte de nutrientes el primer grupo en desarrollarse son las diatomeas y a medida que la turbulencia y cantidad de nutrientes decrece serían gradualmente reemplazadas por cocolitofóridos y finalmente por dinoflagelados (Fig. 10). De este modo define a las diatomeas como un grupo de rápida proliferación (estrategas de la " $r$ "), a los dinoflagelados como un grupo de crecimiento lento (estrategas de la " $k$ ") y a los cocolitofóridos como un grupo intermedio entre los dos últimos. Sin embargo, es importante tener en cuenta que en su trabajo, Margalef no tuvo en cuenta a otros grupos algales tales como cianobacterias, picoeucariotas, algas verde-azuladas y proclorofitos.

Este modelo ha sido mejorado por Balch (2004) con el objetivo de definir con mayor exactitud la ecología de los cocolitofóridos. Este autor propone una nueva versión del modelo de Margalef (1978) añadiendo una nueva dimensión, la duración del día (Fig. 10). Así, las diatomeas son capaces de crecer de forma óptima en ambientes de elevada concentración de nutrientes, elevada turbulencia y días relativamente cortos. Algunas especies de cocolitóforos son capaces de desarrollarse bien en un amplio rango de condiciones, es decir, en turbulencia media-alta en ambientes meso-eutróficos. Sin embargo, los blooms de Emiliania huxleyi han sido separados del resto de los cocolitofóridos por sus requerimientos fisiológicos especiales (Fig. 10), larga duración del día y baja turbulencia. Por otro lado, los dinoflagelados tienden a dominar en ambientes de baja turbulencia, bajos nutrientes y larga duración del día pudiendo desencadenar las denominadas mareas rojas ante un aumento importante de nutrientes.

Sin embargo, estos modelos han de considerarse como genéricos ya que en la naturaleza la sucesión ecológica es un fenómeno mucho más complejo en el que intervienen otros factores clave como la presencia de grazers ("consumidores primarios") o nuevos aportes de nutrientes. Además, dentro del grupo de las diatomeas los diferentes taxones presentan distintas estrategias ecológicas, así por ejemplo, en las primeras fases de la sucesión suelen aparecer géneros de diatomeas de pequeño tamaño que forman cadenas como algunas especies de Chaetoceros, Skeletonema o Thalassiosira. La siguiente etapa de la sucesión está representada por la proliferación de diatomeas de tipo costero tales como Chaetoceros, Asterionella, Thalassionema o Thalassiotrix. Finalmente, en las últimas fases de la sucesión aparecen otras especies de tipo más oceánico o más adaptadas a utilizar concentraciones más bajas de nutrientes tales como Rhizosolenia, Dytilum o Guinardia (Smetacek, 1999b).

Finalmente es importante señalar que en los últimos años, diversos estudios han descrito un descenso en las poblaciones de diatomeas en aguas costeras en diferentes partes del globo probablemente debido a un aumento de fosfatos y nitratos y al estancamiento de las concentraciones de sílice provocado por el aumento de los aportes fluviales (Béthoux et al., 1998). La modificación de la relación Ni:Si y Si:P puede inducir a un cambio de las comunidades dominadas por diatomeas hacia comunidades dominadas por flagelados no silíceos. Esta tendencia se ha observado en Mediterráneo (desembocadura del río Po) así como en otras partes del mundo como en el mar del Norte (Rin/Elva), golfo de México (Missisipi) 
(Smayda, 1990; Jickells, 1998) o la bahía de Brest (Aulne/Elorn) (Le Pape et al., 1996; Del Amo et al., 1997). Diversos autores han sugerido la adición de sílice a las descargas fluviales como posible solución potencial a los problemas de eutrofización (Officer y Ryther, 1980; Wassmann et al., 1996). Además este cambio hacia poblaciones dominadas por flagelados podría afectar a la cadena trófica favoreciendo el crecimiento de las comunidades de zooplancton filtradores (Fernex et al., 1996; Gorsky y Fenaux, 1998) frente a otros grupos de zooplancton de alimentación selectiva como los copépodos (Berggreen et al., 1988). Por lo tanto, el efecto antropogénico sobre las descargas fluviales podría reflejarse en un cambio progresivo de la cadena trófica del Mediterráneo.

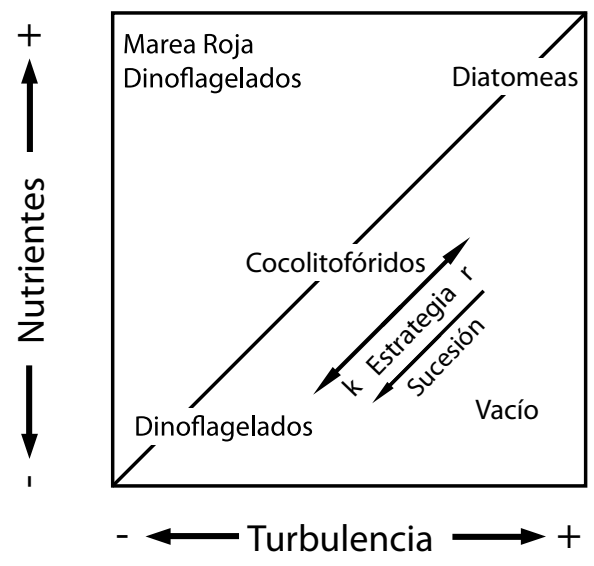

a

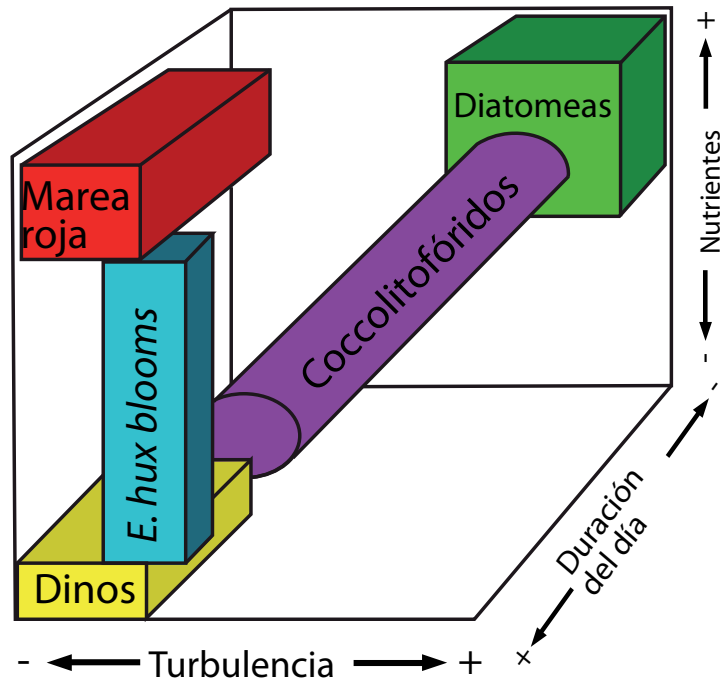

b

Figura 10. a. Estrategias ecológicas generales de los principales grupos de fitoplancton en relación a la turbulencia del medio y la concentración de nutrientes. Modificado de Margalef (1978). b. Esquema tridimensional en el que se ha añadido un eje más (duración del día) al original deMargalef (1978). Se han añadido los blooms de Emiliania huxleyi debido a su comportamiento diferente del resto de cocolitóforos (Young, 1994). Modificado de Balch (2004). 


\subsection{ECOLOGÍA DE LOS SILICOFLAGELADOS}

\subsubsection{Introducción}

Los silicoflagelados son organismos unicelulares, flagelados y autótrofos cuya clasificación aún es motivo de debate debido su posible alimentación mixotrofa (Martini, 1977) y a su posible relación de simbiosis con algas verdeazuladas (Norris, 1967). La bibliografía más actual los agrupa en la división Heterokontophyta, Clase Dictyochophyceae (Strasburguer, 1994; Throndsen, 1997).

En la actualidad los silicoflagelados están presentes en todos los océanos del globo y su distribución en la columna de agua queda restringida a los primeros $200 \mathrm{~m}$. Habitualmente representan una parte minoritaria de las comunidades microplancton, sin embargo, en zonas costeras y estuarinas pueden llegar a ser un componente mayoritario (Jochem and Babenerd, 1989).

Los silicoflagelados presentan un ciclo de vida complejo que consiste en varias fases y del cual numerosos aspectos son desconocidos (Henriksen et al., 1993). Algunas especies de silicoflagelados, a lo largo de su ciclo vital, pueden desarrollar un endoesqueleto característico compuesto por delicadas barras de sílice huecas cuyo tamaño oscila entre 20 y $60 \mu \mathrm{m}$. Este esqueleto silíceo es susceptible de preservarse en el sedimento. Esta característica junto con la sensibilidad de los silicoflagelados a los cambios de temperatura y salinidad (Henriksen et al., 1993) convierte a los silicoflagelados en útiles herramientas paleoceanográficas. Así por ejemplo, Gemeinhardt (1934) describió una relación directa entre la temperatura y la distribución biogeográfica de los géneros Dictyocha (aguas calientes, latitudes bajas) y Distephanus (= Dictyocha speculum) (aguas frías, altas latitudes) en el mar abierto. Basándose en la distribución de los silicoflagelados en el Atlántico Sur, Gemeinhardt (1934) concluyó que la temperatura óptima para Distephanus speculum era aproximadamente $1^{\circ} \mathrm{C}$ y la temperatura óptima para Dictyocha fibula se encontraba entre $\operatorname{los} 18$ y $20^{\circ} \mathrm{C}$. Debido a esta sensibilidad a los cambios de temperatura, los silicoflagelados también han sido empleados por diversos autores para la reconstrucción de paleotemperaturas (Bukry and Monechi, 1985; Ciesielski and Weaver, 1974; Mandra and Mandra, 1970). Además de esto, los silicoflagelados han sido empleados como indicadores bioestratigráficos (Perch-Nielsen, 1985; Tappan, 1980). Finalmente, estudios en trampas de sedimento han descrito cambios en de las poblaciones de silicoflagelados en relación con eventos de El Niño en la Bahía de Santa Bárbara (Lange et al., 2000) y en el Sudeste del Pacífico Sur (Romero et al., 2001).

\subsubsection{Taxonomía}

Con el objetivo de facilitar la comprensión de las descripciones morfológicas de silicoflagelados del Capítulo 8, en la Figura 11 se facilita un resumen de la terminología empleada basada en Bukry y Monechi (1985) y Onodera (2006). 

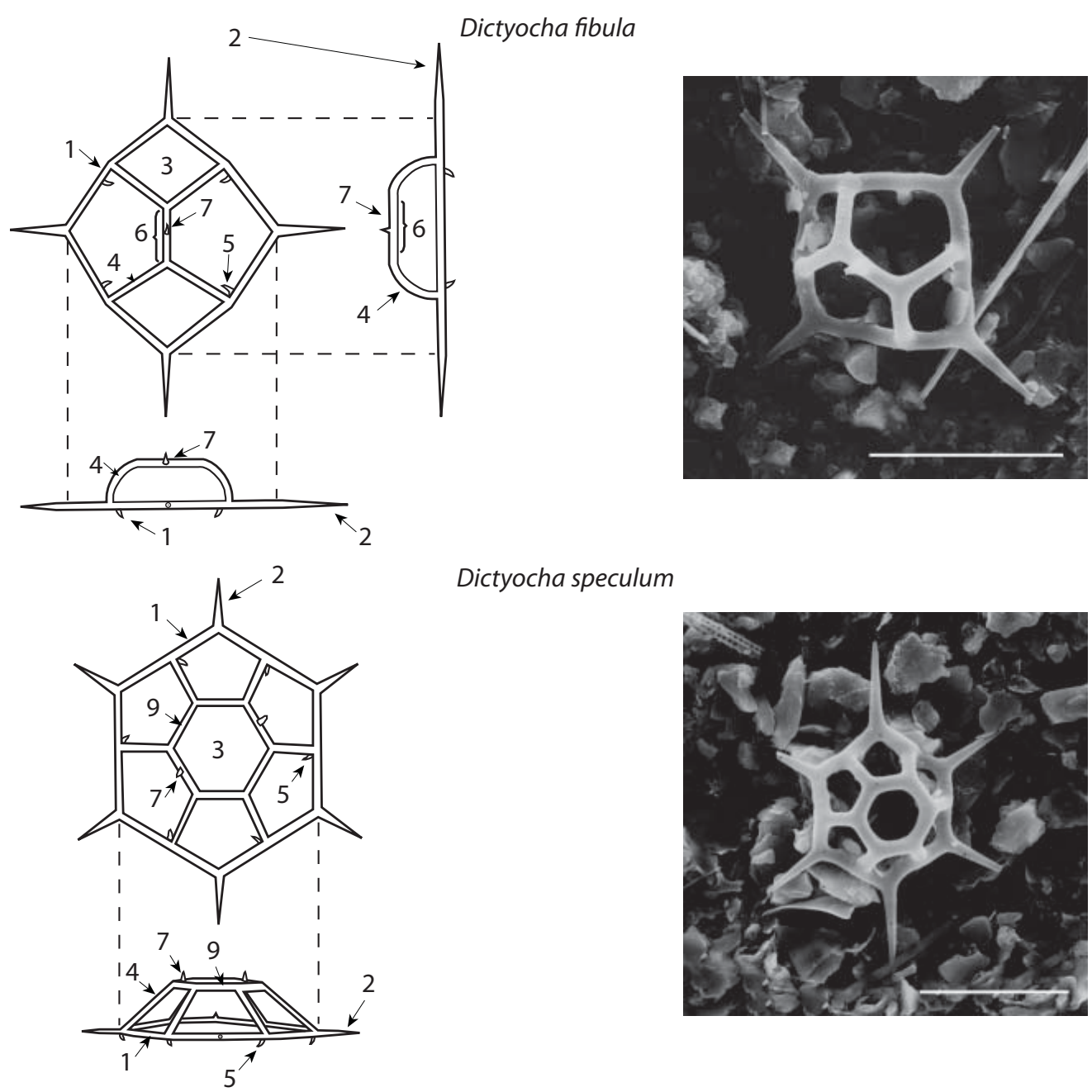

Dictyocha speculum
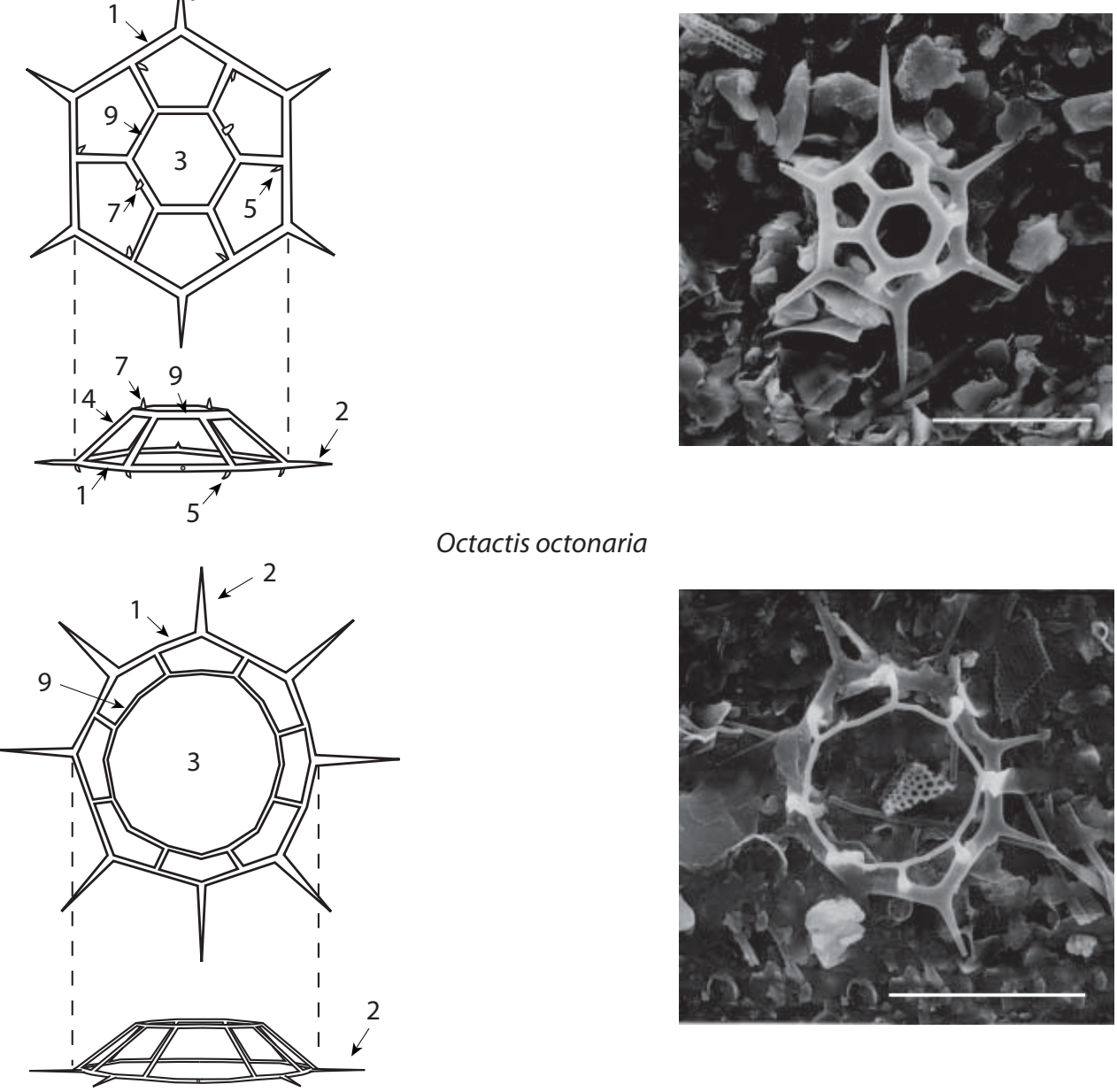

Octactis octonaria

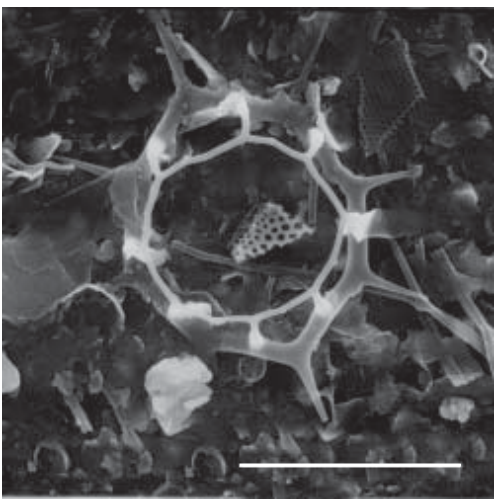

Terminología:

1: Basal ring (anillo basal)

2: Radial spine (espina radial)

5: Supporting spine (espina de apoyo)

6: Apical bar (barra apical)

7: Apical spine (espina apical)

3: Window (ventana)

8: Apical ring (anillo apical)

Figura 11: Teminología morfológica de los esqueletos de las tres especies de silicoflagelados identificados en el Mediterráneo Occidental. 


\subsubsection{Ecología de las especies de silicoflagelados del Mediterráneo Occidental}

Las principales características ecológicas de los silicoflagelados en el Mediterráneo Occidental son descritas en detalle en el Capítulo 8. 


\section{Capítulo 5}

Ecología de los foraminíferos planctónicos

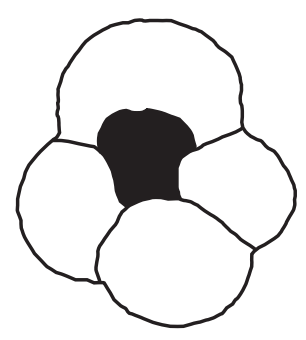





\subsection{INTRODUCCIÓN}

Los foraminíferos planctónicos son organismos unicelulares, diploides y heterótrofos pertenecientes al grupo Rhizaria (Simpson and Roger, 2004). Se encuentran distribuidos por todos los océanos del planeta formando parte del zooplancton. Una de las características más remarcables de este grupo es su capacidad de formar conchas calcíticas enrolladas compuestas por varias cámaras. Su ciclo de vida sigue presentando aún muchas incógnitas, sin embargo, se piensa que siguen un ciclo de vida diplonte, es decir, un individuo adulto diploide sufre meiosis originando gran número de gametos, algunos de ellos se unen a otros del sexo opuesto formando un zigoto diploide que originará un nuevo adulto (Hemleben et al., 1985). Después de la gametogénesis, las conchas vacías de la generación parental se hunden y se acumulan en el lecho marino. Esta estrategia reproductiva relaciona directamente la producción pelágica de carbonato con la exportación de conchas hacia el fondo marino, transfiriendo de este modo, información ambiental del medio donde vivió al fondo marino. Una peculiaridad del ciclo reproductivo de algunas especies espinosas, es su relación con los ciclos lunares (Bijma et al., 1990; Erez et al., 1991; Schiebel et al., 1997, entre otros; Spindler et al., 1979).

La composición y distribución de las asociaciones de foraminíferos planctónicos en los océanos del globo están determinadas en gran medida por las características de la columna de agua, tales como la temperatura o disponibilidad de nutrientes (Bé and Tolderlund, 1971). Asimismo, la composición química de sus conchas también varía en función de las condiciones del entorno (temperatura, salinidad, volumen de hielo global, etc.). Estas características convierten a estos organismos pelágicos en útiles indicadores paleoambientales, permitiéndonos reconstruir el ritmo y magnitud de los cambios climáticos del pasado. Tradicionalmente, la taxonomía de este grupo se ha basado en la morfología de su concha (i.e., forma de la concha y de las cámaras y textura de la concha), distinguiéndose actualmente unas 44 especies vivas (Hemleben et al., 1989). La principal división entre foraminíferos planctónicos se hace en función de la presencia o ausencia de espinas en su pared, definiéndose de este modo dos grupos: espinosos y no espinosos. En líneas generales, las especies espinosas son carnívoras, alimentándose principalmente de copépodos, mientras que las no espinosas se alimentan fundamentalmente de fitoplancton. Sin embargo, esta división no es estricta ya que existen varias especies omnívoras. Además, algunas especies de foraminíferos contienen algas fotosintetizadoras (dinoflagelados o crisofitas) con las que establecen relaciones de simbiosis, comensalismo y parasitismo (Hemleben et al., 1989). La simbiosis es la relación más común y sólo la presentan los foraminíferos espinosos. Mediante esta relación, el foraminífero se beneficia obteniendo oxígeno del alga, mientras que ésta recibe a cambio dióxido de carbono, protección y transporte. Esta relación condiciona la posición en la columna de agua de las especies de foraminíferos que portan estos organismos simbiontes. 


\subsection{DISTRIBUCIÓN VERTICAL, HORIZONTAL Y ESTACIONAL}

Los foraminíferos planctónicos viven principalmente en la zona fótica aunque pueden descender a aguas más profundas (Berger, 1969; Boltovskoy, 1973; Lohmann, 1992), alcanzando, en algunos casos, profundidades de varios miles de metros (Hemleben, 1989). No es posible definir un rango estricto de profundidades para cada especie ya que varían regional y estacionalmente, e incluso algunas especies ajustan su hábitat durante el ciclo de vida (Lohmann, 1992). Por lo tanto, cualquier estratificación de las especies en la columna de agua es únicamente válida dentro del contexto de un estudio estadístico (Bé, 1977). No obstante, las mayores concentraciones se encuentran generalmente por debajo de la superficie, aproximadamente entre los 10 y $50 \mathrm{~m}$ (Fig. 1).
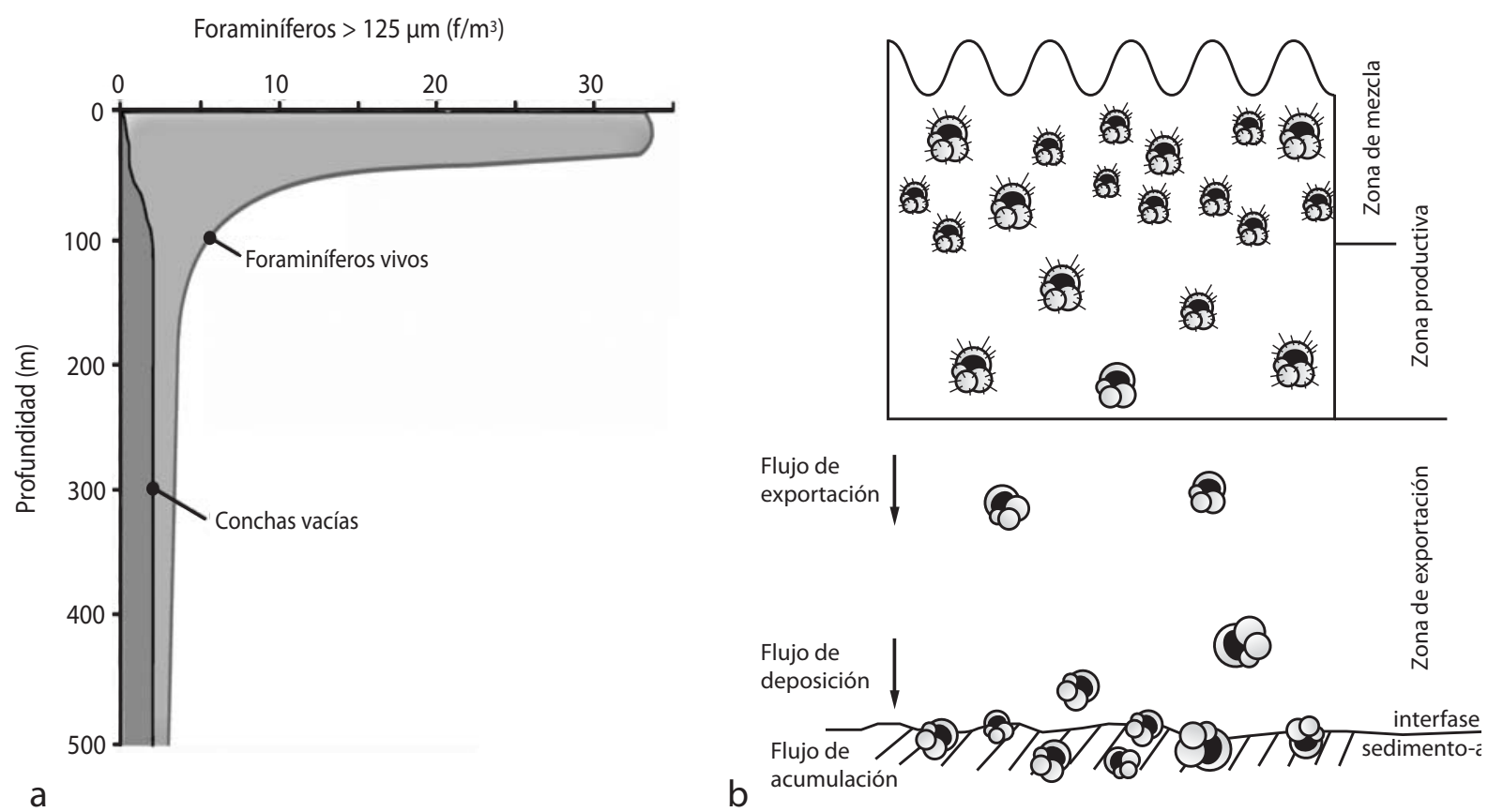

Figura 1: a. Concentración de foraminíferos planctónicos vivos y conchas vacías a varias profundidades. Ejemplo de la Bahía de Santa Barbara (Estados Unidos). Concentración expresada en número de foraminíferos por metro cúbico. b. Esquema de la columna de agua ilustrando el ciclo de los foraminíferos desde su producción hasta su acumulación en el sedimento. Modificado de Berger (1971) y Lončarić (2005).

Los foraminíferos planctónicos que viven en las capas superficiales son generalmente más pequeños y con una pared más fina que aquellos que viven en aguas más profundas. Así, Bé y Ericsson (1963) observaron que los especímenes recogidos en ambientes meso- y batipelágicos generalmente presentaban paredes más gruesas y un protoplasma blanquecino que indicaban su aislamiento de la zona eufótica. No obstante, es posible que muchas especies pasen las primeras etapas de su vida en la zona epipelágica y finalmente busquen hábitats 
más profundos (Bé and Ericson, 1963; Lohmann, 1992). La concentración de foraminíferos planctónicos disminuye exponencialmente con la profundidad en los primeros cientos de metros mientras que la concentración de conchas vacías aumenta rápidamente entre los 50 y $100 \mathrm{~m}$. Sin embargo, este incremento se hace mucho más suave entre los 100 y 500m (Fig. 1). Los especímenes muertos que caen por la columna de agua hacia el fondo forman el llamado flujo de exportación, durante el cual pueden alterarse por diferentes procesos durante su transferencia hacia el fondo (Fig. 1). El flujo de acumulación consiste en las conchas que llegan al fondo mientras que las conchas en la interfase sedimento-agua forman el flujo de acumulación (Fig. 1).

Los foraminíferos planctónicos se pueden dividir en tres grupos en función de su distribución vertical en la columna de agua (Fig. 2):

- Especies de aguas someras. Este grupo engloba a las especies que viven principalmente en los primeros $50 \mathrm{~m}$ de la columna de agua. Está compuesto predominantemente por foraminíferos espinosos e incluye a todas las especies del género Globigerinoides ( $G$. ruber y G. sacculifer) y algunas del género Turborotalita (T. quinqueloba entre otras).

- Especies de aguas intermedias. Los miembros de este grupo viven en los primeros $100 \mathrm{~m}$ de la columna de agua pero muestran preferencia para vivir entre los 50 y $100 \mathrm{~m}$. Entre estos organismos se encuentran los foraminíferos espinosos Globigerina bulloides y Orbulina universa y no espinosos como Globigerinita glutinata.

- Especies de aguas profundas. Este grupo de foraminíferos planctónicos viven durante sus estadios juveniles en la zona eufótica y posteriormente por debajo de los 100 metros cuando son adultos. Entre las especies de este grupo caben destacar Globorotalia inflata, Globorotalia truncatulinoides y Neogloboquadrina pachyderma.

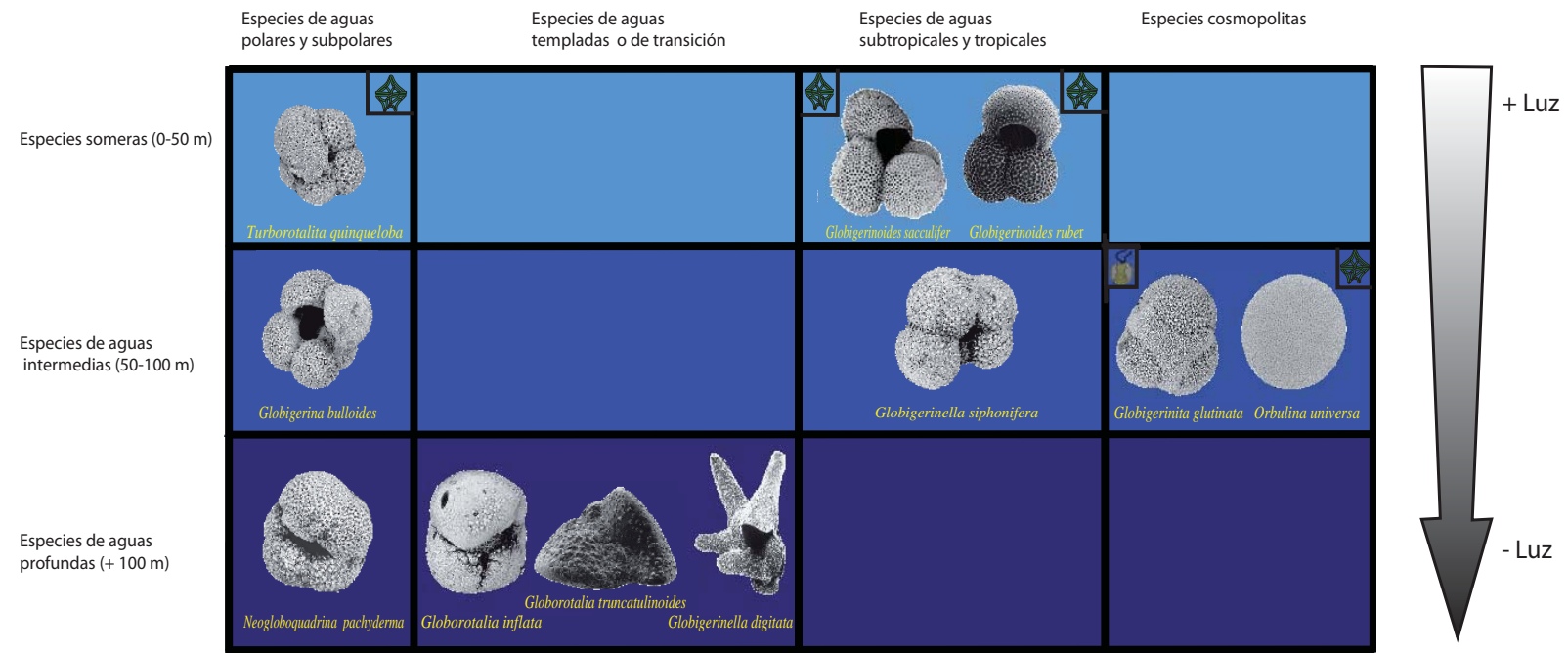

Figura 2. Esquema mostrando la distribución vertical y horizontal de las principales especies de foraminíferos planctónicos vivas encontradas en el golfo de León. Señalados con un dinoflagelado (verde) o una crisofita (marrón) los portadores de simbiontes. 
En lo referente a su distribución horizontal, los foraminíferos planctónicos se distribuyen latitudinalmente de acuerdo con sus requerimientos ecológicos (temperatura, cantidad de nutrientes, luz, etc.). Esto da lugar a una división de los océanos en grandes zonas o provincias biogeográficas en las que viven diferentes especies (Bé, 1977). De este modo, es posible distinguir cinco grandes regiones o provincias: Provincia Tropical, Provincias Subtropicales, Zonas de Transición, Provincias Subpolares y Provincias Polares.

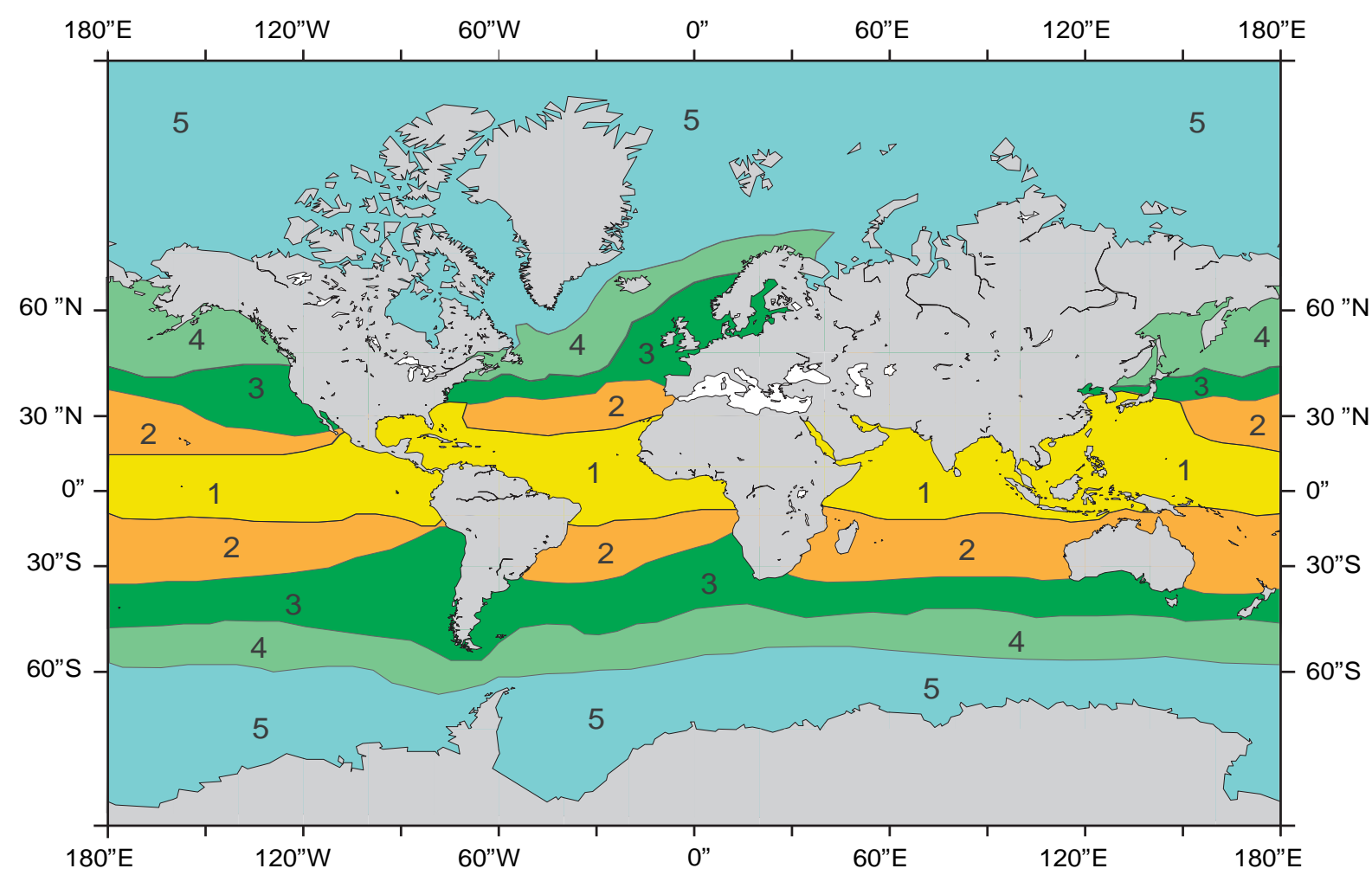

Figura 3: Distribución de las cinco grandes provincias faunísticas de los foraminíferos planctónicos actuales: 1: tropical; 2: subtropical; 3: transicional; 4: subpolar; 5: polar. Modificado de Bé (1977).

Las variaciones estacionales en la abundancia de los foraminíferos planctónicos son el factor más influyente en su distribución (Bé, 1977) y están íntimamente ligadas a los ciclos de nutrientes y a la hidrografía de las aguas donde viven. Así por ejemplo, en latitudes templadas del hemisferio Norte, durante el invierno ocurre una mezcla vertical de la columna de agua que provoca un enriquecimiento de nutrientes de las aguas superficiales con el consecuente aumento de fitoplancton. Dichos incrementos en la productividad primaria están acompañados por incrementos en la abundancia de las poblaciones de foraminíferos planctónicos ya que muchos de ellos se alimentan de fitoplancton (Bé, 1977). Este aumento de las poblaciones de foraminíferos planctónicos ocurre generalmente después del invierno coincidiendo con el bloom de primavera. Numerosos trabajos han puesto de manifiesto el carácter estacional de las asociaciones de foraminíferos en diversas partes del globo (Bárcena et al., 2004; Deuser et al., 1981; Reynolds and Thunell, 1985; Sautter and Sancetta, 1992). Estos estudios se llevan a 
cabo mediante el uso de trampas de sedimento y/o redes de plancton, recogidas de la columna de agua durante periodos de tiempo variables. La sucesión estacional de los diferentes grupos de especies en el océano tiene implicaciones paleoecológicas importantes. Las conchas de foraminíferos planctónicos que encontramos en el sedimento pertenecen a diferentes especies que no habitaban necesariamente al mismo tiempo o en las mismas masas de agua, sino que cada especie puede representar diferentes condiciones ecológicas y estacionales. En este sentido, el conocimiento de la ecología de los foraminíferos actuales es de vital importancia para poder inferir con fiabilidad las condiciones ambientales pretéritas.

\subsection{CARACTERÍSTICAS ECOLÓGICAS DE LAS ESPECIES}

A continuación se describen brevemente las características principales de las especies de foraminíferos planctónicos actuales presentes en el golfo de León agrupadas en función de la clasificación propuesta por Bé (1977):

\section{Especies subpolares}

Neogloboquadrina pachyderma (dextrorsa) (Ehrenberg), 1981

Se trata de una especie de foraminífero planctónico no espinoso característico de aguas frías. En el océano Atlántico forma parte de la provincia subpolar (Bé, 1977; Hemleben et al., 1989) y es más abundante en aquellas zonas donde las temperaturas por debajo de la termoclina descienden por debajo de los $12^{\circ} \mathrm{C}$ (Bé and Tolderlund, 1971). Se alimenta exclusivamente de fitoplancton, normalmente de diatomeas, y carece de simbiontes. Según Bé (1977), en su estadio juvenil vive en los primeros $100 \mathrm{~m}$ de la columna de agua y cuando alcanza su estado adulto vive asociado a la termoclina o por debajo de ella (Bé, 1960; Bé, 1977; Bé and Ericson, 1963; Fairbanks and Wiebe, 1980). Se ha descrito como una especie que se alimenta y desarrolla en el DCM (Deep chlorophyll maximun), es decir, en la zona de máxima concentración de clorofila. Este DCM se da en la base de la zona eufótica cuando la parte superior de la columna de agua está bien estratificada, y como consecuencia de una somerización de la picnoclina (Rohling, 1994). En el Mediterráneo, Pujol and Vergnaud Grazzini (1995) sugieren que la distribución de este taxón está controlada principalmente por la temperatura y por lo tanto se limita a la cuenca Noroccidental, donde alcanza altas concentraciones en las aguas superficiales y mesopelágicas durante el invierno, mientras que en verano sólo ha sido descrita a profundidades mesopelágicas y en baja concentración. Estos autores sugieren que la distribución de esta especie en el Mediterráneo se limita a aquellas zonas donde la temperatura superficial del agua es menor de $13^{\circ} \mathrm{C}$. Posiblemente los pocos ejemplares de Neogloboquadrina pachyderma con enrollamiento hacia la izquierda (formas sinestrorsas) encontrados en el Noroeste del Mediterráneo sean formas aberrantes de $N$. pachyderma dextrorsa y no ejemplares del taxón polar Neogloboquadrina incompta (=antigua $N$. pachyderma sinistrorsa) (Darling et al., 2006). Las temperaturas relativamente elevadas del Mediterráneo impedirían el desarrollo de $N$. incompta. 
Globigerina bulloides d'Orbigny, 1826.

Se trata de un foraminífero planctónico espinoso con gran éxito ecológico. Está considerado como un taxón cosmopolita. Aparece predominantemente en aguas subpolares y asociado a situaciones de elevada productividad como a zonas de upwelling (Bé, 1977; Duplessy et al., 1981) o a blooms de fito- y zooplancton independientemente de su posición geográfica (Bé, 1977; Thunell and Reynolds, 1984). Aunque la mayoría de foraminíferos espinosos poseen algas simbiontes, G. bulloides carece de ellas, lo que puede estar directamente relacionado con que su distribución en la columna de agua no esté limitada a la zona fótica (Hemleben and Spindler, 1983). En el Mediterráneo es una especie abundante, sobre todo, en la Cuenca Occidental (Bé, 1977) donde es especialmente abundante durante la primavera (Bárcena et al., 2004). Al final del verano es esporádico (Pujol and Vergnaud Grazzini, 1995). La respuesta de esta especie a períodos de alta fertilidad ha sido descrita en el mar de Alborán a profundidades por debajo de la termoclina cuando esta se empieza a formar (en primavera) o más tarde, cuando la picnoclina se ha establecido (verano) (Bárcena et al., 2004; Pujol and Vergnaud Grazzini, 1995). En el Mediterráneo Oriental su abundancia decrece gradualmente mostrando una clara relación con la temperatura (Thunell, 1978). En lo referente a su distribución vertical, probablemente habite por debajo de la termoclina, ya que su máxima abundancia ha sido observada entre los 50 y 200 m de profundidad en el Mediterráneo Occidental (Cifelli, 1974; Pujol and Vergnaud Grazzini, 1995).

Turborotalita quinqueloba (Natland), 1938.

Esta especie espinosa es bastante pequeña y a veces difícil de distinguir de otros taxones de pequeño tamaño. T. quinqueloba es portadora de simbiontes y vive principalmente en la zona fótica. La abundancia de esta especie parece disminuir de latitudes altas hacia las más bajas y ha sido asociada a zonas donde no se desarrolla el DCM (Deep Chlorophyll Maximum) (Ottens, 1992). Estudios previos en el Atlántico Norte y en Mar Rojo sugieren que su ciclo reproductivo se encuentra ligado a las fases lunares (Hemleben et al., 1989). Actualmente es un taxón poco abundante en el Mediterráneo (Pujol y Vergnaud-Grazzini, 1995), aunque ha sido descrito en abundancias significativas en el mar de Alborán (Hernández-Almeida et al., 2010).

\section{Especies de la zona de transición}

Globorotalia inflata (d'Orbigny), 1839.

Esta especie de foraminífero planctónico no espinosa vive a cierta profundidad (Bé, 1977; Hemleben et al., 1989) y se trata de la única especie autóctona de las zonas de transición (entre las zonas subpolares y subtropicales). En el Atlántico Norte, la abundancia máxima de este taxón ocurre entre los 35 y 45 N (Bé, 1977). Según Pujol y Vergnaud-Grazzini (1995), G. infata es un componente importante de las asociaciones de invierno del oeste y suroeste del Mediterráneo mientras que en verano pasa a ser escaso. Esta especie parece necesitar una capa 
de mezcla profunda y fría, mientras que la temperatura y la disponibilidad de nutrientes parecen ser factores limitantes secundarios (Pujol and Vergnaud Grazzini, 1995). En el Mediterráneo Oriental esta especie es poco abundante (Thunell, 1978). Además, contenidos relativamente altos de fosfato han sido asociados con incrementos en la productividad de este taxón (Ottens, 1992).

Globorotalia truncatulinoides (d'Orbigny), 1839.

Se trata de una especie sin espinas que habita en latitudes intermedias y que muestra una preferencia por las condiciones de invierno (Bé, 1977). Es una de las especies más estudiadas del registro sedimentario y presenta dos morfotipos en función de su enrollamiento, existiendo formas dextrorsas y sinistrorsas. Actualmente en el Mediterráneo la forma dextrorsa es rara (menos del 1\% de la población) (Pujol and Vergnaud Grazzini, 1995). Kennett (1968) describió un cambio gradual en la morfología de la concha de G. truncatulinoides en function de la latitud, así en latitudes subpolares su forma es biconvexa mientras que pasa a ser cónica en el Ecuador (Kennett, 1968). G. truncatulinoides habita en aguas profundas y necesita los primeros mil metros de la columna de agua para poder completar su ciclo de vida (Bé and Ericson, 1963; Hemleben et al., 1985). Por lo tanto, esta especie parece no desarrollarse en aquellas zonas del océano donde la profundidad de la mezcla vertical es menor que la profundidad necesaria para completar su ciclo reproductivo (Lohmann, 1992). En el Mediterráneo, la máximas concentraciones de este taxón se encuentran en el Golfo de León durante el invierno (Pujol and Vergnaud Grazzini, 1995) mostrando sus máximas abundancias absolutas y relativas en las capas de agua profunda, probablemente como resultado de su ciclo de vida (Lohmann, 1992; Pujol and Vergnaud Grazzini, 1995). Al final del verano, su producción desciende y las máximas abundancias aparecen en la zona sub-termoclina donde las temperaturas son más frías y hay nutrientes disponibles. En esa época, se ha observado el aumento de formas juveniles en zonas poco profundas, cerca del máximo de clorofila (Pujol and Vergnaud Grazzini, 1995). Pujol y Vergnaud-Grazzini (1995) sugieren que los principales factores que controlan la distribución de esta especie en el Mediterráneo son la convección y mezcla vertical que ocurren en invierno. La disponibilidad de alimento y la temperatura son factores limitantes secundarios.

\section{Especies subtropicales}

Globigerinoides ruber (d'Orbigny), 1839.

Es una especie espinosa y está considerada como el foraminífero planctónico cálido más exitoso debido a su abundancia y distribución en los sedimentos superficiales. El éxito de este taxón puede deberse a la presencia en su interior de zooxantelas simbiontes (Bé, 1977). G. ruber presenta dos ecofenotipos, uno rosa (rosea) y otro blanco (alba). Parece ser la especie de foraminífero que vive en la zona más superficial de la columna de agua; por lo que es muy apropiada para realizar estudios isotópicos con el fin de estimar valores de temperatura y salinidad 
en estudios paleoceanográficos (Bé, 1977). En el Mediterráneo, ambas variedades presentan sus máximas abundancias a final del verano cuando las aguas están bien estratificadas (Pujol and Vergnaud Grazzini, 1995). Sin embargo, presentan una clara afinidad por las zonas más cálidas mostrando una escasa presencia en el Mediterráneo Occidental y máxima abundancia en la Cuenca Levantina donde la variedad alba es el máximo representante de las asociaciones de invierno aunque en baja abundancia (Pujol and Vergnaud Grazzini, 1995). Por último, es importante señalar que también se trata de una de las especies de foraminíferos planctónicos menos resistentes a la disolución (Bé, 1977).

\section{Especies tropicales}

Globigerinoides sacculifer (Brady), 1877

Se trata de un foraminífero planctónico espinoso portador de simbiontes y está considerado como la especie tropical más abundante (Hemleben et al., 1989). G. sacculifer presenta un ciclo reproductivo en fase con el ritmo lunar (Hemleben et al., 1989). Se distribuye preferentemente en los 50 primeros metros de la columna de agua (Bé, 1977). En el Mediterráneo esta especie tiene preferencia por condiciones oligotróficas como es el caso del Golfo de León al final del verano (Pujol and Vergnaud Grazzini, 1995). Finalmente, cabe destacar que se trata de una especie relativamente susceptible a la disolución (Hemleben et al., 1989).

\section{Globigerinella digitata (Brady), 1877}

Se trata de una especie espinosa común en el Mediterráneo y cuya distribución vertical parece estar restringida a aguas profundas (Hemleben et al., 1989).

\section{Globigerinella siphonifera (d'Orbigny), 1839.}

Se trata de una especie espinosa y es el único foraminífero planctónico en el que se han encontrado dos tipos de simbiontes, ambos pertenecientes al grupo de las crisófitas. Presenta una gran variabilidad morfológica, habiendo sido descritos diversos ecofenotipos (Hemleben et al., 1989). Se trata de un foraminífero abundante en áreas de upwelling. En el Mediterráneo, presenta afinidad por condiciones invernales cuando alcanza su máxima abundancia entre los 100 y 200 m de profundidad (Pujol and Vergnaud Grazzini, 1995).

\section{Especies cosmopolitas}

Orbulina universa (d'Orbigny), 1839

Se trata de una especie espinosa portadora de dinoflagelados simbiontes con amplia presencia en sedimentos superficiales entre $\operatorname{los} 65^{\circ} \mathrm{N}$ en el Atlántico Norte y $50^{\circ} \mathrm{S}$ en el los océanos del Sur, sin embargo es poco abundante (Bé, 1977). Su distribución parece estar relacionada con la temperatura con afinidad por aguas entre $13^{\circ}$ y $19^{\circ} \mathrm{C}$. Su tamaño ha sido 
relacionado con la temperatura y nutrientes (Hemleben et al., 1989). Es predominantemente carnívora, especialmente durante su fase adulta mientras que durante las fases más jóvenes es herbívora. Estudios en cultivos de laboratorio, muestran una fuerte respuesta de O. universa a la concentración de nutrientes en el medio adquiriendo una forma más esférica a medida que aumentaban los nutrientes. Sin embargo, una excesiva concentración de nutrientes desencadenaba la formación de dos esferas conocida por Biorbulina (Hemleben et al., 1989). $\mathrm{Su}$ tamaño se correlaciona con la temperatura y con los nutrientes. Su ciclo reproductor parece seguir las fases lunares (Hemleben et al., 1989). En el Mediterráneo es más prolífica a final del verano entre los 50-100 m de profundidad en el Norte de África y alrededor de las Islas Baleares siendo la especie dominante de estas áreas al final del verano. En el golfo de León O. universa es más abundante al final del verano. En esta época del año, su máxima abundancia se da por debajo de la termoclina, sugiriendo un ajuste entre la intensidad lumínica (debido a la actividad de sus simbiontes) y sus requerimientos de temperatura (Pujol y Vergnaud-Grazzini, 1995).

Globigerinita glutinata (Egger), 1893.

Se trata de una especie no espinosa con la pared microperforada. Es abundante en aguas tropicales, subtropicales y en aguas polares superficiales y tiene preferencia por aguas ricas en nutrientes (Bé and Tolderlund, 1971; Thunell and Reynolds, 1984). Se trata de una especie tolerante a un amplio rango de temperatura y de salinidad (Hemleben et al., 1989) por lo que es considerada como una especie cosmopolita y oportunista. G. glutinata es portadora de crisófitas simbiontes con las que mantiene una relación facultativa, es decir, inicialmente ante una presencia abundante de crisofitas, hospedador y huésped mantienen una relación de simbiosis, sin embargo estas algas acaban finalmente siendo digeridas por el foraminífero (Hemleben et al., 1989). En el Mediterráneo su presencia es escasa, se encuentra en aguas superficiales del Golfo de León y de la Cuenca Balear en bajas concentraciones a final del verano y es algo más prolífica durante el invierno entre 100 y $200 \mathrm{~m}$ de profundidad en aguas del Norte de África (Pujol and Vergnaud Grazzini, 1995).

\subsection{ECOLOGÍA GENERAL DE LOS FORAMINÍFEROS EN EL GOLFO DE LEÓN}

En este apartado se pretende resumir lo descrito anteriormente por otros autores sobre las preferencias ecológicas y distribución estacional de los foraminíferos planctónicos del golfo de León. Durante el otoño, la rotura de la estratificación de la columna de agua se refleja en un importante crecimiento en las poblaciones de diatomeas y de otros grupos de fitoplancton. Estas condiciones de mezcla y de nutrientes (fitoplancton) son las adecuadas para la reproducción y proliferación de especies como G. truncatulinoides o G. inflata (Pujol y VergnaudGrazzini,1995). G. truncatulinoides ha sido descrita como una especie asociada a condiciones de mezcla, de hecho, Pujol y Vergnaud-Grazzini, (1995) señalan que el principal factor que 
controla la distribución de esta especie en el Mediterráneo es la convección y mezcla vertical que ocurre en invierno, relegando la disponibilidad de alimento y la temperatura a factores limitantes secundarios. G. inflata, al igual que G. truncatulinoides, parece necesitar una capa de mezcla profunda y bastante fría como la existente durante el invierno en el Golfo de León cuando la termoclina desaparece (Pujol y Vergnaud-Grazzini, 1995). A finales de invierno, han sido observados incrementos en la abundancia de Neogloboquadrina pachyderma (Fairbanks et al. 1982 y Pujol y Vergnaud-Grazzini, 1995 ). La picnoclina también es un factor importante al determinar la distribución de varias especies de foraminíferos planctónicos depredadoras ya que siguen los mismos patrones de cambio que hace la densidad de la columna de agua. Durante la primavera, tiene lugar el inicio en la estratificación de la columna de agua y el desarrollo de un importante bloom de fitoplancton. Las especies G. bulloides, N. pachyderma y G. inflata han sido asociadas a altos niveles de producción primaria (Pujol y VergnaudGrazzini, 1995). Durante el verano, las aguas superficiales son oligotróficas, sin embargo, si hay nutrientes disponibles para los grupos de fitoplancton que se desarrollan por debajo de la termoclina (zona fótica profunda). Esto se corrobora con los datos de cocosferas obtenidos por Knappertsbusch (1993) donde los picos de máxima abundancia estaban por debajo de los $50 \mathrm{~m}$. El desarrollo de fitoplancton por debajo de la termoclina favorece la proliferación de especies depredadoras de fitoplancton como G. truncatulinoides. Como consecuencia, las asociaciones oligotróficas coexisten con las eutróficas durante la misma estación. Tanto en la cuenca Provenzal como en las Islas Baleares, grandes cantidades de cocolitofóridos han sido encontrados a profundidades entre 50 y $100 \mathrm{~m}$ al final del verano sugiriendo la fertilización de la base de la zona fótica (Knappertsbusch, 1993). Esto explica que Pujol y Vergnaud-Grazzini (1995) encontraran G.ruber, O. universa (o sus formas juveniles) por debajo de $75 \mathrm{~m}$ junto con consumidores mesopelágicos como G.truncatulinoides o G.inflata. En las capas superiores la presencia de foraminíferos permaneció en baja abundancia al ser pobres en nutrientes y estar limitados el crecimiento del fitoplancton. El rápido agotamiento de los nutrientes en la parte superior de la columna de agua limita la producción de los foraminíferos. 


\section{Capítulo 6}

Annual succession of diatom assemblages in the northwestern Mediterranean Sea based on a 12-year-long sediment trap record

Rigual-Hernández, A.S., Jordan, R.W., Bárcena, M.A., Sierro, F.J., Flores, J.A. and Heussner, S.

To be submitted to Micropaleontology

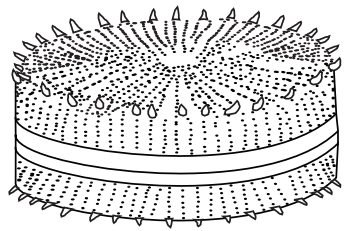





\title{
Annual succession of diatom assemblages in the northwestern Mediterranean Sea based on a 12-year-long sediment trap record
}

Andrés S. Rigual-Hernández ${ }^{1, *}$, Richard W. Jordan², María de los Ángeles Bárcena ${ }^{1}$, Francisco J. Sierro ${ }^{1}$, José A. Flores ${ }^{1}$ and Serge Heussner ${ }^{3}$.

1. Área de Paleontología, Departamento de Geología, Universidad de Salamanca. CP 37008 Salamanca.

2. Department of Earth \& Environmental Sciences, Faculty of Science, Yamagata University, Yamagata 990 8560, Japan

3. CEFREM, UMR 5110 CNRS- University of Perpignan Via Domitia 52 avenue Paul Alduv, 66860 Perpignan Cedex, France.

*Corresponding author. Tlf. 0034 637223439. E-mail: arigual@usal.es

\begin{abstract}
To determine the annual succession of diatom species, as well as the assemblage composition, an "average year" was compiled from a 12-year-long sediment trap record (1993-2006). The study site at the entrance of the Gulf of Lions $\left(43.02^{\circ} \mathrm{N}, 5.18^{\circ} \mathrm{E}\right)$ (northwest Mediterranean) is usually under the influence of the Northern Current (NC), and is only affected by Rhône river plume incursions during periods of strong wind events. The annual diatom assemblage is composed of more than 126 taxa exhibiting a wide range of morphological and physiological characteristics that allow them to thrive in the water column under certain environmental conditions. Despite the monthly resolution, the average year reveals a classical diatom succession: from small, fast-growing and opportunistic species that appear at the beginning of the spring bloom to larger and slower-growing diatoms that succeed under well-stratified and oligotrophic conditions (e.g. Skeletonema-Chaetoceros-Rhizosolenia succession). In addition, the main diatom species are presented in 13 plates of SEM and LM photographs.
\end{abstract}

Key words: diatoms, Northwest Mediterranean, sediment trap, succession. 


\subsection{INTRODUCTION}

Diatoms (Division Bacillariophyta) are one of the main phytoplankton groups in the world's oceans, and usually dominate phytoplankton assemblages in turbulent and nutrient-rich marine environments, such as coastal areas (Ragueneau et al., 2000). Some of the most relevant features of diatoms are their silica frustule, fast-growth rates and capacity to form aggregates that may trigger mass sinking. Due to these characteristics, diatoms play a key role in the silica and carbon cycles in the oceans, especially near continental margins, where $2 / 3$ of the total marine Carbon (C) and 32-39 \% of biogenic Silica (Si) is buried (Liu et al., 2000; Ragueneau et al., 2000). Each diatom species has evolved by adopting a precise shape and size that will increase their survival opportunities under defined conditions (Margalef, 1997). As well as their morphology, their metabolism has evolved too, for example, open ocean diatoms (e.g. Thalassiosira oceanica) require lower iron concentrations than coastal ones (e.g. Thalassiosira weissflogii), and therefore, they usually appear in the final stages of a diatom bloom when nutrients are scarce (Strzepek and Harrison, 2004). Although the photosynthetic rate of open ocean diatoms is unaffected by lower iron concentrations, they have sacrificed their capacity to adapt to abrupt light intensity changes, very common in turbulent environments such as coastal areas (Strzepek and Harrison, 2004). Today there are about 10000 to 12000 diatom species (Hasle and Sylvertsen, 1997) and they live in a wide range of habitats: from freshwater to marine and from benthic to planktonic. The large number of species makes correct identification difficult, but once this problem is overcome, the high diversity of this group is a powerful tool for ecological studies and paleoceanographic and paleoclimatic reconstructions.

In the NW Mediterranean, diatoms are a major component of the phytoplankton populations and tend to dominate the annual spring bloom (Gutiérrez-Rodríguez et al., 2010; Margalef, 1974; Siokou-Frangou et al., 2010). Numerous studies have focused on the structure and dynamics of the plankton communities in this area (e.g. Bustillos-Guzmán et al., 1995; Díaz et al., 2000; Gómez and Gorsky, 2003; Gutiérrez-Rodríguez et al., 2010; Leblanc et al., 2003; Lefevre et al., 1997; Marty et al., 2002; Vidussi et al., 2000), however, none of them have addressed the interannual variability identifying diatoms to specific level. With this work we document the general patterns of diatom annual succession in the Gulf of Lions based on an average year calculated from the data of a 12-year sediment trap record. Furthermore we provide with SEM and LM photos of the frequent diatom taxa identified in the samples in order to help other authors with species identification.

\subsection{STUDY AREA}

The Gulf of Lions (GoL hereinafter) is located in the northwestern part of the Mediterranean Sea and has a wide continental shelf with a shelf break indented with an intricate network of about 10 submarine canyons (Fig. 1). The general circulation in this area is dominated by an along-slope current called the Northern Current (NC) that flows in a cyclonic direction along 
the continental slope (Fig. 1). During winter, intense, cold and dry northwesterlies (Mistral and Tramontana) cause evaporation and cooling of the surface waters inducing water mixing both on the shelf and offshore (Millot, 1990).

The river Rhône is the major river of the Mediterranean Basin and flows into the GoL in its Northeastern part. The Rhône plume can extend over a hundred kilometers (Estournel et al., 1997). Other nine small rivers also deliver material into the Gulf, however, the Rhône is its main source of fresh water and sediments (Ulses et al., 2008).

Although the Mediterranean Sea can be regarded as oligotrophic, the NW Mediterranean can be considered an exception due to their particular hydrographic features. The relatively high productivity of this area is caused by some enrichment mechanisms that supply the euphotic zone with nutrients, such as strong winter water mixing, the shelf-slope density front, and river input (mainly by the Rhône) (Estrada, 1996).

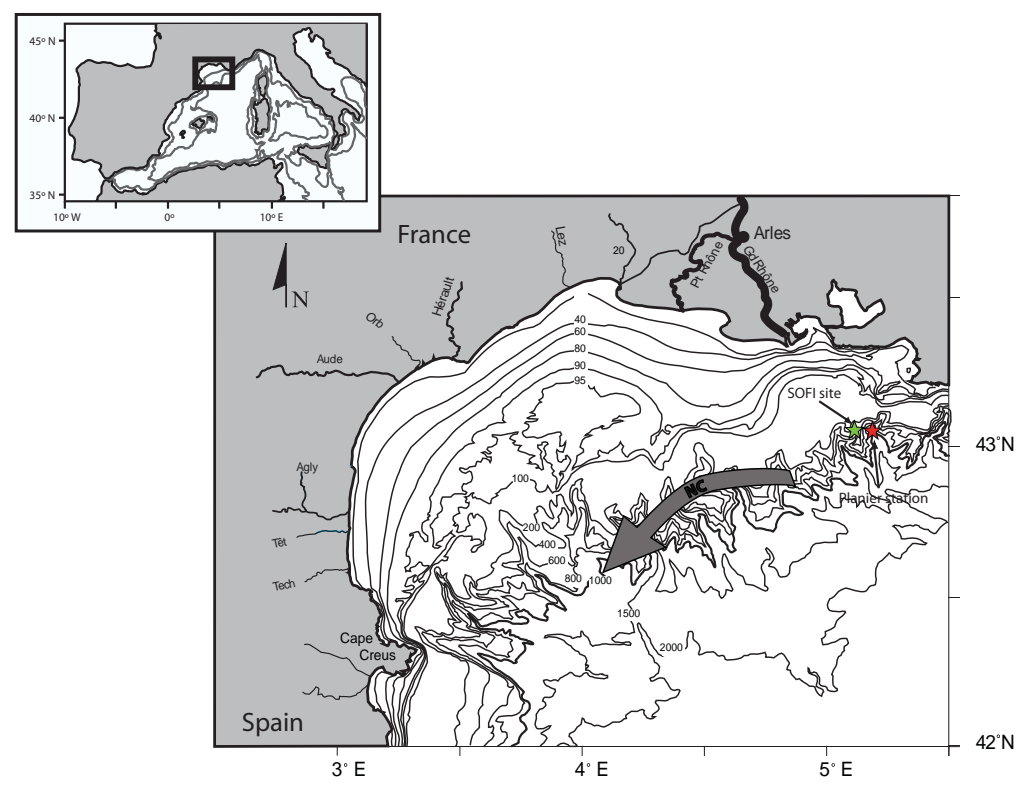

Figure 1. Bathymetric map showing the position of the station Planier (red star) in the Gulf of Lions, northwestern Mediterranean Sea. The position of the station SOFi (green star) is also indicated. The position of the Northern Current is showed. Isobaths are in meters.

\subsection{MATERIALS AND METHODS}

\subsubsection{General processing}

The 12-year sampling was conducted in Planier experimental site $\left(43.02^{\circ} \mathrm{N}, 5.18^{\circ} \mathrm{E}\right)$ (Fig. 1). A total of 120 samples from were collected by a Technicap PPS 3 sediment trap situated over the Planier submarine canyon $\left(43.02^{\circ} \mathrm{N}, 5.18^{\circ} \mathrm{E}\right), 500 \mathrm{~m}$ above the bottom (mab) in a water column of $1000 \mathrm{~m}$. The sampling period can be divided in two segments based on the sampling periods: the first part ran from October 1993 to January 1997 with a 14-day sampling interval, while the 
second segment ran from February 1997 to February 2006 with a sampling interval of 1 month. A more detailed description of the experiment can be found in Heussner et al. $(2006 ; 1990)$ and Rigual-Hernández (2010).

\subsubsection{Siliceous microplankton sample preparation and analysis}

The siliceous microplankton studies were carried out using a fraction of the original sediment trap sample that ranged from $1 / 64$ to $3 / 4$, however, the most common aliquot was $1 / 8$. Two wetsieved processes were performed with $150 \mu \mathrm{m}$ and $63 \mu \mathrm{m}$ meshes, and the different fractions were subsequently stored for further planktonic foraminifer analysis. For the diatom analysis the $<63 \mu \mathrm{m}$ fraction was used. A standard decantation method (Flores and Sierro, 1997) was used to prepare the samples, while the diatoms were counted based on the recommendations of Schrader and Gersonde (1978). Diatom analysis was performed using a Nikon Eclipse 80i light microscope (LM) equipped with phase contrast optics at a magnification of $1000 \times$. For each sample, a minimum of 400 diatom valves were counted, and each diatom specimen was identified to the lowest taxonomic level possible. More than 500 scanning electron microscope (SEM) photographs were taken in order to facilitate the identification process. SEM and LM photos of the most significant taxa are presented in Plates 1 to 11, while those of less relevant species and other remarkable organisms and structures identified in the samples are shown in Plates 12 and 13. For the diatom identification the taxonomic concepts of Hasle and Sylvertsen (1997), Round et al. (1990) and Delgado and Fortuño (1991) were followed.

\subsubsection{Sea surface temperature and chlorophyll $a$ data sets}

Sea surface temperature (SST) data were obtained weekly (October 1993-January 2006) from the NOAA Optimum Interpolation Sea Surface Temperature Analysis (Reynolds et al., 2002). Mean monthly values were then calculated and plotted (Fig. 2). For the chlorophyll $a$ satellite data, monthly values from September 1997 till January 2006 were obtained from NASA's Giovanni program (Acker and Leptoukh, 2007) and the means were calculated for the average year (Fig. 2). Monthly averages of vertical thermal structure of the upper $300 \mathrm{~m}$ for the collecting period was obtained for Planier locations from the World Ocean Atlas 1994 (Levitus and Boyer, 1994) (Fig. 2).

\subsubsection{Diatom valve fluxes and diversity index calculation}

An average year was calculated from 122 samples of the 12-years-long sediment trap record in order to minimize the diatom flux interannual variability (Rigual-Hernández, submitted). To perform this calculation all samples from the same month were gathered and the average flux for each month was estimated (Figs. 2 and 3). Diatom fluxes are given as the number of valves per day and square meter (valves $\mathrm{m}^{-2} \mathrm{~d}^{-1}$ ). In addition, the Shannon-Weaver (1949) diversity index $\left(\mathrm{H}^{\prime}\right)$ was calculated for all the months of the 
average year in order to better understand the evolution of the diatom biocoenosis (Fig. 4) A taxonomic list including all taxa referred in the text as well as the main taxa identified in the present study can be found in the Appendix at the end of the manuscript.

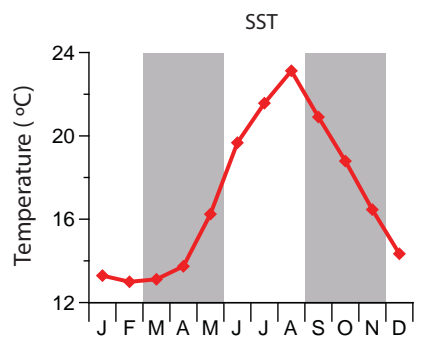

a

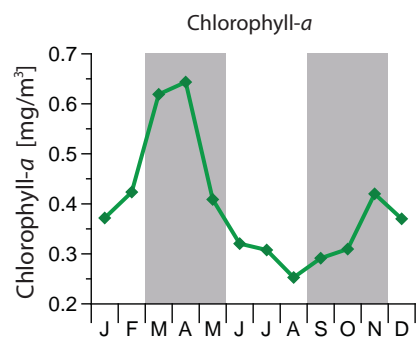

b

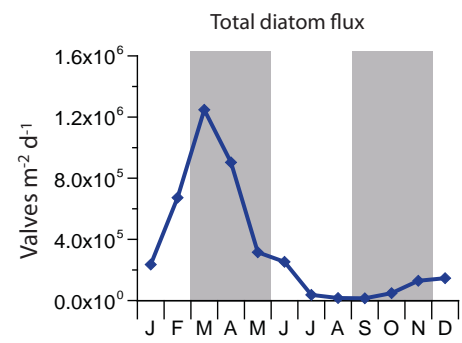

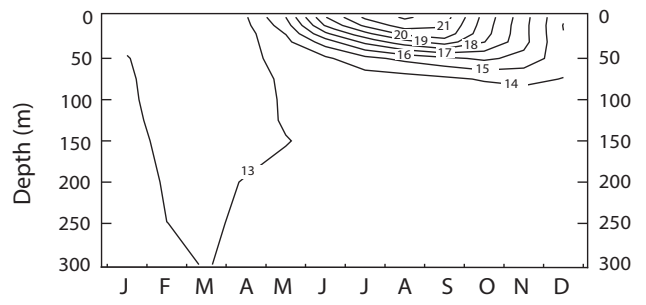

d

Figure 2. a. Sea surface temperature $\left({ }^{\circ} \mathrm{C}\right)$. b. Satellite chlorophyll $a$ concentration $\left(\mathrm{mg} \mathrm{m}^{-3}\right)$ calculated for the Oct 93 to January 2006 period. c. Mean monthly flux of total diatom valve flux at 500 mab (valves $\mathrm{m}^{-2} \mathrm{~d}^{-1}$ ) in the Gulf of Lions. d. Seasonal variation of the vertical structures of temperature at station Planier.

\subsection{RESULTS}

Total diatom flux, chlorophyll $a$ and SST are presented in Figure 2. Total diatom valve flux and SST exhibit unimodal and opposite patterns, while total diatom flux shows a bimodal annual distribution with a pronounced maximum during March-April and a secondary peak in November. There is an excellent correlation between total planktonic diatom flux and chlorophyll $a$ values $(\mathrm{R}=0.91)$, while between the SST and the total diatom fluxes $(\mathrm{R}=0.74)$ and between SST and chlorophyll $a$ is significant $(\mathrm{R}=0.69)$. A total of 126 diatom species were identified in this study. A list of the main diatom taxa identified in the sediment trap samples can be found in the appendix at the end of the manuscript. Moreover, seasonal fluxes and relative contribution of the main diatom species are plotted in Figures 3 and 4 . The average year provides us with general information on the diatom annual succession and ecological trends of the main diatom species in the GoL, however, it is necessary to keep in mind that the variability over one or more years can introduce some bias into the determinations. 

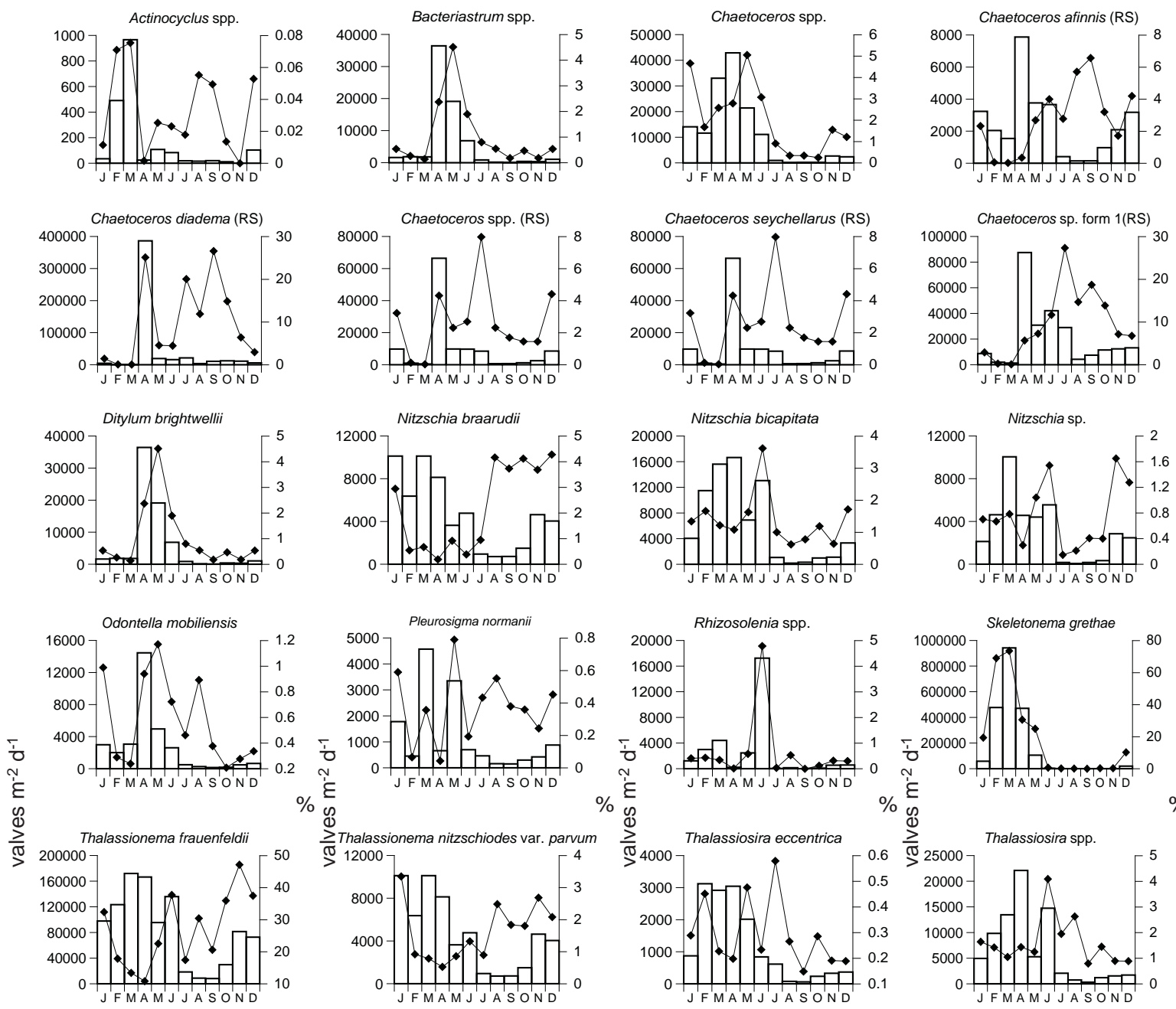

$\% \frac{\text { है }}{\text { थ }}$
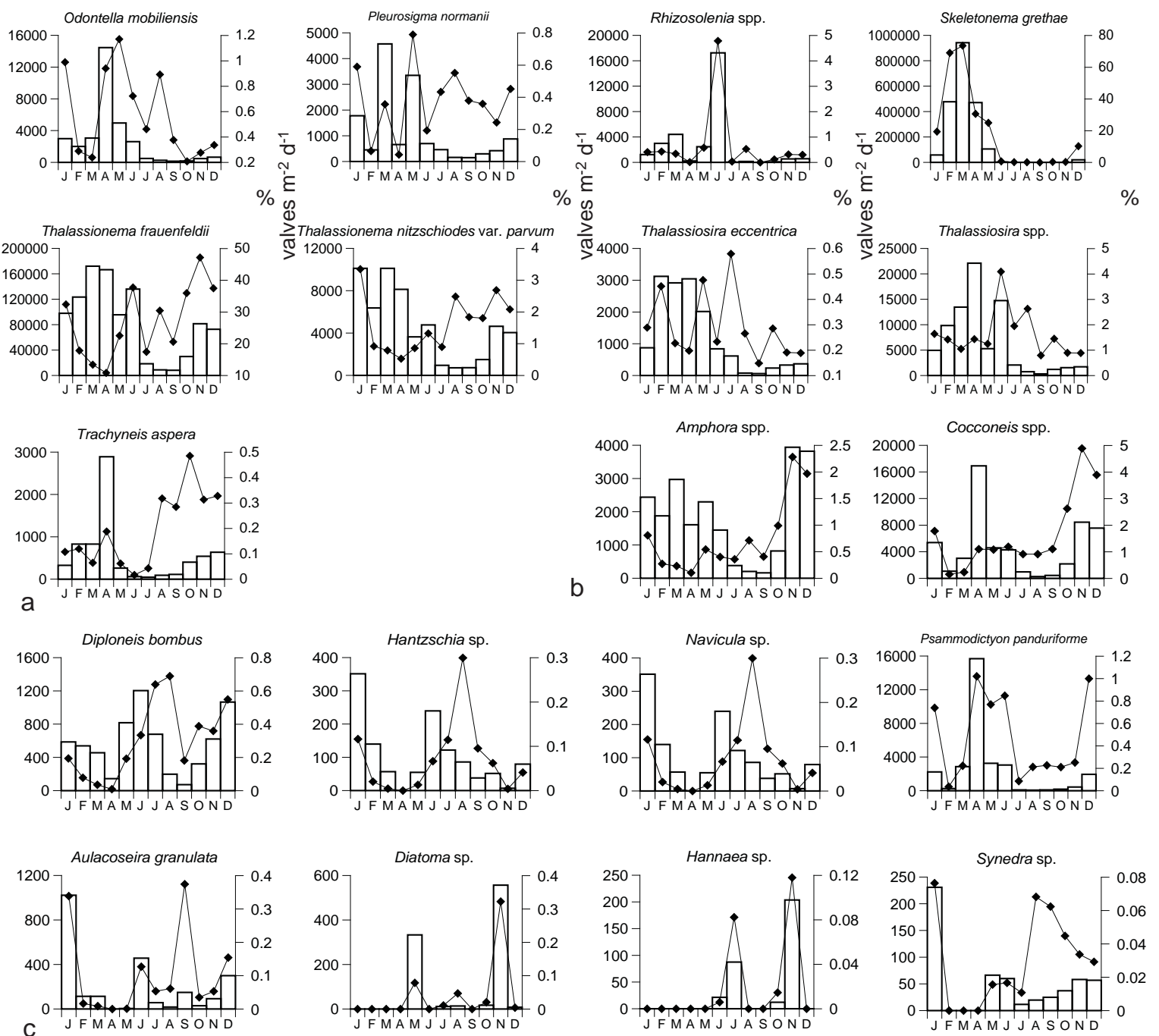

Figure 3. Monthly flux (bars; valves $\mathrm{m}^{-2} \mathrm{~d}^{-1}$ ) and relative abundance (lines; \%) of the main planktonic (a), benthic (b) and fresh-water (c) diatom taxa from a sediment trap set at 500 mab at the station Planier. 


\subsection{DISCUSION}

\subsubsection{General considerations}

According to the reviews of Velásquez and Cruzado (1995) and Gómez and Gorsky (2003), diatoms are one of the main contributors to the phytoplankton assemblages in the NW Mediterranean and represent $43 \%$ to $51 \%$ of the total microphytoplankton species. Nevertheless, prymnesiophytes dominate the phytoplankton assemblage during the whole with the exception of the spring season, when the diatoms become more important (Marty et al., 2002).

The diatom assemblages registered by Planier sediment trap are modified on its way from the euphotic zone to the sediment trap, particularly as a result of silica dissolution (Tréguer et al., 1995). Nonetheless, the good correlation between the total diatom flux and the chlorophyll $a$ values (Fig. 2) suggests that the recorded diatom fluxes reflect the changes in the abundance of diatom assemblages in the euphotic zone.

The annual cycle of the water column and primary productivity in the GoL are closely linked and can be divided into four stages that approximately coincide with the four annual seasons. The beginning of the cycle can be placed in fall. During the first part of this season, summer stratification and oligotrophic conditions prevail. Around mid-November the water column gradually starts to mix (Fig. 2), supplying nutrients to the photic zone (Leblanc et al., 2003). During winter, strong water mixing triggered by the intense northwesterlies and low solar radiation can cause vertical distribution of the biomass (Marty et al., 2002). In February, the intensity of the mixing processes reaches a maximum and the nutrients attain their highest concentrations (Leblanc et al., 2003). During spring, the evolution of the water column follows the opposite path to that of the fall, i.e., the water mixing weakens and the solar radiation increases throughout this season. The tight relationship between the phytoplankton growth and the nutrient availability is clearly reflected during this period. The thermocline is established around late March, however it is formed in stages due to frequent short-term wind events (Marty et al., 2002). The last part of the cycle is the summer season, characterized by strong stratification and oligotrophic conditions.

\subsubsection{Diatom succession in the Gulf of Lions}

The diatom succession at the Planier station can be divided into four stages that are closely related to the hydrographic parameters and nutrient structure of the water column.

\section{Fall (September-November)}

The first stage of the diatom succession can be placed in the fall season. During the first part of this season the water column is strongly stratified despite the gradual cooling of the surface waters (Fig. 2). In November, the thermocline breaks down and the water mixing begins. During fall, the microphytoplankton assemblage is generally dominated by other groups such as dinoflagellates, that have their optimum growth in low nutrient concentrations and stratified 
conditions (Leblanc et al., 2003), and/or by prymnesiophytes (Marty et al., 2002), while the diatom contribution is low (Fig. 2). The maximum concentrations of chlorophyll $a$ biomass are restricted to subsurface layers (around $50 \mathrm{~m}$ ) (Marty et al., 2002). The water mixing at the end of this season (November) (Fig. 2) is coupled with increases in diatom fluxes and chlorophyll $a$ concentration (Fig. 2). The nutrients are probably severely depleted at this time as Leblanc (2003) pointed out for the period 1999-2000 at the SOFi site (15 km from the Planier station) (Fig. 1).

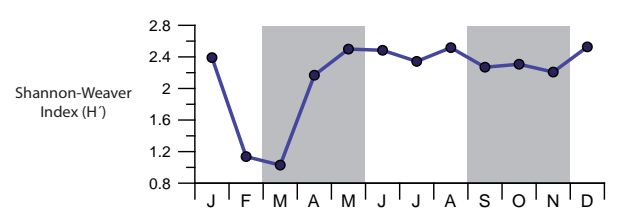

a

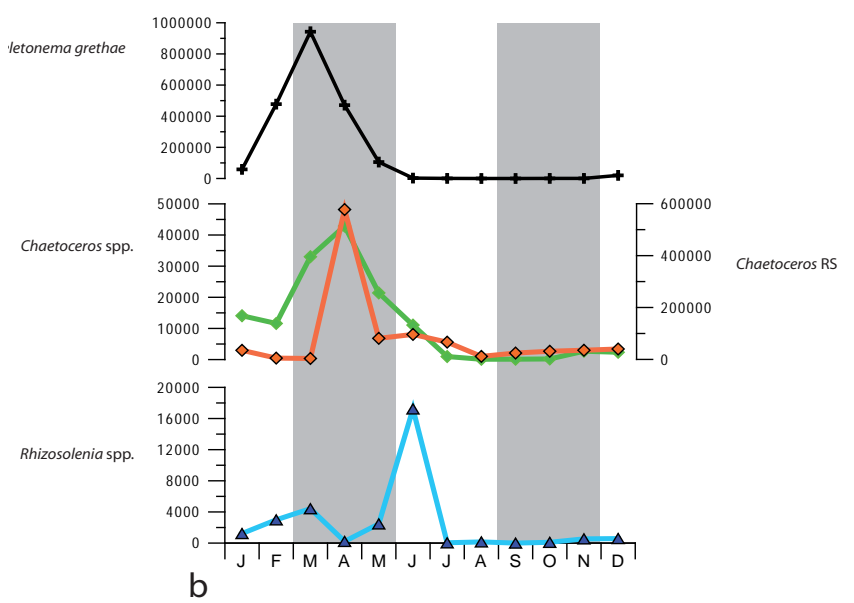

Figure 4. a. Shannon-Weaver diversity index. b. The Skeletonema-ChaetocerosRhizosolenia succession.

The Shannon-Weaver diversity index (Fig. 4) during this three-month period is 2.26, slightly higher than the annual average $\left(\mathrm{H}^{\prime}=2.16\right)$, a normal value for biocoenosis in a nutrientdepleted environment. Thalassionema frauenfeldii (Fig. 3 and Plate 8, b-d) is the dominant taxon of the diatom assemblage during fall till the beginning of winter, reaching its maximum relative contribution in November $\left(47.2 \% ; 81444\right.$ valves $\left.\mathrm{m}^{-2} \mathrm{~d}^{-1}\right)$. T. frauenfeldii is a common neritic, tropical to cold-temperate species (Hallegraeff, 1986; Hasle, 2001; Simonsen, 1974) abundant in the NW Mediterranean (Gómez and Gorsky, 2003; Travers, 1971). Its presence in all the samples of the record suggests that $T$. frauenfeldii can thrive well under a wide range of environmental conditions, showing affinity for the semi-mixing conditions during the fallwinter period. Although less abundant, other taxa also exhibit high relative abundances during this season, such as, several groups of Chaetoceros resting spores (Fig. 3 and Plate 10 and 11), Thalassionema nitzschioides var. parvum (Fig. 3 and Plate 8, e-g), considered to be a tropical to subtropical taxon (Hasle, 2001), Nitzschia braarudii (Fig. 3 and Plate 6, i-1) and Nitzschia spp. (Fig. 3 and Plate 6, d). These taxa are the most representative of the fall assemblage, however, their maximum fluxes occur during winter and the beginning of the spring.

In summary, the fall diatom assemblage is characterized by relatively low fluxes and is mainly 
composed of coastal pennate diatoms and Chaetoceros resting spores with diversity index values close to the annual average.

\section{Winter (December-February)}

The SSTs reach annual minima values during this season (February) (Fig. 2) due to the decrease in solar radiation and to the cold and dry northwesterlies. The water column is homogenized (Fig. 2) and replenished with nutrients upwelled from deeper waters (Leblanc et al., 2003; Marty et al., 2002). The thickness of the mixed layer varies from 100 to $200 \mathrm{~m}$ or more depending on the year (Marty et al., 2002).

Despite the high nutrient concentrations, chlorophyll $a$ does not reach maximum values till spring, probably due to the low light levels. Thalassionema frauenfeldii is still the dominant species of the diatom assemblage during December and January, however, the small-celled genus, Skeletonema (Fig. 3, 4 and Plate 7, g-j), appears in the water column at the beginning of winter increasing its relative abundance from $10.3 \%$ in December to $69 \%$ in February. Skeletonema are pioneer, coastal and chain-forming diatoms that has been described to develop massive blooms in different areas of the Mediterranean (e.g. Caroppo et al., 1999, in the Adriatic Sea; Castellví, 1971, in Barcelona coastal area; Ribera D'Alcalà et al., 2004, in the Gulf of Naples) and are reputed to grow faster under high-nutrient low-light conditions (Margalef, 1978; Smetacek, 1999). As well as Skeletonema, the genus Chaetoceros, is known to grow in the initial stages of a succession and it is a typical component of the spring bloom in the Mediterranean (Margalef, 1978). Chaetoceros spp. (Figs 3, 4 and Plates 10 and 11) are considered to be major contributors to the primary production in near-shore upwelling regions and coastal areas with a contribution to the total marine primary production up to $20-25 \%$ (Werner, 1977). The species of this genus appear in the water column at the same time as Skeletonema, however it lasts longer (till the beginning of summer). Its life cycle is well known; the vegetative phase grows fast in a nutrient-rich environment forming long chains of thinwalled cells and, when the nutrients are depleted, species of the subgenus Hyalochaete form robust, thick-walled resting spores that sink to the sea floor and await the return of favorable conditions (McQuoid and Hobson, 1996). All the specimens found in the samples belong to the subgenus Hyalochaete, characterized by forming resting spores (Fig. 4), which may be viewed as successful life-strategy stages for diatoms inhabiting shallow coastal waters (Hargraves, 1979). In the present study, the vegetative cells of Chaetoceros spp. appear in January but they don't reach their maximum fluxes till April (Fig. 3 and 4). The resting spores appear during this month, coinciding with the maximum fluxes of the vegetative cells, the last stages of the spring bloom and nutrient depletion (Fig. 4). The generation time of the resting spores can vary from hours to weeks to even several years (Hollibaugh et al., 1981). Moreover, according to Kemp et al. (2000), Skeletonema, Thalassionema and Chaetoceros are typical components of the diatom bloom that usually last several days to weeks and often terminate with rapid aggregation and sinking that favors the preservation of the frustules. 
Other taxa show very similar patterns with maximum fluxes at the end of winter and the beginning of the spring (March) coinciding with the maximum chlorophyll $a$ values (Fig. 2). Of these taxa, the most relevant are Nitzschia bicapitata (Fig. 3 and Plate 5, g-h), Nitzschia spp., Thalassiosira eccentrica (Fig 3 and Plate 8, h) and Pleurosigma normanii (Fig. 3 and Plate 6, $\mathrm{i}-\mathrm{j})$.

During February and March, $\mathrm{H}^{\prime}$ shows an abrupt decrease $\left(\mathrm{H}^{\prime}=\sim 1\right)$ (Fig. 4), mainly caused by the massive growth of the pioneer species Skeletonema grethae, T. frauenfeldii and Chaetoceros spp. (Fig. 3). These low values are characteristic of the earliest stages of a succession with one or few dominant species. The dominant species of the spring bloom at the Planier station varies from year to year, but in general it is either S. grethae or T. frauenfeldii (Rigual-Hernández et al., submitted).

As mentioned above, $T$. frauenfeldii is a species that is present throughout the year in the water column, while S. grethae only appears occasionally in the 12-year record (Rigual-Hernández et al., submitted), often triggering massive blooms which lead to their dominance of the assemblage during one to three months. This sporadic massive growth registered in the sediment trap may be explained in two ways: 1- the dissolution rate in the GoL may vary from year to year, and due to the weak silicification of this taxon, only during the years with less silica dissolution in the water column would the frustules be preserved; 2- because of the diatom sex clock (Lewis, 1984), the $S$. grethae life cycle may take more than a year to complete, thus limiting the chances of annual blooms.

Thus, the winter diatom assemblage is characterized by the dominance of a few pioneer species that have high growth rates and the ability to inhabit nutrient-rich turbulent environments, even under moderate-low solar radiation conditions.

\section{Spring (March-May)}

The optimal conditions for diatom growth occur in the water column during the spring season. The day length and the solar radiation increase, while the turbulence in the water column is still moderate (Fig. 2) due to the strong winter mixing and frequent episodic wind events (Marty et al., 2002). The euphotic zone is still rich in nutrients but they steadily decrease due to the high consumption rates (Leblanc et al., 2003). During this season, the chlorophyll $a$ values reach the maximum annual values (Fig. 2).

During March and April the dominant species of the first stages of the diatom bloom (S. grethae, T. frauenfeldii and Chaetoceros spp.) are still the most abundant taxa. However, during April, the next step of the succession takes place, and other taxa become relevant in the water column, such as the resting spores of Chaetoceros: Chaetoceros diadema, Chaetoceros sp. 1 and Chaetoceros seychelarus (Fig. 3 and Plates 10 and 11), which are probably formed at the end of the month when nutrients are scarce (Leblanc et al., 2003). Also, Thalassiosira spp. (Plates 8 and 9), Trachyneis aspera, Odontella mobiliensis (Plate 6, e-h) and N. bicapitata (Plate 5, g-h) (Fig. 3), among others, have their maximum fluxes during this month. In addition, a group of 
species characteristic of the later stages of the succession of the diatom bloom, such as Ditylum brightwellii (Fig., 3 and Plates 3 and 4) and Bacteriastrum spp. (Fig. 3 and Plate 2, c-g), appear in the water column with relatively high fluxes. These two taxa possess weakly silicified valves, and in the case of D. brightwellii, large vacuoles (Margalef, 1978; Smetacek, 1999) that appear during April. The cells and colonies of the species of Bacteriastrum and Chaetoceros can live in a wide spectrum of turbulence according to the length and disposition of bristles (Margalef, 1997).

At the end of the spring (May), dinoflagellates start to play a more important role in the phytoplankton assemblage becoming the most important microphytoplankton group (Gómez and Gorsky, 2003; Leblanc, 2003), although the prymnesiophytes also have been reported to dominate the phytoplankton assemblage (Marty et al., 2002).

As this season progresses, $\mathrm{H}^{\prime}$ drastically increases from $\mathrm{H}^{\prime}=\sim 1$ in March, to $\mathrm{H}^{\prime}=2.5$ in May (Fig. 4). The evolution of the spring bloom is well reflected by the Shannon-Weaver index: the beginning of the bloom is characterized by a few small fast-growing species that are gradually replaced by slow-growing taxa with less nutrient requirements.

Therefore, this season is characterized by a classical spring bloom succession in the northwest Mediterranean.

\section{Summer (June-August)}

The summer is characterized by strong thermal stratification (Fig. 2), high solar radiation and oligotrophic conditions in the water column (Leblanc et al., 2003). It has been reported that the dinoflagellates (Gómez and Gorsky, 2003), cyanobacteria and prochlorophytes (Marty et al., 2002) are the major components of the phytoplankton assemblage during this season. In contrast, diatom fluxes are low (Fig. 2) and their maximum concentrations are probably confined to the deep chlorophyll maximum (DCM) that in summer is located at a water depth of around $50 \mathrm{~m}$, which is quite shallow compared with other oligotrophic areas (Marty et al., 2002). Although the diatom assemblage is still dominated by $T$. frauenfeldii and by Chaetoceros resting spores, another group of diatoms, represented by the genus Rhizosolenia (Fig. 3 and 4 and Plate 7, b-f) exhibit their maximum abundances during this season (Fig. 3). The typical summer diatom species normally possess bigger cells (with more intracellular volume) and longer growing periods than the spring bloom ones (Kemp et al., 2000). These dwellers of the DCM possess characteristics that allow them to grow in stratified conditions, such as their symbiotic relationship with nitrogen-fixing cyanobacteria (e.g. Rhizosolenia) (Villareal, 1990), their capacity to grow in low light conditions at depth (e.g. Stephanopyxis and Coscinodiscus) and/or their capacity to regulate their buoyancy (e.g. Rhizosolenia and Ethmodiscus) (Kemp et al., 2000). The genus Rhizosolenia has been described as one of the main components of the "shade flora" by several authors (Villareal et al., 1993; Kemp et al., 2000).

Kemp et al. (2000) explain that in different temperate areas of the world ocean high diatom fluxes are often recorded after the summer during the breakdown of the thermocline due to a 
mechanism called "fall dump". This so-called "fall dump" could be defined as a massive sinking of diatoms highly sensitive to mixing conditions that die due to the turbulence in the water column. In the present work, Rhizosolenia spp. exhibit a unimodal distribution with maximum fluxes during the stratification period (June), not during fall-winter period. Therefore, although our observations indicate that a "diatom fall dump" does not occur in the Gulf of Lions, the annual distribution of the Rhizosolenia fluxes suggests an affinity of this genus for summer stratification conditions.

During this season, $\mathrm{H}^{\prime}$ shows values relatively higher than the annual average (Fig. 4). The oligotrophic conditions hamper the development of fast-growing species which allow the development of a more diverse diatom assemblage.

In summary, the summer diatom assemblage is characterized by the lowest flux values of the composite year and the appearance in the water column of diatom species adapted to stratification conditions such as Rhizosolenia spp.

Finally, it is worth noting The series Skeletonema-Chaetoceros-Rhizosolenia (Fig. 4) can be considered as a classic example of ecological succession throughout the spring diatom bloom, with species adapted to lower nutrient concentrations gradually appearing in the water column (Margalef, 1978).

\subsubsection{Benthic and fresh water diatoms}

Benthic and fresh water diatom fluxes in this study are low (Fig. 3). Almost all the benthic taxa (Fig. 3) have higher fluxes during the fall-winter season. As mentioned before, during this period there is strong mixing of the water column and benthic species can be transported from the shelf to the sediment trap. The drastic drop in planktonic diatom fluxes during the summer, is perhaps the main reason why the relative contribution of some benthic taxa (such as Diploneis bombus or Hantzschia sp., Fig. 3 and Plate 3, h-I and Plate 4, e) increases. So, the increased relative benthic diatom fluxes during this season are unlikely to be related to the increased productivity of these species. Also, it is worthy to note that some of the most abundant taxa such as Amphora spp., Cocconeis spp. (Plate 2, h-k), Navicula spp. (Plate 5, cd) and Psammodictyon panduriforme (Plate 6 and 7) (Fig. 3) exhibit flux maxima during the spring period which suggests that they might be transported to the euphotic zone attached to different particles or organisms.

Regarding fresh water diatoms, their fluxes are low due to the general circulation in the area. The Planier sediment trap is not usually influenced by the plume of the outflowing Rhône river (Fig. 1), which moves to the southwest. However, during some especially strong wind events the plume can be displaced to the east and some freshwater diatoms can be captured by the Planier sediment trap such as, Aulacoseira granulata, Diatoma sp. (Plate 12, k-1), Hannaea sp. (Plate 12, p-q) or Synedra sp. (Fig. 3). The northwesterlies blow with increased intensity during winter, coinciding with the period of highest discharge of the Rhône river (Heussner et 
al., 2006). Although very low fluxes of freshwater diatoms were observed in this study, they exhibited flux maxima during fall-winter transition.

\subsection{CONCLUSIONS}

Diatoms are one of the most important phytoplankton groups in the NW Mediterranean with more than 126 species identified in the samples. Their good correlation with chlorophyll $a$ values and previous works performed in the area support this idea. Despite the interannual variability (Rigual-Hernández et al., submitted), the calculated average year reveals the general trends of the diatom species in the GoL. Diatoms are especially abundant during the winter-spring period that is characterized by a high turbulent environment, high nutrient concentration and relatively low solar radiation. After the spring diatom bloom, the nutrients and the turbulence decrease, while the solar radiation increases giving way to a succession of optimum growth conditions for different species. A good example of this diatom succession is the sequence SkeletonemaChaetoceros-Rhizosolenia (Fig. 4). The strong water mixing during winter and the episodic wind events, that can displace the Rhône plume to the east, are reflected in the sediment trap data by a small increase of benthic and freshwater species, respectively.

\section{AKNOWLEDGEMENTS}

This study has been realized thanks to the funding from the Ministerio de Ciencia e Innovación (scholarship AP2006-01992) and GRACCIE (PROGRAMA CONSOLIDER-INGENIO 2010CSD 2007-00067). The satellite Chlorophyll $a$ data used in this poster was produced with the Giovanni online data system, developed and maintained by the NASA GES DISC.

\subsection{APPENDIX A. TAXONOMIC APPENDIX.}

The taxonomic list includes all taxa referred in the text, as well as the main taxa identified during the present study. The taxa were grouped as a function of their ecological significance as described in the text. The cited references can be found in Round et al. (1990), Hasle and Sylvertsen (1997) and the databases World Register of Marine Species (WoRMS) (Appeltans et al., 2010) and AlgaeBase (Guiry and Guiry, 2010).

\section{Marine planktonic group}

Alveus marinus (Grunow, 1880) Kaczmarska and Fryxell, 1996

Asteromphalus flabellatus (Brévisson) Greville, 1859

Asteromphalus robustus Castracane, 1886

Asterolampra marylandica (Ehrenberg) Ehrenberg, 1844

Azpeitia sp. M. Peragallo in Tempére and Peragallo, 1912

Bacteriastrum delicatulum Cleve, 1897

Bacteriastrum hyalinum Lauder, 1864

Bacteriastrum sp. Shadbolt, 1854

Coscinodiscus marginatus Ehrenberg, 1841 (1843, 1844)

Coscinodiscus radiatus Ehrenberg, 1840

Coscinodiscus spp. Ehrenberg, 1839

Cyclotella ocellata Pantocsek, 1912 
Hemidiscus cuneiformis Wallich, 1860

Leptocylindrus danicus Cleve, 1889

Nitzschia spp. Hassall, 1845

Nitzschia acicularis (Kützing) Smith, 1853

Nitzschia sicula Hassall, 1845

Nitzschia bifurcate Kaczmarska and Licea, 1986

Nitzschia braarudii Hasle, 1960

Nitzschia bicapitata Cleve, 1900

Nitzschia panduriformis Gregory, 1857

Odontella mobiliensis (J.W.Bailey) Grunow, 1884

Odontella sp. Agardh, 1832

Pleurosigma directum Grunow, 1880

Pleurosigma normanii Ralfs, 1861

Pleurosigma sp. Smith, 1852

Rhizosolenia acicularis Sundström, 1986

Rhizosolenia bergonii Peragallo, 1892

Rhizosolenia setigera Brightwell 1858

Rhizosolenia spp. Brightwell, 1858

Roperia tesselata (Roper) Grunow ex Pelletan, 1883

Stellarima stellaris (Roper) Hasle and Sims, 1986

Thalassionema bacillaris (Heiden) Kolbe 1955

Thalassionema frauenfeldii (Grunow) Tempére and Peragallo ex Hallegraeff 1986

Thalassionema nitzschioides spp. (Grunow) Mereschkowsky 1902

Thalassionema nitzschioides var. capitulata (Castracane) Moreno-Ruiz 1995

Thalassionema nitzschioides var. lanceolata (Grunow) Peragallo and Peragallo 1901

Thalassionema nitzschioides var. parva Heiden and Kolbe 1928

Thalassiosira eccentrica (Ehrenberg) Cleve, 1903-1904

Thalassiosira endoseriata Hasle and Fryxell 1977

Thalassiosira gravida Cleve 1896

Thalassiosira lineata Jousé 1968

Thalassiosira symmetrica Fryxell and Hasle 1972

Thalassiosira oestrupii (Ostenfeld) Hasle 1972

Thalassiosira rotula Meunier 1910

Thalassiosira tenera Proshkina-Lavrenko 1961

Thalassiosira spp. Cleve, 1973

\section{Neritic group}

Actinocyclus curvatulus Janisch, 1874

Actinocyclus octonarius Ehrenberg, 1838

Actinocyclus sp. Ehrenberg, 1837

Actinoptychus sp. Ehrenberg, 1843

Cyclotella litoralis Lange and Syvertsen, 1989

Dimeregramma sp. Ralfs, 1861

Ditylum brightwellii (West) Grunow in Van Heurck, 1883

Grammatophora angulosa Ehrenberg, 1841

Grammatophora oceanica Ehrenberg, 1841

Grammatophora serpentina (Ralfs) Ehrenberg, 1844

Grammatophora sp. Ehrenberg, 1840

Licmophora sp. Agardh, 1827

Paralia sulcata (Ehrenberg) Cleve, 1873

Skeletonema grethae Zingone \& Sarno, 2005

Trachyneis aspera Cleve, 1894

Triceratium sp. Ehrenberg, 1839

Toxarium undulatum Bailey, 1854 
Toxarium sp. Bailey, 1854

Chaetoceros curvisetus Cleve, 1889

Chaetoceros didymus Ehrenberg, 1845

Chaetoceros spp. Ehrenberg, 1844

\section{Chaetoceros resting spore group}

Chaetoceros affinis Lauder 1864

Chaetoceros diadema (Ehrenberg) Gran 1897

Chaetoceros lauderi Ralfs 1864

Chaetoceros lorenzianus Grunow 1863

Chaetoceros mitra (Bailey) Cleve 1896

Chaetoceros seychelarus Karsten 1907

Chaetoceros vanheurckii Gran 1897

\section{Benthic group}

Achnanthes longipes C.A. Agardh, 1824

Achnanthes sp. Bory de Saint-Vincent, 1822

Amphiprora sp. Ehrenberg, 1843

Amphora binodis Gregory, 1857

Amphora proteus Gregory, 1857

Amphora spp. Ehrenberg, 1840

Amphora eunotia, Cleve, 1873

Bacillaria sp. Gmelin, 1791

Biddulphia alternans (J.W.Bailey) Van Heurck, 1885

Campylopyxis sp. Medlin, 1985

Climacosphenia moniligera Ehrenberg, 1843.

Cymatoneis sp. Cleve, 1894

Cymatosira belgica Grunow, 1881

Cymatosira sp. Grunow, 1862

Entomoneis alata (Ehrenberg) Ehrenberg 1845

Delphineis surirella (Ehrenberg) Andrews, 1981

Delphineis sp. Andrews, 1977

Cocconeis britannica Naegeli ex Kütz, 1849

Cocconeis pseudomarginata Gregory 1857

Cocconeis scutellum Ehrenberg, 1838

Cocconeis spp. Ehrenberg, 1837

Diploneis bombus (Ehrenberg) Cleve, 1894

Fallacia sp. Stickle and Mann, 1990

Hantzschia virgata (Roper) Grunow 1880

Hantzschia sp. (Ehrenberg) Grunow, 1877

Gyrosigma sp. Hassall, 1845

Mastogloia peragalli (Cleve) Yohn and Gibson, 1982

Mastogloia sp. Thwaites ex Smith, 1856

Melosira sp. Agardh, 1824

Navicula sp. Bory de Saint-Vincent, 1822

Opephora sp. Petit, 1889

Psammodictyon panduriforme (Greg.) Mann, 1990

Pseudoeunotia doliolus (Wallich) Grunow, 1981

Podocystis Americana Bailey, 1854

Podocystis sp. Bailey, 1854

Rhaphoneis sp. Ehrenberg, 1844

Rhoicosphenia sp. Grunow, 1860

Rhopalodia sp. Müller, 1895

Surirella sp. Turpin, 1828

Tabularia sp. (Kützing, 1844) Williams and Round, 1986 


\section{Fresh-water group}

Aulacoseira granulata (Ehrenberg) Thwaites, 1848

Cyclotella atomus Hustedt, 1937

Cyclotella striata (Kützing) Grunow in Cleve and Grunow, 1880

Cyclotella meneghiniana Kützing, 1844

Cymbella sp. C.A. Agardh, 1830

Diatoma vulgare Bory de Saint-Vincent, 1824

Diatoma sp. Bory de St-Vincent, 1824

Hannaea sp. Patrick, 1966

Pseudostaurosira brevistriata (Grunow in Van Heurck, 1885) Williams and Round, 1988 (1987)

Stephanodiscus astraea (Kützing) Grunow 1880

Synedra sp. (Ehrenberg) Königl, 1830 

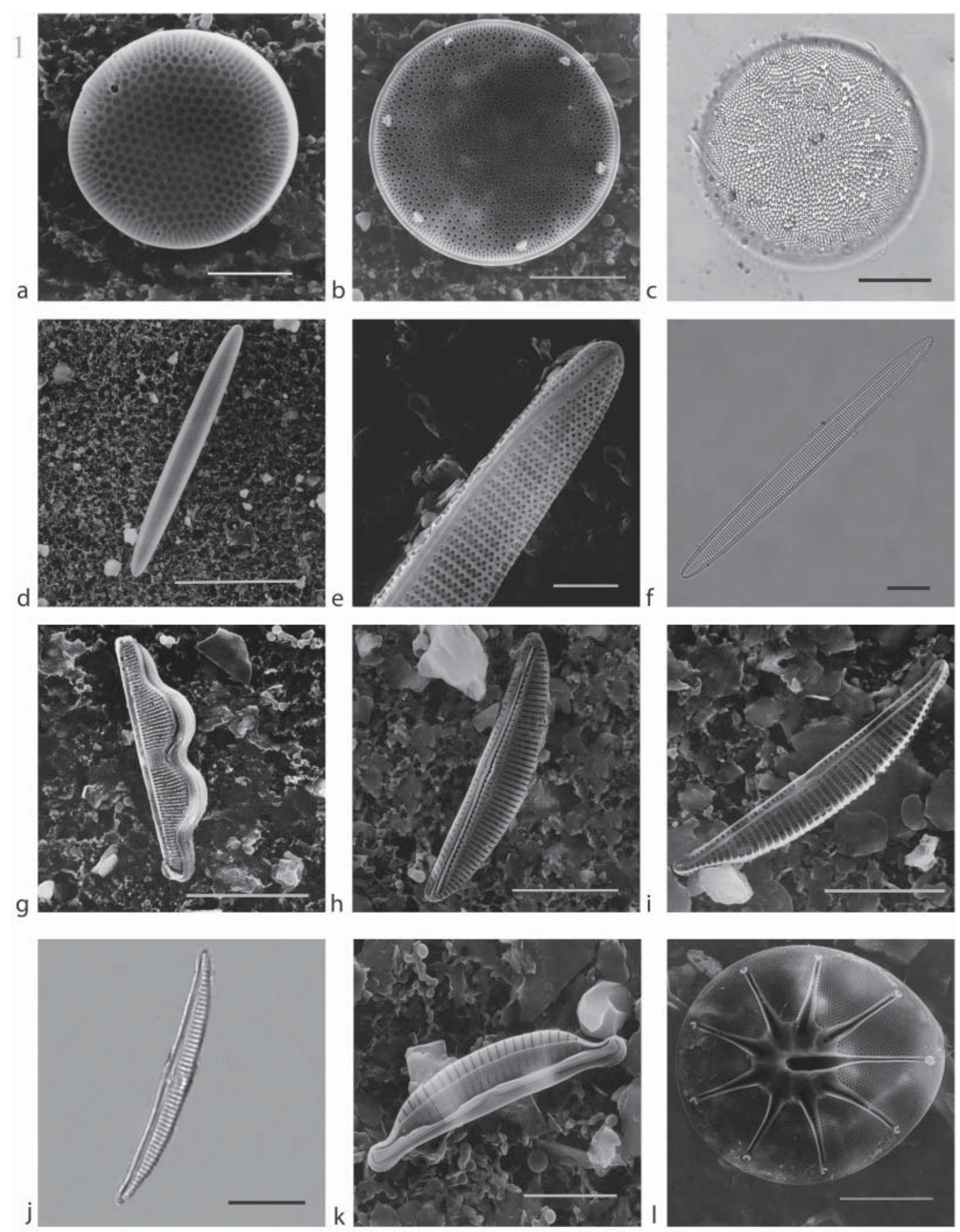

Plate 1. a-c. Actinocyclus sp. SEM (a, b), LM (b). d-f. Alveus marinus (Grunow) Kaczmarska and Fryxell. SEM (c-d), LM (d). f. Amphora bigibba Grunow. SEM. h. Amphora sp. SEM. i-j. Amphora eunotia Cleve. SEM (h), LM (i). k. Amphora spp. SEM (j), LM (k). l. Asteromphalus flabellatus (Brébisson) Greville. SEM. SEM Scale bars: a, e, $\mathrm{k}=5 \mu \mathrm{m} ; \mathrm{b}, \mathrm{c}, \mathrm{f}, \mathrm{h}, \mathrm{i}, \mathrm{j},=10 \mu \mathrm{m} ; \mathrm{g}=20 \mu \mathrm{m} ; \mathrm{d}=50 \mu \mathrm{m}$. 

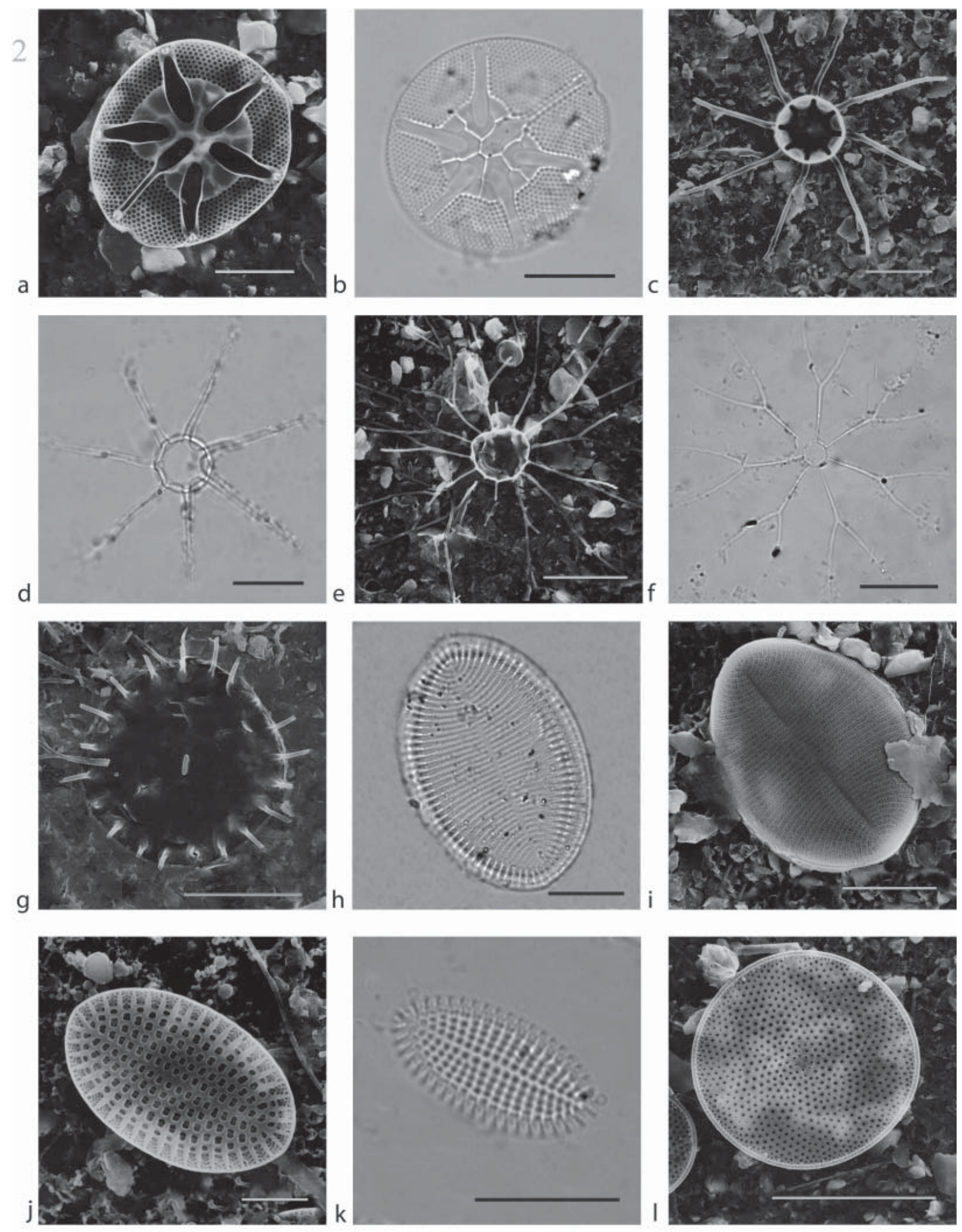

Plate 2. a-b. Asteromphalus robustus Castracane. SEM (a), LM (b). c-f. Bacteriastrum delicatulum Cleve or varians Lauder. SEM (c, e), LM (d, f). g. Bacteriastrum hyalinum Lauder. SEM. h. Cocconeis britannica Naegeli. LM. i. Cocconeis pseudomarginata Gregory. SEM. j-k. Cocconeis scutellum Ehrenberg. SEM (j), LM (k). l. Coscinodiscus radiatus Ehrenberg. SEM. Scale bars: j= $5 \mu$ m; a, b, c, d, $\mathrm{h}, \mathrm{i}, \mathrm{k}=10 \mu \mathrm{m} ; \mathrm{f}, \mathrm{g}, \mathrm{l}=20 \mu \mathrm{m}$; e $=25 \mu \mathrm{m}$. 

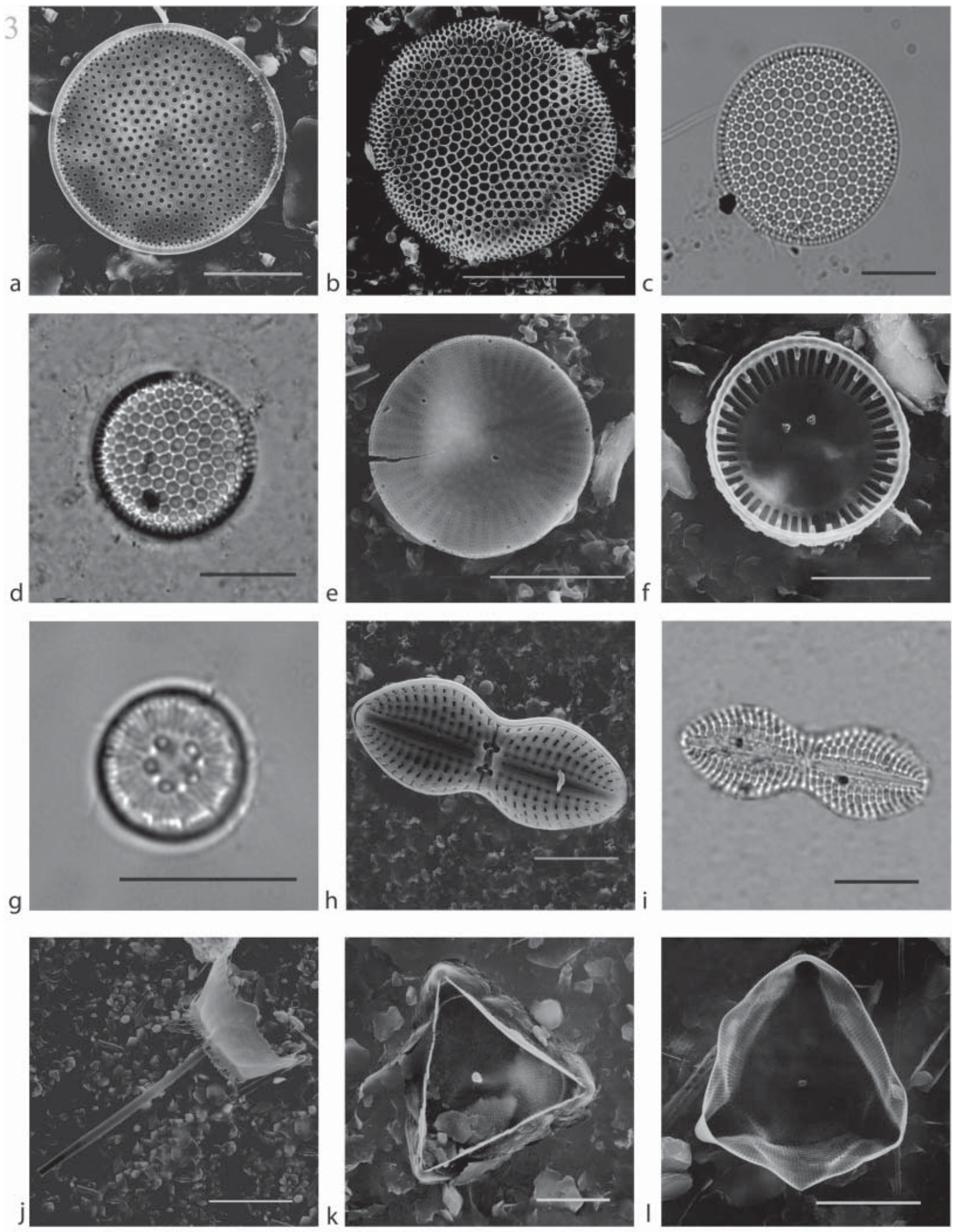

Plate 3. a. Coscinodiscus radiatus Ehrenberg. SEM. b. Coscinodiscus sp. SEM. c-d. Coscinodiscus spp.? LM. e. Cyclotella atomus Hustedt. SEM. f. Cyclotella sp. SEM. g. Cyclotella ocellata Pantocsek. LM. h-i. Diploneis bombus (Ehrenberg) Cleve. SEM (k), LM (1). j-l. Ditylum brightwellii (T. West) Grunow. SEM. Scale bars: e, f, $g,=5 \mu \mathrm{m}$; b, c, d, h, i, k, $1=10 \mu \mathrm{m} . \mathrm{j}=25 \mu \mathrm{m}$. a $=50 \mu \mathrm{m}$. 

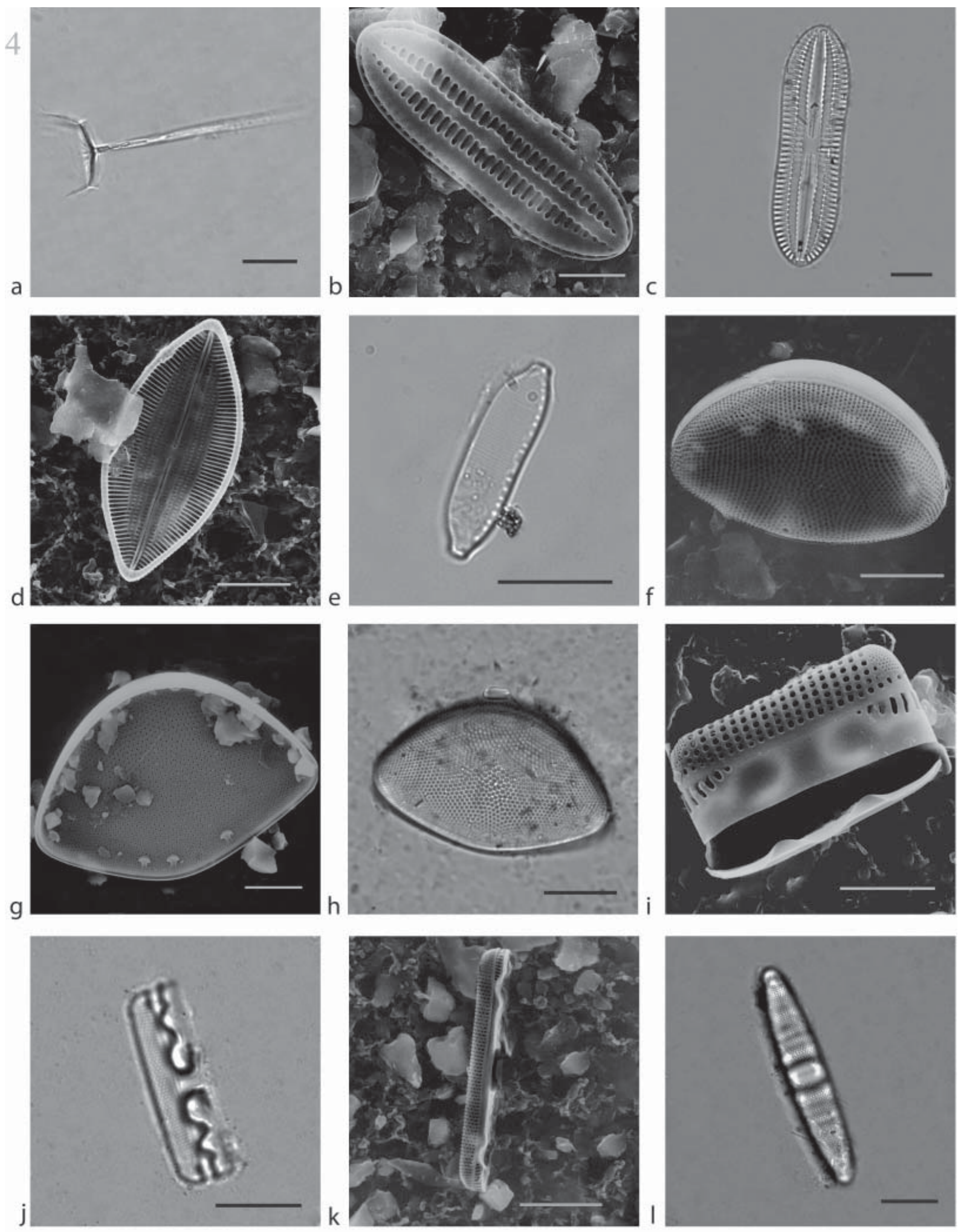

Plate 4. a. Ditylum brightwellii (T. West) Grunow. LM. b-c. Fallacia ? spp. SEM (b), LM (c). d. Mastogloia peragalli Cleve. SEM. e. Hantzschia virgata (Roper) Grunow. LM. f-h. Hemidiscus cuneiformis Wallich. SEM (f-g), LM (h). i-j. Grammatophora angulosa Ehrenberg var. islandica (Ehrenberg) Grunow. SEM (i), LM (j). k. Grammatophora oceanica Ehrenberg var. macilenta (W. Smith) Grunow. SEM. l. Grammatophora serpentina (Ralfs) Ehrenberg. LM. Scale bars: a, b, d, i = 5 $\mu \mathrm{m} ; \mathrm{c}, \mathrm{e}, \mathrm{f}, \mathrm{g}, \mathrm{h}, \mathrm{j}, \mathrm{k}, \mathrm{l}=10 \mu \mathrm{m}$. 

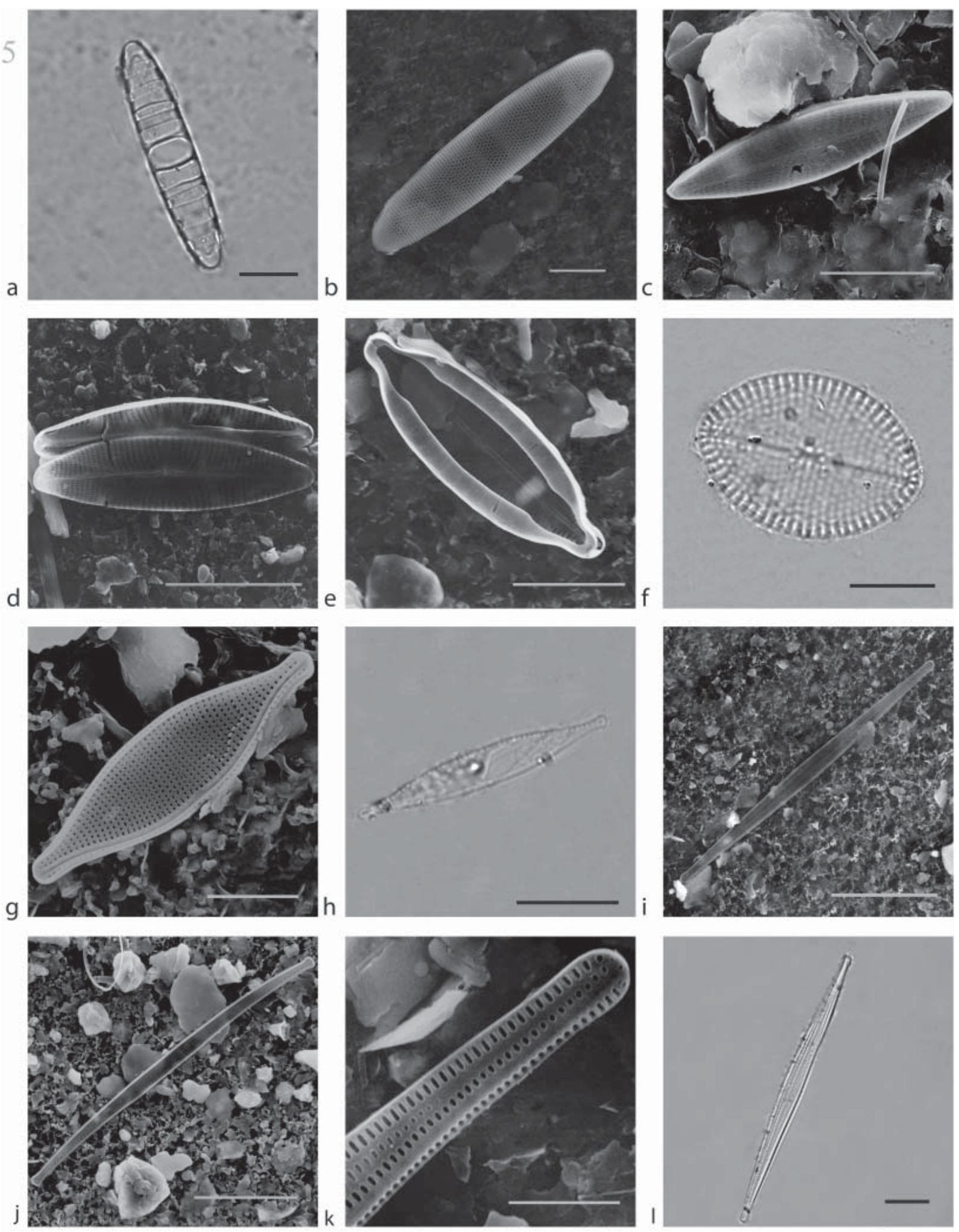

Plate 5. a. Grammatophora serpentina (Ralfs) Ehrenberg. LM. b. Grammatophora sp. SEM. cd. Navicula spp. SEM. e. Mastogloia ignorata Hustedt. SEM. f. Mastogloia sp. LM. g-h. Nitzschia bicapitata Cleve. SEM (g), LM (h). i-l. Nitzschia braarudii. Scale bars: g, k = $5 \mu \mathrm{m}$; a, b, c, e, f, h, $1=$ $10 \mu \mathrm{m} ; \mathrm{d}, \mathrm{j}=20 \mu \mathrm{m} ; \mathrm{i}=25 \mu \mathrm{m}$. 

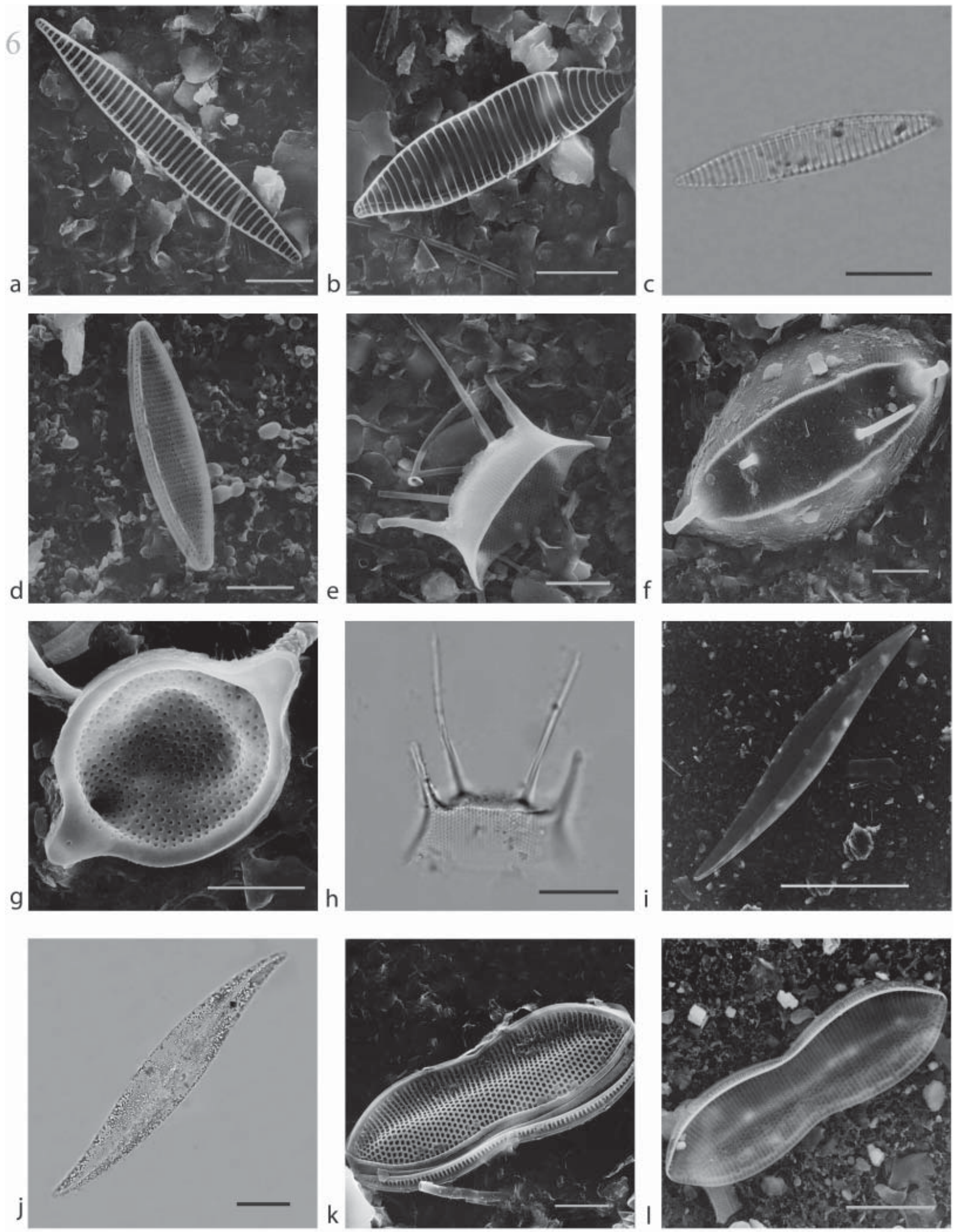

Plate 6. a-c. Nitzschia sicula? (Castracane) Hustedt SEM (a-b), LM (c). d. Nitzschia sp. SEM. e-h. Odontella mobiliensis (Bailey) Grunow. SEM (e-g), LM (h). i-j. Pleurosigma normanii Ralfs. SEM (i), LM (j). k-l. Psammodictyon spp. SEM. Scale bars: g, k = $5 \mu \mathrm{m}$; a, b, c, d, e, f, h = $10 \mu \mathrm{m} ; 1=25 \mu \mathrm{m}$; i $=100 \mu \mathrm{m}$. 

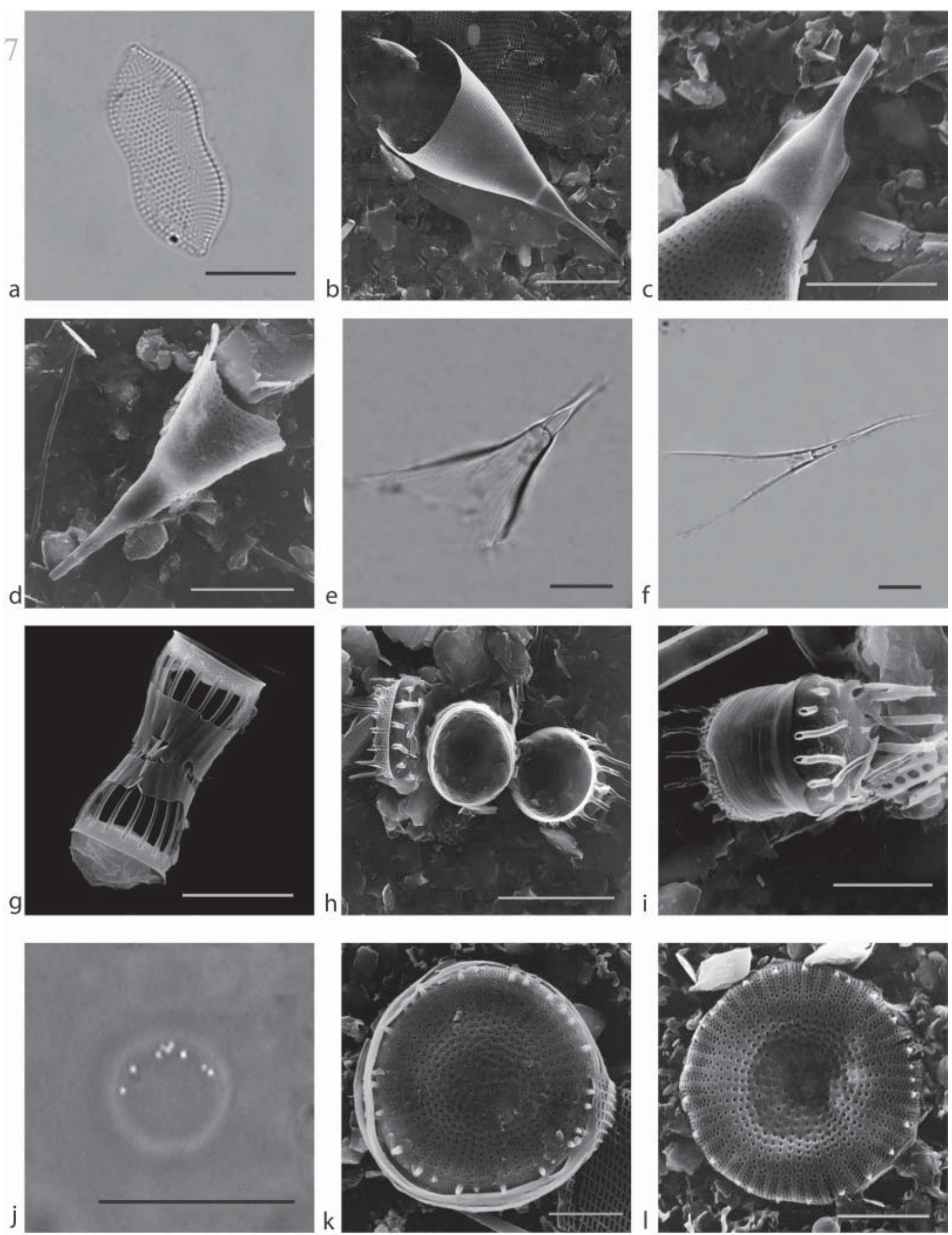

Plate 7. a. Psammodictyon spp. SEM. b-f. Rhizosolenia spp. SEM (b-d), LM (e-f). g-j. Skeletonema grethae Zingone \& Sarno. SEM (g-i), LM (j). k-l. Stephanodiscus sp. SEM. Scale bars: c, i, j, k, $1=5$ $\mu \mathrm{m} ; \mathrm{a}, \mathrm{b}, \mathrm{d}, \mathrm{e}, \mathrm{f}, \mathrm{g}, \mathrm{h}=10 \mu \mathrm{m}$. 

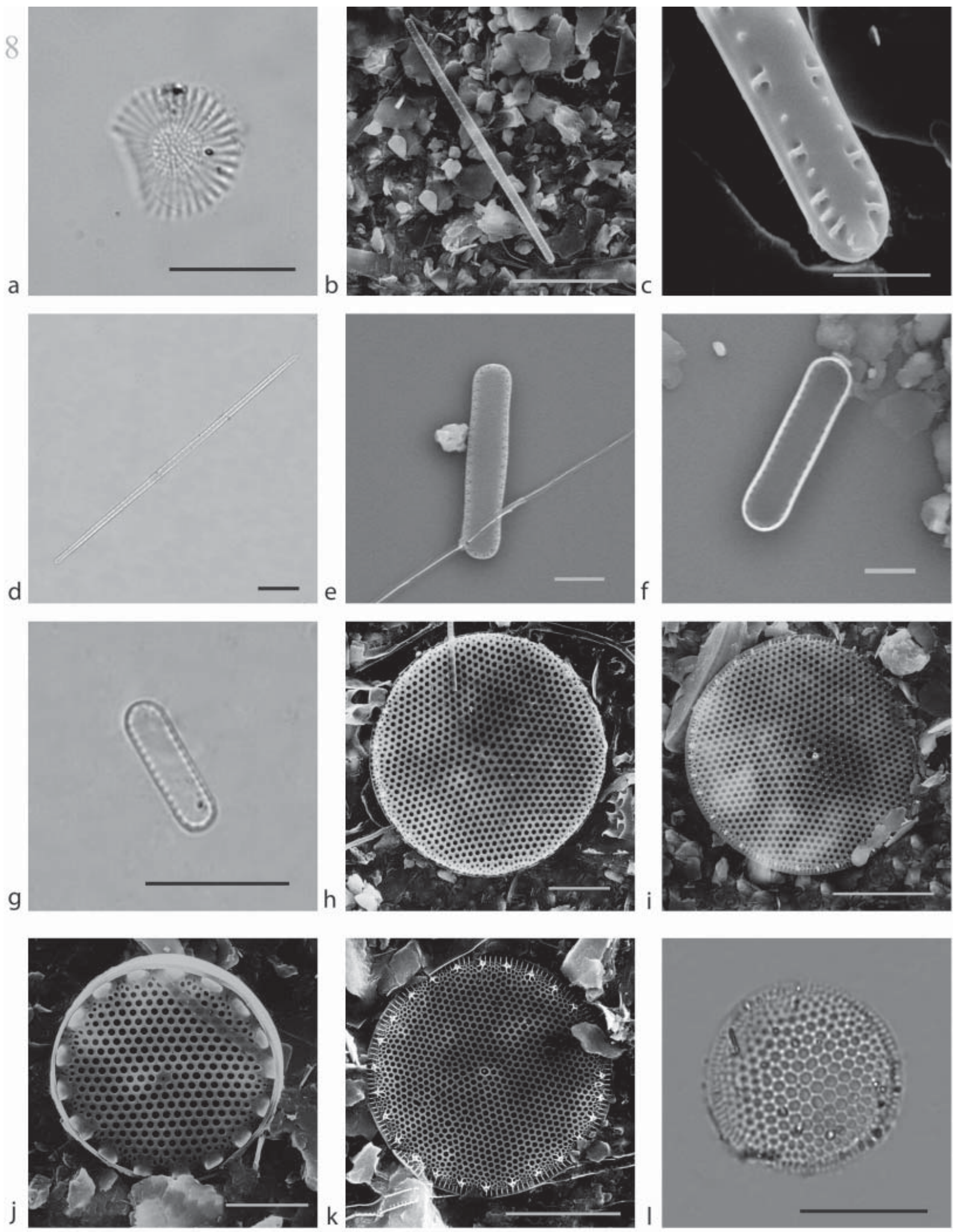

Plate 8. a. Stephanodiscus sp. LM. b-d. Thalassionema frauenfeldii (Grunow) Hallegraeff. SEM (b-c), LM (d). e-g. Thalassionema nitzschioides var. parvum Heiden. SEM (e-f), LM (g). h. Thalassiosira eccentrica (Ehrenberg) Cleve. SEM. i. Thalassiosira symmetrica Fryxell and Hasle. SEM. j. Thalassiosira tenera Proschkina-Lavrenko. SEM. k-l. Thalassiosira spp. SEM (k), LM (l). Scale bars: c $=2 \mu \mathrm{m}$; e, f, $\mathrm{j}=5 \mu \mathrm{m} ; \mathrm{a}, \mathrm{d}, \mathrm{g}, \mathrm{h}, \mathrm{k}, \mathrm{l}=10 \mu \mathrm{m} ; \mathrm{i}=20 \mu \mathrm{m} ; \mathrm{b}=25 \mu \mathrm{m}$. 

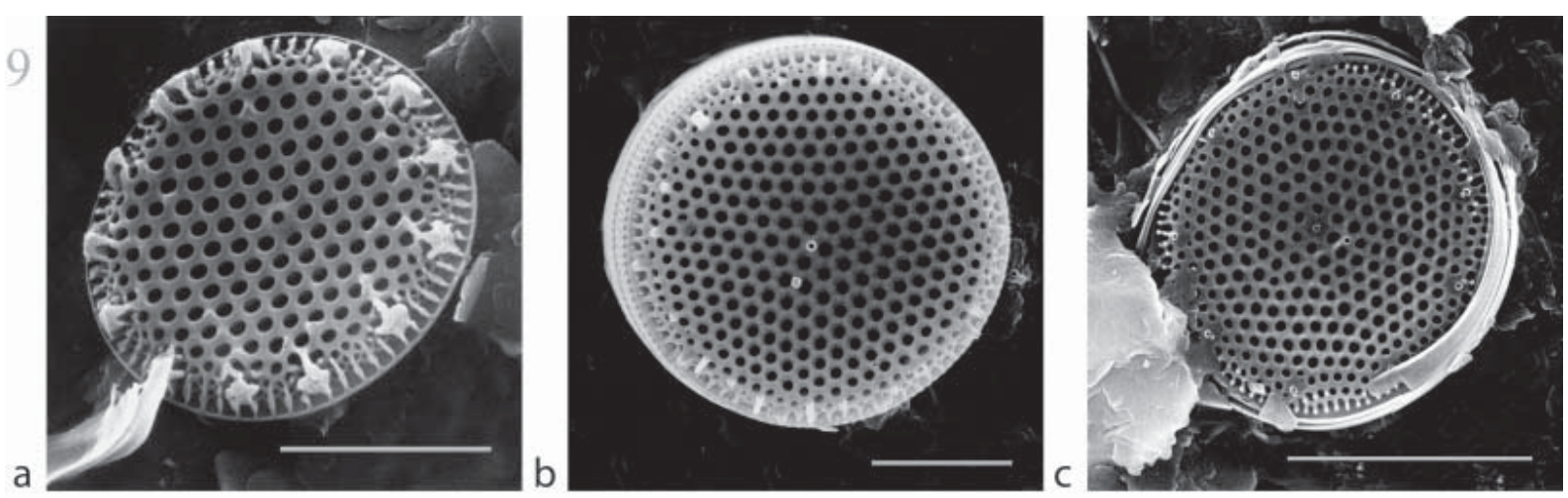

d

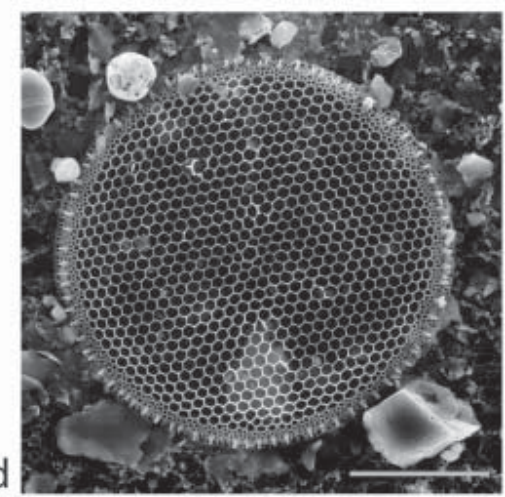

Plate 9. a-d Thalassiosira spp. SEM. Scale bars: $b, c=5 \mu \mathrm{m} ; \mathrm{a}=15 \mu \mathrm{m} ; \mathrm{d}=25 \mu \mathrm{m}$. 

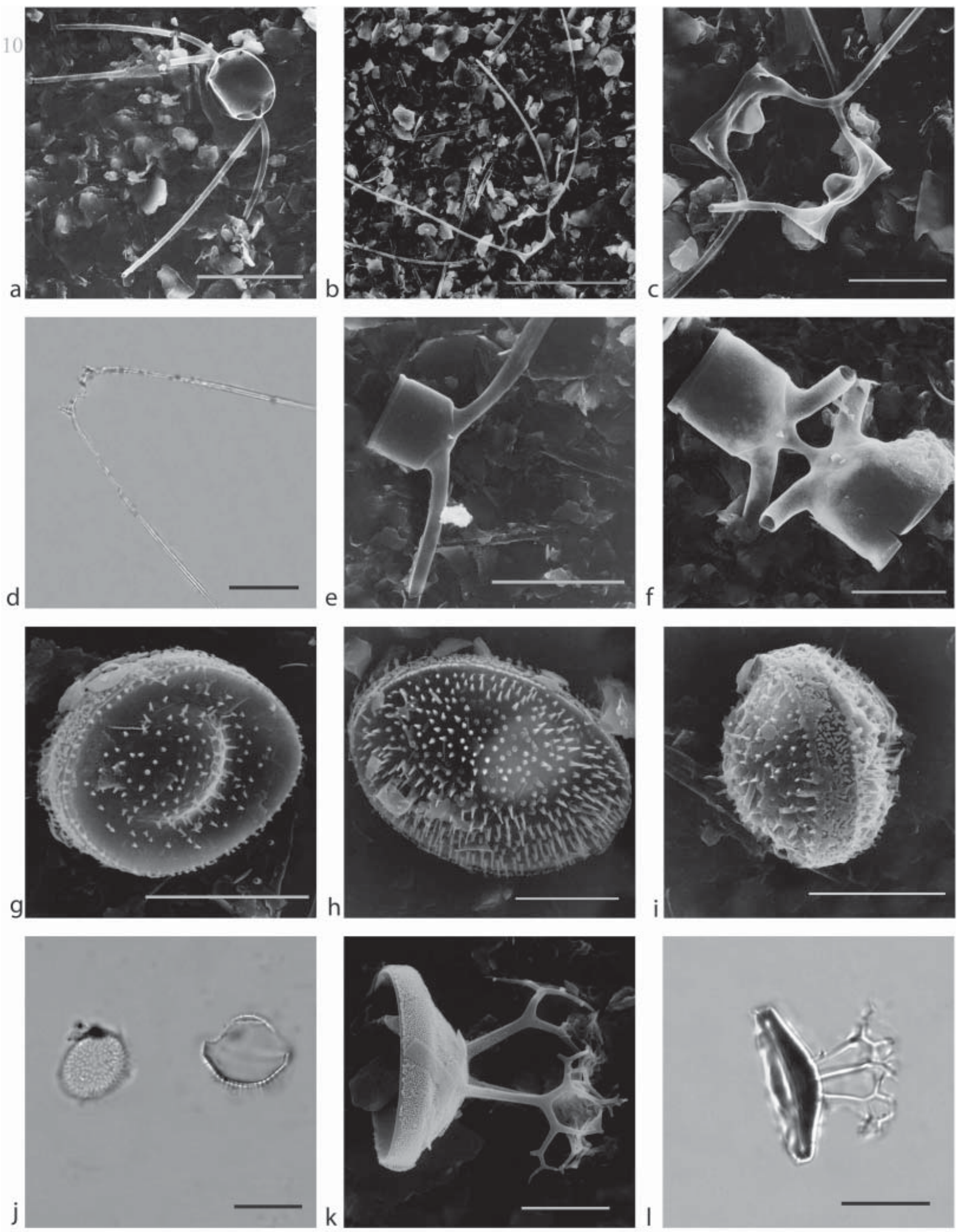

Plate 10. a. Chaetoceros curvisetus Cleve. SEM. b-c. Chaetoceros didymus var. anglica Ehrenberg. SEM. d-e. Chaetoceros sp. Ehrenberg LM (d) SEM (e). f. Chaetoceros rostratus Lauder. SEM. g-j. Chaetoceros affinis Gran (RS). k-l. Chaetoceros diadema (Ehrenberg) Gran (RS). SEM (k), LM (1). Scale bars: f, $k=5 \mu \mathrm{m} ; \mathrm{b}, \mathrm{c}, \mathrm{d}, \mathrm{g}, \mathrm{h}, \mathrm{i}, \mathrm{j}, \mathrm{l}=10 \mu \mathrm{m}$; $\mathrm{a}, \mathrm{e}=20 \mu \mathrm{m}$. 

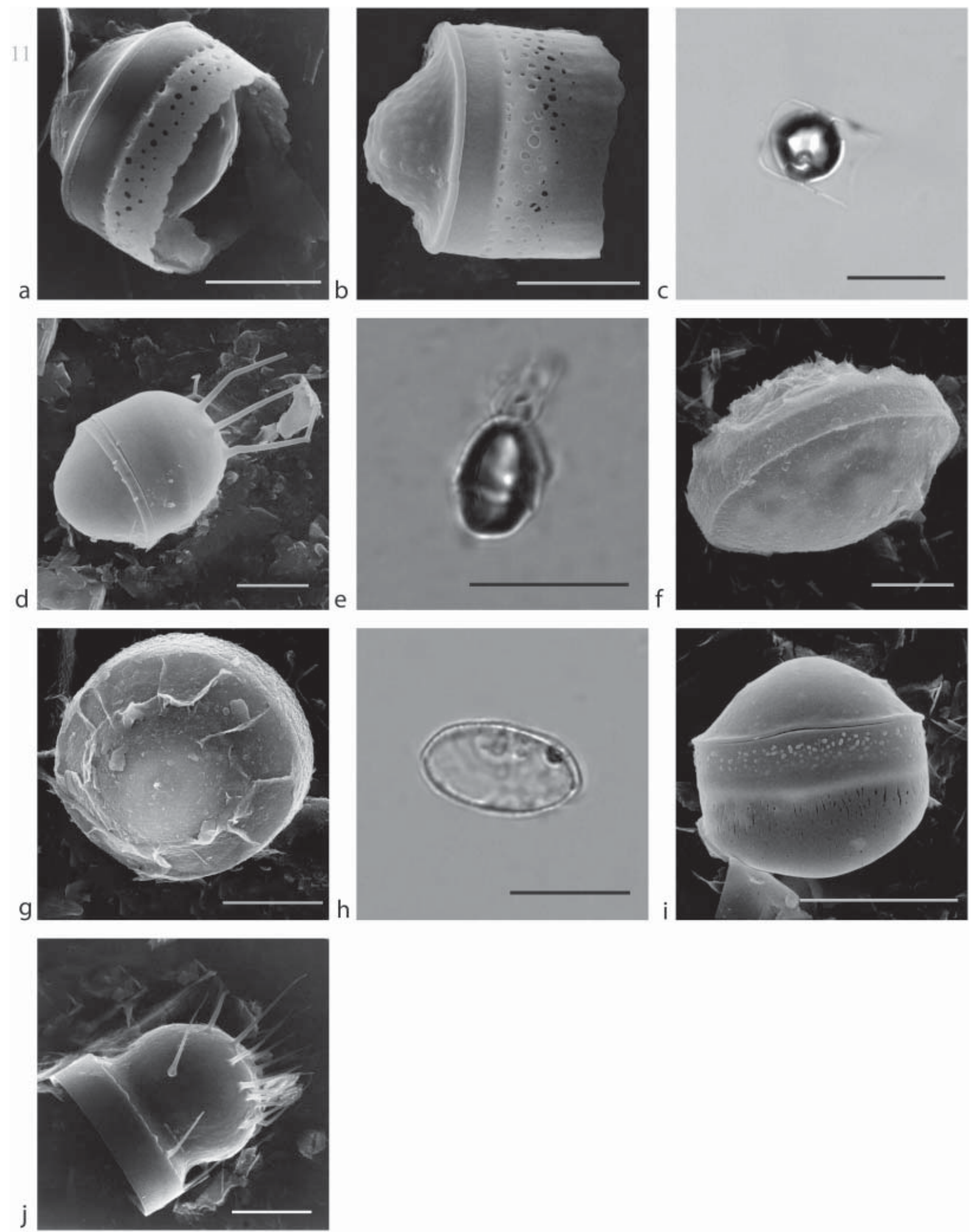

Plate 11. a-c. Chaetoceros seychelarus Karsten (RS). SEM (a-b), LM (c). d-e. Chaetoceros sp. (RS). SEM (d), LM (e). f-h. Chaetoceros sp. form 1 (RS). SEM (f-g), LM (h). i. Chaetoceros (RS) spp. SEM. j. Chaetoceros lauderi Ralfs (RS). SEM. Scale bars: a, b, d= $5 \mu \mathrm{m}$; c, e, f, g, h, i, j= $10 \mu \mathrm{m}$. 

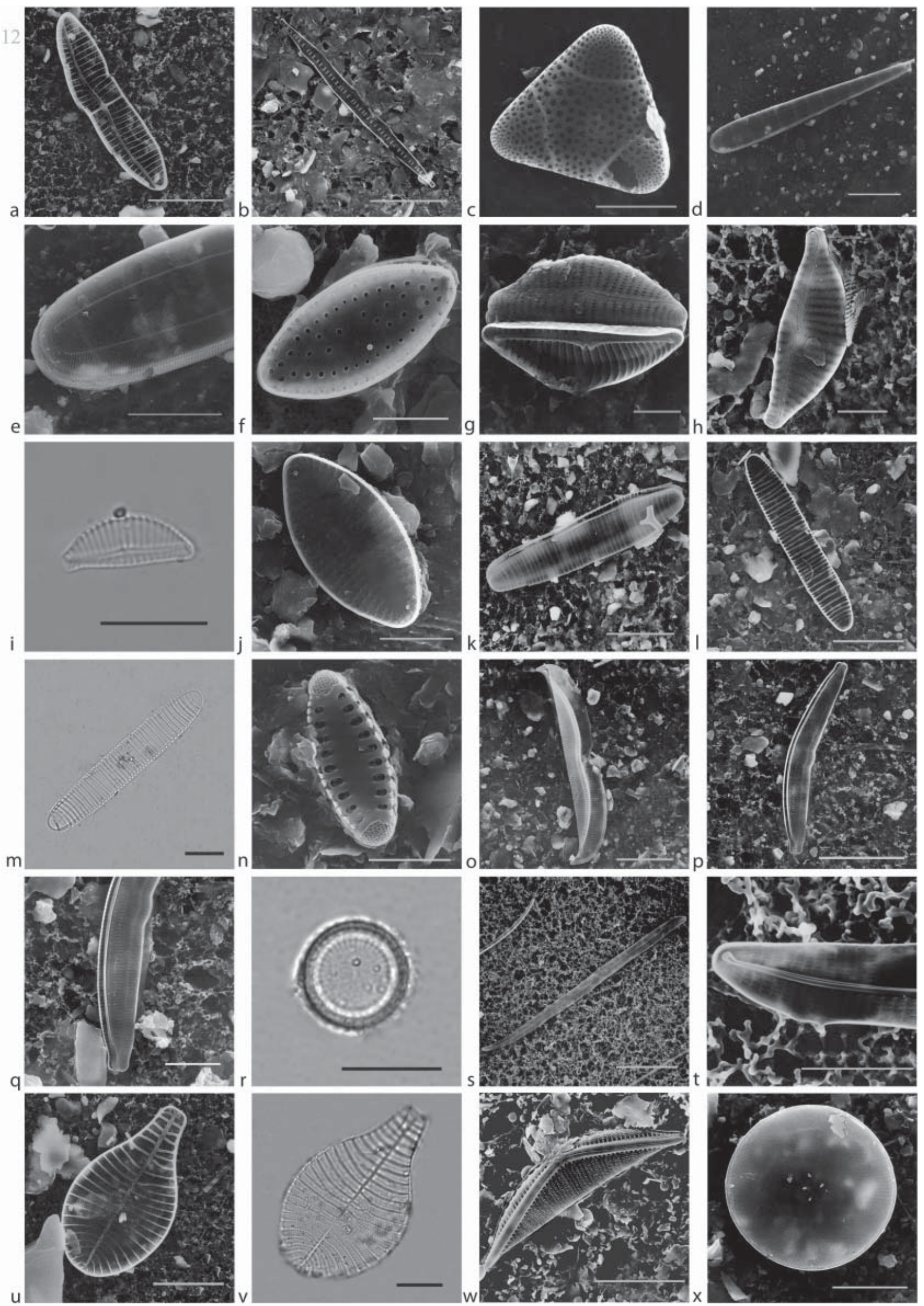
Plate 12. a. Achnanthes longipes C.A. Agardh. SEM. b. Bacillaria sp. SEM. c. Biddulphia alternans (J.W. Bailey) Van Heurck. SEM. d-e. Climacosphenia moniligera Ehrenberg. SEM. f. Cymatosira belgica Grunow. SEM. g-i. Cymbella sp. SEM (g-h), LM (i). j. Delphineis surirella (Ehrenberg) Andrews. SEM. k-m. Diatoma vulgare Bory St. Vincent. SEM (k-1), LM (m). n. Dimeregramma sp. (D. minor (Gregory) Ralfs?) SEM. o. Entomoneis sp. (=Amphiprora sp.). SEM. p-q. Hannaea sp. SEM. r. Paralia sp. LM. s-t. Pleurosigma/Gyrosigma ? spp. SEM. u-v. Podocystis americana J.W. Bailey. SEM (u), LM (v). w. Rhopalodia sp. SEM. x. Stellarima stellaris (Roper) Hasle and Sims. SEM. Scale bars: f, $\mathrm{g}, \mathrm{h}, \mathrm{t}, \mathrm{n}=5 \mu \mathrm{m} ; \mathrm{c}, \mathrm{i}, \mathrm{j}, \mathrm{m}, \mathrm{q}, \mathrm{r}, \mathrm{v}, \mathrm{w}=10 \mu \mathrm{m} ; \mathrm{a}, \mathrm{b}, \mathrm{e}, \mathrm{k}=20 \mu \mathrm{m} ; 1, \mathrm{o}, \mathrm{p}, \mathrm{s}, \mathrm{u}=25 \mu \mathrm{m} ; \mathrm{d}=50 \mu \mathrm{m}$. 

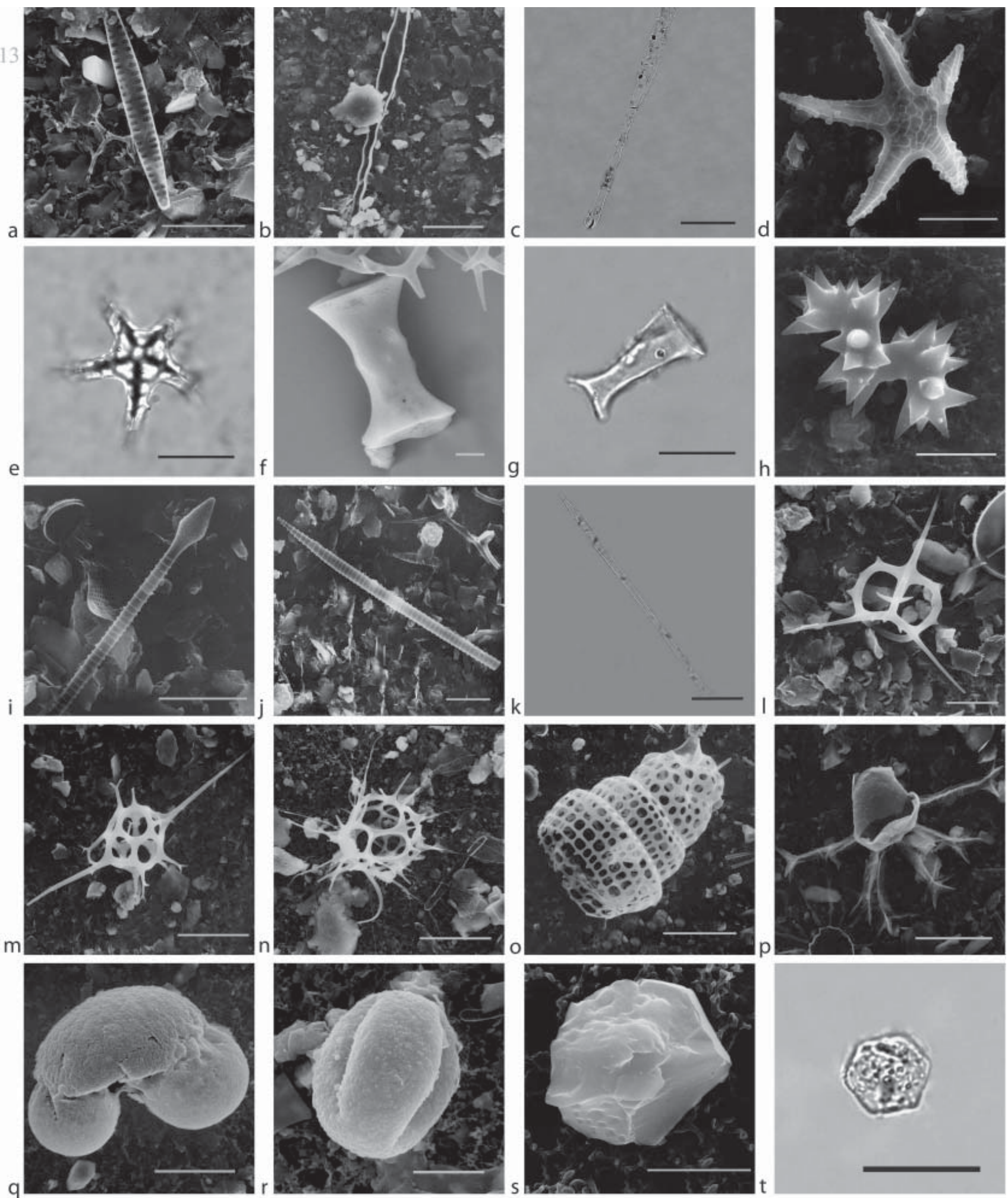

Plate 13. a. Tabularia sp. SEM. b-c. Toxarium undulatum J.W. Bailey. SEM (b), LM (c). d-e. Dinoflagellate: Actiniscus pentasterias (Ehrenberg) Ehrenberg. SEM (d), LM (e). f-g. Phytoliths. SEM (f), LM (g). h. Sponge spicule. SEM. i-k. Protozoan: Sticholonche zanclea Hertwig. SEM (i-j), LM (k). l. Radiolarian: Cladoscenium sp.?. SEM. m. Radiolarian: unknown species. SEM. n. Radiolarian: unknown species SEM. o. Radiolarian: unknown species. SEM. p. Dinoflagellate cyst: unknown species. SEM. q. Pollen: Pinus sp. SEM. r. Pollen: Quercus sp. SEM. s-t. Lithogenic material. SEM (s), LM (t). Scale bars: f, $\mathrm{s}=5 \mu \mathrm{m}$; a, d, e, g, h, i, j, $1, \mathrm{r}, \mathrm{t}=10 \mu \mathrm{m} ; \mathrm{c}, \mathrm{k}, \mathrm{m}, \mathrm{p}=20 \mu \mathrm{m} ; \mathrm{b}, \mathrm{n}, \mathrm{o}, \mathrm{q}=25 \mu \mathrm{m}$. 


\section{Capítulo 7}

Seasonal and interannual variability of diatom and coccolith fluxes in the northwestern Mediterranean: a 12-yr sediment trap record

Rigual-Hernández, A.S., Bárcena, M.A., Sierro, F.J., Jordan, R.W., Flores, J.A., Sebastian Meier, K.J., Beaufort, L. and Heussner S.

Marine Micropaleontology (reviewed) 



\section{Seasonal and interannual variability of diatom and coccolith fluxes in the northwestern Mediterranean: a 12-yr sediment trap record.}

Andrés S. Rigual-Hernández ${ }^{1, *}$, María A. Bárcenaํ, Francisco J. Sierro ${ }^{1}$, Richard W. Jordan², José A. Flores $^{1}$, K.J. Sebastian Meier ${ }^{3}$, Luc Beaufort ${ }^{4}$ and Serge Heussner ${ }^{5}$

1. Área de Paleontología, Departamento de Geología, Universidad de Salamanca, 37008 Salamanca, Spain.

2. Department of Earth \& Environmental Sciences, Faculty of Science, Yamagata University, Yamagata 990 8560, Japan.

3. Christian-Albrechts-Universität Institut für Geowissenschaften Ludewig-Meyn-Str. 10, D-24118 Kiel, Germany.

4. CNRS-Université Aix-Marseille III, CEREGE, Europôle de l'Arbois, BP 80, 13545 Aix-en-Provence Cedex 04, France.

5. CEFREM, UMR 5110 CNRS - University of Perpignan Via Domitia, 52 avenue Paul Alduy, 66860 Perpignan Cedex, France.

*Corresponding author.

We studied the seasonal to interannual evolution of the diatom, coccolith and bulk compound fluxes in the Gulf of Lions through the analysis of a 12-yr-long sediment trap record. The temporal particle flux pattern reflected the variations in surface oceanographic conditions and primary productivity, which underwent strong annual cycles. Highest diatom, coccolith and total mass fluxes always occurred during the spring bloom while minima were recorded during summer. Changes in the diverse diatom communities reflected the water column conditions throughout the record. Thalassionema frauenfeldii, a diatom well-adapted to a wide range of conditions, was the main component of the diatom assemblage that dominates during periods of medium to elevate turbulence and moderate primary productivity, i.e. fall and winter. The neritic and bloom-forming species, Skeletonema grethae and Chaetoceros spp. depicted the most productive periods of the record, i.e. spring. Resting spores of the genus Chaetoceros were the main component of the summer diatom assemblages, characterized by oligotrophic and stratified waters. The intensity of the annual diatom spring blooms seems to be enhanced those years with strong winds during winter and low wind stress during the outset of the solar radiation intensification (March), while years with weak winter mixing and/or intense wind stress at beginning of the radiation increase are related to low diatom fluxes. Coccolith fluxes showed a more stable interannual pattern than diatoms, often exhibiting maximum values those years of low diatom productivity, which suggests a possible competition between the two groups. No straightforward relationship was found between the North Atlantic Oscillation (NAO) and phytoplankton skeleton fluxes. Nevertheless, other phenomena such as the 1997-98 El Niño Event and the 2003 summer heat wave over the Western Mediterranean had remarkable consequences on the composition and timing of the phytoplankton spring bloom.

Keywords: diatoms, coccoliths, sediment trap, ENSO, NAO. 


\subsection{INTRODUCTION}

Diatoms and coccolithophores are two of the main primary producers in the world ocean. Despite their co-occurrence, diatoms tend to dominate in eutrophic environments such as upwelling regions, river mouths, equatorial divergences, transient open-ocean blooms triggered by wind-mixing events and spring blooms (Nelson et al., 1995; Ragueneau et al., 2000), while coccolithophores usually exhibit high abundances in mesotrophic and oligotrophic waters (Margalef, 1978) and in those situations, such as the last stages of a diatom bloom, where low silica concentrations prevent diatom growth (Egge and Jacobsen, 1997). Both phytoplankton groups play a major role in global biogeochemical cycles. Bloom-forming diatoms significantly contribute to the opal and organic carbon export due to their silica exoskeleton and their tendency to form mass aggregates, which rapidly sink to the seabed. Their contribution is especially relevant along the continental margins where roughly $45 \%$ and $32-39 \%$ of the total burial of marine organic carbon and biogenic opal occurs, respectively (Hedges and Keil, 1995; Ragueneau et al., 2000). On the other hand, some species of coccolithophores are considered to be the most productive calcifiying organisms on earth (Rost and Riebesell, 2004) that, in addition to their ability to photosynthesise, make them key contributors to the oceanic carbonate and organic carbon pumps (Baumann et al., 2005; Winter and Siesser, 1994). Therefore, diatom valves and coccoliths may be useful proxies for paleoceanographic and paleoproductivity reconstructions. However, to make reliable interpretations of the fossil record it is crucial to decipher the ecological mechanisms controlling the distribution and life cycle of the extant phytoplankton species. In this sense, sediment traps are a useful method to monitor sea surface processes on a seasonal to multiyear basis, bridging the gap between biological oceanography and paleoceanography. The limitations and bias of sediment traps have been widely discussed in the literature (e.g. Deuser, 1996; Gust et al., 1994; Siegel et al., 1990; Waniek et al., 2000; 2005; among others). They remain however the best tool to collect, on the long term, settling particles in marine environments (Deuser, 1996).

As pointed out by Heussner et al. (2006), sediment trap experiments covering periods long enough ( $>5$ years) to address the interannual variability of particle transfer are scarce (e.g., Deuser, 1996; Karl et al., 2001; Takahashi et al., 2000; Waniek et al., 2005). Long-term timeseries experiments have proved to be of great importance to register changes related to the El Niño Southern Oscillation (ENSO), the Pacific Decadal Oscillation (PDO) and the North Atlantic Oscillation (NAO) (Karl et al., 2001). These climate-related oscillations may have profound effects on marine ecosystems, ocean biogeochemistry and net balance of carbon between the atmosphere and the ocean. Moreover, stochastic or "unusual" events such as strong wind events (Leblanc et al., 2005) or storms (Palanques et al., 2006) can have remarkable effects on downward particle transfer.

Here we present a 12-yr sediment trap record from the Gulf of Lions (NW Mediterranean) where diatom valves, coccoliths and the bulk compound fluxes have been studied in order to: 
(1) decipher the mechanisms that control the seasonal and interannual flux variability of these two fossilizable phytoplankton groups;

(2) analyze the specific composition of diatom assemblages and their relationship with regional environmental conditions.

\subsection{REGIONAL SETTING}

The Gulf of Lions (hereafter GoL) together with the Ligurian Provencal Basin form the Northern Mediterranean Basin, located in the northwestern Mediterranean Sea (Fig. 1). The GoL continental margin is crescent-shaped, with a slope incised by about ten submarine canyons. The complex circulation in the GoL is dominated by the Northern Current (NC), a permanent cyclonic alongslope current (Fig. 1) (Millot, 1990). The NC is fed by the two currents flowing on either sides of Corsica (Fig. 1): the Ligurian Current (LC) and the Tyrrhenian Current (TC). Due to the orographic setting around the gulf (Pyrenees, the Massif Central and the Alps), two groups of northwesterly winds blow strongly during winter (Mistral and Tramontana). These cold and dry northwesterlies cause evaporation and cooling of the surface waters inducing water mixing and dense water formation both on the shelf and offshore (Millot, 1990). Dense-water formation in the GoL shows important interannual variability, and in especially cold and dry years dense-water formed over the shelf may sink and cascade downslope, reaching the bottom and eroding the sea floor (Béthoux et al., 2002; Canals et al., 2006; Heussner et al., 2006).

The Rhone River provides most of the fresh water input to the gulf, largely during spring and fall (Ulses et al., 2008). The Rhone plume is directed southwards by the general circulation and can extend over a hundred kilometers (Estournel et al., 1997).

The GoL is considered as being one of the most productive areas of the Mediterranean Sea (Estrada, 1996). The main fertilizing mechanisms in this area are river runoff, coastal upwelling and vertical water mixing during winter triggered by intense and dry northwesterly winds (Estrada, 1996; Millot, 1999).

\subsection{MATERIAL AND METHODS}

\subsubsection{Field experiment}

A mooring line was deployed at $1000 \mathrm{~m}$ water depth within the axis of the Planier submarine canyon $\left(43.02^{\circ} \mathrm{N}, 5.18^{\circ} \mathrm{E}\right)$ (Fig. 1), at the northeastern entrance of the GoL. The mooring was equipped with two PPS3 Technicap sediment traps at 500 and 30 meters above bottom (mab hereafter) paired with current meters (Heussner et al., 2006). The sampling period considered here ranged from October 1993 until January 2006 with a sampling interval of 14 days until early 1997, and of 1 month till the end of the experiment. Gaps in the temporal series were caused by mooring recovery periods or by problems in the sediment trap functioning. Despite 
these hiatuses, the diatom and coccolith flux data cover close to $80 \%$ of the total deployment time.

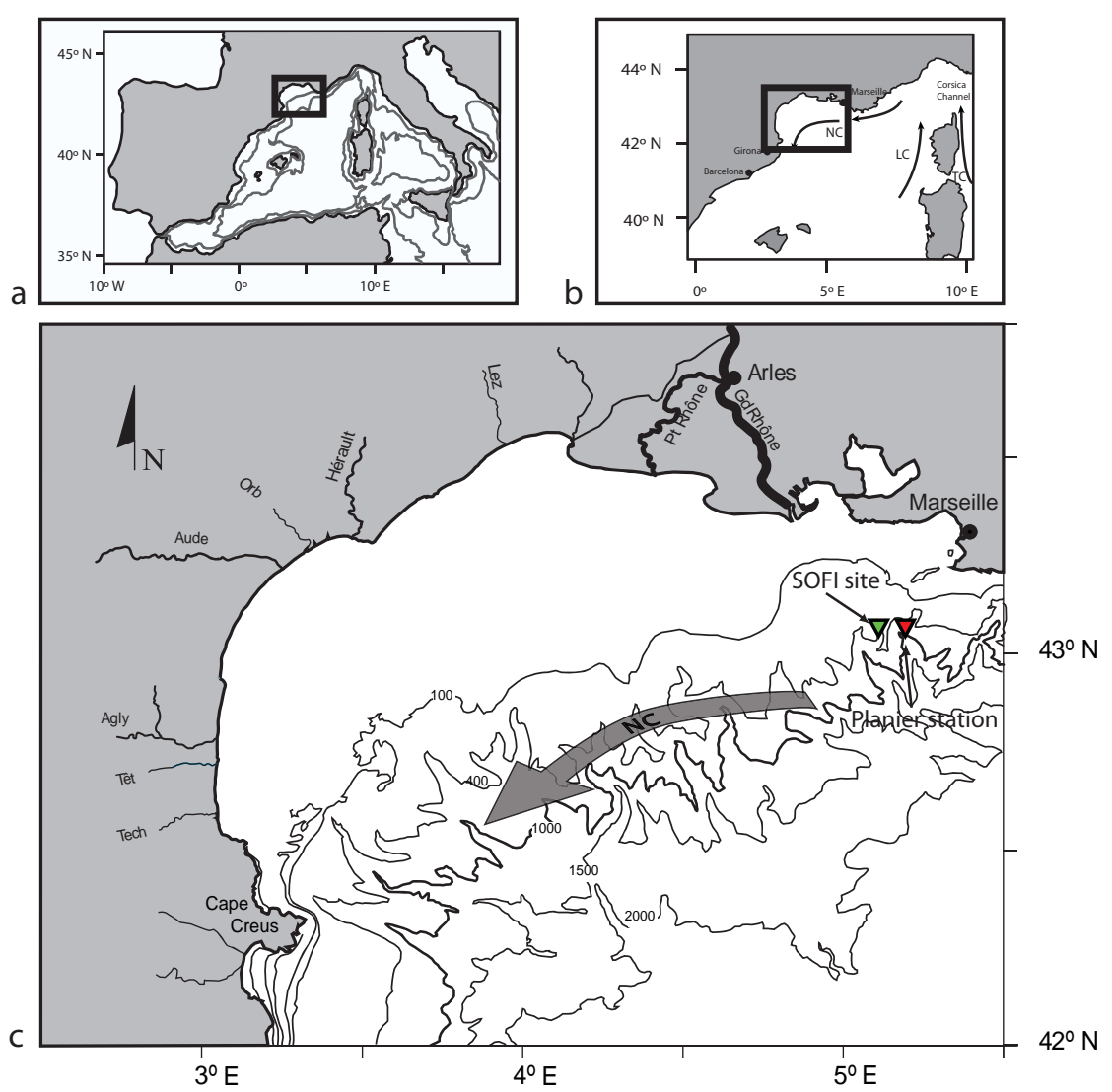

Figure 1. Geographic setting of the Gulf of Lions in the NW Mediterranean. b. Mediterranean Northern Basin. c. Bathymetric map of the Gulf of Lions with the location of the Planier and SOFi sediment traps (triangles). Arrows represent the theoretical surface circulation.

\subsubsection{General processing of the sediment traps}

A detailed description of the PPS3 sediment trap, the general sample processing used for this experiment and the determination of the total mass fluxes and its major constituents (lithogenic material, opal, carbonate and organic carbon) can be found in Heussner et al. (2006; 1990). A description of the treatment for the siliceous and calcareous microfossil analyses is summarized here.

\subsubsection{Specific treatment for siliceous microplankton and calcareous nannoplankton}

A total of 119 samples were processed for the siliceous plankton analysis. Different aliquots from the original samples were used. Although the most common aliquot was $1 / 8$ of the total sample, other fractions were also employed depending on sample availability, ranging from 1/64 to 3/4. Original samples were wet-sieved through a $150 \mu \mathrm{m}$ mesh to separate large foraminifera from smaller diatoms and silicoflagellates. An additional sieving was done on a $63 \mu \mathrm{m}$ mesh to break up organic aggregates and separate the foraminifera fraction $63-150 \mu \mathrm{m}$. The $<63-\mu \mathrm{m}$ fraction 
was used for the siliceous skeleton analysis. Samples underwent the standard decantation method outlined in Bárcena and Abrantes (1998). Diatom and silicoflagellate analyses were carried out on permanent slides of acid-cleaned material (Permount mounting medium). Qualitative and quantitative analyses were done at 400x and 1000x magnifications using a Nikon Eclipse 80i light microscope with phase contrast illumination. The recommendations of Schrader and Gersonde (1978) were followed as a basis for counting diatom valves. A minimum of 400 diatom specimens per sample were counted. The total diatom fluxes are given in number of skeletons per day and square meter.

For coccoliths, aliquots of trap material were diluted in 250 to $1000 \mathrm{ml}$ of tap water depending on the amount of material. The samples were then thoroughly mixed and dispersed by ultrasonic treatment for 30 seconds. Subsamples of 5 to $50 \mathrm{ml}$ were taken immediately afterwards with a volumetric pipette and added to $200 \mathrm{ml}$ tap water in a filtration device and filtered through a $47 \mathrm{~mm}$ diameter, $0.43 \mu \mathrm{m}$ porosity cellulose nitrate filter. The amount of material on the filter varied between 0.2 and $2 \mathrm{mg}$. The pipette was thoroughly rinsed to make sure that none of the material was lost. A membrane pump was used to filter the suspension. The filters were dried at $50{ }^{\circ} \mathrm{C}$ over night in an oven and embedded with Canada balsam on glass slides with a cover slip. Forty fields of view were captured per sample with a Spot insight camera and analysed with an automated coccolith recognition system (SYRACO, Beaufort and Dollfus, 2004). The system recognizes the 14 most common coccolithophore species. An average of about 850 specimens was recognized by the system. Non-coccolithophore particles that can be included in the counts were eliminated by visual checking of the automated counts.

\subsubsection{Additional data sets on environmental variables}

Daily global solar radiation data from the nearest meteorological stations (Girona and Barcelona) (Fig. 1) were provided by the Spanish "Instituto Nacional de Meteorología" from August 1996 until the end of the experiment. Weekly sea surface temperatures (SSTs) from October 1993 until March 2006 (Fig. 1) were obtained from NOAA Optimum Interpolation Sea Surface Temperature Analysis (Reynolds et al., 2002). SeaWiFS satellite monthly chlorophyll- $a$ concentrations from September 1997 until March 2006 (Fig. 1) were obtained from NASA's Giovanni program (Acker and Leptoukh, 2007). The monthly concentration was averaged over a relatively small area around the mooring location $\left(0.2^{\circ} \times 0.2^{\circ}\right)$ to avoid the high productivity signal generated by the Rhone River plume. Daily wind speed and air temperature records from the Marseille airport weather station (Fig. 1) were obtained from the Weather Underground Forecast website (Fig. 2) from July 1996 until the end of the experiment. 

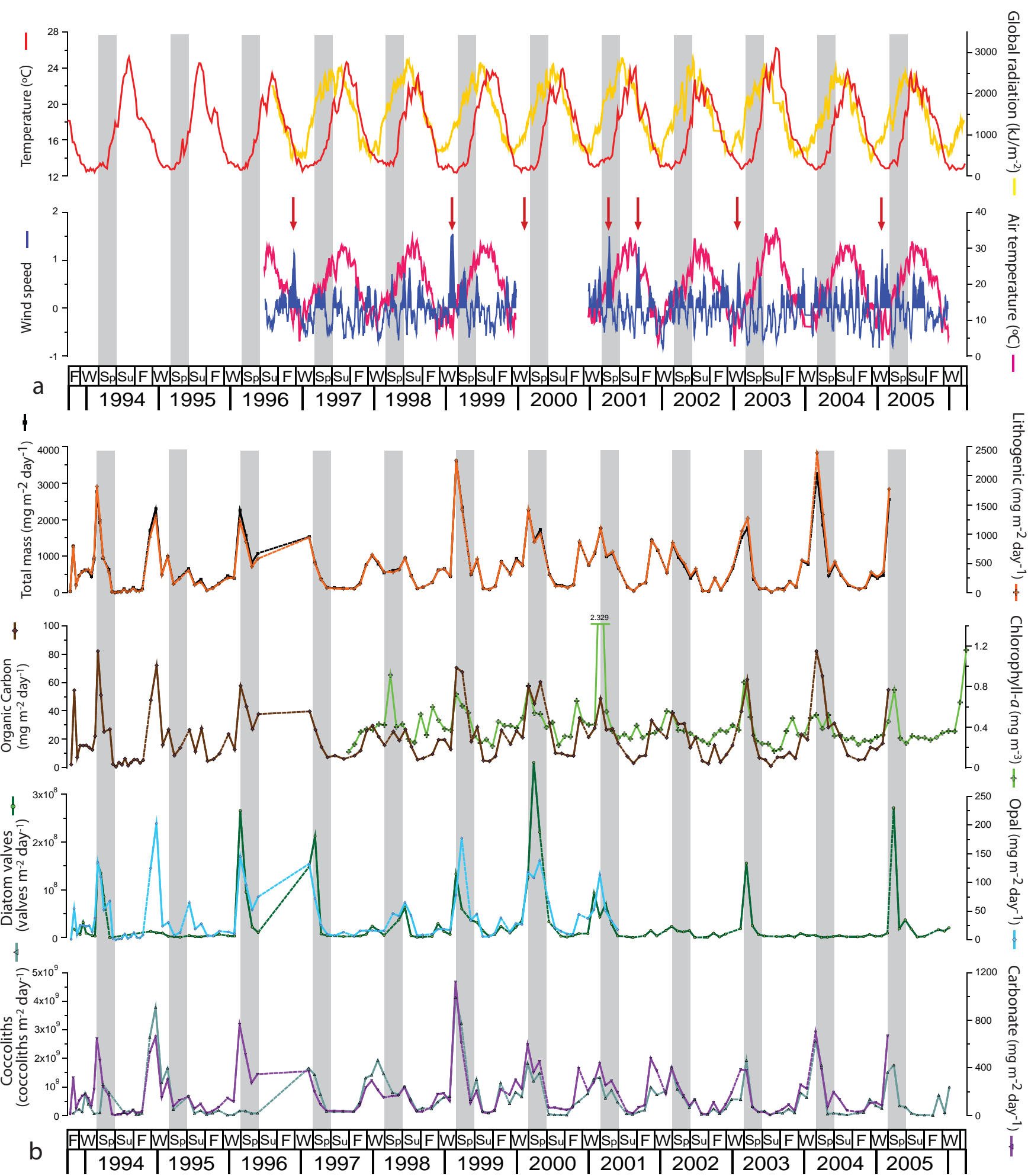

Figure 2. a. Temporal changes of the Sea Surface Temperature $(\mathrm{SST})\left({ }^{\circ} \mathrm{C}\right)$, solar global radiation $(\mathrm{KJ} /$ $\mathrm{m}^{2}$ ), wind speed anomaly and air temperature $\left({ }^{\circ} \mathrm{C}\right)$. Intense wind events are represented by arrows. Although no wind data was available for the year 2000, the major wind events during this period are marked following the description of Leblanc et al. (2005). b. Temporal changes in the flux of total particles, lithogenics, organic carbon, carbonate, opal $\left(\mathrm{mg} \mathrm{m}^{-2} \mathrm{~d}^{-1}\right)$, diatom valves (valves $\left.\mathrm{m}^{-2} \mathrm{~d}^{-1}\right)$ and coccoliths (coccoliths $\mathrm{m}^{-2} \mathrm{~d}^{-1}$ ) and in the chlorophyll- $a$ concentration $\left(\mathrm{mg} \mathrm{m}^{-3}\right)$. Period Oct-1993 until Jun-2001 in Heussner et al. (2006); Jun-2001 until Mar-2005 new dataset presented in this work. Green shading highlights the spring season. 


\subsubsection{Principal Component Analysis (diatoms)}

A principal component analysis (PCA, Statistica 7.0® software) was carried out to investigate the covariation between the different diatom assemblages (samples). Only species and groups with relative contributions that accounted for more than $0.4 \%$ to the entire record ( 22 out of 121 taxa) were considered. The relative contribution of the 22 most abundant taxa was recalculated for each sample and a $\log$-transformation $(\log x+1)$ was applied to normalize the distribution of the data. Diatom assemblages were determined using PCA with a maximized variance (VARIMAX) rotation. "Factor loading" represents the weighting of a factor on any given sample while "Factor score" identifies the species that turn out to be important in defining the factors (Pérez-Cruz, 2006).

\subsection{RESULTS}

\subsubsection{Total particle flux}

A description of total mass fluxes and bulk composition of particle fluxes at the Planier site (500 mab) from October 1993 until June 2001 can be found in Heussner et al. (2006). In addition, a complementary new dataset concerning the particle fluxes and their composition from June 2001 till March 2005 are presented in this work (Fig. 2).

Particle flux maxima were often recorded during February and March, however with varying magnitude from year to year (Fig. 2). The major particle flux pulses were recorded during March 1999 (3600 mg m² $\mathrm{d}^{-1}$ ), March 2004 (3257 $\left.\mathrm{mg} \mathrm{m}^{-2} \mathrm{~d}^{-1}\right)$ and March 1994 (2762 $\left.\mathrm{mg} \mathrm{m}^{-2} \mathrm{~d}^{-1}\right)$ (Fig. 2). The composition of settling particles was mainly represented by lithogenics $(68.5 \%)$, followed by carbonate $(21.9 \%)$, organic matter ( $6.5 \%$; twice the organic carbon content) and opal (3.1\%). All these major constituents exhibited maximum fluxes during the winter-spring season every year, matching those of total mass, (Fig. 2 and 3) although during the fall-winter period they often exhibit a secondary annual maximum (Fig. 2). Carbonate fluxes were especially high during March 1999 (1121 $\mathrm{mg} \mathrm{m}^{-2} \mathrm{~d}^{-1}$ ) and March 1996 (764 $\left.\mathrm{mg} \mathrm{m}^{-2} \mathrm{~d}^{-1}\right)$, while the opal fluxes exhibited maxima during late December 1994 (203 $\left.\mathrm{mg} \mathrm{m}^{-2} \mathrm{~d}^{-1}\right)$ and late March 1999 (177 mg $\mathrm{m}^{-2} \mathrm{~d}^{-1}$ ) (Fig. 2). The highest fluxes of organic carbon were recorded during March 1994 (82 $\mathrm{mg} \mathrm{m}^{-2} \mathrm{~d}^{-1}$ ) and early March $2004\left(82 \mathrm{mg} \mathrm{m}^{-2} \mathrm{~d}^{-1}\right)$ (Fig. 2). It is important to notice that fluxes of major constituents matched those of total mass.

\subsubsection{Correlation analysis}

Pearson correlation coefficient $\left(\mathrm{r}^{2}\right)$ was calculated to estimate the degree of dependence between diatom valve and coccolith fluxes and satellite chlorophyll- $a$ values. Due to the difference in the fluctuation range of the variables and the high scattering of data, a Log-transformation (log $(x+1))$ was applied to all variables before analysis to compress the scale at both ends of the distributions and straighten the relationship. The correlation was significant between diatom valves and chlorophyll- $a\left(\mathrm{r}=0.65^{* * *}, \mathrm{n}=56\right)$ and between coccoliths and chlorophyll- $a(\mathrm{r}=$ 
$0.54^{* * *}, \mathrm{n}=93$ ) despite several biases are present in this calculation such as, the presence of other phytoplankton groups in the water column, the variability in the chlorophyll- $a$ content in different diatom and coccolithophore species, the intrinsic bias of the measurement tools (i.e., satellite and sediment trap biases), different sampling resolution, and the silica and carbonate dissolution processes. Moreover, it is worth noting that the highest chlorophyll- $a$ value of the whole record (March 2001) (Fig. 2) was considered as an outlier and was not taken into account when calculating the correlation coefficients.
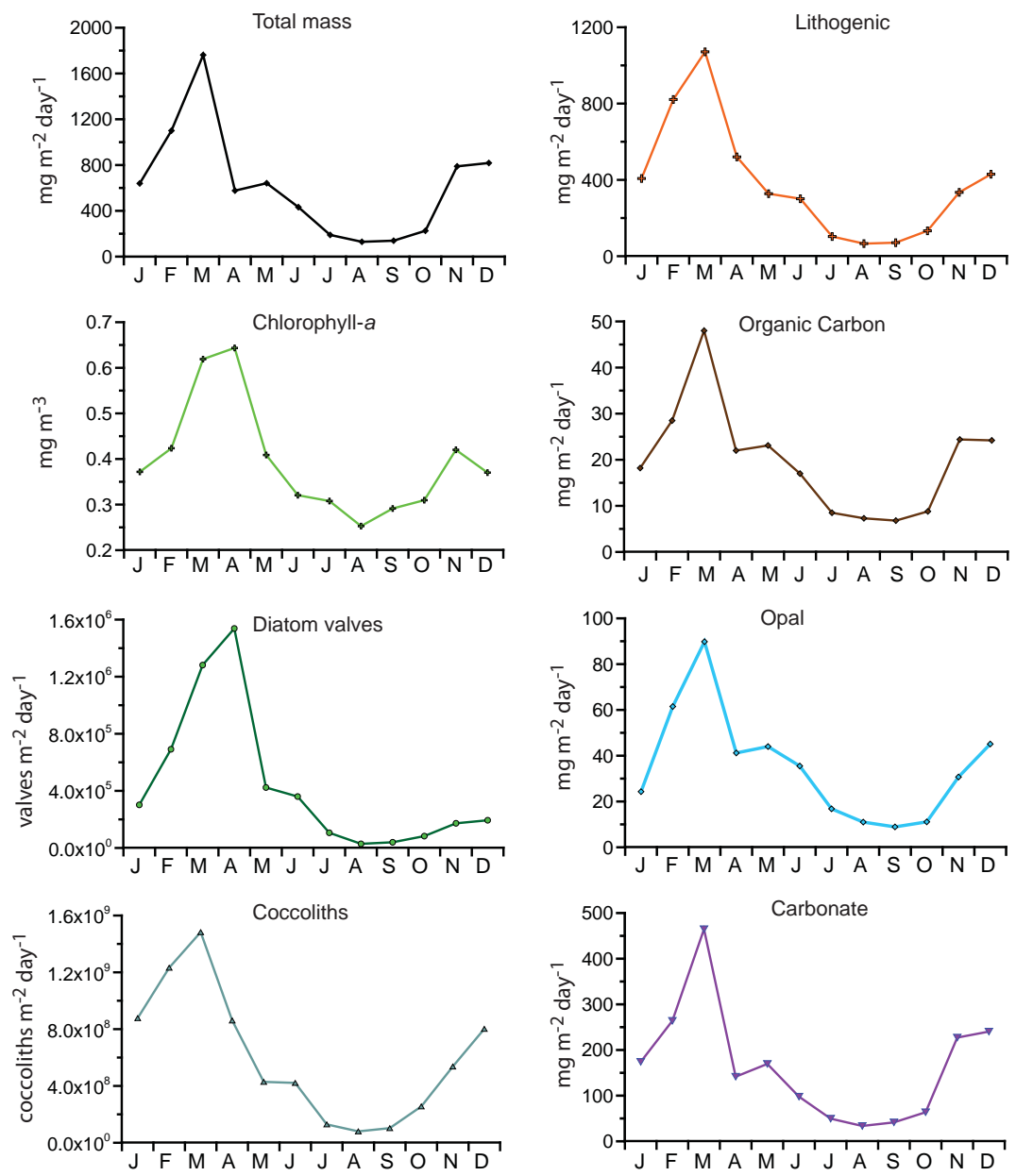

Figure 3. Mean monthly flux of total mass, lithogenics, organic carbon, carbonate, opal $\left(\mathrm{mg} \mathrm{m}^{-2} \mathrm{~d}^{-1}\right)$, diatom valves (valves $\mathrm{m}^{-2} \mathrm{~d}^{-1}$ ) and coccoliths (coccoliths $\mathrm{m}^{-2} \mathrm{~d}^{-1}$ ) determined at $500 \mathrm{~m}$ depth in the Planier Canyon trap and mean monthly surface chlorophyll- $a$ concentration $\left(\mathrm{mg} \mathrm{m}^{-3}\right)$ calculated for the Oct 93 to January 2006 period.

\subsubsection{Seasonal to interannual variations in total diatom and coccolith fluxes.}

The opal fraction was mainly composed of diatoms and silicoflagellates. Diatoms were the numerically dominant siliceous phytoplankton group during the study and they were ca. one order of magnitude higher than the silicoflagellates (Rigual-Hernández et al., 2010). Nevertheless, other siliceous groups also contributed to the total opal production such as radiolarians, phytoliths and the dinoflagellate Actiniscus pentasterias. As a general trend, diatom fluxes 
showed a unimodal distribution with maximum fluxes from February to April (Fig. 3). The flux during this period represented two-thirds $(67 \%)$ of the total annual diatom fluxes. Diatoms daily fluxes ranged between $1.6 \times 10^{5}$ and $3.6 \times 10^{8}$ with a mean of $3.1 \times 10^{7}$ valves $\mathrm{m}^{-2} \mathrm{~d}^{-1}$. Annual diatom flux maxima were especially high during late March 2000 (3.6 x $10^{8}$ valves $\mathrm{m}^{-2}$ $\left.\mathrm{d}^{-1}\right)$, early April 2005 (2.7 x 10 valves $\left.\mathrm{m}^{-2} \mathrm{~d}^{-1}\right)$, early March $1996\left(2.6 \times 10^{8}\right.$ valves $\left.\mathrm{m}^{-2} \mathrm{~d}^{-1}\right)$ and March 1997 (2.1 x $10^{8}$ valves $\left.\mathrm{m}^{-2} \mathrm{~d}^{-1}\right)$ (Fig. 2). Secondary spring maxima occurred in most of the other years except 1995, 2002, and 2004 when low fluxes were recorded (Fig. 2).

The diatom specimens were identified to the lowest taxonomic level possible. A total of 121 diatom taxa were identified in the samples. Despite their high diversity, only a handful of species dominated the assemblage, i.e., 9 species made up $74.5 \%$ of the total. On average, the most important taxa were the pelagic species Thalassionema frauenfeldii (34.6\%) and the Chaetoceros (Hyalochaete) Resting Spores (RS) group (25.8\%) that was mainly composed by Chaetoceros RS sp. 1 (9.1\%), Chaetoceros diadema RS (7.3\%), Chaetoceros seychelarum RS (3.2\%), Chaetoceros spp. RS (3.2\%) and Chaetoceros affinis RS (3.1\%). In addition, Skeletonema grethae (8.2\%), Nitzschia braarudii (3.5\%) and Thalassionema nitzschioides var. parvum $(2.3 \%)$ completed the list.

The biogenic calcareous fraction was mainly composed of coccoliths and planktonic foraminifera. However, other calcareous organisms were also found in very low abundances, such as benthic foraminifera, small shells of bivalves, gastropods and pteropods. Numerically, calcareous plankton fluxes were dominated by coccoliths. The average year (Fig. 3) reveals a unimodal distribution, with maxima from November to April. Coccolith fluxes were more spread out during the average year (Fig. 3) than those of the diatoms, with half of their annual abundance (48\%) occurring from February to April (spring bloom) and one-third (30\%) from November to January (autumn-winter bloom). Coccolith daily fluxes ranged between $4.3 \mathrm{x}$ $10^{6}$ and $4.1 \times 10^{9}$, with a mean of $8.4 \times 10^{8}$ coccoliths $\mathrm{m}^{-2} \mathrm{~d}^{-1}$. Coccolith fluxes exhibited more stable and repetitive interannual fluctuations than those of the diatoms (Fig. 2). The highest fluxes of coccoliths were recorded during early March 1999 (4.1 x $10^{9}$ coccoliths $\left.\mathrm{m}^{-2} \mathrm{~d}^{-1}\right)$, end of December $1994\left(3.8 \times 10^{9}\right.$ coccoliths $\left.\mathrm{m}^{-2} \mathrm{~d}^{-1}\right)$ and early $2004\left(2.6 \times 10^{9}\right.$ coccoliths $\left.\mathrm{m}^{-2} \mathrm{~d}^{-1}\right)$ (Fig. 2). Annual secondary maxima occurred during the other years of the record (Fig. 2). The main contributors of the coccolith assemblage were Emiliania huxleyi, Florisphaera profunda, Gephyrocapsa ericsonii, Gephyrocapsa muellerae and Helicosphaera spp. The species-specific nature of the coccolith fluxes will be discussed elsewhere (S. Meier, unpublished data).

\subsubsection{Principal Components Analysis (PCA)}

Factor analysis of the diatom assemblages resulted in 3 factors (sample groups 1 to 3 ) that account for ca. $83 \%$ of the original variance (Table 1). The importance of the different species in each factor or assemblage is shown in Table 2. Additionally, in order to identify the periods of dominance of each factor throughout the record, factor loadings are plotted versus time (Fig. 4). Considering the water column conditions during the periods that each factor depicts, the 


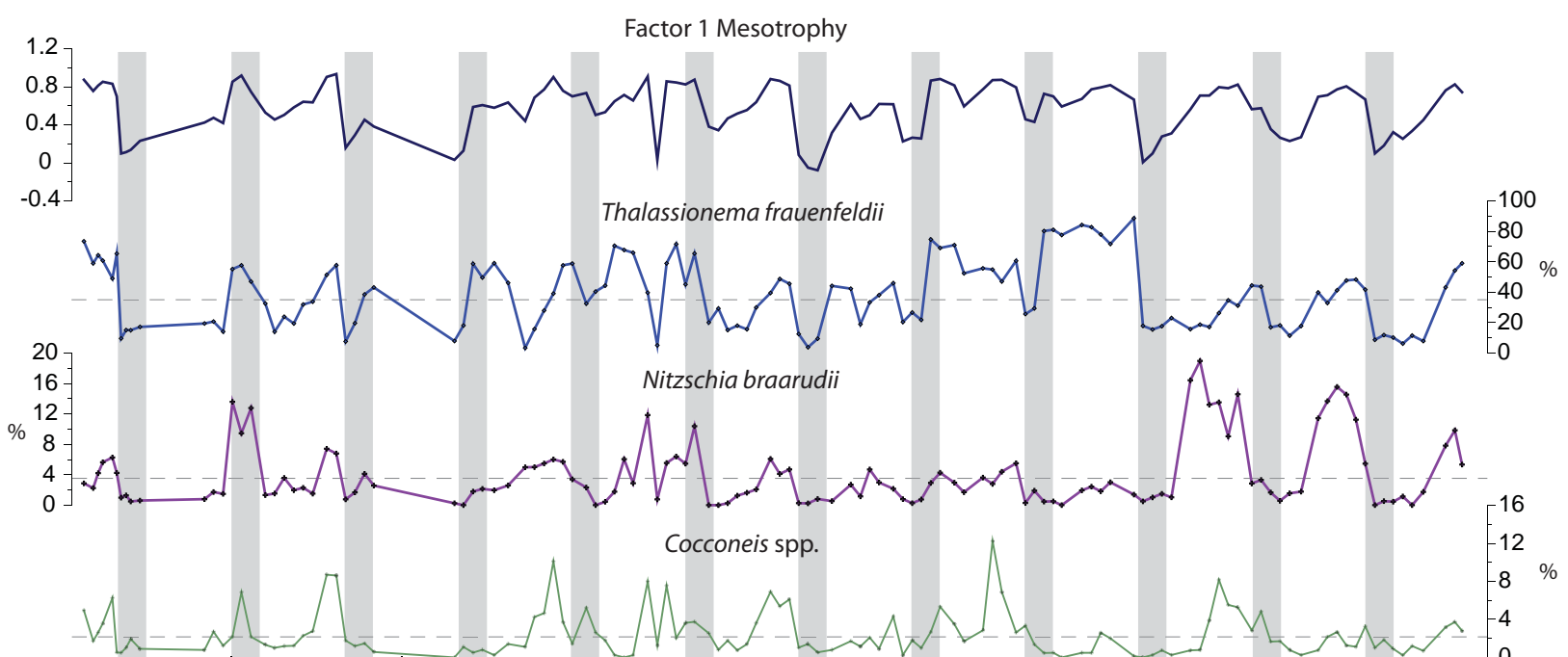

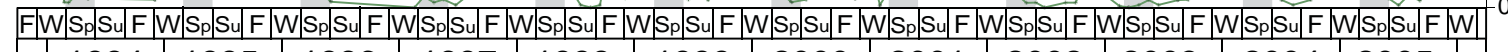
\begin{tabular}{|l|l|l|l|l|l|l|l|l|l|l|l|l|}
\hline & 1994 & 1995 & 1996 & 1997 & 1998 & 1999 & 2000 & 2001 & 2002 & 2003 & 2004 & 2005 \\
\hline
\end{tabular}
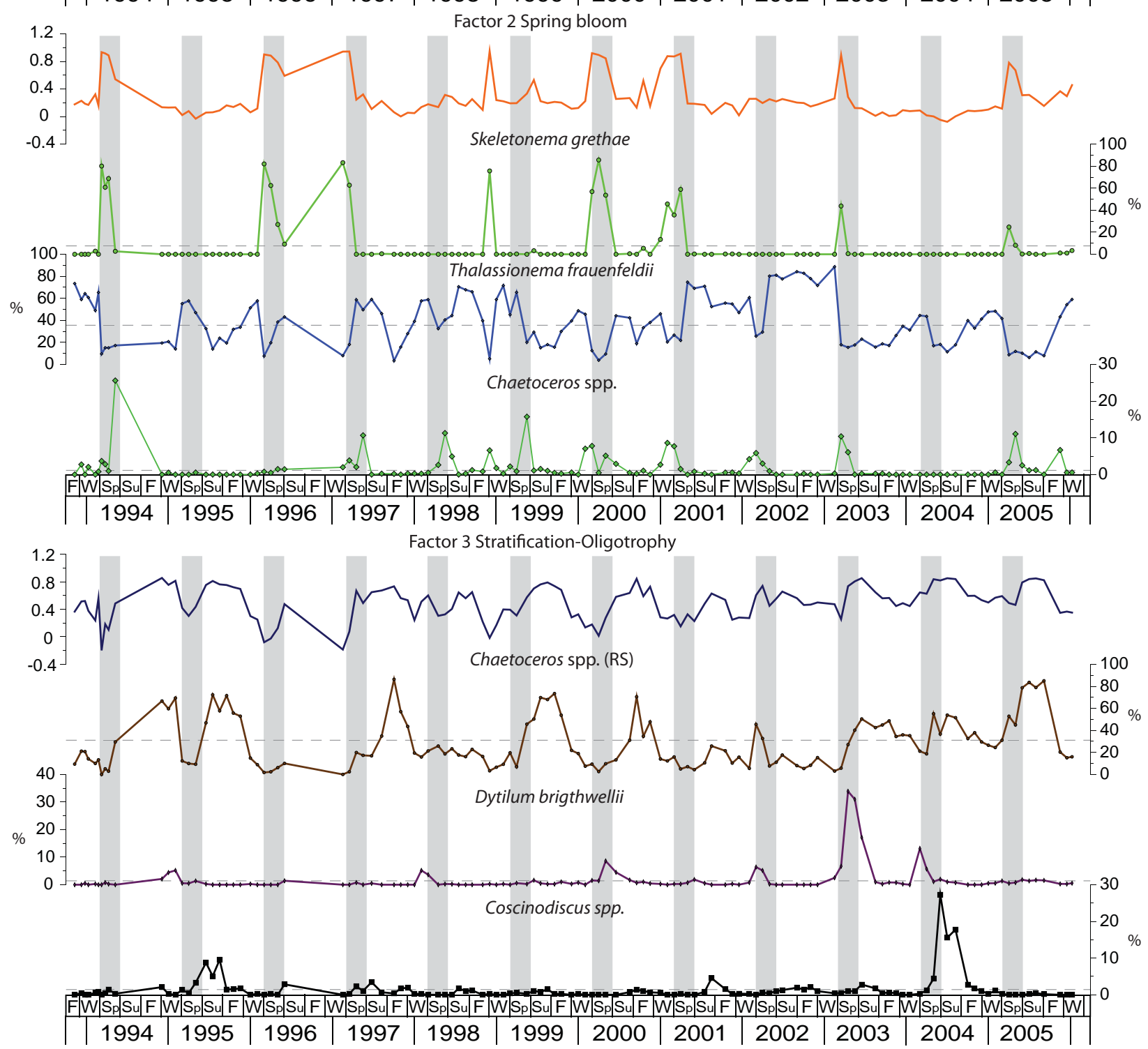

Figure 4. Temporal changes in the factor loadings and in the relative abundance of its main components throughout the record. Green shading highlights the spring season. 
factors are defined as (1) Mesotrophy, (2) Spring bloom (3) and Stratification-Oligotrophy. Factor 1: Mesotrophy. This factor alone depicts $66.3 \%$ of the total variance and its main contributors are Thalassionema frauenfeldii followed by Nitzschia braarudii and Cocconeis spp., whose factor scores are 3.02, 1.54 and 1.13, respectively (Table 2, Fig. 4). This factor exhibits high values during most of the record, especially during the autumn and winter periods (Fig. 4). T. frauenfeldii is the main component, and is the most abundant diatom species at the Planier station (average relative contribution $=34.6 \%$ ). Maximum annual fluxes of $T$. frauenfeldii were recorded every year during the spring period and were especially high during March 1999 (3.8 x 10 valves $\left.\mathrm{m}^{-2} \mathrm{~d}^{-1}\right)$ and March 1997 (3.4 x 10 $0^{7}$ valves $\left.\mathrm{m}^{-2} \mathrm{~d}^{-1}\right)$ (Fig. 5). $N$. braarudii (average relative contribution $=3.5 \%$ ) is the second most important component of factor Mesotrophy and its maximum fluxes occurred during March 1999 (5.2 x $10^{6}$ valves m $\left.{ }^{2} \mathrm{~d}^{-1}\right)$ and early March 1996 (1.9 x $10^{6}$ valves $\left.\mathrm{m}^{-2} \mathrm{~d}^{-1}\right)$ (Fig. 5). In the case of Cocconeis spp. (average relative contribution $=2.2 \%$ ), maximum fluxes were recorded during late March 2000 $\left(5 \times 10^{6}\right.$ valves $\left.\mathrm{m}^{-2} \mathrm{~d}^{-1}\right)$ and early March 1996 (4.5 x $10^{6}$ valves $\left.\mathrm{m}^{-2} \mathrm{~d}^{-1}\right)$ (Fig. 5). Factor 1 was also important during the spring bloom in a few years (1998, 1999, 2002 and 2003) that were characterized by low diatom productivity (except for 1999) as well as low or zero S. grethae fluxes (Fig. 5).

\begin{tabular}{ccc}
\hline Factor & \% Total Variance & Cumulative \% \\
\hline 1 & 66,29 & 66,29 \\
2 & 11,46 & 77,75 \\
3 & 5,94 & $\mathbf{8 3 , 6 9}$ \\
\hline
\end{tabular}

Table 1. Variance explained by the three factors obtained in the PCA.

Factor 2: Spring bloom. This factor explains $11.4 \%$ of the total variance and depicts the most productive events in the record (Table 1, Fig. 4). Factor 2 is mainly represented by three species: Skeletonema grethae, Chaetoceros spp. and T. frauenfeldii. The factor scores of these species are 3.8, 1.50 and 1.04, respectively. Skeletonema grethae (average relative contribution $=8.2 \%)$ exhibited its highest pulses during late March $2000\left(3 \times 10^{8}\right.$ valves $\left.\mathrm{m}^{-2} \mathrm{~d}^{-1}\right)$ and early March $1996\left(2.1 \times 10^{8}\right.$ valves $\left.\mathrm{m}^{-2} \mathrm{~d}^{-1}\right)$ (Fig. 5), while those of Chaetoceros spp. (average relative contribution $=1.6 \%)$ occurred during March $2003\left(1.5 \times 10^{7}\right.$ valves $\left.\mathrm{m}^{-2} \mathrm{~d}^{-1}\right)$ and May $2000(1$ $\mathrm{x} 10^{7}$ valves $\mathrm{m}^{-2} \mathrm{~d}^{-1}$ ) (Fig. 5). T. frauenfeldii also contributed to Factor 2 as a component of the diatom spring bloom every year.

Factor 3: Stratification-Oligotrophy. This factor depicts 5.9\% of the total variance (Table 1) and its highest values are reached during periods of strong stratification and oligotrophic conditions, i.e. in summer (Fig. 4). Its three main components are the Chaetoceros RS group, Ditylum brightwellii and Coscinodiscus spp. whose factor scores are 3.61, 0.97 and 0.95, respectively. Chaetoceros RS maximum fluxes were recorded during April-May 2005 (1.3 x 10 $0^{8}$ valves $\mathrm{m}^{-2} \mathrm{~d}^{-}$ $\left.{ }^{1}\right)$ and May $2000\left(1.9 \times 10^{7}\right.$ valves $\left.\mathrm{m}^{-2} \mathrm{~d}^{-1}\right)$ (Fig. 5). D. brightwellii (average relative contribution $=1.5 \%)$ shows two remarkable pulse fluxes in the record: May $2000\left(1.7 \times 10^{7}\right.$ valves $\mathrm{m}^{-2}$ $\mathrm{d}^{-1}$ ) and March 2003 (9.9 x $10^{6}$ valves $\mathrm{m}^{-2} \mathrm{~d}^{-1}$ ) (Fig. 5). Coscinodiscus spp. (average relative 
contribution $=1.3 \%)$ have maximum fluxes during August $1994\left(1.2 \times 10^{6}\right.$ valves $\left.\mathrm{m}^{-2} \mathrm{~d}^{-1}\right)$ and March 2003 (7.3 x $10^{5}$ valves $\left.\mathrm{m}^{-2} \mathrm{~d}^{-1}\right)$ (Fig. 5).

Finally, it is worth noting that despite the weighting of Rhizosolenia spp. their contribution was negligible (Table 2). However, their flux distribution along the record should be taken into account because of their use as stratification indicators (Kemp et al., 2000). Rhizosolenia spp. (average relative contribution $=0.4 \%$ ) show three high flux pulses throughout the record (Fig. 5). The highest pulse was registered during June 1998 (5.8 X $10^{6}$ valves $\left.\mathrm{m}^{-2} \mathrm{~d}^{-1}\right)($ Fig. 5).

\begin{tabular}{lccc}
\hline Species & Factor $\mathbf{1}$ & Factor $\mathbf{2}$ & Factor $\mathbf{3}$ \\
\hline Amphora sp. & 0,63 & $-0,59$ & $-0,87$ \\
Bacteriastrum sp. & $-0,96$ & 0,03 & $-0,06$ \\
Cocconeis spp. & $\mathbf{1 , 1 3}$ & $-0,27$ & $-0,75$ \\
Coscinodiscus spp. & $-0,92$ & $-0,85$ & $\mathbf{0 , 9 5}$ \\
Diploneis bombus & $-0,29$ & $-0,85$ & 0,00 \\
Ditylum brightwellii & $-1,24$ & $-0,30$ & $\mathbf{0 , 9 7}$ \\
Fallacia sp. & $-0,05$ & $-0,78$ & $-0,41$ \\
Hemidiscus cuneiformis & $-0,63$ & $-0,88$ & 0,33 \\
Navicula sp. & 0,62 & $-0,48$ & $-0,94$ \\
Nitzschia bicapitata & 0,00 & 0,37 & $-0,65$ \\
Nitzschia sp. & 0,21 & $-0,25$ & $-0,71$ \\
Nitzschia braarudii & $\mathbf{1 , 5 4}$ & $-0,65$ & $-0,54$ \\
Odontella sp. & $-0,52$ & $-0,09$ & $-0,26$ \\
Psammodictyon panduriforme & $-0,07$ & $-0,21$ & $-0,66$ \\
Rhizosolenia sp. & $-0,53$ & $-0,42$ & $-0,23$ \\
Skeletonema grethae & $-1,16$ & $\mathbf{3 , 5 8}$ & $-0,94$ \\
Thalassionema frauenfeldii & $\mathbf{3 , 0 2}$ & $\mathbf{1 , 5 0}$ & 0,87 \\
T. nitzschoides var. parvum & 0,66 & $-0,23$ & $-0,08$ \\
Thalassiosira lineata & $-0,71$ & $-0,36$ & 0,16 \\
Thalassiosira sp. & $-0,41$ & 0,27 & 0,38 \\
Chaetoceros sp. & $-0,70$ & $\mathbf{1 , 0 4}$ & $-0,17$ \\
Chaetoceros Resting Spores & 0,38 & 0,43 & $\mathbf{3 , 6 1}$ \\
\hline
\end{tabular}

Table 2. Factor scores obtained by the PCA (including a Varimax normalized rotation) of the 22 most abundant diatom species. Bold values indicate the species which define each factor.

\subsection{DISCUSSION}

\subsubsection{Sources and preservation of trap-collected phytoplankton in the Planier Canyon}

One of the first problems we had to face when we approached this study was how to discern the origin of the material recorded at the Planier site, at the entrance of the GoL with respect to the general cyclonic circulation. Due to the location of the sediment trap above the axis of a submarine canyon and the complex hydrodynamic small- and mesoscale pattern of the GoL, the trapped material could have come from different sources: Rhône river plume material, 


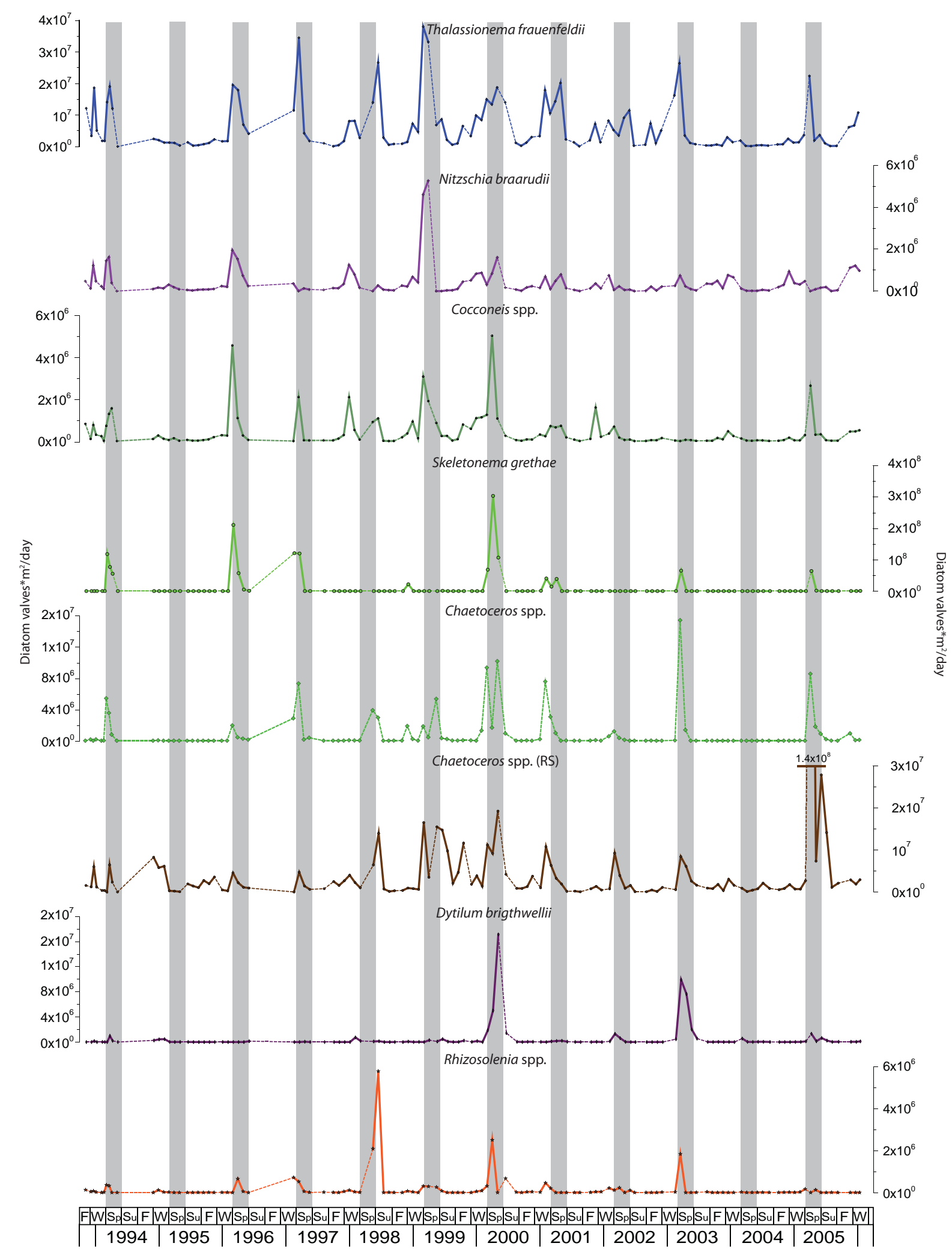

Figure 5. Valve fluxes (valves $\mathrm{m}^{-2} \mathrm{~d}^{-1}$ ) of the main diatom species throughout the Planier record. 
resuspended sediments from the continental shelf or upper slope, and biogenic material as either in-situ production from the upper part of the water column or laterally advected from the shelf or surrounding areas. Despite the range of possibilities, some of them can be ruled out based on previous investigations in the GoL. Firstly, the 500 mab Planier sediment trap is considered the most marine site and the one that experiences the minimum influence of particle inputs from the shelf of all the GoL key sampling points studied by Heussner et al. (2006). Second, the experimental site in the Planier Canyon is probably less influenced if not completely free of influence by input of suspended particulate matter from the Rhône River located in the West, as pointed out by Durrieu de Madron et al. (1990) for the adjacent Marseille canyon (Fig. 1). This idea is supported by the negligible fluxes of chrysophytes and fresh-water diatoms found in our trap. Moreover, the former authors described almost no nephelometric structures at midslope in the same canyon during fall. Nevertheless, previous studies have shown that the annual total mass flux maxima recorded every year during the winter-spring transition at mid-depth in the GoL submarine canyons are probably largely related to lateral advection of suspended sediments from the shelf and the upper slope due to the intense physical processes that occur during this period (Durrieu de Madron et al., 1999; Heussner et al., 2006; Monaco et al., 1999). The main component of this total mass flux peak is lithogenic material, while the biogenic contribution represents only a small fraction (Fig. 2 and Heussner et al., 2006). Therefore, the registered phytoplankton skeletons could be of diverse origin: biogenic particles settling from the overlying water masses or advected from adjacent areas, as well as biogenic resuspended particles temporarily deposited on the shelf or upper slope. However several evidences suggest that the biogenic fraction recorded by Planier sediment trap is a general reflection of the phytoplankton communities of the photic zone in the GoL: (1) the relatively good correlation between satellite chlorophyll- $a$ concentration and coccolith and diatom fluxes (2) the classical Mediterranean diatom species succession reflected in the PCA analysis and in the average year (Rigual-Hernández et al. submitted); (3) the high abundances and good preservation in the trap samples of weakly-silicified and bloom-forming diatoms (e.g. Chaetoceros spp. or Skeletonema grethae) that are not found in core-tops of the GoL continental shelf (RigualHernández, unpublished data) and (4) the low fluxes of benthic diatoms and foraminifera. All these evidences suggest that the biogenic flux mainly reflects changes in the phytoplankton assemblages of surface waters from this region of the GoL although we do not completely understand the processes that drive particle transfer to the bottom. Part of the biogenic particles recorded in the trap can be advected from neighbor areas. Maximum biogenic setting during spring may have been favoured by the more intense processes of shelf-basin particle transfer at that time.

SST (Fig. 2) is a rough indicator of the stratification of the water column (Martinez et al., 2009). In the GoL, the SST reflects the classic annual cycle of a temperate sea: a summer season characterized by strong stratification and oligotrophic conditions, a winter season with strong water mixing and nutrient injection into the photic zone and two transitional periods 
of semimixing conditions during autumn and spring. Seasonal and interannual variability of the diatom, coccolith and chlorophyll- $a$ fluxes at the Planier site mirrored the water column and atmospheric dynamics in the NW Mediterranean. Maxima of annual chlorophyll-a concentration always occurred during spring (Fig. 2) indicating the predominance of the spring phytoplankton bloom. The significant correlation values between coccolith and diatom fluxes and chlorophyll- $a$ corroborates previous studies that described the Prymnesiophytes (that include the coccolithophores) and the Bacillariophytes (diatoms) as the main contributors to the chlorophyll-a production in the NW Mediterranean (Barlow et al., 1997; Bustillos-Guzmán et al., 1995; Leblanc et al., 2003; Marty et al., 2002).

Regarding the preservation of the siliceous phytoplankton, it varied throughout the record, especially from the end of spring until mid-autumn when Si is scarce in the photic zone (Leblanc et al., 2003). In contrast, during winter and the first stages of the spring bloom, the concentration of dissolved Si is relatively high in the water column (Leblanc et al., 2003). Furthermore, longterm studies on photosynthetic pigments in the NW Mediterranean (Marty et al., 2002) described fluctuations of interannual fucoxanthin concentrations (a pigment characteristic of the diatoms) that are similar to those observed in our diatom valve fluxes. This suggests that the fluxes recorded in the Planier sediment trap reflected the size and composition of the assemblage of the diatom populations in the photic zone, at least during the most productive periods, i.e. winterspring season. Nevertheless, it should be taken into account that, as a general estimation, at $500 \mathrm{~m}$ depth the recorded diatom frustules are expected to be ca. $5 \%$ of the original assemblage (Tréguer et al., 1995). On the other hand, coccolith dissolution can be considered as negligible in the samples due to (1) the saturation of calcite and aragonite in western Mediterranean waters (Millero et al., 1979; Schneider et al., 2007) and (2) the good preservation of the coccoliths in the Scanning Electronic Microscope (Heussner et al., 2006).

\subsubsection{Seasonal siliceous and calcareous phytoplankton flux variability}

The three factors obtained from the PCA reflect the main differences in the water column conditions throughout the record. In this sense, Factor 1 "Mesotrophy" depicts periods of medium to elevated turbulence of the water column and relatively weak solar forcing characterized by moderate primary productivity (Fig. 2 and 4), i.e. autumn and winter. Its main component, Thalassionema frauenfeldii (Fig. 4 and 5), is considered as a tropical/subtropical to warmtemperate diatom (Hasle, 2001; Simonsen, 1974) that seems to be well adapted to a wide range of environmental conditions owing to its ubiquity in the samples. This corroborates previous studies that have described this species as perennial in the NW Mediterranean. Concerning Cocconeis spp., they live attached to different substrata (from plants to rocks) (Round et al., 1990) and therefore, their flux maxima during autumn and winter could be related to the capture of material from relatively shallow areas of the continental shelf. However, the similar annual distribution pattern of Cocconeis spp. with some planktonic diatoms indicates that it could also live attached to pelagic organisms. The third most important component of Factor 1 is 
$N$. braarudii that has been described as an open ocean planktonic species that can be found in warm to temperate waters (Tomas, 1997).

Despite the increasing trend in the nutrient supply during the autumn-winter period, the diatom fluxes only exhibited a moderate increase probably due to the gradual decline of the solar radiation and the intense winter convection. In contrast, coccolithophores seem to respond better to these conditions (Fig. 2 and 3). Their low nutrient concentration requirements (Brand, 1994) and the absence of diatom competition are likely to be the cause of the relatively high coccolith fluxes during this period. This so-called "coccolithophore fall-winter bloom" has already been observed in other parts of the Mediterranean such as the Alboran Sea (Bárcena et al., 2004; Hernández-Almeida et al., submitted). During February, the mixing of the water column reaches its maximum intensity (Marty et al., 2002), which is reflected by a drop in the coccolith and diatom fluxes probably caused by their redistribution to deeper waters .

Factor 2 or Factor "-Spring Bloom" depicts the most productive intervals of the record (except spring 1999) that always take place during the end of winter and spring (Fig. 2 and 3), i.e. spring bloom. Skeletonema grethae and Chaetoceros spp. are typical components of coastal Mediterranean waters (Castellví, 1971; Margalef, 1974, 1978; Ribera D’Alcalà et al., 2004) and are known to grow fast under high-nutrient and relatively turbulent conditions (Egge and Jacobsen, 1997; Margalef, 1978; Smetacek, 1999). Diatoms are especially well adapted to the spring conditions when two-thirds of their annual fluxes are recorded (Fig. 3). Moreover, coccolith fluxes exhibit their annual maximum at this time although their response is often smoother than that of diatoms.

Regarding Factor 3, its maximum values are reached during summer, a period characterized by a strong stratification and oligotrophic conditions. Hence, this factor was named "StratificationOligotrophy". Its most representative component is the resting spores of the subgenus Hyalochaete (genus Chaetoceros) that are formed as a survival strategy when nutrients are depleted in the upper water column (McQuoid and Hobson, 1996). The resting spores sink to deeper waters and remain there until convective mixing of the water column brings them back to the euphotic layer where they can bloom again. The other two relevant contributors to this factor are Ditylum brightwellii and Coscinodiscus spp. that are typical components of oligotrophic and stratified waters. Ditylum brightwellii is a characteristic diatom of coastal waters (Round et al., 1990) with weakly silicified valves and large vacuoles (Margalef, 1978; Smetacek, 1999) that allow them to survive when nutrients are scarce. Coscinodiscus spp. have been defined as a component of the "shade flora", i.e. the flora that dwells at depth under low-light and stratification conditions and grows slower than those diatoms characteristic of the spring bloom (Kemp et al., 2000). From summer to approximately mid-autumn, the low chlorophyll- $a$ values and diatom and coccolith fluxes are due to the stratification and oligotrophic conditions of the euphotic layer. 


\subsubsection{Wind-driven interannual fluctuations of the diatom and coccolith fluxes}

It is widely accepted that the seasonal establishment of the thermocline, in combination with the increasing solar radiation in spring, is a prerequisite for the development of a diatom bloom in shelf and open ocean environments (Townsend et al., 1994). Diatoms are considered as an opportunistic group that usually grow in the first stages of a phytoplankton succession (Margalef, 1974). Due to faster growth rates and higher nutrient uptake rates (Fogg, 1991) diatoms can outcompete the other phytoplankton in a relatively turbulent, nutrient-rich environment. The latter conditions regularly occur in the GoL during the winter-spring season, when strong wind events are often followed by periods of low intensity winds and intense solar radiation (Fig. 2) (Leblanc et al., 2005). Since the increase in solar radiation from winter to spring is rather constant throughout the record (Fig. 2), the turbulence of the water column at this time seems to be decisive for the composition and size of the spring bloom. In this sense, diatom blooms seem to be favored by (1) strong and cold winds during the winter season that replenish the photic zone with nutrients, and (2) low wind stress during the outset of the radiation intensification (March). Good examples of this situation are the spring blooms of 1997, 1999, 2000, 2001, 2003 and 2005 when high wind stress during winter (Fig. 2) fertilized the photic zone. In addition, for the years 1997, 2000, 2003 and 2005, the beginning of the spring period was coupled with weak winds which provoked a decrease in the turbulence optimizing the conditions for the development of massive diatom growth (Fig. 2). Regarding 1999 and 2001 some nuances should be taken into account: the 1999 spring bloom took place during a relatively calm period between two strong wind events (Fig. 2). It is probable that the second wind episode inhibited the development of a stronger bloom due to the redistribution of the diatom population to deeper waters. Something similar might have occurred in 2001 when a early diatom bloom at the end of the winter was hampered by a wind episode that led to vertical convective mixing, shaping the spring diatom fluxes that year into a bimodal distribution. Moreover, the remarkable chlorophyll- $a$ maximum that year (six times the average), the highest of the whole record. Diatom and coccolith fluxes were not higher than other years, therefore, the massive growth of other phytoplankton groups such as naked nanoflagellates and/or an incursion of the Rhone plume over the study area could have been the cause of these high values.

In contrast, the spring bloom of years with a weaker winter mixing and/or intense wind stress at the beginning of the radiation increase are prone to be less productive as seen by the dominance of the diatom assemblage from Factor 1 and the lower diatom fluxes. This scenario occurred in 1998, 2002 and 2004 when there was no spring diatom bloom. In this sense, the winter SST of 1998 was the highest of the whole record while the wind speed anomaly was low (Fig. 2). The latter factors might have caused the delay of the maximum chlorophyll-a concentration till April, the low diatom fluxes and the change of the diatom assemblage composition (see section 5.5). Something similar occurred in the winter-spring period of 2004 when, the high SST recorded the previous summer may have induced a stronger winter stratification, and hence a weaker spring diatom bloom owing to the more limited nutrient supply. However, a gap in 
the time series at the end of winter could be hiding an early diatom bloom. Regarding 2002, no diatom bloom was recorded probably due to the low winds during winter and the high wind stress during the beginning of spring.

In the latter scenarios, other phytoplankton groups may have taken advantage over the diatoms. Nanoflagellates are good candidates due to their ubiquity and adaptability, irrespective of the water mass conditions, and they exhibit high species diversity (Bustillos-Guzmán et al., 1995; Liu et al., 2009). Nanoflagellates could compete for the nutrients more efficiently than diatoms during (1) years with mild winters and/or (2) years when at the time of the solar radiation increase the turbulence is still high due to strong wind stress (Bustillos-Guzmán et al., 1995). In these two situations, nanoflagellates could consume an important part of the nutrient stock before the adequate light and stratification conditions favour diatom growth. Since wind data were unavailable until summer 1996, it would be too risky to interpret these results without this key piece of information.

Coccolith fluxes showed a more stable interannual pattern than diatoms. Coccolithophores probably are a notable contributor to the primary productivity during autumn and spring blooms (Fig. 2 and 3), as well as an important fraction of the nanoflagellate assemblage in the NW Mediterranean. However, the nature of our study does not allow us to quantify their total contribution to the nanoflagellate populations. Furthermore, during two of the three years with the highest coccolith fluxes, i.e. 1995 and 2004, no diatom bloom was recorded. From this, one may speculate that either coccolithophores took the advantage in those years preventing diatom proliferation or, the inhibition of diatom growth was caused by other factors that may have enhanced the coccolithophore development by the absence of diatom competitors for nutrients. However, other factors such as selective grazing or competition by other phytoplankton groups may have played an important role in the interannual variability of the diatom and coccolith fluxes. Additionally, it is worth noting that the coccolith maximum in autumn is recurrent every year in our time series (Fig. 2). This phenomenon has already been observed in other parts of the western Mediterranean such as the Alboran Sea (Bárcena et al., 2004; Hernández-Almeida et al., 2010). Coccolithophores seem to proliferate well under autumn semi-mixing conditions in the Mediterranean when nutrients are still relatively scarce and the solar radiation is high. In contrast, diatom growth during this period seems to be limited by the lower turbulence and the silica-poor environment.

Finally, it is worth noting that during the coldest and windy winters of the record (1998-99 and 2004-05) intense Dense Shelf Water Cascading (DSWC) events were recorded in the GoL (Canals et al., 2006). The DSWC formation was synchronous with high biological production levels in shelf waters (Canals et al., 2006), as well as, with relatively high diatom and coccolith fluxes in Planier sediment trap (Fig. 2). The stronger water mixing and the consequent increase in nutrient supply and the enhanced vertical transport by the cascading waters are likely to be the main factors controlling the higher phytoplankton remain fluxes. 


\subsubsection{Impact of NAO and ENSO variability on phytoplankton skeletons fluxes}

Most of the variability in the flux of phytoplankton skeletons in the Gulf of Lions is linked to the annual period. Nevertheless, they also exhibit an evident interannual variability, especially for diatom fluxes (Fig. 2). Phenomena with longer-than-annual periodicities affecting the NW Mediterranean should be considered as possible sources of interannual variability. In this sense, the North Atlantic Oscillation (NAO) and El Niño Southern Oscillation (ENSO) are the most suitable candidates (Fig. 6).

NAO is the most prominent and recurrent pattern of atmospheric variability over the middle and high latitudes of the Northern Hemisphere (Hurrell et al., 2003). Its effects over the European continent and the Mediterranean Sea are stronger during the boreal cold season (Hurrell, 1995). The winter state of the NAO (Fig. 6) influences the climate and the oceanic circulation of the Northern Basin (Ligurian-Provençal Basin and Gulf of Lions) (Vignudelli et al., 1999). Positive NAO winter values are coupled with warm and moist air masses conveyed towards the Northern Basin, leading to mild winters and relatively low heat loss from the sea to the atmosphere. In contrast, negative values involve colder and drier winds blowing over the northwestern Mediterranean that increase the evaporation and heat loss rates of the water column. As a result of this, the water transport through the Corsica Channel increases, enhancing the flow of the Northern Current (Vignudelli et al., 1999). Gómez and Gorsky (2003) pointed out that the state of the winter NAO could have a direct effect over the composition and magnitude of the spring bloom in the Northern Basin since historical data showed that low or negative NAO winter values were usually coupled with strong diatom spring blooms while positive values were often associated with weaker ones.

In our time series, the years 2001 and 2006 recorded the most negative NAO winter values since the beginning of the chlorophyll- $a$ record (1997) (Fig. 6) and were coupled with notable chlorophyll- $a$ spring maxima (Fig.2). Regarding the diatom fluxes, only the years with the most extreme NAO winter values followed the hypothesis proposed by Gómez and Gorsky (2003). During 1996, the NAO index showed the most negative values of the record at a time when high diatom valve fluxes were recorded (Fig. 6). During 1995, the NAO winter index exhibited its highest values when no spring diatom bloom was observed. However, for the rest of the years this relationship was not straightforward. Therefore, although the intensity of the phytoplankton spring bloom in the Northern Basin may be affected by the winter state of the $\mathrm{NAO}$, the diatom fluxes were not controlled by the NAO.

Regarding ENSO, its major influence occurs over the Southern Hemisphere, though extreme ENSO events may affect the North Atlantic and European climate (Wanner et al., 1997). According to McPhaden (1999), the 1997-98 El Niño Event (Fig. 6) was the strongest one of the last century and the former author suggested that the major climatic impacts around the world were related to this event. In the western Mediterranean, Bárcena et al. (2004) and HernándezAlmeida (submitted) observed anomalous 1997 high summer and autumn SST and weak wind stress in the Alboran Sea that delayed the 1997-98 winter mixing and consequently decreased 
the winter-spring bloom intensity. In the GoL, the changes in environmental conditions were rather similar to those of the Alboran Sea: low wind regime and the relatively high summer, autumn and winter SSTs. This seems to be a direct cause of the lower diatom productivity during that year. In addition, it is worth noting an important change in the diatom assemblage: the highest fluxes of the whole record of Rhizosolenia spp. were recorded at the end of spring and the beginning of summer 1998 (Fig. 5). Rhizosolenia spp. have been described as "shade flora species" that dwell between the euphotic zone and the nutricline during periods of water column stratification owing to their ability to regulate their buoyancy and to their symbiosis with nitrogen-fixing cyanobacteria (Kemp et al., 2000; Villareal et al., 1993). In this sense, Rhizosolenia spp. are good indicators of the stronger stratification conditions that year. However, it should be taken into account that a gap in the time series at the beginning of the spring 1998 (Fig. 2 and 5) could hide part of the spring bloom record.

Furthermore, the 2003 summer heat wave over the Western Mediterranean Basin has been pointed out as a cause of phytoplankton variability in the GoL (Rigual-Hernández et al., 2010). The 2003 summer heat wave was coupled with an increase in air temperature and a decrease in wind stress that affected SST over the Western Basin (Olita et al., 2007). The Planier SST time series (Fig. 2) recorded the highest SST of the whole record that summer, which probably contributed to a reduction in the spring chlorophyll- $a$ concentration and diatom fluxes (Fig. 2) due to weaker winter mixing.

Finally, episodic or "unusual" events should be considered as a source of variability. Unpredictable high flux pulses could have important repercussions on ecosystems (Deuser, 1996). This could be the case of the high diatom pulse recorded during the winter-spring transition of year 2000 . These unusual high fluxes were also recorded by (Leblanc et al., 2005) at the nearby SOFI shelf site (Fig. 1) at $56 \mathrm{~m}$ and $142 \mathrm{~m}$ and were attributed to two possible phenomena: strong lateral advection of fresh pelagic material from the continental shelf or an early bloom. In our study, high fluxes of all the main diatom species were recorded during two or three months (Fig. 5), which rules out the possibility of a transient input of pelagic material of continental shelf origin. However, the unusual pronounced fluxes of Ditylum brightwellii, which has been described as a neritic species that rarely form large populations (Round et al., 1990), suggest that the diatom assemblage could have been transported from the continental shelf and developed afterwards over the study area. 

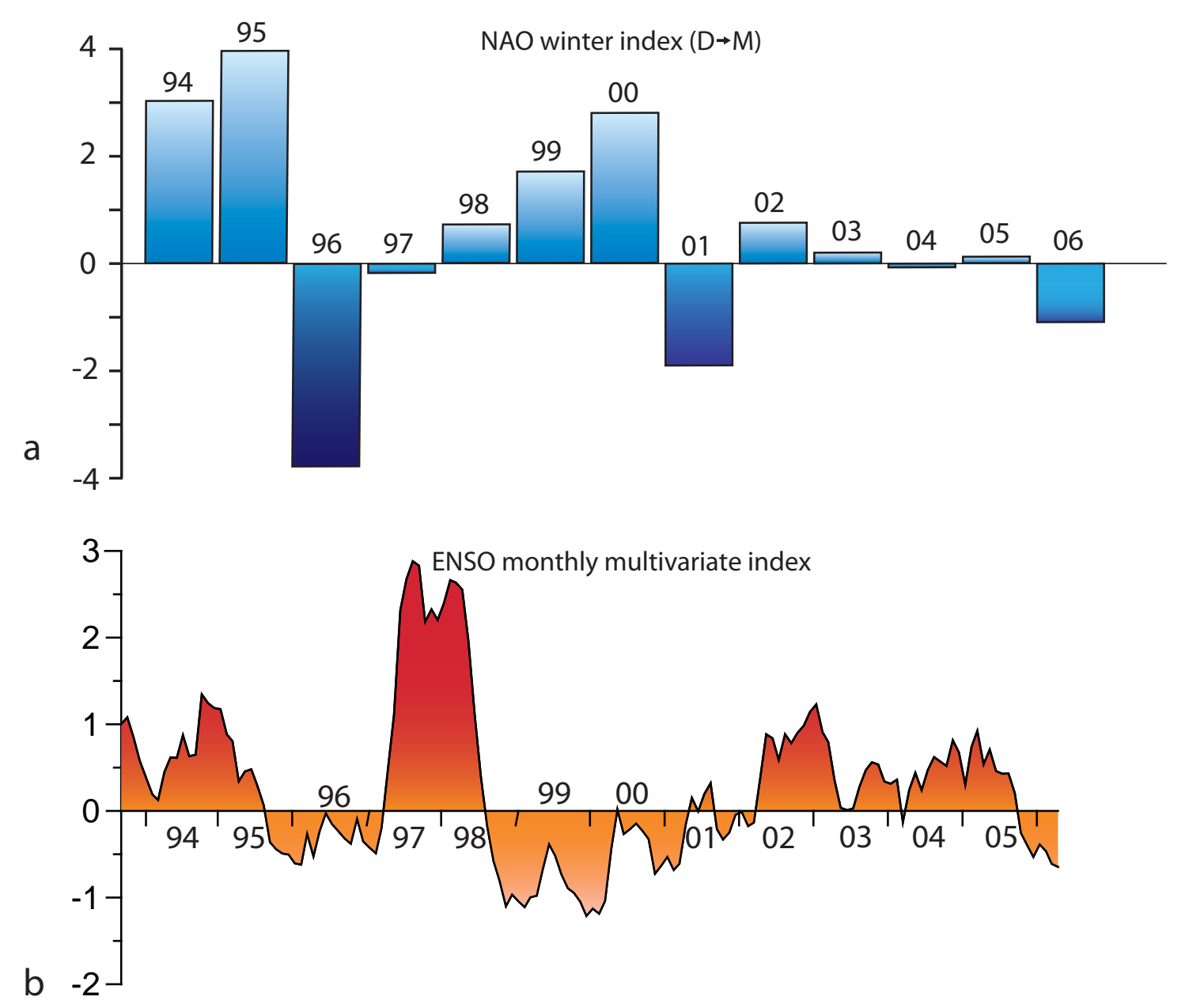

Diatom flux and chlorophyll-a concentration

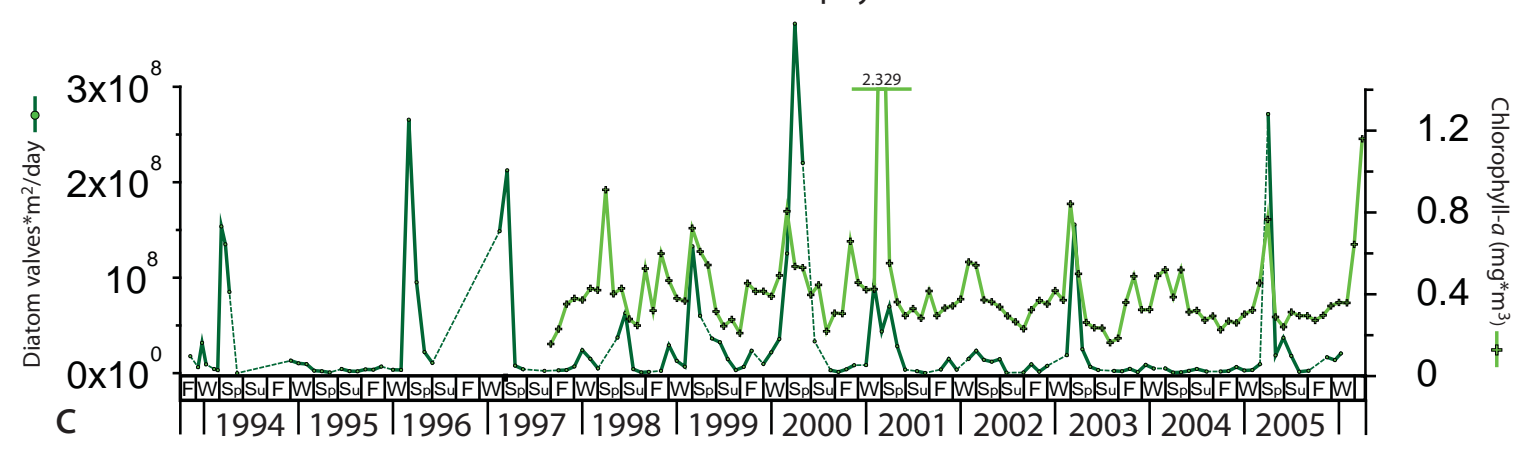

Figure 6. a. NAO Winter index. b. monthly multivariate ENSO index. c. Planier station total diatom flux (valves $\left.\mathrm{m}^{-2} \mathrm{~d}^{-1}\right)$ and chlorophyll- $a$ concentration $\left(\mathrm{mg} \mathrm{m}^{-3}\right)$.

\subsection{CONCLUSIONS}

The main objective of our study was to document the seasonal to interannual variability in the export of diatoms and coccoliths in the Gulf of Lions (northwestern Mediterranean). To examine this issue we studied a 12-year sediment trap record from October 1993 through January 2006. The main conclusions are summarized as follows: 
- Diatoms were the most important contributor to the opal productivity while coccoliths together with planktonic foraminifera mainly integrated the biogenic calcareous fraction. Previous studies in the NW Mediterranean together with the good correlation between the chlorophyll- $a$ and the phytoplankton skeleton fluxes suggest that diatoms and coccolithophores are the main components of the mineralized test-bearing phytoplankton communities in the Gulf of Lions.

- Diatom and coccolith fluxes mirrored the atmospheric and water column dynamics. Their fluxes were maxima during the winter-spring transition, coinciding with the spring phytoplankton bloom, while their minima occurred during summer in response to the oligotrophic and stratified waters. The main diatom species were grouped in three factors that depicted the main conditions of the water column throughout the record: mesotrophy, spring bloom and stratification-oligotrophy.

- The development of the strongest spring diatom blooms in the record occurred during those years with intense and cold winds during winter and low wind stress during the beginning of the spring period. In contrast, the coccolith downward fluxes seem to be favored by weak winter mixing and/or intense wind stress at the beginning of spring (i.e. March).

- Diatom and coccolith fluxes did not show a straightforward relationship with the NAO winter index. However, the strong 1997-1998 ENSO event and the 2003 summer heat wave seem to have been the cause of the low phytoplankton skeleton fluxes of the spring season of the following year, due to the higher winter temperatures and the delay of the spring phytoplankton bloom. 


\subsection{OTHER CONSIDERATIONS}

\section{Biological and physical processes that control the particle flux*.}

One of the most outstanding results of this study was the recurrent coupling between the annual oscillations in the flux of total mass with those of coccolithophores and diatoms and the seasonal changes in chlorophyll-a concentration in the water column throughout the record (Fig. 2 and Table 1). Especially enigmatic is the high correlation between the annual variations of the lithogenic flux with those of biogenic particles (Table 1), such as organic carbon, coccoliths or diatom valves when the source of these types of particles is completely different. In Gulf of Lions, the main sources of lithogenic particles to the water column are the river discharge and sediment resuspension. Because the maximum intensity of the latter processes usually occurs during fall-winter season (Heussner et al., 2006), we should expect maximum lithogenic fluxes during that season. However, this is not the case as the highest lithogenic fluxes coincide with the maximum biogenic fluxes in spring. Similar behaviors between changes in primary productivity and fluctuations of the bulk constituents have already been observed in the Gulf of Lions (Miquel et al., 1994) and Alboran Sea (Bárcena et al., 2004), as well as, in other parts of the Earth (e.g. Deuser et al., 1983;Jickells et al., 1996; Waniek et al., 2005;Loncaric et al., 2007) and seems to be driven by the seasonal cycle of nutrients and phytoplankton growth and decay. Previous studies in the Gulf of Lions (Leblanc et al., 2005) showed up that the bulk of biogenic silica and organic matter is transfer to depth in association with diatoms during the spring bloom. However the latter facts do not explain the coupling between primary productivity and lithogenic fluxes. Moreover, it is worth noting that, regardless the composition of the phytoplankton bloom, the total mass fluxes and the spring bloom were always synchronous (Fig. 2) (e.g. while during the 2000 spring bloom the phytoplankton fluxes were dominated by diatoms, during 2002 they were mainly composed by coccolithophores).

We suggest that the coupling between the maximum primary productivity and the greatest particle flux to the ocean interior is driven by particle concentration in the water column, that is the number of particles per volume of water. A higher particle concentration triggers the rate of aggregate (marine snow) formation that led to a faster rate of particle sedimentation due to the higher density of these aggregates. A better knowledge of the processes that regulate the vertical particle transport is crucial to understand the mechanisms of export production and the Mediterranean role on atmospheric CO2 capture. One of the pathways for the marine snow formation is the collision and subsequent attachment of small particles present in the water column. These aggregates or "marine snowflakes" reflect the different types and relative abundances of the particles available in the water column, from diatoms to fecal pellets (Alldredge and Gotschalk, 1990). Moreover, bloom diatoms are known to form "sticky" mucous aggregates that scavenge mineral and other particles during descent increasing their sinking rates of $\sim 100 \mathrm{~m} \mathrm{~d}-1$ or more (Smetacek, 1985). Hence, during the fall-winter and spring blooms, the diatom and coccolithophore massive growth (as well as the development of 
other phytoplankton groups) would increase the particle concentration in the photic zone which would favor the formation of aggregates by coagulation of the particles suspended in the water column. These flocs largely increment the sinking rates of their components alone (50-100 m day-1; Shanks and Trent, 1980;Alldredge and Gotschalk, 1990) and could be the cause of the coupling between lithogenic mass fluxes and primary productivity registered in our sediment trap. A second possibility would be the formation of aggregates mediated by zooplankton, i.e. fecal pellets. However, it would require organisms capable of efficiently filtering large volumes of water, such as the salps that can retain even the finest particles contained in the water column and packed them into large fecal pellets (Deuser et al., 1983). Previous studies in the NW Mediterranean (Marty et al., 1994) described the absence of salps pellets at 200m depth, and estimated the contribution of zooplankton fecal pellets to the particle flux up to $10 \%$ in summer and $30 \%$ in spring. Therefore, although fecal pellets may partially contribute to the particle transport to depth, the evidence suggests that the main phenomenon controlling the vertical flux during periods of high primary productivity is the formation of aggregates (= marine snow) triggered by saturation of the euphotic layer by phytoplankton.

Regarding the annual secondary particle flux pulse, often registered during the fall-winter season (Fig. 2), it seems to be induced by the strong deep water convection as well as the development of the coccolithophore fall-winter bloom and the high input of lithogenic material by river discharge.

*Not included in the submitted manuscript. 


\section{Acknowledgments}

The authors wish to thank Nicole Delsaut for her help in the preparation of the material supplied. Xavier Durrieu de Madron is greatly acknowledged for his assistance. The authors wish to thank A. Cortina that kindly assisted in statistical analyses and to J. A. García Rodríguez and J. Madrigal González for their constructive comments. The chlorophyll- $a$ data used in this paper were produced with the Giovanni online data system, developed and maintained by the NASA GES DISC. Global solar radiation data was provided by the AEMET (Agencia Española de Meteorología). This study has been performed thanks to funding from the Ministerio de Ciencia e Innovación Project GRACCIE (PROGRAMA CONSOLIDER-INGENIO 2010-CSD 2007-00067), CGL 2006-10593, CGL 2008-05560 and CGL 2009-08651 and the support from Junta de Castilla y León (Grupo GR34) and a MEC FPU grant awarded to Andrés S. RigualHernández (AP2006-01992). 



\section{Capítulo 8}

Seasonal to interannual variability and geographic distribution of the silicoflagellate fluxes in the Western Mediterranean

Rigual Hernández, S.A., Bárcena, M.A., Sierro, F.J., Flores, J.A., Hernández-Almeida, I., Sanchez-Vidal, A., Palanques, A. and Heussner, S.

Marine Micropaleontology 77: 46-57, 2010

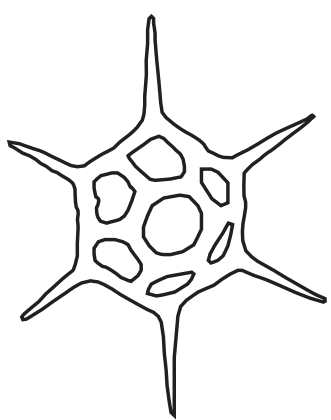





\section{Seasonal to interannual variability and geographic distribution of the silicoflagellate fluxes in the Western Mediterranean.}

Andrés S. Rigual-Hernández ${ }^{1, *}$, María A. Bárcena ${ }^{1}$, Francisco J. Sierro ${ }^{1}$, José A. Flores ${ }^{1}$, Iván Hernández-Almeida ${ }^{1}$, Anna Sanchez-Vidal ${ }^{2}$, Albert Palanques $^{3}$ and S. Heussner ${ }^{4}$.

1. Área de Paleontología, Departamento de Geología, Universidad de Salamanca, 37008 Salamanca, Spain.

2. GRC Geociènces Marines. Departament d'Estratigrafia, Paleontologia i Geociències Marines, Universitat de Barcelona, 08028 Barcelona, Spain.

3. Institut de Ciències del Mar, CSIC, Passeig Marítim de la Barceloneta, 37-49, Barcelona E08003, Spain.

4. CEFREM, UMR 5110 CNRS- University of Perpignan Via Domitia, 52 avenue Paul Alduy, 66860 Perpignan Cedex, France.

\section{ABSTRACT}

A total of 337 samples collected from five sediment traps located in the Gulf of Lions, Catalan margin and the Alboran Sea have been analyzed in order to study the seasonal, interannual and geographical distribution of silicoflagellate fluxes in the Western Mediterranean. As a general trend, maximum fluxes of silicoflagellate skeletons always occurred during the spring bloom; i.e. during the winter-spring transition, while minimum fluxes were recorded during summer, characterized by a strong stratification and oligotrophic conditions. However, the sediment trap record of the Catalan margin did not exhibit any clear seasonal signal, probably owing to the fertilizing effect of the rivers Llobregat and Besos. Regarding interannual variability, no clear relationship between the NAO (North Atlantic Oscillation) and the silicoflagellate fluxes was found. In contrast, the silicoflagellate assemblages from the Alboran Sea and the Gulf of Lions responded with low fluxes and a delay in their annual maximum to the anomalous conditions elicited by the 1997-98 El Niño Event. Furthermore, the 2003 summer heat wave over the Western Mediterranean had similar repercussions on the silicoflagellate spring maximum 2004 in the Gulf of Lions. Three silicoflagellate species were identified in the samples, following the taxonomic concepts of Throndsen (1997): Dictyocha fibula (Ehrenberg), Dictyocha speculum (Ehrenberg) and Octactis octonaria (Ehrenberg) Hovasse 1946. D. fibula was cosmopolitan and the dominant species at all sites, always accounting for more than $80 \%$. Moreover, its maximum fluxes were recorded in those sampling sites which were under the influence of high nutrient concentrations caused by the river input. D. speculum was only recorded in the northern locations, which suggests an affinity for colder water masses. In contrast, O. octonaria was restricted to the Alboran Sea stations, where temperatures reached the highest values and nutrients were scarcer.

Key words: silicoflagellates, sediment trap, Western Mediterranean, NAO, ENSO. 


\subsection{INTRODUCTION}

The silicoflagellates are a group of marine photosynthetic flagellates with a cosmopolitan distribution. They occur in all ocean environments but have a small contribution to the phytoplankton communities. Despite this, they can be a major component in coastal and estuarine waters (e.g. Jochem and Babenerd, 1989; Gómez and Gorsky, 2003). Silicoflagellates are generally considered as photosynthetic algae, however they have also been suggested to have mixotrophic behavior (Martini, 1977) and/or to contain symbiotic blue-green algae (Norris, 1967). Owing to their siliceous skeleton, silicoflagellates can be preserved in the sediment. Nevertheless, naked forms have also been described (Jochem and Babenerd, 1989; Moestrup and Thomsen, 1990; Henriksen et al., 1993). The taxonomy of this group has been based on the morphology of the siliceous skeleton of its representatives. However, as pointed out by Onodera and Takahashi (2005) this classification is in state of confusion due to its broad morphological variations in relation to environmental conditions (Van Valkenburg and Norris, 1970; Van Valkenburg, 1971a and 1971b). The most recent literature (Throndsen, 1997) reports eight extant species grouped in three genera: Dictyocha Ehrenberg 1837, Octactis Schiller 1925 and Mesocena Ehrenberg 1843.

Traditionally, silicoflagellates have been used for biostratigraphic studies, mainly in high-latitude areas, where calcareous micro- and nannofossils are missing or not diagnostic (Perch-Nielsen, 1985). Additionally, they have been used as proxies for paleotemperature reconstructions across a wide range of latitudes in both hemispheres (Mandra and Mandra, 1970; Ciesielski and Weaver, 1974; Martini, 1977; Bukry, 1983; Schrader et al., 1986; Ciesielski and Case, 1989). The ratio between the "warm" genus Dictyocha spp. and the "cold" species Dictyocha speculum (synonymous with six-sided Distephanus) has been used to infer paleo-SST (Ciesielski and Weaver, 1974; Perch-Nielsen, 1985; Whitehead and Bohaty, 2003; Escutia et al., 2009). Silicoflagellates have also been suggested to be indicators of atmospheric and water mass variations e.g. studies on sediment traps registered changes in silicoflagellate fluxes in relation with El Niño events (Lange et al., 1997; Romero et al., 2001; Onodera and Takahashi, 2005), and as productivity indicators (e.g. Takahashi et al., 1989). Moreover, laboratory cultures of living silicoflagellates have shown that their growth rates are strongly influenced by environmental conditions, especially by temperature and salinity (Henriksen et al., 1993). Few authors have addressed the extant species of this cryptic group, however, some work has been done in our study area: the Western Mediterranean. Nival (1965) and Travers and Travers (1968) have described the seasonal distribution of silicoflagellates in Villefranche-sur-mer and the Gulf of Marseille respectively.

In this work, an array of five sediment traps set in three key areas (Fig. 1) of the Western Mediterranean was studied in order to record silicoflagellate information from different representative environments:

- Two sites in the Gulf of Lions (Fig. 1a): the Planier canyon station, considered as an 
oceanic station with lower influence of shelf-slope exchanges of particulate matter; and the Lacaze-Duthiers canyon station, with a higher input of particulate matter resuspended from the shelf and upper slope and affected by the fertilizing effect of the Rhône river plume.

- A third trap in the Foix canyon on the Catalan margin (Fig. 1b), characterised by sporadic inputs of particulate matter resuspended from the shelf and/or discharged by the Llobregat and Besos rivers.

- Two open-sea sediment traps set within the influence of the two quasi-permanent anticyclonic gyres of the Alboran Sea (Fig. 1c).

In this sense, the present study attempts to complement current knowledge of the ecology and present distribution of silicoflagellates in the Western Mediterranean. Thus, the main objectives of this study were:

(1) To define the geographical distribution of the group;

(2) To characterize the annual and interannual variations of the silicoflagellate assemblages and their relationship with environmental conditions;

(3) To integrate the data recorded in the sediment traps in further paleoceanographic constructions.

\subsection{OCEANOGRAPHIC SETTING}

The Mediterranean Sea is a semi-enclosed basin that behaves as an antiestuarine circulation system: the surface waters enter through the Strait of Gibraltar from the Atlantic while deeper Mediterranean waters leave the basin (Bormans et al., 1986). The driving force of the general circulation has a thermohaline origin due to an excess of evaporation over precipitation and is controlled by the exchange of water through the Strait of Gibraltar.

The Mediterranean Sea is considered to be oligotrophic, however the Western Basin shows a number of hydrographic features that contribute to increasing its potential fertility (Estrada, 1996).

Here, three areas of the Western Mediterranean were considered; the Gulf of Lions, the Catalan margin, and the Alboran Sea (Fig. 1). 

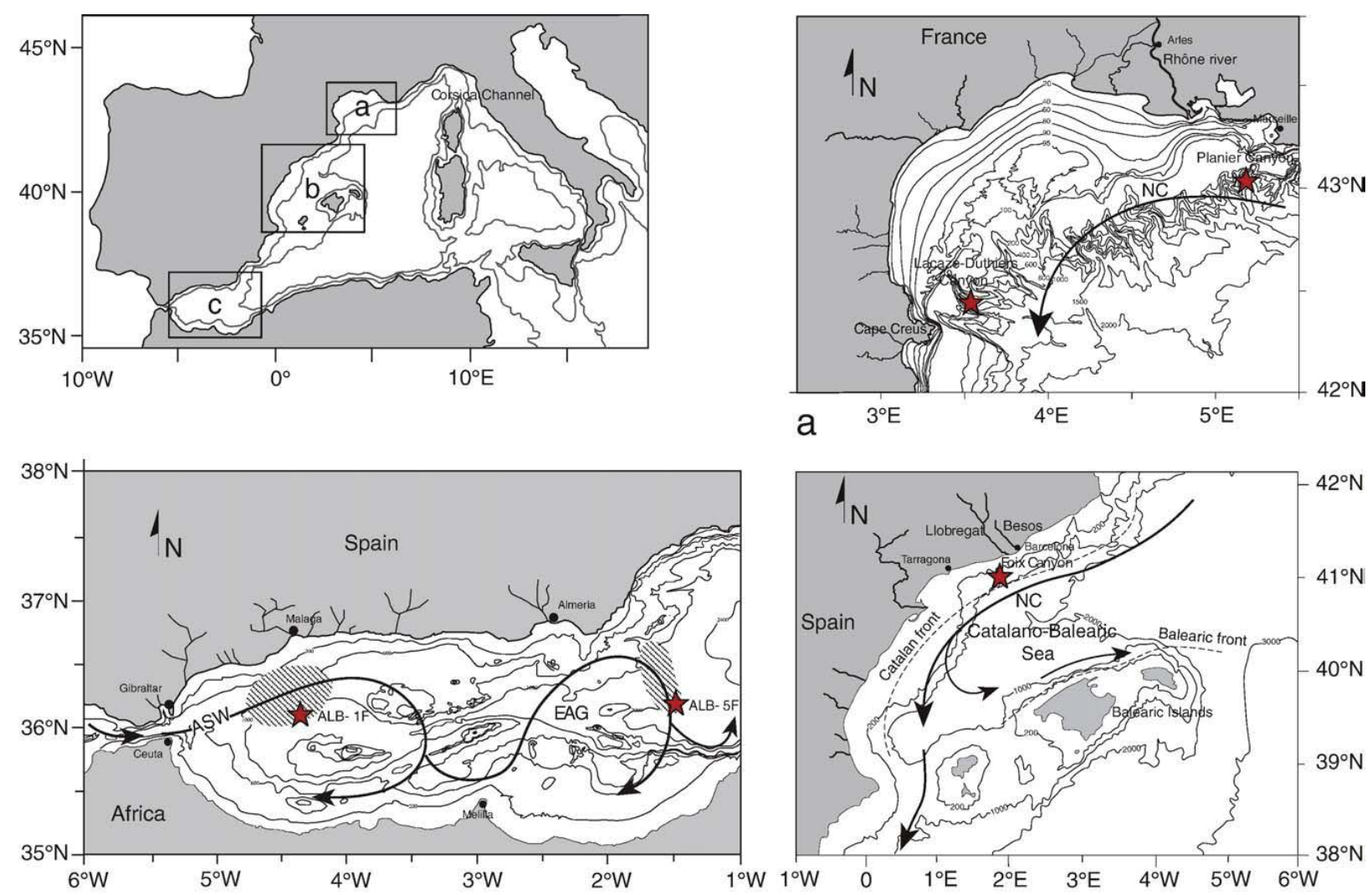

C

b

Figure 1. Geographical setting of the sampling stations in the Western Mediterranean. The position of the sediment traps is represented with stars. Arrows represent the theoretical surface circulation. a. Gulf of Lions. b. Catalan margin. c. Alboran Sea. Dashed areas represent the northern border of the Western Alboran Gyre (WAG) and the Almeria-Oran Front (AOF).

\subsubsection{Gulf of Lions}

From the hydrodynamic point of view, the Gulf of Lions can be considered a complex region (Millot, 1990). The general circulation in this area is dominated by the Northern Current (NC), whose flux is directed to the south along the continental slope (Fig. 1a). Additionally, the Gulf of Lions is one of the few locations in the Mediterranean where dense-water formation takes place (Millot, 1990) and it is therefore a key area for the functioning of the thermohaline circulation in the Mediterranean. Dense-water formation occurs during winter when persistent, cold and dry northwesterlies (Mistral and Tramontana) cause heat losses and evaporation, that induce cooling and mixing of shelf waters that sink, overflow the shelf edge and cascade downslope (Béthoux et al., 2002). Dense-water formation shows important interannual variability, and in especially cold and dry years dense water cascading may reach the bottom and erode the sea floor (Canals et al., 2006).

Regarding productivity, the Gulf of Lions can be considered as an exception to the general oligotrophy of the Mediterranean. The main mechanisms of nutrient supply in this area are the mesoscale variability of the Northern Current, the central divergence zone of the Liguro- 
Provençal Sea, and river runoff (Estrada, 1996), especially from the Rhône, which is one of the rivers with the highest flow to the Mediterranean area (Fig. 1a).

\subsubsection{Catalan margin}

The general circulation in this area is controlled by the Northern Current, which flows from the northeast to the southwest along the coast, between a permanent shelf-slope density front and the upper continental slope (Font et al., 1988) (Fig. 1b). The main nutrient enrichment mechanisms in this area are similar to those reported for the Gulf of Lions: the mesoscale variability of the Northern Current, which induces exchange of inorganic and organic elements between the ocean and the shelf, and the river input (Estrada, 1996). In particular, the plumes of the rivers Llobregat and Besos, which flow into the Catalano-Balearic Sea in its southern part (Fig. 1b), may affect the site studied. Both rivers flow through the large industrial belts of Barcelona and surrounding localities and receive agricultural, industrial and domestic wastes (Céspedes et al. 2005; Bosch et al., 1986).

\subsubsection{Alboran Sea}

The Alboran Sea can be considered a transition area between the Atlantic Ocean and the Mediterranean Sea. The pattern of circulation is intense, subject to strong seasonal variations related to fluctuations in the intensity of the water exchange through the Strait of Gibraltar. At the surface, the main oceanographic feature of the area is the entrance of a jet of Atlantic Surface Water (ASW) that forms two almost permanent anticyclonic gyres: the Western Alboran Gyre (WAG) and the Eastern Alboran Gyre (EAG) (Fig. 1c). Associated to the gyres, the Alboran Sea has two systems of high biological productivity as shown in Fig. 1c. For a detailed description of the physiography and oceanography of the Alboran Sea, see Parrilla and Kinder (1987).

In terms of sea surface productivity, the persistence of four main regimes is noticeable along the year: the winter bloom regime (November to March), the summer non-bloom regime (May to September), and two transition periods: from April to May, when thermal stratification starts, and October-November, coinciding with the highest wind variability and water column destratification (García-Gorriz and Carr, 2001).

Table 1. Summary of the main characteristics and environmental conditions of the 5 stations.

\begin{tabular}{|c|c|c|c|c|c|}
\hline & Planier & Lacaze Duthiers & Foix & ALB-5F & ALB-1F \\
\hline Coordinates & $43.02 N, 5.18 \mathrm{E}$ & $42.41 \mathrm{~N}, 3.54 \mathrm{E}$ & $41.04 \mathrm{~N}, 1.93 \mathrm{E}$ & $35.91 \mathrm{~N}, 1.5 \mathrm{~W}$ & $36.01 \mathrm{~N}, 4.26 \mathrm{~W}$ \\
\hline Depth $(\mathrm{m})$ & 1000 & 1000 & 680 & 2070 & 1004 \\
\hline Meters above botton (mab) & 500 & 500 & 530 & 30 & 30 \\
\hline Sampling period & Oct 1993- Jan 2006 & Oct 1993 - Jan 2006 & Abr 1993 - May 1994 & Jul 1997 - May 1998 & Jul 1997 - May 1998 \\
\hline Sampling interval (days) & 14 till Oct-94 and 30 till Jan-06 & 14 till Jan-97 and 30 till Jan-06 & 15 & $3-11$ & $3-11$ \\
\hline SST $\left({ }^{\circ} \mathrm{C}\right)$ & $12.35-26.22$ & $11.82-26.55$ & $12.82-26.42$ & $15.81-24.69$ & $15.12-23.88$ \\
\hline Salinity & $37.98-38.48$ & $37.98-38.48$ & $37.69-38.79$ & $36.74-38.62$ & $36.43-38.83$ \\
\hline Chlorophyll-a & Available data (1997-2006) & Available data (1997-2006) & No data & Available data & Available data \\
\hline
\end{tabular}




\subsection{MATERIAL AND METHODS}

\subsubsection{Field experiments}

The present study is a compilation of data from sediment trap samples recorded in different European (Euromarge-MB, MTP II-MATER and EUROSTRATAFORM) and French (PNEC: Programme National Environnement Côtier) projects performed in the Western Mediterranean.

All traps used were PPS3 Technicap sediment traps with a cylindrical-conical shape with a $0.4 \mathrm{~m}$ opening diameter ( $2.5 \mathrm{height} /$ diameter aspect ratio for the cylindrical part) and equipped with 6 or 12 sampling cups (Heussner et al., 1990). Gaps in the temporal series were caused by mooring recovery periods or by problems in the functioning of the sediment traps.

In the Northwestern Mediterranean, three moorings were deployed at different locations (Fig. 1): one at the entrance of the Gulf of Lions, over the Planier Canyon $\left(43.02^{\circ} \mathrm{N}, 5.18^{\circ} \mathrm{E}\right)$; one at the southwestern exit of the Gulf of Lions, over the Lacaze-Duthiers Canyon $\left(42.41^{\circ} \mathrm{N}, 3.54^{\circ} \mathrm{E}\right)$ (Fig. 1a); and one in the Barcelona continental basin, over the Foix Canyon (41.04N, 1.93 E) (Fig. 1b).

At the Planier and Lacaze-Duthiers sites, the moorings were deployed at a water depth of around $1000 \mathrm{~m}$ and they were equipped with two sediment traps at 500 and $30 \mathrm{~m}$ above the bottom (mab hereafter), paired with current meters (Heussner et al., 2006). Only the data from the sediment traps at $500 \mathrm{mab}$ are reported in this work. The information recorded by these two sediment traps is especially relevant owing to the exceptional length of the time series: from October 1993 until January 2006. The sampling interval was set at 14 days until early 1997, and at 1 month from 1997 onwards (Table 1).

At the Foix Canyon station (Fig. 1b), the mooring was set at a water depth of $680 \mathrm{~m}$ and it was also equipped with two sediment traps at 530 and 30 mab (Puig et al., 1998). Here, only the samples from the sediment trap at 530 mab were studied. In this experiment, the sampling period comprised one year, from April 1993 to May 1994, with a collection interval of 15-16 days (Table 1).

In the Alboran Sea two mooring lines were deployed: ALB-1F and ALB-5F (Fig. 1c). ALB$1 \mathrm{~F}$ was set up on the continental slope at a depth of $1004 \mathrm{~m}$ and located at $36.01 \mathrm{~N} ; 4.26 \mathrm{~W}$ while ALB-5F was deployed over the African continental margin at $2070 \mathrm{~m}$ depth and located at $35.91 \mathrm{~N} ; 1.5 \mathrm{~W}$ (Fig. 1c). In both moorings, the sediment traps were set at 30 mab (Fabrés et al., 2002, Sanchez-Vidal et al., 2005). The two moorings were deployed from July 1997 to May 1998 along three different periods. The sampling interval was set at 10-11 days for the whole period, except between April $20^{\text {th }}$ and May $16^{\text {th }}$ for ALB-1F, and between April $1^{\text {st }}$ and May $22^{\text {nd }}$ for ALB-5F, when the sampling interval was 3 days (Table 1). 

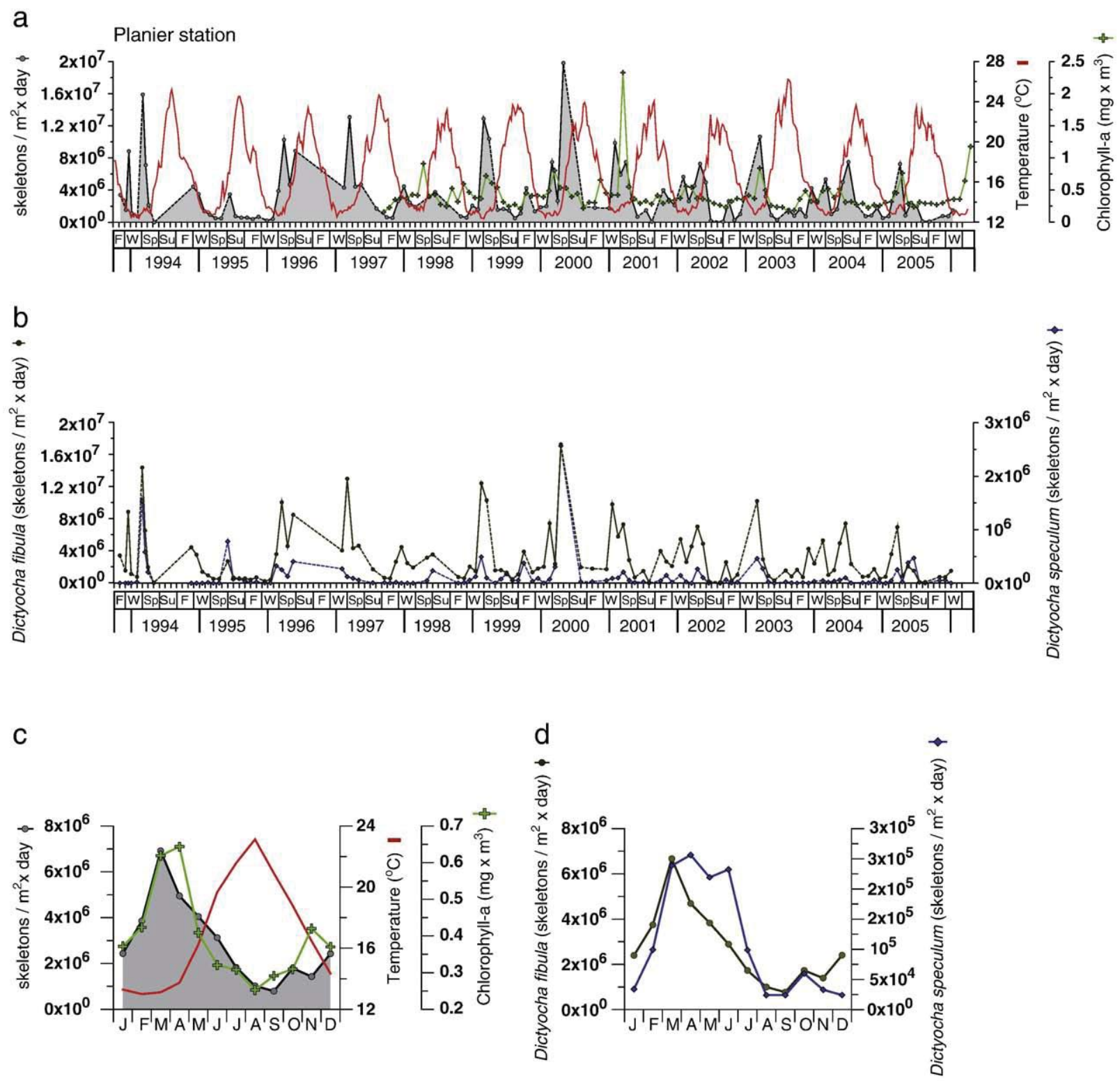

Figure. 2. Planier station. a. Total skeleton flux (skeletons / day x $\left.\mathrm{m}^{2}\right)$, temperature $\left({ }^{\circ} \mathrm{C}\right)$ and chlorophyll$a$ concentration $\left(\mathrm{mg} \mathrm{x} \mathrm{m}^{3}\right)$. b. D. fibula (squares) and D. speculum flux (skeletons day $/ \mathrm{m}^{2}$ ). Gaps in the time series are represented by a dotted line. The relative abundance of the different species and the SST are represented with solid lines. c. Composite year. Total skeleton flux (skeletons / day $\mathrm{x} \mathrm{m}^{2}$ ), temperature and chlorophyll- $a$ concentration $\left(\mathrm{mg} \mathrm{x} \mathrm{m}^{3}\right)$. d. Composite year. D. fibula and D. speculum flux (skeletons / day $\mathrm{x} \mathrm{m}^{2}$ ). 
a
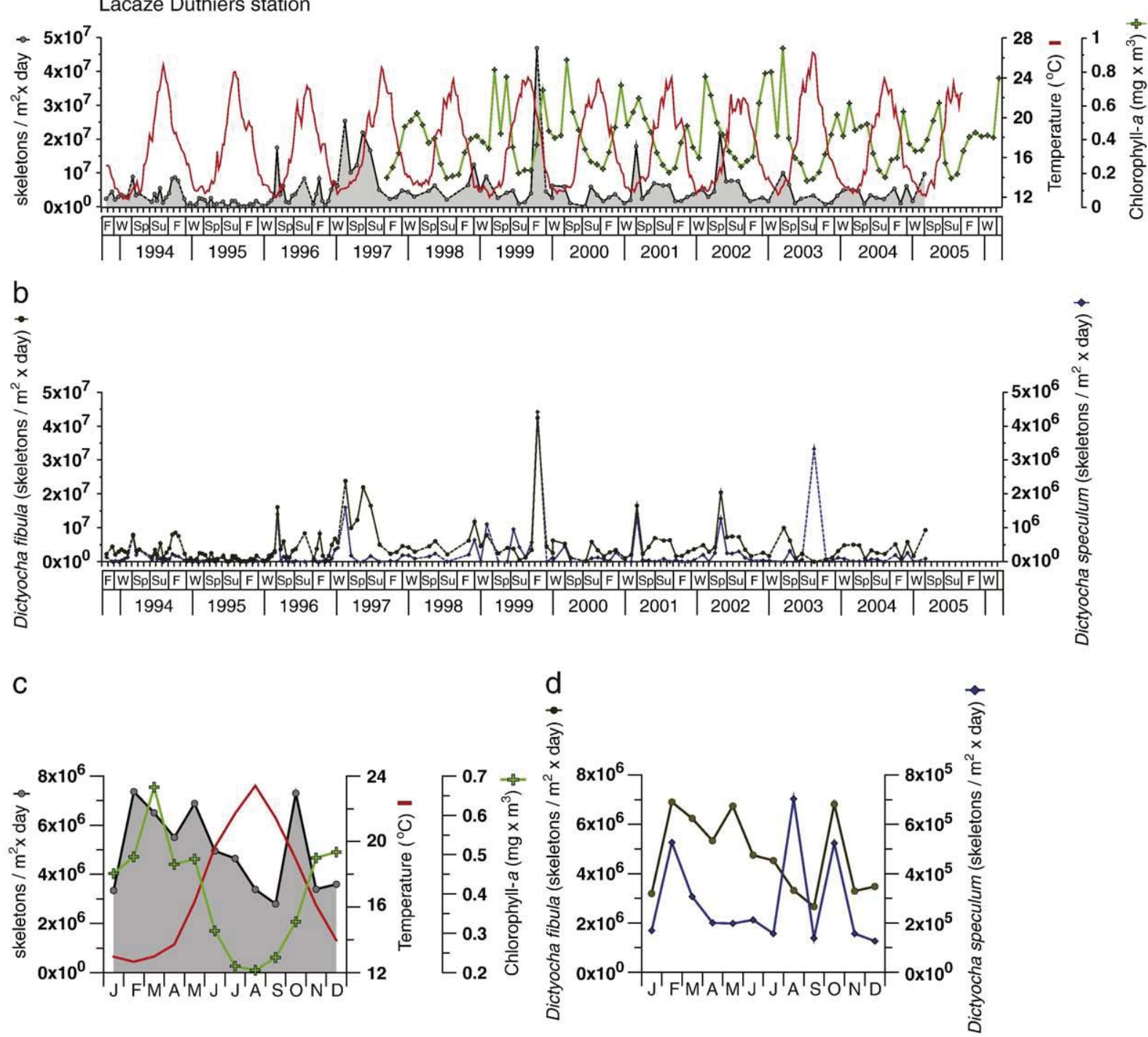

Figure. 3. Lacaze-Duthiers station. a. Total skeleton flux (skeletons / day $\mathrm{x} \mathrm{m}^{2}$ ), temperature $\left({ }^{\circ} \mathrm{C}\right)$ and chlorophyll- $a$ concentration $\left(\mathrm{mg} \mathrm{x} \mathrm{m}^{3}\right)$. b. $D$. fibula and $D$. speculum flux (skeletons / day x $\mathrm{m}^{2}$ ). Gaps in the time series are represented by a dotted line. c. Composite year. Total skeleton flux (skeletons / day $\left.\times \mathrm{m}^{2}\right)$, temperature and chlorophyll- $a$ concentration $\left(\mathrm{mg} \mathrm{x} \mathrm{m}^{3}\right)$. d. Composite year. D. fibula and $D$. speculum flux (skeletons / day $\mathrm{x} \mathrm{m}^{2}$ ). 


\subsubsection{General processing of the sediment traps}

A detailed description of the PPS3 sediment trap and the sample processing used for this experiment can be found in Heussner et al. (1990). Here, we summarize a description of the treatment for siliceous microfossils analyses.

\subsubsection{Specific treatment for siliceous microplankton}

Different aliquots from the original samples were used for the micropaleontological analyses; although the most common was $1 / 8$, other fractions were also used depending on availability, ranging from $1 / 64$ to $3 / 4$. The original samples were wet-sieved onto a $150 \mu \mathrm{m}$ mesh in order to separate foraminifera larger than $150-\mu \mathrm{m}$ from smaller diatoms, silicoflagellates and coccolithophores.

The samples studied were prepared with a standard decantation method according to the methodology proposed by Flores and Sierro (1997). Qualitative and quantitative analyses were performed at 1000 and 400 magnification, using a Nikon Eclipse 80i light microscope.

Owing to the high seasonal flux changes of this group, we detected some periods when almost no silicoflagellates were present in the water column and hence in the samples. The number of skeletons identified was usually higher than 100, but a compromise between the number of skeletons to be counted and the time spent analyzing them had to be accepted for some samples in which abundance was really low. In addition, diatom valves were counted in the Foix station samples. A minimum of 400 diatom specimens per sample were counted.

Silicoflagellate and total diatom fluxes are given as the number of skeletons or valves per day per square meter. In addition, an average year was calculated for the two 12-years-long sediment traps records of the Gulf of Lions. For this calculation, a flux value was assigned to each day of each collecting period. Then, all the days of the same month were placed in the same group and the flux average was estimated (Fig. 2 and 3).

\subsubsection{Environmental variables}

Weekly SSTs data from October 1993 until March 2006 were obtained using NOAA Optimum Interpolation Sea Surface Temperature Analysis (Reynolds et al., 2002). Monthly chlorophyll- $a$ satellite data (since September 1997) were obtained from the NASA Giovanni program (Acker and Leptoukh, 2007). General salinity values for each site were taken from MEDATLAS 2002. All this information is summarized in Table 1.

\subsection{RESULTS}

\subsubsection{General considerations}

Three silicoflagellate species were identified at the five stations of the Western Mediterranean: Dictyocha fibula (Ehrenberg), Dictyocha speculum (Ehrenberg) and Octactis octonaria 
(Ehrenberg) (Plate 1). D. fibula exhibited greater morphological and size variability than the others, although these variations were considered to be intraspecific (Plate 1). No remarkable morphological differences were found between seasons or locations in the samples studied. Dictyocha speculum and Octactis octonaria (Plate 1) showed more homogeneous skeletons with few aberrant specimens.

\subsubsection{Gulf of Lions}

Total silicoflagellate fluxes were one order of magnitude lower than diatom fluxes in both traps (Rigual-Hernández, unpublished data). At the Planier site, despite the time series exhibiting interannual variability, the observations for the composite year revealed a clearly unimodal trend (Fig. 2c and 2d). The highest fluxes were generally recorded in winter and spring and the minima in summer until the beginning of fall (Fig. 2c). The mean flux at the Planier station was $2.89 \times 10^{6}$ skeletons $\mathrm{m}^{-2} \mathrm{~d}^{-1}$, while the maximum and minimum fluxes occurred in May $2000\left(1.98 \times 10^{7}\right.$ skeletons $\left.\mathrm{m}^{-2} \mathrm{~d}^{-1}\right)$ and August $2001\left(6.69 \times 10^{4}\right.$ skeletons $\left.\mathrm{m}^{-2} \mathrm{~d}^{-1}\right)$ (Fig. 2a) respectively.

The total silicoflagellate flux at the Lacaze-Duthiers site also exhibited interannual variability and a clear seasonal trend. The 12-year mean showed a trimodal distribution (Fig. 3c and 3d) with maximum values during February-March (winter-spring transition), a secondary maximum at the end of the spring (May), and a third peak in October, while minimum values were reached during summer and the beginning of fall. The mean flux at the Lacaze-Duthiers station was $4.97 \times 10^{6}$ skeletons $\mathrm{m}^{-2} \mathrm{~d}^{-1}$. The highest flux at this station was recorded in October 1999 $\left(4.68 \times 10^{7}\right.$ skeletons $\left.\mathrm{m}^{-2} \mathrm{~d}^{-1}\right)$, whereas the minimum was recorded in September $1995\left(9.77 \times 10^{4}\right.$ skeletons $\left.\mathrm{m}^{-2} \mathrm{~d}^{-1}\right)$ (Fig. 3a).

Regarding the composition of the silicoflagellate assemblage, $D$. fibula was by far the most abundant species, with a mean of $95.5 \%$ for both sites. D. speculum represented $4.3 \%$ of the assemblage for both stations, while only a handful of specimens of $O$. octonaria were identified in both records, affording a relative contribution of $0.08 \%$ for the Planier site and $0.18 \%$ for the Lacaze-Duthiers station. Owing to the scarce presence of $O$. octonaria in these two records, its relative abundance was considered negligible and hence it is not plotted in Figures 2 and 3. The seasonal distribution of $D$. fibula and $D$. speculum was slightly different for both sampling sites: while at Planier $D$. speculum reached its maximum relative abundance in June (Fig. 2b and 2d), at Lacaze-Duthiers the maximum occurred during August (Fig. 3b and 3d).

\subsubsection{Catalan margin}

Silicoflagellate fluxes at Foix station were one order of magnitude lower than the diatom fluxes (Fig. 4a). Total silicoflagellate fluxes did not show any clear seasonal trend and paralleled those of diatoms (Fig. 4a). Total diatom fluxes (Fig. 4a) showed three remarkable maxima (April 1993, fall 1993 and February to April 1994) that were linked to relatively high silicoflagellate 
fluxes. The highest silicoflagellate fluxes were recorded during the first half of August 1993 $\left(3,80 \times 10^{7}\right.$ skeletons $\left.\mathrm{m}^{-2} \mathrm{~d}^{-1}\right)$, while minima were recorded during the winter and March of 1994 (Fig. 4a). The mean flux at this site was the highest of the five sediment trap records $\left(6,36 \times 10^{6}\right.$ skeletons $\left.\mathrm{m}^{-2} \mathrm{~d}^{-1}\right)$. Moreover, it is worth noting that the most important discharge pulses of the river Llobregat (Puig and Palanques, 1998) (Fig. 4a) were followed by relatively high silicoflagellate fluxes; i.e., in the spring and fall of 1993.

D. fibula represented $96.7 \%$ of the annual assemblage, the highest of the five records studied, while D. speculum represented 3.3\% of the assemblage. During June 1993, D. speculum reached its highest relative abundance (17.6\%) (Fig. 4b). No Octactis octonaria specimens were found in Foix record.
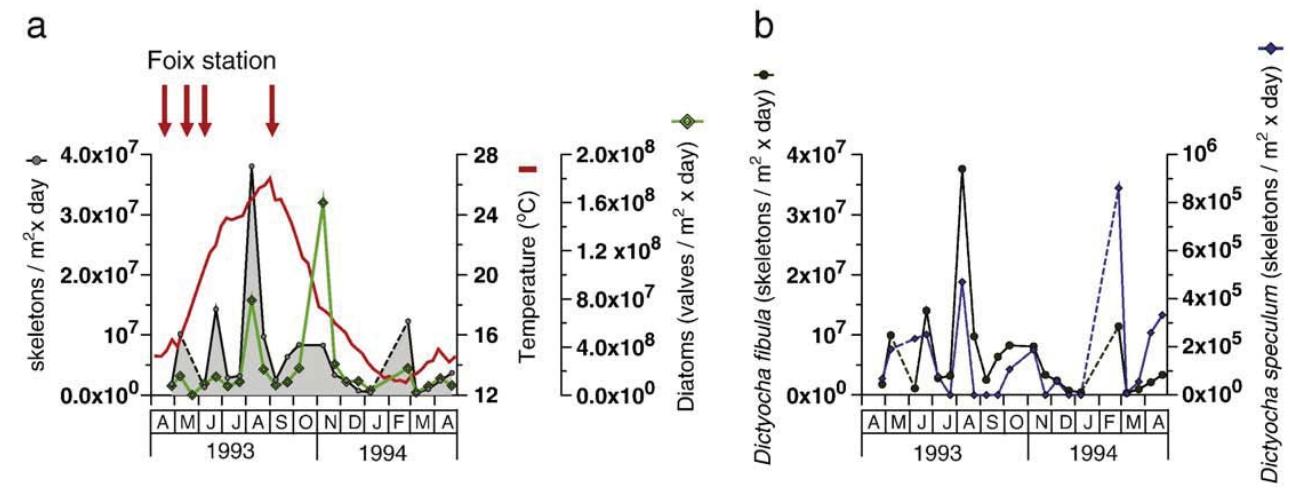

Figure 4. Foix station. a. Total skeleton flux (skeletons / day $\left.\mathrm{x} \mathrm{m}^{2}\right)$, temperature $\left({ }^{\circ} \mathrm{C}\right)$, total diatom flux (valves / day $\mathrm{x} \mathrm{m}^{2}$ ) and main river discharge events (red arrows). b. D. fibula and D. speculum flux (skeletons / day $\times \mathrm{m}^{2}$ ).

\subsubsection{Alboran Sea}

Total silicoflagellate fluxes were one order of magnitude lower than the diatom fluxes in both traps (Bárcena et al., 2004; Hernández-Almeida et al. submitted). The ALB 1F total silicoflagellate flux exhibited a trimodal distribution, with a clear seasonal pattern (Fig. 5a). The maximum values were recorded in summer 1997 and winter 1997-98, but a third peak was recorded at the end of the spring 1998. The mean flux in ALB-1F was 3.05 $\times 10^{5}$ skeletons $\mathrm{m}^{-2} \mathrm{~d}^{-1}$. In December 1997 , the highest fluxes were recorded $\left(1.05 \times 10^{6}\right.$ skeletons $\left.\mathrm{m}^{-2} \mathrm{~d}^{-1}\right)$ while the lowest values were recorded during fall, the end of winter and the beginning of the summer in 1998.

ALB-5F also exhibited a trimodal distribution, but different from that seen for ALB-1F. The mean silicoflagellate flux at this site was $5.49 \times 10^{5}$ skeletons $\mathrm{m}^{-2} \mathrm{~d}^{-1}$. The maximum flux was recorded in May 1998 (2.35 x $10^{6}$ skeletons $\left.\mathrm{m}^{-2} \mathrm{~d}^{-1}\right)$ and the minimum fluxes were recorded in October $1997\left(2.52 \times 10^{4}\right.$ skeletons $\left.\mathrm{m}^{-2} \mathrm{~d}^{-1}\right)$.

Dictyocha fibula was the dominant taxon at ALB-1F and Alb-5F (Fig. 5b and 5d), representing $81.69 \%$ and $88.8 \%$ of the annual assemblage, respectively. Dictyocha speculum relative abundance in the Alboran Sea stations was negligible, with only one specimen found in the whole 
record of Alb- $1 \mathrm{~F}$ and a relative abundance of $0.4 \%$ in Alb-5F. Because of these insignificant values, D. speculum is not plotted in Figure 5. Regarding O. octonaria, its relative abundance reached the highest values of the study in the Alboran Sea stations, where it accounted for $16.74 \%$ in Alb-1F and $10.9 \%$ in Alb-5F (Fig. 5b and 5d).

a

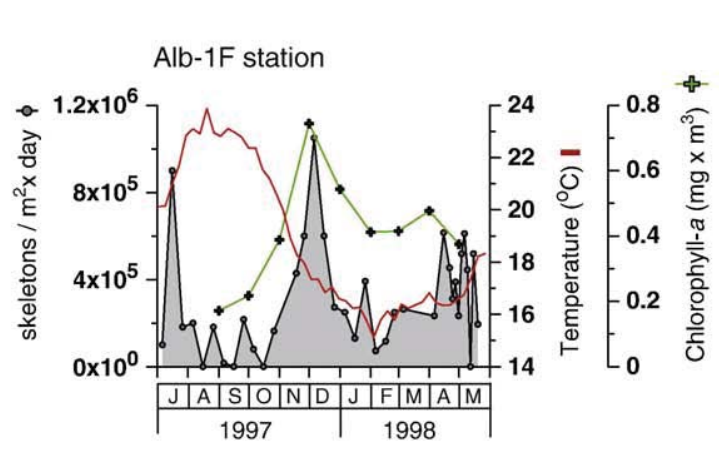

C

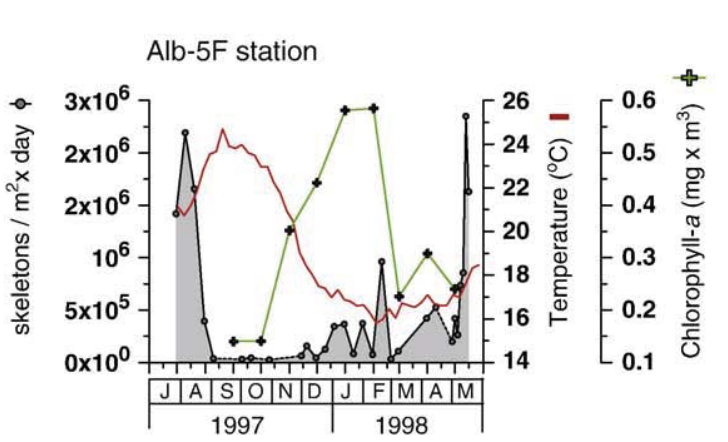

b
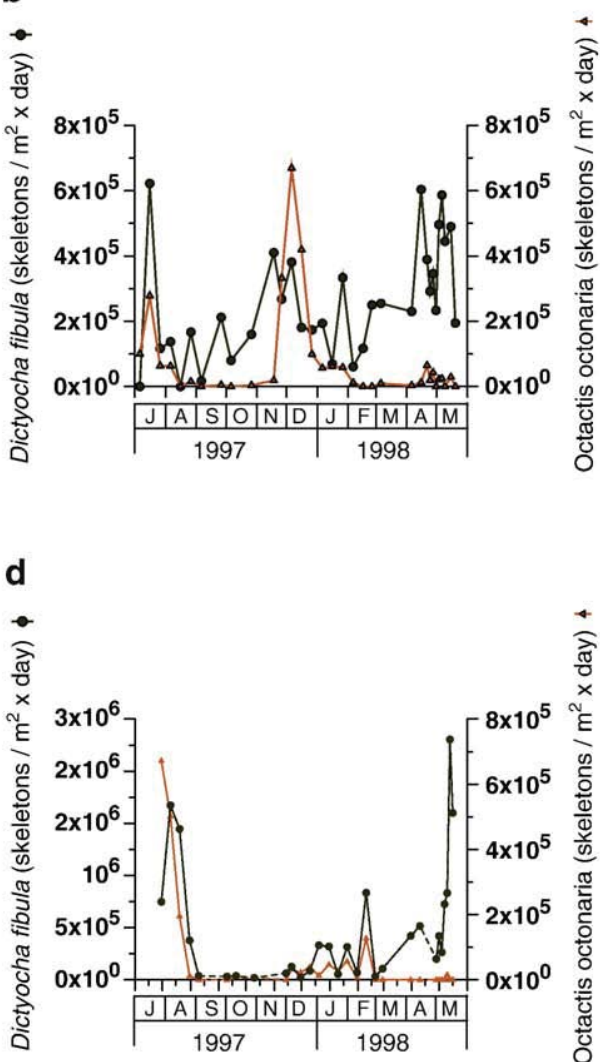

Fig. 5. Alboran Sea (ALB-1F and ALB-5F) stations. a. ALB-1F total skeleton flux (skeletons / day $\mathrm{x}$ $\left.\mathrm{m}^{2}\right)$, temperature $\left({ }^{\circ} \mathrm{C}\right)$ and chlorophyll- $a$ concentration $\left(\mathrm{mg} \mathrm{x} \mathrm{m}^{3}\right)$. b. ALB-1F D. fibula and O. octonaria flux (skeletons / day $\mathrm{x} \mathrm{m}^{2}$ ). c. ALB-5F total skeleton flux (skeletons / day $\mathrm{x}^{2}$ ), temperature, and chlorophyll- $a$ concentration $\left(\mathrm{mg} \mathrm{x} \mathrm{m}^{3}\right)$. d. ALB-5F D. fibula and O. octonaria flux (skeletons / day x $\mathrm{m}^{2}$ ). Gaps in the time series are represented by a dotted line. c. Composite year.

\subsection{DISCUSION}

This study aims to shed new light on silicoflagellate ecology defining, at least in broad outlines, the seasonal, interannual, and geographic distribution of silicoflagellates in the Western Mediterranean.

\subsubsection{Biological and physical processes controlling the seasonal changes of the silicoflagellate fluxes}

The fluxes recorded at the two stations in the Gulf of Lions were markedly seasonal and reflected changes in the water column and atmosphere dynamics. In terms of input of particulate 
material, the Planier site is subject to less influence from the shelf, while the Lacaze-Duthiers site is more affected by the continental shelf and the Rhône river plume (Heussner et al., 2006) (Fig. 1a). The material recorded may be of diverse origin, such as shelf bottom and shelf break resuspended sediments, Rhône river material, and shelf and open-ocean pelagic biogenic material. Vertical transport and sediment resuspension are more important during winter periods when the hydrodynamics in the Gulf of Lions are more intense (i.e, currents, water mixing, and dense-water formation) (Millot, 1990). The silicoflagellate fluxes recorded by both sediment traps may be partially affected by the latter factors, although several lines of evidence suggest that the skeletons recorded by our sediment traps reflect silicoflagellate assemblages dwelling in the euphotic layer. First, previous studies on water samples from the NW Mediterranean (Nival, 1965; Travers and Travers, 1968; Gómez and Gorsky, 2003) have described a similar seasonal silicoflagellate distribution and assemblage composition to those observed in our investigation. In addition, the silicoflagellate flux annual maxima coincided with the highest annual chlorophyll- $a$ values (Fig. $2 \mathrm{c}$ and $3 \mathrm{c}$ ), which indicates that phytoplankton skeleton fluxes mirrored the phytoplankton community of the photic zone. Finally, both sediment traps were set at $500 \mathrm{mab}$, which hinders the recording of important amounts of resuspended sediments.

The nutrient-rich euphotic layer and solar radiation increase during the winter-spring transition (Leblanc et al. 2003) favor the development of the spring phytoplankton bloom (BustillosGuzmán et al., 1995; Marty et al., 2002), and hence of the silicoflagellate assemblages in both Planier and Lacaze-Duthiers stations. The low skeleton fluxes recorded during summer and the beginning of fall at both stations (Fig. 2 and 3) are due to the strong oligotrophy and stratification conditions of the water column (Leblanc et al. 2003).

The higher silicoflagellate fluxes at the Lacaze-Duthiers than at the Planier site (almost twice as high) (Fig. 3) seem to be elicited by the influence of the dilution zone of the Rhône plume, which enriches the southwestern part of the Gulf of Lions shelf with nutrients (Lefevre et al., 1997). This could be the cause of the silicoflagellate skeleton peak at the beginning of fall at the Lacaze-Duthiers site (Fig. 3c and 3d), when the Rhône river reaches its maximum discharge values (Heussner et al., 2006).

Previous studies in the NW Mediterranean (Nival, 1965; Travers and Travers, 1968; Gómez and Gorsky, 2003) have described that during summer D. fibula sinks to deeper and colder waters. Since D. speculum follows a similar annual cycle (Fig. 2 and 3), it is possible that it could have a similar kind of behavior and could sink to deeper waters during the stratification period. Despite the low $D$. speculum fluxes, the relative abundance of this species increases during summer (up to 12\%), suggesting a better adaptation of this taxon to oligotrophic conditions than D. fibula.

Regarding the Catalan margin, the Foix station does not exhibit a clear seasonal signal, probably due to the proximity of the Llobregat and Besos rivers (Fig. 1b) that could have influenced the plankton communities by means of nutrient and freshwater inputs along the collecting period. 
This, together with the fact that the Foix station is closest to the coast of the five sampling sites, seems to be the reason why the highest silicoflagellate fluxes of the five sampling locations were recorded at the Foix site. Owning to the similar distribution of diatom and silicoflagellate fluxes (Fig. 4a), both phytoplankton groups seem to respond to the same conditions of the water column. Little is known about the influence of river input on silicoflagellate populations, but Jochem and Babenerd (1989) described a progressive increase of the silicoflagellates assemblages in relation with the gradual eutrophication of the estuarine waters of the Kiel Bight. The absence of a clear seasonal pattern, together with the fact that the discharge pulses of the river Llobregat (Puig and Palanques, 1998) were often followed by relatively high silicoflagellate fluxes (Fig. $4 a$ ), suggests that the silicoflagellate skeleton fluxes recorded at the Foix station could have been determined by the river input. The plumes of the rivers Llobregat and Besos might have enhanced the growth of phytoplankton communities, and hence the silicoflagellate skeleton fluxes. In addition to this, it is worth noting that the highest silicoflagellate fluxes of the whole record occurred during August, a period of strong stratification as indicated by the SSTs (Fig. 4), that can be used as a rough indicator of stratification (e.g. Martinez et al., 2009). We speculate that certain anthropogenic macro- or micro- nutrient inputs to any of the rivers could have triggered the massive growth of silicoflagellates during August, regardless of the river flow.

The sediment traps from the Alboran Sea were set in two systems of high biological productivity associated with the Western Alboran Gyre (WAG) and the Almeria-Oran density front (AOF) (Fig. 1), and were relatively less influenced by coastal inputs as compared to the other sampling sites. The lowest silicoflagellate fluxes of this study were recorded at the Alboran Sea stations, probably reflecting their location in the relatively open sea. Both silicoflagellate flux records exhibited a marked seasonality and responded to the same conditions as those observed by Bárcena et al. (2004) and Hernández-Almeida (submitted). At ALB 1F, the silicoflagellate skeleton pulses during the beginning of summer and fall 1997 (Fig. 5a and 5b) were related to the last steps of a high productivity period and to upwelling-favourable winds (Bárcena et al., 2004) respectively. Furthermore, the especially warm fall conditions of that year elicited a delay in the winter-spring bloom (García-Gorriz and Carr, 2001), and hence of the development of the silicoflagellate populations. Concerning the ALB 5F sediment trap (Fig. 5c and 5d), the similar distribution of the silicoflagellate fluxes to those found in ALB 1F suggest that both records respond to the same conditions. However, the 1997 fall silicoflagellate flux maximum was displaced to the winter, probably owning to the warmer temperatures in this area (Fig. 5c).

\subsubsection{Impact of NAO and ENSO variability on silicoflagellate fluxes}

Because the Gulf of Lions time series spanned more than one year we will focus on these two sediment traps to address interannual variability. The first point to be noted is that the maximum fluxes in both sediment traps did not always occur at the same time of year. The lower influence from the shelf, the Rhône, and dense-water formation events (Canals et al., 2006; Ulses et al., 
2008) at the Planier site might explain their different behavior.

The climate of the Northern Basin (the Gulf of Lions and the Ligurian-Provencal Basin), as well as transport through the Corsica Channel (Fig. 1), are under the influence of the North Atlantic Oscillation (NAO), especially during winter (Fig. 6a) (Hurrell, 1995; Vignudelli et al., 1999). In the Northern Basin, negative NAO winter index values are associated with an intensification of heat losses to the atmosphere and with a consequent increase in water transport through the Corsica Channel, which feeds the Northern Current (Fig. 1a). Conversely, positive values of the NAO index mean that warmer and moister air masses are conveyed towards the Northwestern Mediterranean, leading to milder winters and a consequent decrease in the total amount of heat lost (Vignudelli et al., 1999). In their review of the interannual phytoplankton variability of the Northern Basin, Gómez and Gorsky (2003) pointed out that low or negative NAO indices are often associated with a remarkable spring diatom bloom, while positive values are associated with a lower spring bloom. Since the beginning of the chlorophyll-a record (September 1997), the most extreme negative winter NAO values occurred during 2001 and 2006 (Fig. 6). At the Planier site, the springs of 2001 and 2006 were coupled to remarkably high chlorophyll$a$ concentrations and elevated silicoflagellate fluxes, which reflect a positive response of the phytoplankton communities to the environmental conditions of those years (Fig. 6). In contrast, the spring chlorophyll- $a$ values at Lacaze Duthiers did not show anomalously high values during 2001 and 2006, although the silicoflagellate fluxes at this station were relatively high (Fig. 6). The different response of the phytoplankton communities at the Lacaze Duthiers station could be related to the influence of the Rhone plume and the particulate matter supply from the shelf and upper slope. Regarding the years with the most extreme positive NAO values (1999 and 2000) (Fig. 6a), both stations showed intermediate spring chlorophyll-a concentrations while silicoflagellate fluxes behaved differently: at the Planier site the silicoflagellates showed high fluxes, but relatively low silicoflagellate fluxes were recorded in Lacaze-Duthiers station (Fig. 6c and d). Therefore, although negative NAO values could be related to remarkable phytoplankton spring blooms in the Northern Basin, our silicoflagellate flux time series do not reveal a straightforward relationship with the winter state of the NAO, indicating that the process that generates silicoflagellate flux variability is not controlled by the NAO.

Another major source of climatic variability should be considered: i.e., the El Niño Southern Oscillation (ENSO). The ENSO (Fig. 6b) is the dominant mode throughout the tropical climate system and its major effects occur over the southern hemisphere. However, there is evidence that extreme ENSO events can modify the North Atlantic and European climate (Wanner et al., 1997). According to McPhaden (1999), the 1997-98 El Niño Event (Fig. 6b) was the strongest one of the last century and that author suggested that the major climatic impacts around the world were related to this event. This could be the case of the anomalously high summer and fall SSTs recorded in the Alboran Sea (Bárcena et al., 2004; Hernández-Almeida submitted) and the Gulf of Lions in 1997 (Fig. 5a, 5c, 6c and 6d). The winds at both locations were also unusually weak, favouring a strong water stratification that delayed the typical winter 
destratification and fertilization events, resulting in a weaker than usual winter-spring bloom regime (Bárcena et al., 2004; Rigual-Hernández in prep.).

The anomalous warm conditions during the winter of 1997-98 in the Alboran Sea elicited a delay in the spring phytoplankton bloom until April-May (Bárcena et al., 2004), and hence in the silicoflagellates collected in both sediment traps. Something similar occurred in the Gulf of Lions: at the Planier site the spring bloom was also delayed until April and was linked to low silicoflagellate fluxes (Fig. 6c), while at the Lacaze-Duthiers station the bloom took place as in a normal year during the winter-spring transition (Fig. 6d). However, the chlorophyll-a values, as well as the silicoflagellate fluxes, were lower than in other years. Our observations coincide with those of Gómez and Gorsky (2003) for the NW Mediterranean, who described lower silicoflagellate concentrations and warmer temperatures during the winter of 1997-98 in comparison with 1998-99.

The 1997-98 El Niño Event also altered the silicoflagellate fluxes in other parts of the globe, such as in the North Pacific, where Onodera and Takahashi (2005) described changes in the silicoflagellate assemblage, or in the Santa Barbara Basin, where Lange et al. (2000) reported the lack of the annual fall-winter silicoflagellate peak.

Apart from the NAO and ENSO, other phenomena could also affect the silicoflagellate fluxes in the Western Mediterranean. In this sense, the 2003 summer heat wave over Western Europe and the Western Mediterranean Basin was coupled with an increase in air temperature and a decrease in wind stress that affected the SSTs over the Western Mediterranean (Olita et al., 2007). During that year, the Planier and Lacaze-Duthiers stations recorded the highest summer SSTs of the record that probably contributed to reduce the spring chlorophyll-a productivity and the silicoflagellate fluxes (Fig. 2a and 3a) owned to the weaker winter mixing.

\subsubsection{Geographic distribution of the Western Mediterranean silicoflagellates}

The three areas studied in the Western Mediterranean show important differences in the composition of silicoflagellate assemblages (Fig. 7) that seem to be closely related to environmental factors, especially temperature.

Dictyocha fibula is a cosmopolitan species, and was the dominant species in all the assemblages (Fig. 7). Its fluxes are maximum during winter-spring periods and minimum during summer, when it probably sinks to deeper and colder water masses. D. fibula seems to be well adapted to a wide range of temperatures and to be especially sensitive to nutrient inputs, reaching its maximum fluxes in areas where the influence of a river is important (i.e. at the Lacaze-Duthiers and Foix stations).

The distribution of Dictyocha speculum however, is restricted to the Northern region (Gulf of Lions and the Catalan margin), being almost absent in the Alboran Sea. In fact the Northern region can be considered among the coldest areas in the Mediterranean, where annual SSTs range from 12 to $26^{\circ} \mathrm{C}$ (Table 1). Using cultures, Henriksen et al. (1993) determined that 
a

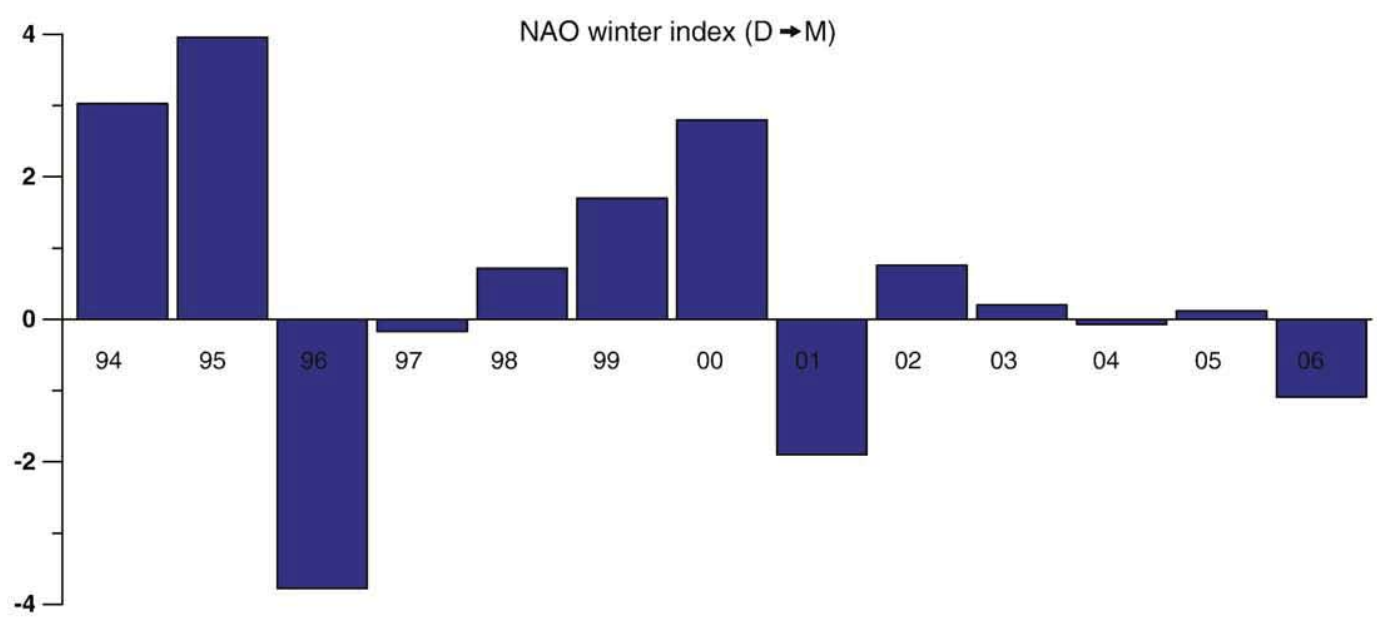

b
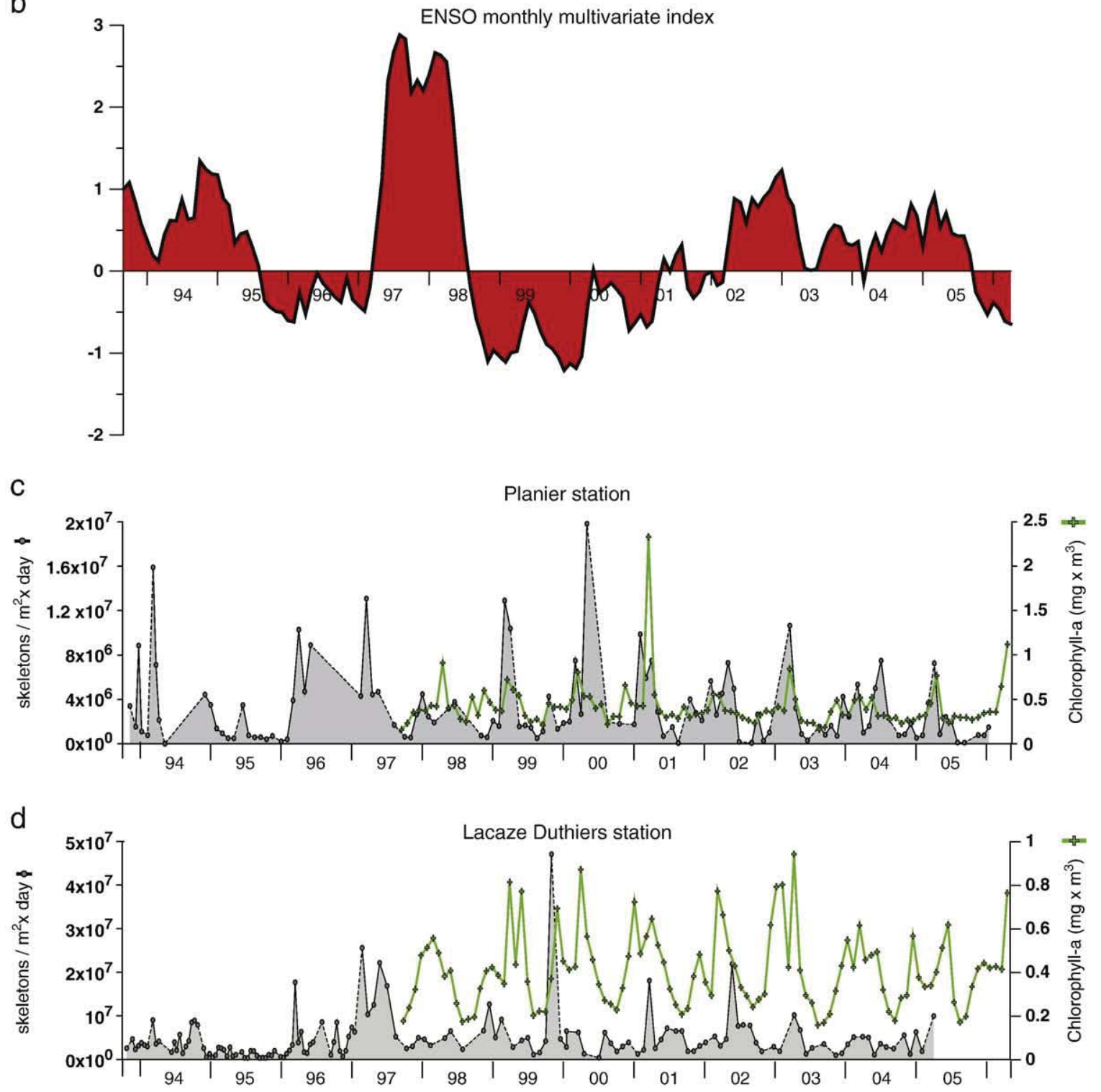

Figure 6. a. NAO Winter index. b. monthly multivariate ENSO index. c. Planier station total skeleton flux (skeletons / day $\mathrm{x} \mathrm{m}^{2}$ ) and chlorophyll-a concentration $\left(\mathrm{mg} \mathrm{x} \mathrm{m}^{3}\right)$. d. Lacaze Duthiers station total skeleton flux (skeletons / day $\mathrm{x} \mathrm{m}^{2}$ ) and chlorophyll-a concentration $\left(\mathrm{mg} \mathrm{x} \mathrm{m}^{3}\right)$. 
the optimum growth of $D$. speculum occurs at temperatures between $11-15^{\circ} \mathrm{C}$ at salinities of $30 \%$. Higher temperatures dramatically decrease the number of cell divisions. In nature, the skeleton-bearing and naked stages of $D$. speculum grow within similar temperature ranges, whereas the skeleton-bearing stage of $D$. speculum is generally found at higher salinities. In addition, these authors reported that salinities over $30 \%$ would reduce the optimal temperature range of this taxon. Taking into account that the salinity in the Mediterranean Sea is higher than the concentration used for the cultures (Table 1), the optimal growth temperature of $D$. speculum would be more restricted than for laboratory cultures. In our study, the restriction of D. speculum to higher latitudes (Fig. 7) suggests an affinity for relatively cold water masses. Its growth would be inhibited at the other regions where annual SSTs do not reach values below $15^{\circ} \mathrm{C}$; i.e., the Alboran Sea.

In contrast, the distribution of Octactis octonaria is restricted to the Alboran Sea (Fig. 7), where temperatures range between 15 and $24{ }^{\circ} \mathrm{C}$ (Table 1). The absence of significant relative abundances of this species in the coldest and most fertile sampling locations (Gulf of Lions and Catalan margin) (Fig. 7) suggests an affinity of O. octonaria for warmer and/or relatively oligotrophic water masses.

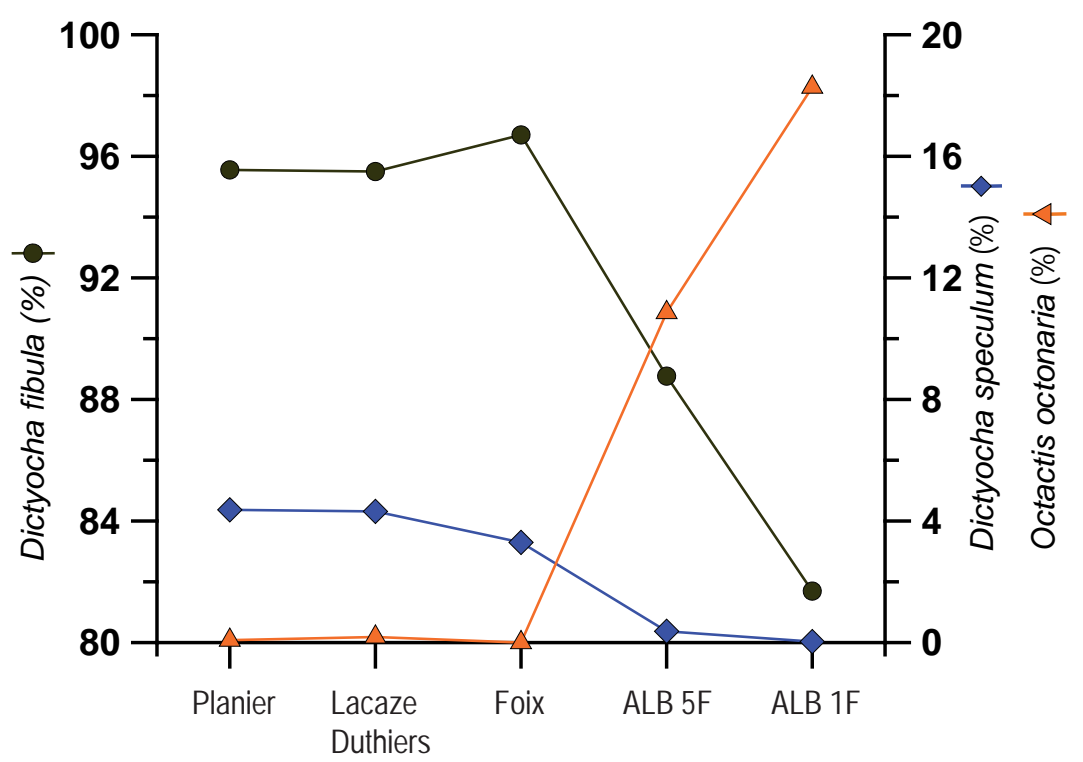

Fig. 7. Relative abundance of the three silicoflagellate taxa along a N-S transect from the Gulf of Lions to the Alboran Sea.

\subsection{Conclusions}

Silicoflagellate fluxes in the Western Mediterranean mirror the atmospheric and water column dynamics. Their fluxes are often maximum during the winter-spring transition, coinciding with the spring phytoplankton bloom. However, they seem to be especially sensitive to river input, showing their maximum fluxes and a less clear seasonal pattern at the stations affected by 
river plumes (e.g. the Lacaze Duthiers and Foix stations). Of the three identified species found in the Western Mediterranean, Dictyocha fibula is the most widespread and abundant taxon, always accounting for more than $80 \%$ of the silicoflagellate assemblage in the five studied sites. The distribution of Dictyocha speculum and Octactis octonaria seem to be controlled by temperature. While $D$. speculum is restricted to the northern part of the Western Mediterranean Basin, where annual temperatures often drop to $12{ }^{\circ} \mathrm{C}$ during winter, O. octonaria is limited to the Alboran Sea stations, where annual minimum temperatures are never colder than $15^{\circ} \mathrm{C}$. Regarding interannual variability, the silicoflagellate fluxes do not show a straightforward relationship with the NAO winter index. However, the strong 1997-1998 ENSO event and the 2003 summer heat wave seem to have been the cause of the low silicoflagellate fluxes of the spring season of the following year, due to the higher winter temperatures and the delay of the spring phytoplankton bloom. 

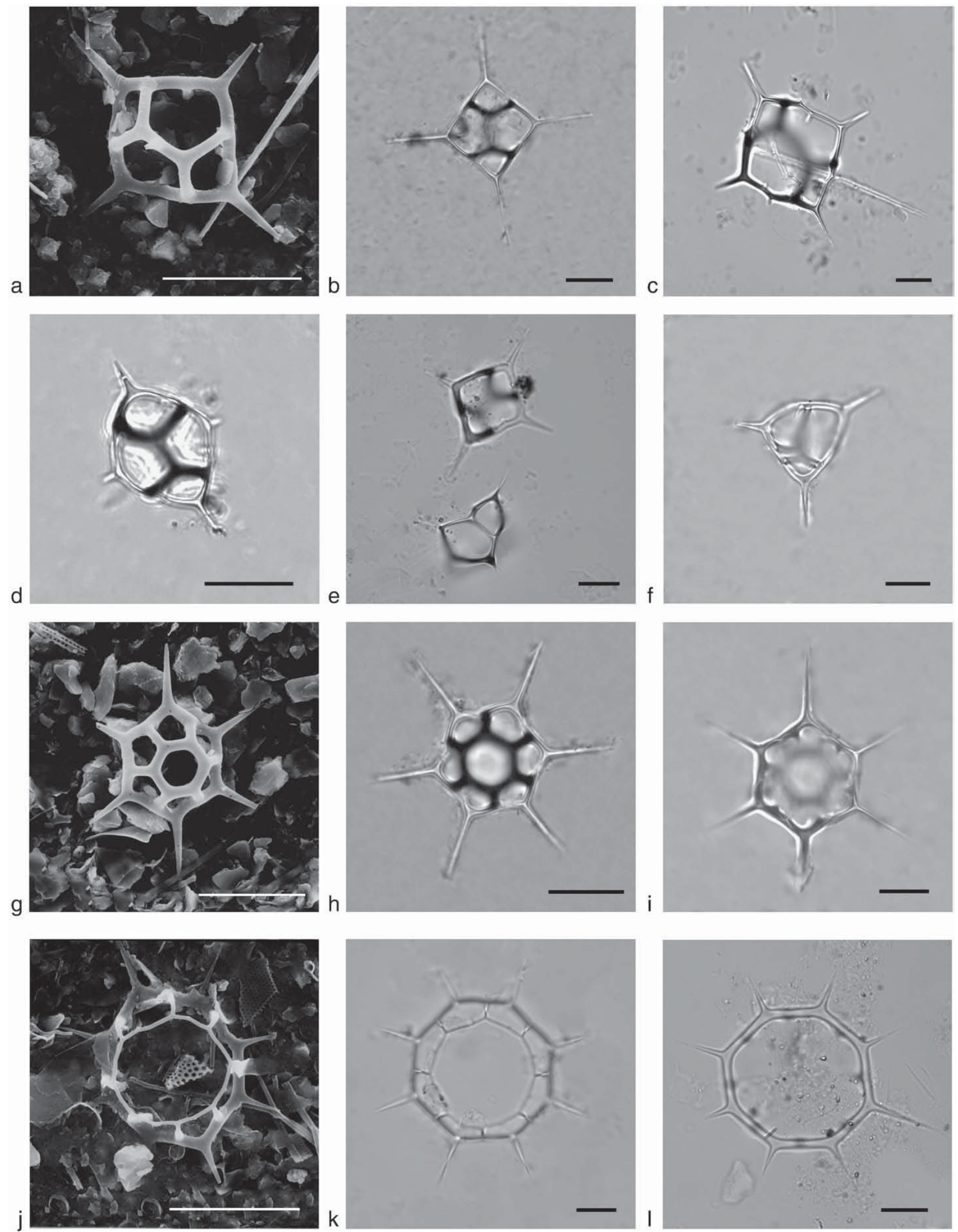

Plate 1. SEM and LM photos of the three silicoflagellate species found in the samples. a-f. Dictyocha fibula (Ehrenberg). SEM (a), LM (b-f). g-i Dictyocha speculum (Ehrenberg). SEM (g), LM (h,i). j-l.

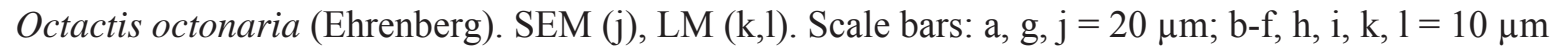




\section{Appendix}

The following descriptions of the three species identified (Fig. 1) are based on our observations and the descriptions of Throndsen (1997) and Hernández-Becerril and Bravo-Sierra (2005).

\section{Dictyocha fibula Ehrenberg 1839}

The siliceous skeleton size is $29-47 \mu \mathrm{m}$ in width and $32-58 \mu \mathrm{m}$ in length. The skeleton is square to rhomboid, with four radial spines and four "windows". The apical bar (bridge) exhibits an apical spine in the middle. Four supporting spines are situated in the basal ring close to the junctions with the apical struts. This species exhibited more morphological variations than the other two taxa, such as variations in the size of the radial spines and in the shape of the basal ring, as well as the presence of different aberrant skeletons (e.g. Plate 1f).

Dictyocha speculum Ehrenberg 1839

The skeleton of $D$. speculum (size $26-31 \mu \mathrm{m}$ in width, $30-43 \mu \mathrm{m}$ in length) has a hexagonal basal ring with six radial spines. An apical ring is supported by six apical struts. All the components of the skeleton appear to have the same thickness. Six supporting spines are conspicuous in the basal ring. No remarkable morphological variations were found in the specimens studied.

Octactis octonaria (Ehrenberg) Hovasse 1946

The skeleton of this taxon has an octagonal basal ring with eight radial spines. The shape of the skeleton is approximately circular with a diameter of $48-61 \mu \mathrm{m}$. It exhibits an apical ring supported by 8 apical struts. The apical ring is thinner than the rest of the skeleton. The basal ring does not have supporting spines. The morphological variations of this skeleton were mainly caused by the absence of the apical ring (e.g. Plate 11), which could be related to silica dissolution in the water column.

\section{Acknowledgments}

The authors wish to thank Nicole Delsaut and Joan Fabrés for their help and the preparation of the material supplied, as well as, Richard Jordan to put the electronic microscope at our disposal. Durrieu de Madron is greatly acknowledged for his assistance. The chlorophyll-a data used in this paper were produced with the Giovanni online data system,developed andmaintained by the NASA GES DISC. This study has been performed thanks to funding from the Ministerio de Ciencia e Innovación Project GRACCIE (PROGRAMA CONSOLIDER-INGENIO 2010CSD 2007-00067), CGL 2006-10593, CGL 2008-05560 and CGL 2009- 08651 and the support fromJunta de Castilla y León (Grupo GR34) and a MEC FPU grant awarded to Andrés S. Rigual-Hernández (AP2006-01992). Critical comments and suggestions from two anonymous reviewers helped greatly to improve the initial version of this work. 



\section{Capítulo 9}

Seasonal and interannual changes of planktonic foraminifer fluxes in the Gulf of Lions (NW Mediterranean) and their implications for paleoceanographic studies: Two 12-year sediment trap records

Rigual-Hernández, A.S., Sierro, F.J., Bárcena, M.A.,Flores, J.A. and Heusnner S.

To be submitted

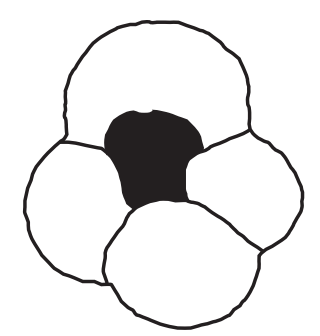





\section{Seasonal and interannual changes of planktonic foraminifer fluxes in the Gulf of Lions (NW Mediterranean) and their implications for paleoceanographic studies: Two 12-year sediment trap records.}

Andrés S. Rigual-Hernández ${ }^{1, *}$, Francisco J. Sierro ${ }^{1}$, María A. Bárcena ${ }^{1}$, José A. Flores ${ }^{1}$ and Serge Heussner ${ }^{2}$

1. Área de Paleontología, Departamento de Geología, Universidad de Salamanca, 37008 Salamanca, Spain.

2. CEFREM, UMR 5110 CNRS - University of Perpignan Via Domitia, 52 avenue Paul Alduy, 66860 Perpignan Cedex, France.

*Corresponding author.

\section{Abstract}

In order to investigate the seasonal and interannual variability of the foraminifer fluxes in the NW Mediterranean, 266 samples from two 12-year-long sediment traps were analyzed. Two mooring lines were deployed at the entrance (station Planier) and at the exit (station Lacaze Duthiers) of the Gulf of Lions. The moorings were deployed at a water depth of around $1000 \mathrm{~m}$ and they were equipped with sediment traps at 500 mab. In addition, an array of 13 core-tops recovered from different key areas of the Gulf of Lions is presented. Average foraminifer fluxes were double in Lacaze-Duthiers (411.8 shells $\mathrm{m}^{-2} \mathrm{~d}^{-1}$ ) than in Planier experimental site (225.4 shells $\mathrm{m}^{-2} \mathrm{~d}^{-1}$ ), probably due to the fertilizing effect of the Rhône river plume and the general oceanographic circulation. The annual total foraminifer fluxes exhibited a unimodal trend with maxima registered during the winter-spring transition, i.e. the spring bloom, and minima during summer. A total of eleven planktonic foraminifer species were identified in the sediment trap and core-top samples, nevertheless just four species are dominant in the assemblages: Globigerina bulloides Neogloboquadrina pachyderma, Globorotalia inflata and Globorotalia truncatulinoides. The foraminifer assemblages at the Gulf of Lions reflected the relative cold conditions of the Northern Basin. No relationship between the NAO (North Atlantic Oscillation) and the planktonic foraminifer fluxes was found in the sediment trap records. However, the low planktonic foraminifer fluxes recorded during the spring 1998, was probably related to the anomalous environmental conditions triggered by the 1997-98 El Niño Event. This study shed light on the habitat and ecological conditions of the planktonic foraminifer species living today in the Gulf of Lion, which is crucial on biogeochemical and paleoceanographic reconstructions. Knowledge of the life cycle of the species and when they form their calcite shells is essential in paleoceanographic studies when trying to estimate the nutrient content, the $\mathrm{d} 18 \mathrm{O}$ or the temperature of surface water. Furthermore, discrepancies between sediment traps and sediment samples and the application of these results in further paleoceanographic reconstructions are discussed.

Key words: foraminifera, sediment trap, sediment trap, core top, ENSO, NAO 


\subsection{INTRODUCTION}

Planktonic foraminifera have been widely used for paleoclimatic and paleoceanographic reconstructions. The abundance and composition of the modern day foraminiferal assemblages are intimately related to the environmental conditions of the water masses where they live (e.g., temperature, salinity, radiation intensity and food availability). These environmental preferences allow for the reconstruction of the oceanographic conditions through geologic time. However, to make valid interpretations of the fossil record it is fundamental to know the ecology and environmental factors controlling the spatial and temporal distribution of the species utilized to make these reconstructions. In this sense, several lines of research have been followed for decades to shed light on different aspects of the biology and sedimentary processes of the living planktonic foraminifera: (1) Laboratory cultures, to determine the effects of different controlled environmental conditions on the growth and reproductive potential of planktonic foraminifera (e.g., Bé et al., 1981; Bijma et al., 1990; Bijma et al., 1992; Bemis et al., 2000; Dueñas-Bohórquez et al., 2009); (2) Direct studies of the living assemblages through the collection of living specimens with plankton tows (e.g. Berger, 1969; Berger, 1970; Bé and Tolderlund, 1971; Williams et al., 1981; Pujol and Vergnaud Grazzini, 1995) that provide information of the magnitude and composition of planktonic foraminifer standing stocks, their depth and seasonal distribution, and more recently they have also been also used to sample living specimens for genetic studies (e.g., Darling et al., 2003; Darling et al., 2006; Darling and Wade, 2008); (3) Sediment trap experiments that register the integrated faunal flux bridging the gap between living populations, and the fossil foraminiferal record (Deuser et al., 1981; Thunell and Reynolds, 1984; Kincaid et al., 2000); (4) the study of modern thanatocenoses in core tops from the deep sea floor that are compared with the physico-chemical properties of the water mass in order to reconstruct paleoceanographic conditions through modern analog techniques (Thiede, 1978; Thunell, 1978; Kallel et al., 1997).

The Mediterranean Sea has been the object of numerous paleoclimatic studies where planktonic foraminifers have played a vital role in the reconstruction of the evolution of the basin (Thiede, 1978; e.g., Schilman et al., 2001; Sierro et al., 2009). Nonetheless, as pointed out by Pujol and Vergnaud Grazzini (1995), scarce substantial studies focused on the living foraminiferal populations have been carried out in the Mediterranean basin (Cifelli, 1974; Thiede, 1978; Pujol and Vergnaud Grazzini, 1995; Bárcena et al., 2004; Hernández-Almeida et al., 2010). In this work, we present the first long-term study of planktonic foraminifer fluxes in the Western Mediterranean through the analysis of two 12-year-long sediment trap records and an array of 13 core-tops along a transect covering key areas of the Gulf of Lions (i.e., continental shelf, open slope, submarine canyons and deep basin). The main objectives of this research are to determine the general seasonal distribution patterns of the different foraminiferal species in the Gulf of Lions as well as to ascertain the influence of primary productivity and river runoff over the abundance and species composition of the foraminiferal fluxes. Besides to attempt to analyze the imprint of recent climatic phenomena such as ENSO and NAO over the foraminiferal fluxes of the northwestern Mediterranean. 


\subsection{OCEANOGRAPHIC SETTING}

The Gulf of Lions is set in the northwestern part of the Mediterranean Sea. It exhibits a wide crescent-shape continental shelf and a continental slope incised by an intricate network of submarine canyons (Fig. 1). The general circulation in this area is governed by the Northern Current (NC) that enters the Gulf on its eastern side and flows to the south along the shelf break in a counter clockwise direction (Millot, 1991) (Fig. 1). During winter, cold and dry continental northwesterlies (Mistral and Tramontana) blow with special intensity over the Gulf, being responsible of the formation of dense water both on the shelf and offshore. During abnormally cold and windy winters (e.g. 1999 and 2005), large volumes of dense water are formed over the shelf dragging important amounts of sediment and organic matter from the continental shelf to the deep basin (Canals et al., 2006). This phenomenon is called cascading and occurs along the entire shelfbreak although it is more pronounced at the southwestern exit of the Gulf (Heussner et al., 2006).

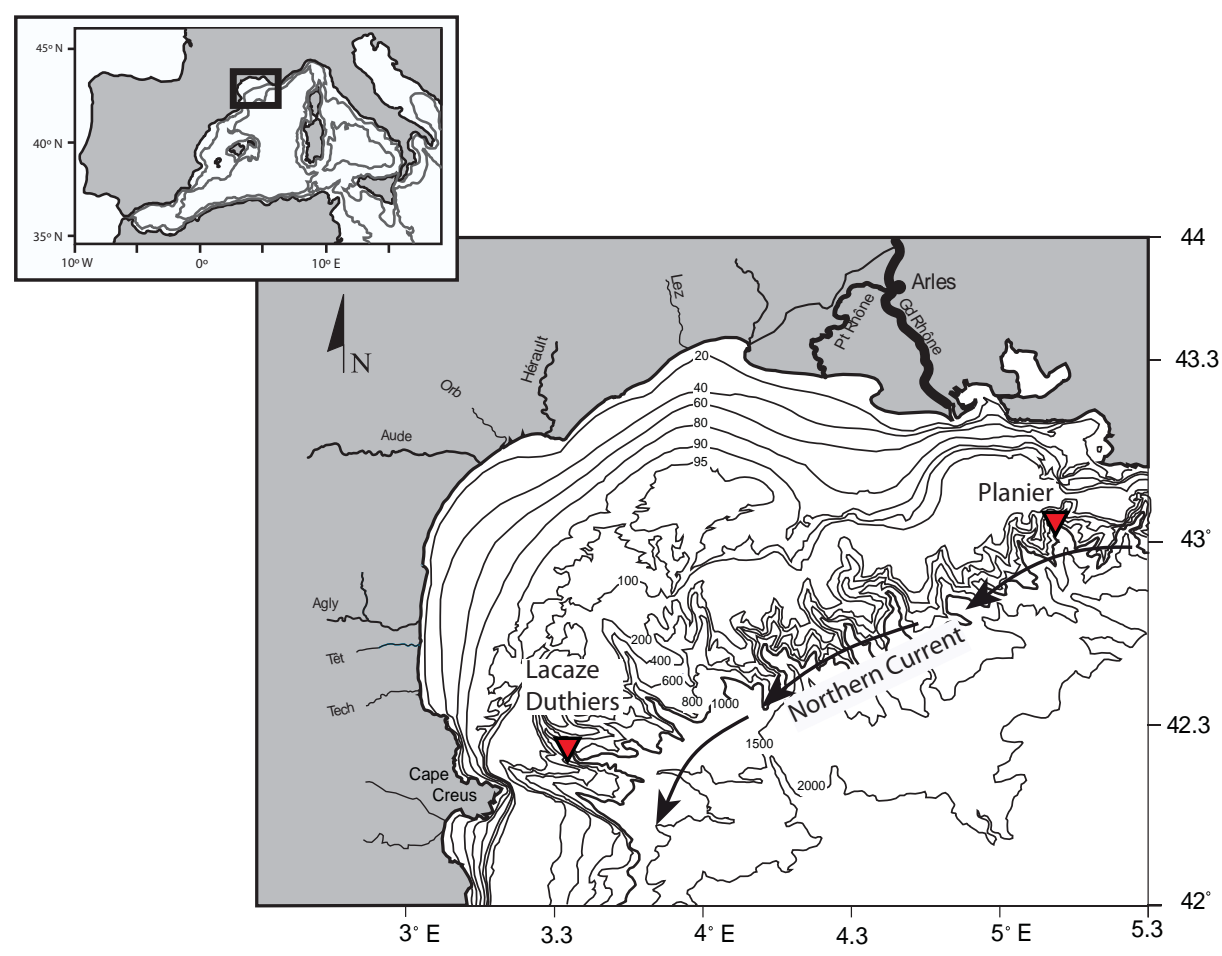

Figure 1. Geographic setting and bathymetric map of the Gulf of Lions. Triangles represent the position of Planier and Lacaze-Duthiers sediment traps, arrows represent the theoretical surface circulation.

The Rhône flows into the Gulf of Lions in its northern part (Fig. 1) and it is the river with greatest discharge in the Mediterranean Sea. Other nine small rivers also deliver material into the Gulf, however, the Rhône is its main source of fresh water and sediments (Ulses et al., 2008). From the productivity point of view, the Northern Basin can be considered as an exception of the general oligotrophy of the Mediterranean due to several features that contribute to increase its potential fertility, such as, the mesoscale variability of the $\mathrm{NC}$, the winter vertical mixing 
and the nutrient-rich waters from the Rhone (Estrada, 1996).

The annual cycle of the water column in the northwestern Mediterranean follows the classical seasonal evolution of a temperate ocean. After summer, the seasonal cooling breaks up the strong stratification. During winter, the persistent northwesterlies promote the dense water formation and deep mixing, advecting nutrients to the surface and setting the stage for the spring bloom. By late-winter-early-spring, the enriched waters and the solar radiation increase, triggering the development of the annual maximum of primary productivity. Finally, the gradual insolation increase throughout the spring season eventually restratifies the nutrient-depleted surface waters, ending the annual cycle.

\subsection{MATERIAL AND METHODS}

\subsubsection{Field experiment}

Two moorings lines were deployed in the NW Mediterranean: one at the entrance of the Gulf of Lions, in the axis of Planier Canyon $\left(43.02^{\circ} \mathrm{N}, 5.18^{\circ} \mathrm{E}\right)$ and one at its southwestern exit, in the axis of Lacaze-Duthiers Canyon $\left(42.41^{\circ} \mathrm{N}, 3.54^{\circ} \mathrm{E}\right)$ (Fig. 1). Both moorings were deployed at ca. $1000 \mathrm{~m}$ water depth and were equipped with two sediment traps (500 and $1000 \mathrm{mab}$ ) paired with current meters (Heussner et al., 2006). Both traps were PPS 3 Technicap sediment traps: cylindro-conical in shape with $0,4 \mathrm{~m}$ opening diameter $(2.5$ height/diameter aspect ratio for the cylindrical part) and equipped with 6 or 12 sampling cups (Heussner et al., 1990).

Here, we present the data registered by the two sediment traps set at 500 mab from October 1993 until January 2006. The experiment can be divided in two phases based on the collecting periods: a first phase until early 1997 with a sampling interval at 14 days, and at one month onwards until the beginning of 2006. Gaps in the time series were caused by mooring recovery periods or by problems in the sediment trap functioning. Despite these gaps, the foraminiferal test flux data represent more than $75 \%$ and $82 \%$ of the deployment time for Planier and Lacaze Duthiers stations, respectively.

\subsubsection{Core tops}

A compilation of 13 core tops from representative areas of the Gulf of Lions are presented in this work. The location of the core tops is shown in Figure 2 while their main characteristics are summarized in Table 1.

\subsubsection{General processing of the sediment trap and core top samples}

The general sample processing and a detailed description of the PPS3 sediment trap can be found in Heussner et al. (1990 and 2006), while the specific treatment for the foraminiferal analysis is described next. Different aliquots from the original samples were used for the micropaleontological analysis. The most common was $1 / 8$, but other fractions were also used depending on the sample availability, ranging from 1/64 to $3 / 4$. The samples were wet-sieved 
with a potassium phosphate buffered solution $(\mathrm{pH}=7,5)$ into two size fractions: $63-150 \mu \mathrm{m}$ and $150 \mu \mathrm{m}$. The aim of this solution was to prevent the carbonate dissolution during the sieving process without affecting the shell composition. After the sieving process, the $>150 \mu \mathrm{m}$ fraction was strained with cellulose filter paper and dried at ambient temperature afterwards. Regarding the core-top preparation, each sample wet sieved through a $63 \mu \mathrm{m}$ screen and dry-sieved through a $150 \mu \mathrm{m}$ screen. The larger than $150 \mu \mathrm{m}$ residue was then split as many times as necessary to obtain an aliquot of 400 or more planktonic foraminifers using a microsplitter.

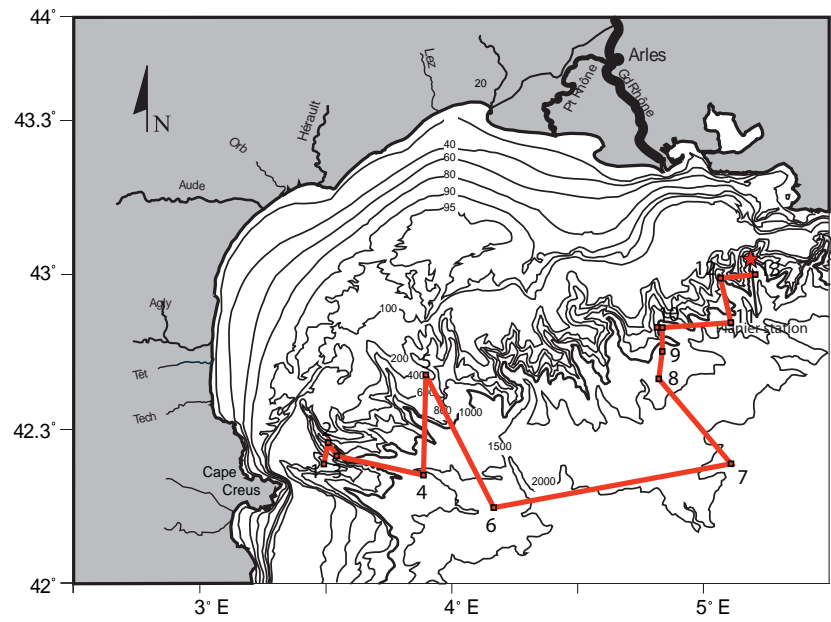

a

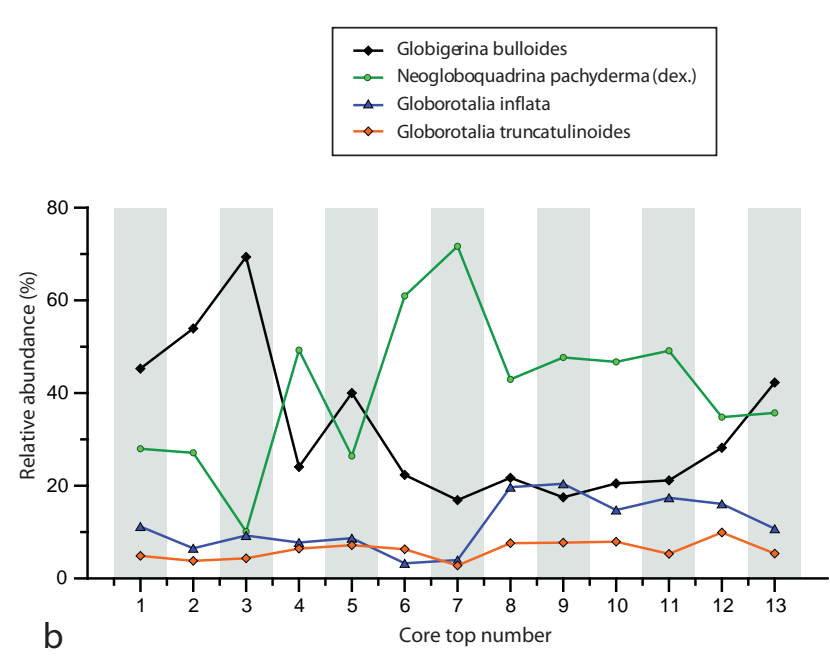

Figure 2. a. Bathymetric map of the Gulf of Lions with the location of the core tops. The red line represent the core top transect. $\mathbf{b}$. Relative abundance of the four main taxa along the core top transect.

\begin{tabular}{lrrrrrrrrrrrrrrr}
\hline Core tops & $\mathbf{1}$ & $\mathbf{2}$ & $\mathbf{3}$ & $\mathbf{4}$ & $\mathbf{5}$ & $\mathbf{6}$ & $\mathbf{7}$ & $\mathbf{8}$ & $\mathbf{9}$ & $\mathbf{1 0}$ & $\mathbf{1 1}$ & $\mathbf{1 2}$ & $\mathbf{1 3}$ & Planier & L D \\
\hline G. bulloides & 45.3 & 53.9 & 69.4 & 24.1 & 40.0 & 22.3 & 16.9 & 21.7 & 17.5 & 20.5 & 21.2 & 28.2 & 42.3 & 36.5 & 50.8 \\
N. pachyderma (dex.) & 28.0 & 27.1 & 10.1 & 49.3 & 26.4 & 61.0 & 71.7 & 43.0 & 47.7 & 46.7 & 49.1 & 34.8 & 35.7 & 18.7 & 16.0 \\
G. inflata & 4.9 & 3.8 & 4.3 & 6.4 & 7.2 & 6.3 & 2.8 & 7.6 & 7.7 & 7.9 & 5.3 & 9.9 & 5.4 & 10.1 & 9.2 \\
G. truncatulinoides & 11.2 & 6.5 & 9.2 & 7.7 & 8.7 & 3.3 & 4.0 & 19.7 & 20.4 & 14.8 & 17.4 & 16.1 & 10.7 & 30.3 & 17.5 \\
O. universa & 1.2 & 1.1 & 3.5 & 0.3 & 0.8 & 0.4 & 0.2 & 0.9 & 0.7 & 0.8 & 1.1 & 1.5 & 1.0 & 1.3 & 2.4 \\
G. siphonifera & 0.2 & 0.0 & 0.0 & 0.0 & 0.8 & 0.0 & 0.0 & 0.0 & 0.0 & 0.0 & 0.0 & 0.0 & 1.0 & 1.3 & 1.1 \\
G. ruber & 4.1 & 3.5 & 1.2 & 5.9 & 11.3 & 0.9 & 0.4 & 4.3 & 2.7 & 6.3 & 2.4 & 6.0 & 2.4 & 0.2 & 0.3 \\
G. ruber (pink) & 0.0 & 0.0 & 0.3 & 0.0 & 0.0 & 0.0 & 0.0 & 0.0 & 0.0 & 0.0 & 0.0 & 0.0 & 0.2 & 0.0 & 0.1 \\
G. sacculifer & 0.0 & 0.0 & 0.0 & 0.0 & 0.0 & 0.0 & 0.0 & 0.0 & 0.2 & 0.0 & 0.0 & 0.0 & 0.0 & 0.5 & 1.7 \\
G. glutinata & 1.0 & 1.4 & 0.3 & 2.3 & 0.0 & 2.6 & 1.6 & 1.1 & 1.0 & 0.3 & 0.7 & 0.9 & 0.6 & 0.2 & 0.3 \\
G. digitata & 0.0 & 0.0 & 0.9 & 0.0 & 0.0 & 0.0 & 0.0 & 0.0 & 0.0 & 0.0 & 0.0 & 0.0 & 0.6 & 0.2 & 0.3 \\
T. quinqueloba & 0.0 & 0.5 & 0.0 & 0.8 & 1.1 & 0.2 & 0.9 & 0.0 & 0.0 & 0.0 & 0.2 & 0.2 & 0.0 & 0.7 & 0.2 \\
\hline
\end{tabular}

Table 1. Relative abundances of planktonic foraminiferal species in core-top and sediment trap samples.

A total of 278 sediment trap samples and 2 core-top samples $(>150 \mu \mathrm{m})$ were examined under a dissecting microscope for species identification and counting. Due to the high seasonal flux variations of this group, there were some periods when almost none foraminifer was present in the water column and therefore in the traps. Because of this, the number of tests in the samples was very variable ranging from 0 to 1946. The foraminifer flux estimates are given in specimens $/ \mathrm{m}^{2} /$ day, and were calculated based on the duration of each collection period, the 
aliquot of the original sample and the diameter of the sediment trap $(0,4 \mathrm{~m}$ diameter $)$.

Monthly averages of planktonic foraminifer species, chlorophyll- $a$ and SST fluxes were elaborated to discern their general seasonal trends (Fig. 5). To calculate the monthly average flux, an average daily flux value was assigned to each day of the collecting period. Then, the total flux for a particular month was the result of the addition of all daily fluxes during this month. Finally, we estimated the average monthly flux for each month for the 12 year record.
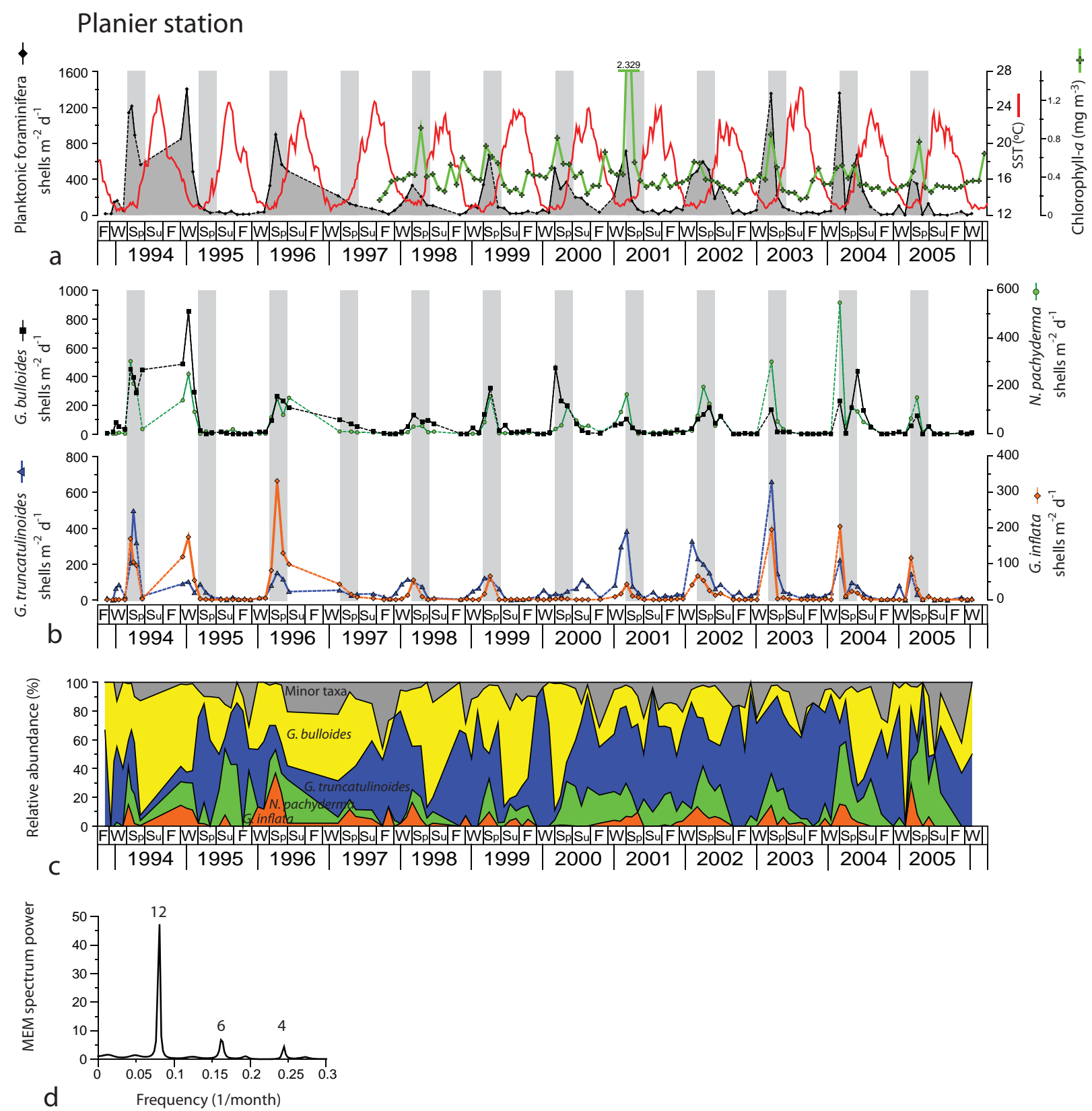

Figure 3. Planier station a. Total foraminifer flux (shells day $\left.{ }^{-1} \mathrm{~m}^{-2}\right)$, temperature $\left({ }^{\circ} \mathrm{C}\right)$ and chlorophyll- $a$ concentration $\left(\mathrm{mg} \mathrm{m}^{3}\right)$. b. G. bulloides, N. pachyderma, G. inflata and G. truncatulinoides flux (shells day $^{-1} \mathrm{~m}^{-2}$ ) c. Relative abundance of the foraminifer assemblage d. Frequency versus power from the maximum entropy method for total foraminiferal fluxes at Planier site. 


\subsubsection{Satellite imagery, meteorological and oceanographic data}

SeaWiFS satellite monthly Chlorophyll-a concentration from September 1997 till March 2006 (Fig. 3 and 4) were obtained from NASA's Giovanni program (Acker and Leptoukh, 2007). The Chlorophyll- $a$ concentration was averaged over an area of $0.2^{\circ} \times 0.2^{\circ}$ around the mooring location. Weekly sea surface temperatures (SSTs) from October 1993 until March 2006 (Fig. 3 and 4) were obtained from NOAA Optimum Interpolation Sea Surface Temperature Analysis
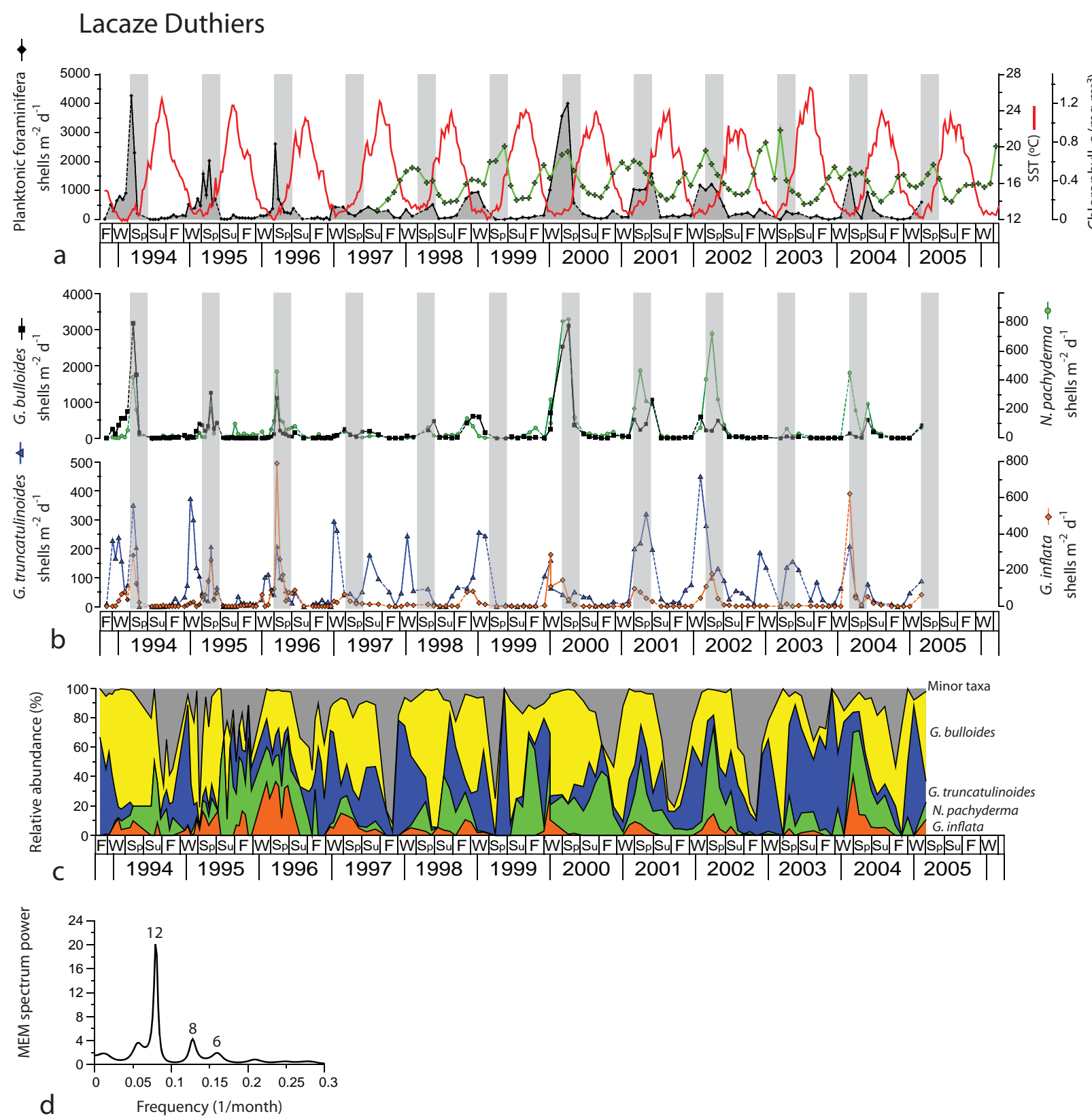

Figure 4. Lacaze Duthiers station a. Total foraminifer flux (shells day $\left.{ }^{-1} \mathrm{~m}^{-2}\right)$, temperature $\left({ }^{\circ} \mathrm{C}\right)$ and chlorophyll-a concentration $\left(\mathrm{mg} \mathrm{m}^{3}\right)$. b. G. bulloides, N. pachyderma, G. inflata and G. truncatulinoides flux (shells day ${ }^{-1} \mathrm{~m}^{-2}$ ) c. Relative contribution of the foraminifer assemblage d. Frequency versus power from the maximum entropy method for total foraminiferal fluxes at Lacaze-Duthiers site. 
(Reynolds et al., 2002). Monthly averages of vertical thermal structure of the upper $300 \mathrm{~m}$ for the period 1996-2006 was obtained for both sampling locations from the World Ocean Atlas 1994 (Levitus and Boyer, 1994).

\subsubsection{Spectral analysis}

To investigate the periodicity in the flux of total foraminifers at stations Planier and Lacaze Duthiers, the maximum entropy spectral method was carried out by means of "Analysis Series" program, Version 1.1. Before the spectral analysis, the data sets were normalized and linearly detrended. Owned to the gaps until 1997 in Planier time-series, the analysis was only performed for the period 1997-2006 for this station (Fig. 3), while for Lacaze Duthiers the complete data set was used. The MEM analysis results in only one significant cycle of 12-month period in both stations (Fig. 3 and 4).

\subsection{RESULTS}

\subsubsection{Total planktonic foraminiferal flux}

Total planktonic foraminifer fluxes followed the cycle of the primary productivity and were negatively correlated with temperature in both sampling locations (Fig. 3 and 4). In Planier station, planktonic foraminifer fluxes ranged from 0 to 2144 shells $\mathrm{m}^{-2} \mathrm{~d}^{-1}$, while in Lacaze Duthiers ranged from 2 to 4268 shells $\mathrm{m}^{-2} \mathrm{~d}^{-1}$. The 12-years average of the total foraminifer fluxes $(>150 \mu \mathrm{m})$ in Planier site was 225.4 shells $\mathrm{m}^{-2} \mathrm{~d}^{-1}$ while in Lacaze Duthiers station was approximately double (411.8 shells $\left.\mathrm{m}^{-2} \mathrm{~d}^{-1}\right)$.

Annual maxima of total foraminifer fluxes were registered every year during the winter-spring season in both sites. In Planier site, the highest fluxes were registered during December 1994 (1405 shells $\left.\mathrm{m}^{-2} \mathrm{~d}^{-1}\right)$, March 2003 (1356 shells $\mathrm{m}^{-2} \mathrm{~d}^{-1}$ ), and March 2004 (1360 shells $\left.\mathrm{m}^{-2} \mathrm{~d}^{-1}\right)$ (Fig. 3). Regarding Lacaze Duthiers station, the highest values were recorded during March 1994 (4268 shells m $\mathrm{d}^{-1}$ ), March 1996 (3565 shells $\mathrm{m}^{-2} \mathrm{~d}^{-1}$ ) and April-March 2000 (3999 and 3565 shells $\left.\mathrm{m}^{-2} \mathrm{~d}^{-1}\right)$ (Fig. 4).

\subsubsection{Foraminiferal assemblages}

Foraminifer tests were the major component of the sediment fraction $>150 \mu \mathrm{m}$. Eleven species of planktonic foraminifers were identified in the samples, however the assemblage at both stations was mainly composed by four species: Globigerina bulloides, Neogloboquadrina pachyderma (dex.), Globorotalia inflata and Globoralia truncatulinoides. These four taxa account for $94.55 \%$ and $87.8 \%$ of the assemblages for Planier and Lacaze-Duthiers stations, respectively. However, other less abundant species were also identified and counted, such as, Globigerinella siphonifera, Neogloboquadrina pachyderma (sin.), Globigerinoides ruber morphotype white and pink, Globigerinoides sacculifer, Globigerinita glutinata, Globigerinella digitata, Orbulina universa and Turborotalita quinqueloba.

The four main planktonic foraminifer species showed a similar annual unimodal distribution 
at both stations (Fig. 5), however they exhibit slightly different annual patterns. In Planier site, the four major species peaked in March, coinciding with the spring phytoplankton bloom (Fig. 3). In contrast, in Lacaze Duthiers station a succession is observed (Fig. 5). Firstly G. truncatulinoides shows its maximum fluxes during winter, period with the most intense water mixing. Then, during the winter-spring transition, G. bulloides flux drastically increases, and finally N. pachyderma and G. inflata peak during March, coinciding with the maximum of the phytoplankton spring bloom.

Regarding the minor species, the number of specimens identified in the samples was low, and hence, the estimation of their fluxes is not as reliable as for the major taxa. The main components of the minor taxa group are O. universa (1.3\%), G. siphoniphera (1.3\%) for Planier and O. universa (2.4\%), G. sacculifer (1.7\%) and G. siphonifera (1.1\%) for Lacaze-Duthiers experimental site (Table 1). These species exhibit different annual distribution patterns in each experimental station (Fig. 5). In this sense, O. universa exhibits its maximum fluxes at the end of spring and summer in Planier station, and during fall in Lacaze Duthiers. G. siphonifera fluxes were maximum during spring in Planier, and during winter in Lacaze Duthiers station. Concerning G. sacculifer, its fluxes in Planier station were low and disperse while in Lacaze Duthiers site they were higher and exhibit a clear pattern with a unimodal distribution with maximum values in fall (Fig. 5).

\subsubsection{Core tops}

The core-top transect covers the main areas of the Gulf of Lions (Fig. 2). The relative contribution of all the foraminifer species found in the sediment samples are resumed in Table 1, while the relative abundances of the major taxa are plotted in Figure 2. The same four taxa that dominate the planktonic foraminiferal fluxes in the sediment traps are the principal components of the core-top assemblages. Globigerina bulloides is the main contributor of the core tops located in Planier canyon and in the southwestern part of the GoL (Fig. 2) while Neogloboquadrina pachyderma exhibits an opposite distribution to G. bulloides, being the dominant taxon in the northeastern part of the GoL (except in Planier site) and in the deep basin where it reaches its highest values (up to 71\%) (Fig. 2). Regarding Globorotalia truncatulinoides, its highest relative abundance values are registered in the southwestern part of the Gulf. Globorotalia inflata is the fourth most important planktonic foraminifer species and its contribution is relatively constant in all the samples of the array. 

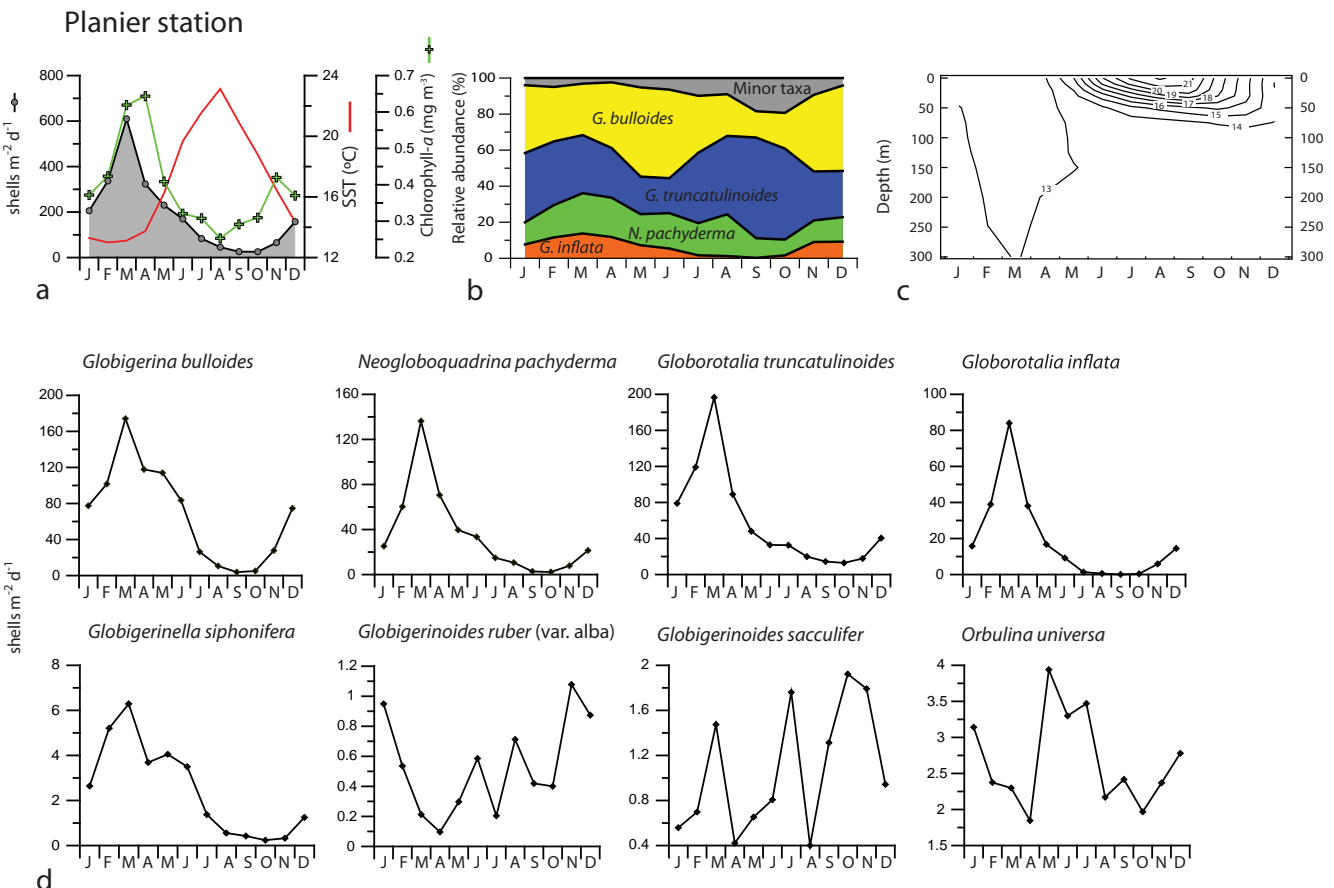

Lacaze Duthiers station
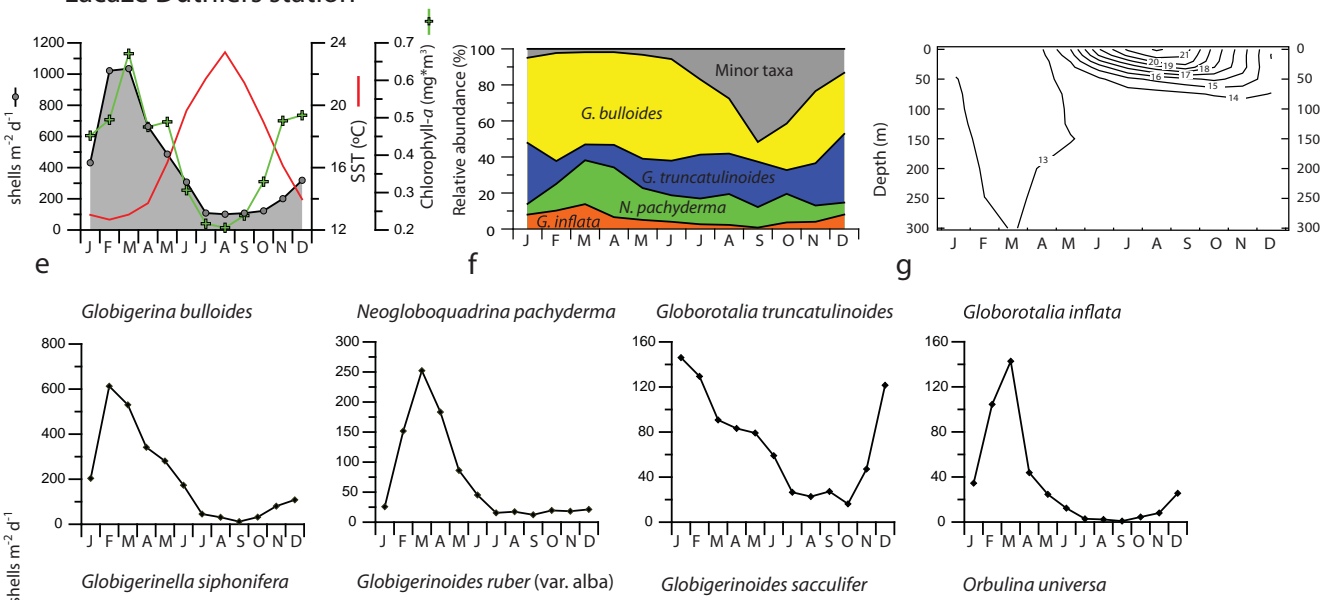

Globorotalia inflata
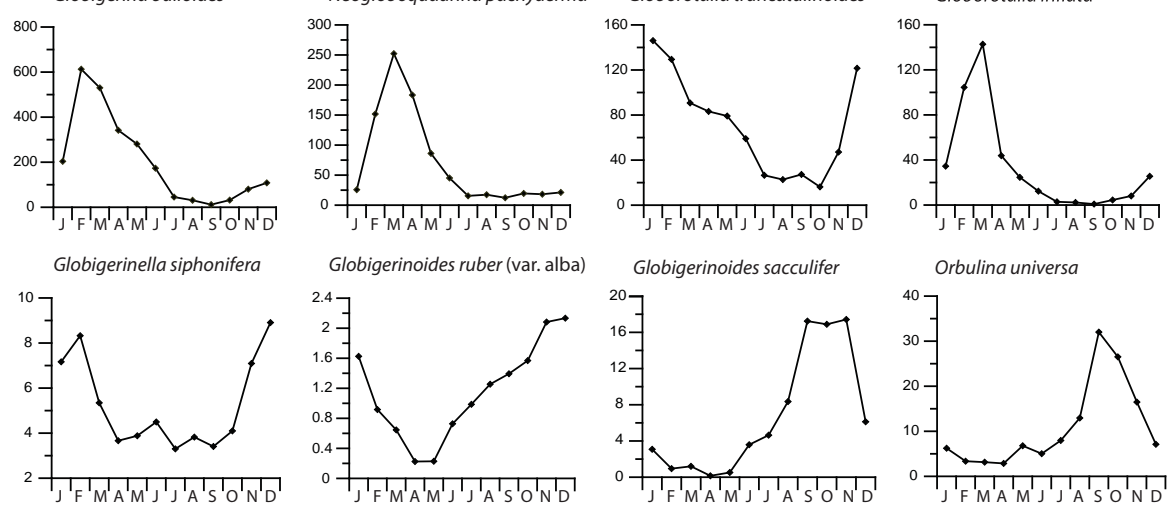

Turborotalita quinquelobo
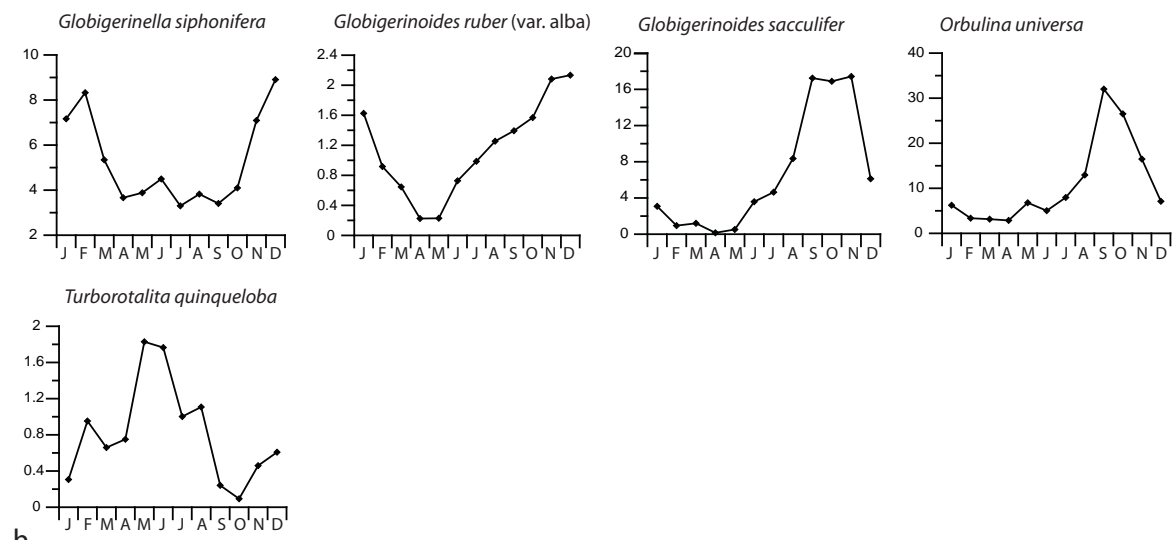

Figure 5. a. Average year of total foraminifer flux (tests day ${ }^{-1} \mathrm{~m}^{-2}$ ), temperature and chlorophyll-a concentration $\left(\mathrm{mg} \mathrm{m}^{3}\right)$ for Planier site. $\mathrm{b}$. Average year of relative abundance of the main foraminifer groups of Planier site. c. Seasonal variation of vertical structure of temperature at station Planier. d. Average year of the main foraminifer fluxes $\left(\right.$ shells day ${ }^{-1} \mathrm{~m}^{-2}$ ) in Planier site. e. Average year of total foraminifer flux (tests day ${ }^{-1} \mathrm{~m}^{-2}$ ), temperature and chlorophyll-a concentration $\left(\mathrm{mg} \mathrm{m}^{3}\right)$ for Lacaze Duthiers site. f. Average year of relative abundance of the main foraminifer groups of Lacaze Duthiers site. g. Seasonal variation of vertical structure of temperature at station Lacaze Duthiers. h. Average year of the main foraminifer fluxes (shells day ${ }^{-1} \mathrm{~m}^{-2}$ ) in Lacaze Duthiers site. 


\subsection{DISCUSSION}

\subsubsection{Sources and preservation of trap-collected planktonic foraminifers}

Owned to the complex hydrography of the GoL and the location of the sediment traps in the axis of submarine canyons, the material captured by the two sediment traps could be of diverse origin: sediments delivered by the Rhône river, resuspended sediments either from the continental shelf or upper slope, and biogenic material as either in-situ production from the upper part of the water column or laterally advected from the shelf or surrounding areas. Nevertheless, some of the possible sources of material can be discarded based on previous studies in the GoL. First of all, both sediment traps are far from the bottom (500 mab) which hampers the collection of resuspended sediments from the continental shelf. Planier sediment trap was considered the most marine site of all the sampling stations studied by Heussner et al. (2006) and the one that experiences the minimum influence of particle inputs from the shelf. Moreover, Planier experimental site is probably free of influence of the Rhône river plume (Durrieu de Madron et al., 1990). Regarding Lacaze-Duthiers site, it exhibits a "degradation" of the seasonal signal (Heussner et al., 2006) because it is located under the influence of the dilution area of Rhône river plume (Lefevre et al., 1997) and it registers more particulate material from the shelf due to the general circulation in the Gulf (Heussner et al., 2006) and the presence of denser nephelometric structures than at Planier site (Durrieu de Madron et al., 1990).

A second point to consider is the time lag between the production of a foraminifer specimen and its record by the sediment trap. As pointed out by Sautter and Thunell (1991) the settling velocities of the planktonic foraminifer tests between their depth habitat and a sediment trap set at $500 \mathrm{~m}$ depth is greater than $75 \mathrm{~m} /$ day. Thus, it could be assumed that the skeletons of planktonic foraminifers would need less than one week to settle through the water column. On the other hand, the life cycle of a foraminifer has been estimated to span from two to four weeks (Hemleben and Spindler, 1983), although high fertility periods could increase their growth rate reducing their life span (Berger, 1971). Therefore, we can assume a delay of two to five weeks between the production of individuals in the water column and their collection by the sediment trap (Sautter and Thunell, 1991).

Regarding the carbonate dissolution, it can be considered as negligible throughout the first 500 $\mathrm{m}$ due to the saturation of calcite and aragonite of western Mediterranean waters (Millero et al., 1979; Schneider et al., 2007) and the good preservation of the planktonic foraminifer tests in the samples, that often exhibit intact spines.

\subsubsection{Seasonal and geographical flux variability}

Planktonic foraminifer fluxes underwent consistent annual cycles and variable interannual fluctuations that mirrored the hydrographic and atmospheric conditions off the Northwestern Mediterranean. The MEM power spectrum analysis identified one significant cycle of a 12month period in both stations (Fig. 3 and 4) that refers to the winter-spring maxima of total 
foraminifer flux. This total foraminifer flux annual maximum is always accompanied by the annual chlorophyll-a maximum (spring bloom) in both stations (Fig. 3 and 4) that indicates a strong relationship between foraminifer growth and food availability. Nevertheless, it also should be taken into account that during this period the processes controlling the particle transfer between the shelf and the deep basin also reach their maximum intensity and, therefore, planktonic foraminifer fluxes could be enhanced by the advection phenomena (Durrieu de Madron et al., 1999).

By contrast the minimum annual foraminifer fluxes were always recorded during summer and autumn at both locations (Fig. 3 and 4), i.e. the period of lowest primary productivity and strongest stratification (Fig. 5).

The two-fold total foraminiferal fluxes registered by Lacaze-Duthiers station is mainly attributable to its geographical location. Lacaze-Duthiers station is set under the influence of the Rhône river dilution area (Lefevre et al., 1997), and therefore, it is subject to higher concentrations of nutrients and phytoplankton than Planier site. Moreover, Lacaze-Duthiers experimental site is subject to higher influence of particulate matter from the shelf than Planier (Heussner et al., 2006).

\subsubsection{Interannual planktonic foraminifer fluctuations}

Despite much of the spectral energy of the planktonic foraminifer fluxes in the Gulf of Lions is comprised in the annual period, they also exhibit an evident interannual variability (Fig. 3 and 4). Several oceanographic and climatic phenomena recorded in the North Atlantic and Mediterranean, such as, DSWC events, North Atlantic Oscillation (NAO) and El Niño Southern Oscillation (ENSO) with recurrent periodicities longer than one year could leave an imprint on the variability of planktonic foraminifer fluxes.

The Gulf of Lions is one of the few areas of the Mediterranean where dense water formation occurs (Durrieu de Madron et al., 2005). During anomalously cold and windy winters, large volumes of dense water are formed over the shelf and funneled to the deep ocean by the submarine canyons of continental slope (Canals et al., 2006). This process occurs along the entire shelfbreak although it is more pronounced at the exit of the GoL (Heussner et al., 2006). The strongest cascading events along our record took place during winter 1999 and 2005 (Canals et al., 2006; Heussner et al., 2006). These intense DSWC events could alter the planktonic foraminifer fluxes recorded by both sediment traps, dragging planktonic foraminifer tests previously deposited over the shelf sediments and/or enhancing the growth of the living planktonic foraminifer assemblages by means of an increase in the food supply. However, during these two years no remarkably high pulses of planktonic foraminifers were recorded in the stations which evidence that intense cascading events did not significantly altered planktonic foraminifer fluxes at $500 \mathrm{mab}$.

The North Atlantic Oscillation (NAO) can be defined as a north-south seesaw oscillation in atmospheric mass with centers of action near Iceland and over the subtropical Atlantic, being the 
dominant mode of winter climate variability in the North Atlantic region. NAO winter positive phase (Hurrell, 1995) is associated with warm and moist air masses conveyed towards the NW Mediterranean resulting in mild winters and in a decrease of the NC flow. While, negative NAO winter values are related to severe weather conditions, i.e. cold and dry air masses from polar regions prevail, leading to an intensification of the of the heat losses to the atmosphere and an intensification of the NC circulation (Vignudelli et al., 1999). It has been observed that low or negative NAO winter index was often associated with strong diatom blooms while positive values were normally coupled with weak diatom blooms (Gómez and Gorsky, 2003). Therefore, an enhancement of the planktonic foraminifer fluxes due to increase food supply (nutrients and phytoplankton), is expected those winters with the most negative NAO values throughout our record, i.e., 1996 and 2001 (Fig. 6). Nevertheless, planktonic foraminifers did not significantly intensify their fluxes during those years at any of the experimental stations, which suggests that the processes that lead the foraminifera flux variability are not controlled by the NAO.
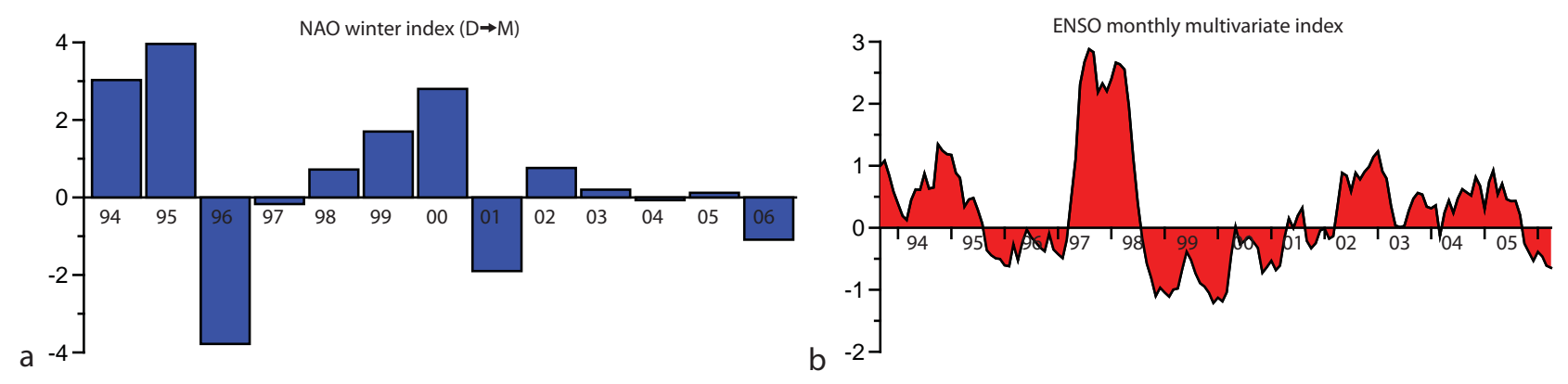

Figure 6. a. NAO Winter index. b. monthly multivariate ENSO index.

El Niño Southern Oscillation (ENSO) is a quasi-periodic climate fluctuation with its major effects recorded over the Pacific Ocean. El Niño events are characterized by warming of the tropical Pacific and a weakening of the trade winds. It has been suggested that severe El Niño events could rise the global mean temperatures (McPhaden, 1999a) and/or modify the climate of the North Atlantic and Europe (Wanner et al., 1997). During 1997-98, the strongest El Niño event of the last century took place (Fig. 6), and major climatic impacts felt around the world were related to this event (McPhaden, 1999b). In this sense, anomalously high SST and weak winds were registered during summer and fall 1997 in the Alboran Sea (Western Mediterranean) (García-Gorriz and Carr, 2001) that yield the development of a weak winter upwelling during 1998 and important changes in the plankton living assemblages (2005; Mercado et al., 2007) and downward fluxes of plankton remains (Bárcena et al., 2004; Hernández-Almeida et al., 2010).

In the NW Mediterranean abnormally high SST (Fig. 3 and 4) and low wind intensity were registered during fall 1997 and winter 1998 (Rigual-Hernández et al., 2010) which resulted in a debilitated winter mixing (Marty et al., 2002; Rigual-Hernández et al., 2010). This scenario yield low siliceous plankton fluxes in the NW Mediterranean (Rigual-Hernández et al., 2010) and a 
remarkable change in the diatom assemblages (Rigual-Hernández et al., submitted). Planktonic foraminifer fluxes in both stations exhibited notable low values during this period, probably owned to weak winter mixing and the subsequent scarce food supply. This fact suggests that the anomalous meteorological and hydrographic conditions induced by the El Niño event 1997-98 had direct repercussions over the planktonic foraminifer assemblages in the Gulf of Lions.

\subsubsection{Foraminifer faunal composition in the sediment trap records}

The assemblages of foraminiferal test fluxes at Planier and Lacaze Duthiers stations are mainly composed by four species: Globigerina bulloides, Neogloboquadrina pachyderma (dex.), Globorotalia inflata and Globoralia truncatulinoides (Table 1). This assemblage is characteristic of the NW Mediterranean (Pujol and Vergnaud Grazzini, 1995; Core top database of Kallel et al., 1997) and reflects the relative cold conditions of the Gulf of Lions. Maximum fluxes of the main taxa were always recorded during periods of maximum primary productivity, i.e. winter-spring season, which suggests that food availability is a first order limiting factor for foraminifer species growth in the Mediterranean, as already pointed out by Pujol and Vergnaud Grazzini (1995).

\section{Globigerina bulloides}

Globigerina bulloides is the most abundant species in both sediment trap records, with a mean relative abundance of $36 \%$ and $50 \%$ in Planier and Lacaze-Duthiers experimental sites, respectively. G. bulloides is a successful and cosmopolitan species with an omnivorous diet (Bé and Hutson, 1977; Anderson et al., 1979) that has been often associated to elevate primary productivity (e.g. Bé, 1977; Duplessy et al., 1981; Thunell and Reynolds, 1984). In the Western Mediterranean, G. bulloides occurs in significant abundances (Bé, 1977; Core top database of Kallel et al., 1997), specially during the spring phytoplankton bloom (Bárcena et al., 2004; Hernández-Almeida et al., 2010). While in the Eastern Mediterranean Basin its abundance gradually decreases, showing a clear temperature dependence (Thunell, 1978; Core top database of Kallel et al., 1997). Regarding the vertical distribution of this taxon, it probably dwells below the thermocline in the Western Mediterranean (Pujol and Vergnaud Grazzini, 1995). In our study, the highest fluxes of $G$. bulloides are always associated to the maximum chlorophyll- $a$ productivity (Fig. 3 and 4), however its maximum relative abundance often occur at the onset of the spring bloom (May-June) in Planier site and during winter and spring in Lacaze-Duthiers (Fig. 5). The higher relative contribution and threefold fluxes of Lacaze Duthiers station are probably related to the fertilizing effect of Rhône river plume, which evidences the tight linkage of this taxon to food supply.

\section{Globorotalia truncatulinoides}

Globorotalia truncatulinoides is the second most abundant foraminiferal species in Planier $(30.3 \%)$ and Lacaze Duthiers site (17.3\%), although in the latter station its relative contribution 
is equal to $N$. pachyderma (dex.). In the Gulf of Lions, G. truncatulinoides populations are dominated by the left coiling specimens. Only a handful of dextral forms were identified in both records $(<1 \%)$. Maximum abundances of this taxon in the Mediterranean has been described in the Western Basin (Core top database of Kallel et al., 1997) during winter (Pujol and Vergnaud Grazzini, 1995), while in the Eastern Basin is rarely found (Core top database of Kallel et al., 1997). G. truncatulinoides is a mid-latitude planktonic foraminifer with affinity for winter conditions (Bé, 1977). It is considered as a deep-dwelling species that needs the first $1000 \mathrm{~m}$ of the water column to complete its life cycle (Bé and Ericson, 1963; Hemleben et al., 1985). Hence, it has been suggested that G. truncatulinoides would only thrive in those areas where deep vertical mixing occurs (Lohmann, 1992). In this sense, the elevate fluxes and high relative contribution of G. truncatulinoides registered in this study evidences the affinity of this taxon for those areas of the Mediterranean where intense winter convection occurs. Furthermore, higher fluxes of G. truncatulionoides are registered in Lacaze Duthiers than Planier trap (average flux for the entire sampling period $=58.6$ and 70.75 shells $\mathrm{m}^{-2} \mathrm{~d}^{-1}$, respectively), nevertheless the difference between sites is not as remarkable as for other species, such as, G. bulloides that increases its fluxes three times in Lacaze Duthiers site. Therefore, as pointed out by Pujol and Vergnaud Grazzini (1995), the primary factor controlling the distribution of G. truncatulionoides within the Mediterranean is the winter convection and vertical mixing while food availability and temperature are secondary factors.

\section{Neogloboquadrina pachyderma (right coiling form)}

Neogloboquadrina pachyderma (dex.) is the third most abundant taxon in Planier site record (18.6\%) and the second in Lacaze Duthiers station together with G. truncatulinoides (17.3\%). $N$. pachyderma (dex.) is a cold water species that reaches its maximum abundance in subpolar regions (Bé, 1969; Bé and Tolderlund, 1971) and it is considered a deep-dweller (Fairbanks and Wiebe, 1980) that might live at or below the thermocline (Bé, 1960; Bé and Ericson, 1963; Bé, 1977). The distribution of N. pachyderma in the Mediterranean is almost restricted to the Northern Basin(Core top database of Kallel et al., 1997), where it reaches high concentrations at surface waters and at mesopelagic depth during winter (Pujol and Vergnaud Grazzini, 1995). Pujol and Vergnaud Grazzini (1995) suggested that the distribution of this species in the Mediterranean was mainly controlled by temperature, being only present in those areas were SST were below $13^{\circ} \mathrm{C}$. N. pachyderma fluxes are the double in Lacaze-Duthiers site than in Planier which indicates a positive response of this taxon to nutrient supply by the Rhône river plume.

Few left coiling tests were found in the samples $(<1 \%)$. Despite the Gulf of Lions is among one of the coldest regions of the Mediterranean, its conditions are too warm for the development of the polar taxon Neogloboquadrina incompta (= left coiling N. pachyderma) (Darling et al., 2006). Thus, these specimens probably are aberrant coiling forms of $N$. pachyderma (dex.). 


\section{Globorotalia inflata}

Globorotalia inflata is the fourth most abundant species at Planier and Lacaze Duthiers stations. The mean relative abundance are $10 \%$ at Planier and $8,3 \%$ at Lacaze Duthiers site. G. inflata is the warmer species of the four major taxa identified in this study and it is considered the only foraminifera species indigenous to the transitional zone between the subpolar and subtropical regions in the Atlantic (Bé and Tolderlund, 1971). In the Mediterranean, large standing stocks of G. inflata are found in the Western Basin during winter (Cifelli, 1974; Pujol and Vergnaud Grazzini, 1995; Bárcena et al., 2004) while to the East is poorly represented (Thunell, 1978; Pujol and Vergnaud Grazzini, 1995). Regarding to its distribution in surface sediments, the higher contribution of this taxon occurs in the Alboran Sea and along the North African coast (Core top database of Kallel et al., 1997), coinciding with the path of the Modified Atlantic Waters. Pujol and Vergnaud Grazzini (1995) suggested that G. inflata requires a rather cool and deep mixed layer such as the prevailing in winter in those areas, while temperature and food availability are probably secondary limiting factors.

\section{Minor taxa}

Regarding the rest of planktonic foraminifer species, they only represent a small fraction of the 12-year assemblage (4.4\% for Planier and 6.4\% for Lacaze Duthiers) (Table 1). However, their relative contribution to the foraminifer faunal assemblages is often important during periods of low total planktonic foraminifer flux, i.e. the end of summer and the beginning of fall, especially in Lacaze Duthiers station where minor taxa represent ca. $50 \%$ of the assemblage (Fig. 5). Most of the components of the minor species group are warm water species such as O. universa, G. siphonifera, G. sacculifer and G. ruber, and therefore, they exhibit their maximum relative abundance values during the stratification period, i.e. summer and part of fall. Two of the main components of the minor taxa group require special attention: $O$. universa and G. sacculifer. O. universa has been defined as a subtropical species (Bé, 1977) that, in the Mediterranean, is more prolific at the end of the summer (Pujol and Vergnaud Grazzini, 1995), while G. sacculifer is a tropical taxon that dwells in superficial and oligotrophic waters and reach its maximum abundances in the Eastern Basin (Pujol and Vergnaud Grazzini, 1995; Core top database of Kallel et al., 1997). These two species were the main components of a remarkable pulse of minor species recorded during fall 1997 in both experimental sites (Fig. 3 and 4). O. universa reached up to $25 \%$ in Planier and up to $57.5 \%$ in Lacaze Duthiers station while (2) G. sacculifer reached up to $13.3 \%$ in Planier and $52.6 \%$ in Lacaze Duthiers. Average fluxes of these two species were also high in fall that year. As already mention in section 5.2, during fall 1997 anomalous atmospheric and hidrographic conditions were registered in the Western Mediterranean that were probably related to the intense 1997-98 El Niño event. We surmise that the increase in the relative contribution of these warm water taxa was induced by the exceptional conditions in the NW Mediterranean during this period. Although in a far distant environment, a drop in the total planktonic foraminifer fluxes accompanied by a $O$. 
universa pulse was recorded in the central subartic Pacific by Asahi and Takahashi (2007) at the end of 1997. The former authors related the appearance of this taxon to the anomalous warm conditions elicited by 1997-98 El Niño event.

Minor taxa, however, are the main component of the core top foraminifer assemblages from the Eastern Mediterranean that reflect the strong, annually permanent water stratification in that region. Most of the Eastern Mediterranean is oligotrophic because there is no vertical mixing in winter or spring and, consequently, the planktonic foraminifer species that usually benefit from the high nutrient content of surface waters do not thrive in that region. By contrast, the intense vertical mixing in the Gulf of Lions during winter and the subsequent high food availability in surface waters in winter and spring led the proliferation of typically eutrohic species such as $G$. bulloides or $N$. pachyderma, reducing the relative abundance of the oligotrophic species such as O. universa, G. sacculifer or G. ruber.

\subsubsection{Sediment traps versus sediments: implications for paleorecontructions}

The composition of planktonic foraminifer assemblages preserved in sediments should reflect the relative concentration of the foraminifers living in the water column However, we have studied a 12 year record and the topmost centimeter of surface sediments reflects the accumulation of planktonic foramininiferal shells over decades or even hundreds of years. In particular, in some areas of the Gulf of Lions continental slope sedimentation rates during the Holocene are extremely slow because of the low supply of detrital material by the Rhone river at this distance from the coast (Sierro et al., 2009). In order to test if foraminifer assemblages recovered in core-tops reflects the characteristics of the planktonic communities living in the area we compared the foraminifers recorded in the sediment traps with those recorded in the core tops. The planktonic foraminifer assemblages of the core tops are mainly composed by the same four species that dominate the sediment trap records. This characteristic assemblage reflects the relative cold conditions of the Gulf of Lions. Nevertheless, some notable discrepancies have been observed between trap and core top samples. While sediment trap foraminifer faunal assemblages are dominated by G. bulloides, in two thirds of the core top samples $N$. pachyderma prevails as the most abundant taxon (Fig. 2). As previously mentioned, G. bulloides is a good indicator of productivity, and therefore it dominates in the foraminifer assemblages of the most productive areas of the Gulf: the southwestern zone, affected by the Rhône river plume, and the continental slope that is under the influence of the permanent shelf-slope density front. The core-tops recovered far from the continental slope and in the northeastern part of the Gulf show the maximum abundances of $N$. pachyderma probably caused by a drop in G. bulloides productivity. Regarding $G$. truncatulinoides, it exhibits its maximum relative abundance values in the northeastern part of the Gulf. Despite this taxon needs a deep mixing of the water column to fulfill its life cycle, the intense circulation and mixing that occurs in the western part of the Gulf could hamper its growth. G. inflata does not show any remarkable change either along the core top transect or in the trap samples which suggest that its growth is not altered by changes in the productivity. 
At least part of the discrepancies between sediment traps and sediment samples could be due to: (1) difference in time scale, since surface sediments represent an integrated signal of several hundred years; (2) the modern thanatocenosis found in the sediments could have been altered by sedimentary processes (Vénec-Peyré, 1990). The activity of macrobenthic organisms can bioturbate the sediments and mixed older shells, which may have lived under different conditions, towards the surface; (3) differential preservation of the foraminifer shells.

The relative contribution of the minor species group is low in the core top and sediment trap samples. Nevertheless, it is worth noting a notable contribution of G. ruber in coretop number $5(11.3 \%)$. Since G. ruber is scarce in the actual assemblages as inferred from the sediment trap samples and it has been more abundant in the past in the Gulf of Lions (Melki et al., 2009) the high values of this species registered in core top number 5 could be related to sediment bioturbation.

The 12-years-long sediment trap records provide us with reliable information of the seasonal behavior and periodicity of planktonic foraminifer fluxes in the Gulf of Lions that could be used in future paleoceanographic reconstructions. Most of the total planktonic foraminifer flux signal is registered during winter and spring season $(81.7 \%$ in Planier and $80.6 \%$ in LacazeDuthiers station) (Table 2). Therefore, when analyzing the fossil record in the Northwestern Mediterranean it should be taking into account that most of the planktonic foraminifera $(>80 \%)$ developed during the coldest period of the year, approximately between $13-14.5^{\circ} \mathrm{C}$. Nonetheless, few taxa exhibited a different seasonal behavior such as G. ruber and G. sacculifer. Fluxes of these two taxa were more widespread along the year. G. ruber showed its maximum values from late-summer to early-winter summer (SST 13-23 ${ }^{\circ} \mathrm{C}$ ) while G. sacculifer during summer until mid-fall (SST ca. $16-23^{\circ} \mathrm{C}$ ).

These data are specially relevant for paleobiogeochemical studies, in particular trace element and stable isotope analyses in planktonic foraminifers, and when comparing biogeochemical records from different Mediterranean regions. In the NW Mediterranean G. bulloides, $N$. pachyderma or $G$. inflata mainly precipitate their shells in winter and spring, a great percentage in March, and consequently, oxygen isotope records performed in these species should reflect SST during this season. In contrast, the same trace element and stable isotope analyses in the Alboran Sea should record surface conditions in May and June because that is the season of highest fluxes of G. bulloides and G. inflata in that region. On the other hand, G. ruber and G. sacculifer are clearly more appropriate for reconstruction of the physico-chemical properties of surface waters in summer, although they are more abundant towards fall, because water stratification in summer is so strong that almost no foraminifer species is living in that season. 
Planier station

\begin{tabular}{|c|c|c|c|c|c|c|c|c|c|c|c|c|c|c|c|c|}
\hline & $\mathrm{J}$ & $\mathbf{F}$ & $\mathbf{M}$ & A & $M$ & J & J & A & $S$ & 0 & $\mathbf{N}$ & D & Fall & Winter & \multicolumn{2}{|c|}{ Spring Summer } \\
\hline Total foraminifera & 9,0 & 14,8 & 26,8 & 14,2 & 10,1 & 7,5 & 3,7 & 2,0 & 1,1 & 1,1 & 2,9 & 6,9 & 5,1 & 30,7 & 51,0 & 13,1 \\
\hline G. bulloides & 9,5 & 12,5 & 21,3 & 14,4 & 13,9 & 10,2 & 3,2 & 1,3 & 0,5 & 0,6 & 3,4 & 9,1 & 4,5 & 31,1 & 49,7 & 14,7 \\
\hline G. siphonifera & 8,9 & 17,6 & 21,3 & 12,5 & 13,7 & 11,8 & 4,7 & 1,9 & 1,4 & 0,8 & 1,1 & 4,2 & 3,3 & 30,8 & 47,5 & 18,4 \\
\hline N. pachyderma (dex.) & 5,9 & 14,2 & 32,0 & 16,6 & 9,3 & 7,9 & 3,5 & 2,5 & 0,7 & 0,5 & 1,8 & 5,0 & 3,0 & 25,2 & 58,0 & 13,9 \\
\hline N. pachyderma (sin.) & 10,6 & 10,8 & 69,3 & 9,3 & 0,0 & 0,0 & 0,0 & 0,0 & 0,0 & 0,0 & 0,0 & 0,0 & 0,0 & 21,4 & 78,6 & 0,0 \\
\hline G. inflata & 7,0 & 17,3 & 37,2 & 16,9 & 7,4 & 4,1 & 0,6 & 0,3 & 0,0 & 0,2 & 2,6 & 6,4 & 2,8 & 30,7 & 61,5 & 4,9 \\
\hline G. ruber & 14,9 & 8,4 & 3,3 & 1,5 & 4,7 & 9,2 & 3,2 & 11,2 & 6,6 & 6,3 & 16,9 & 13,7 & 29,8 & 37,1 & 9,5 & 23,6 \\
\hline G. ruber (pink) & 0,0 & 0,0 & 0,0 & 0,0 & 0,0 & 0,0 & 0,0 & 7,9 & 10,0 & 38,8 & 43,4 & 0,0 & 92,1 & 0,0 & 0,0 & 7,9 \\
\hline G. sacculifer & 4,4 & 5,5 & 11,6 & 3,3 & 5,1 & 6,3 & 13,8 & 3,1 & 10,3 & 15,1 & 14,1 & 7,4 & 39,4 & 17,3 & 20,0 & 23,3 \\
\hline G. glutinata & 4,9 & 10,3 & 23,9 & 11,2 & 18,8 & 17,8 & 10,9 & 0,0 & 0,0 & 0,0 & 0,0 & 2,3 & 0,0 & 17,4 & 53,9 & 28,6 \\
\hline G. truncatulinoides & 11,2 & 16,9 & 28,0 & 12,7 & 6,8 & 4,7 & 4,6 & 2,8 & 2,1 & 1,8 & 2,5 & 5,8 & 6,4 & 33,9 & 47,5 & 12,2 \\
\hline G. digitata & 6,6 & 19,6 & 10,2 & 13,1 & 17,8 & 18,3 & 3,1 & 1,2 & 2,8 & 3,1 & 0,0 & 4,3 & 5,9 & 30,5 & 41,1 & 22,5 \\
\hline O. universa & 9,8 & 7,4 & 7,2 & 5,8 & 12,3 & 10,3 & 10,8 & 6,8 & 7,5 & 6,1 & 7,4 & 8,7 & 21,1 & 25,9 & 25,2 & 27,9 \\
\hline T. quinqueloba & 1,4 & 36,4 & 36,9 & 2,3 & 7,5 & 6,2 & 4,6 & 0,9 & 0,0 & 0,1 & 1,4 & 2,1 & 1,6 & 40,0 & 46,7 & 11,7 \\
\hline Temperature & 13,3 & 13,0 & 13,1 & 13,7 & 16,2 & 19,7 & 21,6 & 23,1 & 20,9 & 18,8 & 16,5 & 14,3 & 18,7 & 13,5 & 14,4 & 21,5 \\
\hline
\end{tabular}

Lacaze Duthiers

\begin{tabular}{|c|c|c|c|c|c|c|c|c|c|c|c|c|c|c|c|c|}
\hline & J & $\mathbf{F}$ & $\mathbf{M}$ & A & $\mathbf{M}$ & J & J & A & $S$ & $\mathbf{0}$ & $\mathbf{N}$ & D & Fall & Winter & \multicolumn{2}{|c|}{ Spring Summer } \\
\hline Total foraminifera & 8,8 & 20,8 & 21,1 & 13,5 & 9,9 & 6,3 & 2,2 & 2,1 & 2,2 & 2,5 & 4,1 & 6,5 & 8,8 & 36,1 & 44,5 & 10,5 \\
\hline G. bulloides & 8,3 & 25,0 & 21,6 & 13,9 & 11,5 & 7,1 & 1,9 & 1,3 & 0,5 & 1,3 & 3,3 & 4,4 & 5,1 & 37,7 & 47,0 & 10,2 \\
\hline G. siphonifera & 11,3 & 13,1 & 8,4 & 5,8 & 6,1 & 7,1 & 5,2 & 6,0 & 5,4 & 6,5 & 11,2 & 14,0 & 23,0 & 38,4 & 20,3 & 18,3 \\
\hline N. pachyderma (dex.) & 3,0 & 17,9 & 29,7 & 21,6 & 10,2 & 5,3 & 1,8 & 2,0 & 1,5 & 2,3 & 2,1 & 2,5 & 5,9 & 23,4 & 61,5 & 9,2 \\
\hline N.p.(sin.) & 10,7 & 42,0 & 18,4 & 1,9 & 6,2 & 3,7 & 0,0 & 0,0 & 1,9 & 3,3 & 7,0 & 4,9 & 12,1 & 57,7 & 26,5 & 3,7 \\
\hline G. inflata & 8,5 & 25,7 & 35,1 & 10,8 & 6,1 & 3,0 & 0,7 & 0,6 & 0,2 & 1,1 & 2,0 & 6,3 & 3,3 & 40,5 & 51,9 & 4,3 \\
\hline G. ruber & 11,8 & 6,7 & 4,7 & 1,6 & 1,7 & 5,3 & 7,2 & 9,1 & 10,1 & 11,4 & 15,1 & 15,5 & 36,6 & 33,9 & 8,0 & 21,5 \\
\hline G. ruber (pink) & 3,8 & 0,0 & 0,0 & 0,0 & 4,4 & 0,0 & 0,0 & 3,6 & 16,5 & 16,4 & 37,1 & 18,1 & 70,0 & 21,9 & 4,4 & 3,6 \\
\hline G. sacculifer & 3,8 & 1,2 & 1,5 & 0,2 & 0,6 & 4,5 & 5,8 & 10,4 & 21,5 & 21,1 & 21,7 & 7,6 & 64,3 & 12,7 & 2,3 & 20,7 \\
\hline G. glutinata & 10,3 & 18,4 & 19,0 & 13,2 & 11,5 & 8,9 & 3,7 & 1,3 & 0,0 & 0,0 & 4,1 & 9,7 & 4,1 & 38,4 & 43,7 & 13,9 \\
\hline G. truncatulinoides & 17,2 & 15,2 & 10,7 & 9,8 & 9,3 & 7,0 & 3,1 & 2,7 & 3,2 & 1,9 & 5,6 & 14,3 & 10,7 & 46,8 & 29,8 & 12,8 \\
\hline G. digitata & 3,6 & 25,8 & 29,8 & 16,5 & 3,3 & 2,2 & 0,0 & 0,2 & 4,5 & 4,7 & 4,2 & 5,3 & 13,4 & 34,6 & 49,5 & 2,4 \\
\hline O. universa & 4,8 & 2,6 & 2,4 & 2,2 & 5,2 & 3,9 & 6,1 & 9,9 & 24,5 & 20,3 & 12,6 & 5,4 & 57,5 & 12,8 & 9,8 & 19,9 \\
\hline T. quinqueloba & 3,1 & 9,7 & 6,7 & 7,7 & 18,7 & 18,1 & 10,3 & 11,3 & 2,5 & 1,0 & 4,7 & 6,2 & 8,1 & 19,1 & 33,1 & 39,6 \\
\hline Temperature & 13,0 & 12,7 & 13,0 & 13,7 & 16,3 & 19,7 & 21,7 & 23,4 & 21,4 & 18,9 & 16,1 & 14,0 & 18,8 & 13,2 & 14,3 & 21,5 \\
\hline
\end{tabular}

Table 2. Monthly and seasonal distribution of foraminifer species flux (\%). Monthly average surface temperature is also showed.

\subsection{CONCLUSIONS}

The distribution patterns of the planktonic foraminifera defined by the sediment-trap flux data recorded in the Gulf of Lions suggest that these trends are driven by both seasonal and interannual changes in the upper water column. The 12-year mean foraminifer flux was the double at Lacaze-Duthiers (411.8 shells $\left.\mathrm{m}^{-2} \mathrm{~d}^{-1}\right)$ than in Planier station (225.4 shells $\left.\mathrm{m}^{-2} \mathrm{~d}^{-1}\right)$, probably owned to the fertilizing effect of the Rhône river plume and the general oceanographic circulation. 
Total foraminifer fluxes typically showed unimodal maxima in winter-spring transition in both stations, coinciding with the spring phytoplankton bloom. While minimum fluxes were always registered during summer. The latter suggests that total foraminifer fluxes were mainly controlled by food availability.

Regarding interannual variability, the planktonic foraminifer fluxes do not exhibit a clear relationship with the winter state of the NAO, nonetheless, the anomalous conditions elicited by the 1997-98 ENSO event could be the cause of the low foraminifer fluxes recorded in both stations during spring 1998. Foraminifer fluxes at the study sites were mainly comprised of four species Globigerina bulloides, Neogloboquadrina pachyderma, Globorotalia inflata and Globorotalia truncatulinoides, which reflects the relative cold conditions of the Northern Basin compared with the rest of the Mediterranean. Planktonic foraminifer species tyipically living in warm-waters, such as Globigerinoides sacculifer, Globigerinoides ruber or Orbulina universa are very scarce throughout the year but they reach maximum fluxes and relative abundances in fall, after the period of strong summer stratification.

Knowledge of the seasonal distribution of the planktonic foraminifer species living today in the Mediterranean and the time of the year when they precipitate their shells is essential in paleoceanographic studies, in particular, to interpret stable isotope or trace element records obtained in foraminifers.

Notable discrepancies between the planktonic foraminifer assemblages found in the sedimenttrap samples and in the core-top array were found. While both sediment-trap records were dominated by $G$. bulloides, superficial sediment samples were principally dominated by $N$. pachyderma except in the most productive area of the Gulf, i.e. the southeastern area where $G$. bulloides predominates in the core-top samples. These differences were mainly owned to the different time scale of the samples, sedimentation processes and bioturbation. 


\section{Conclusiones}

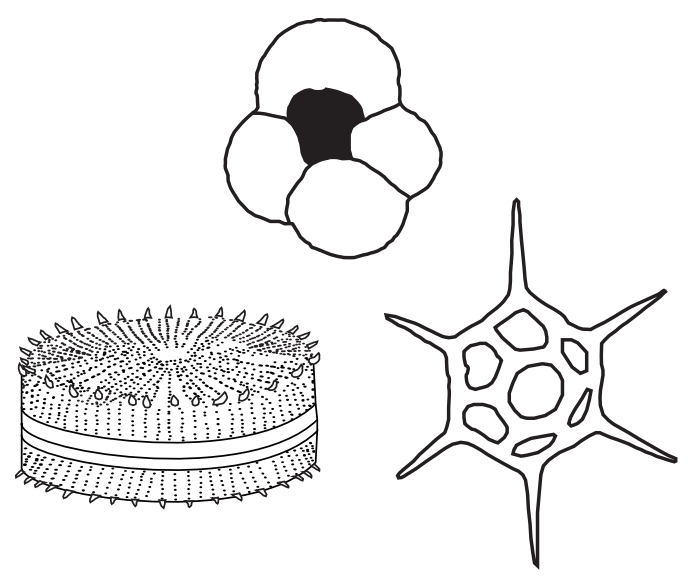





\section{CONCLUSIONES GENERALES}

El análisis de los flujos de diatomeas, silicoflagelados y foraminíferos planctónicos en trampas de sedimento del Mediterráneo Occidental dan lugar a las siguientes conclusiones generales:

1. La técnica desarrollada para el procesamiento de muestras de trampas de sedimento para el análisis micropalentológico ha permitido una preservación óptima de los esqueletos de microplancton silíceo y calcáreo, lo que garantiza una mayor calidad de los resultados.

2. Dada la buena resolución temporal y espacial de los registros de trampas de sedimento presentados en este trabajo, ha sido posible caracterizar las asociaciones de diatomeas y foraminíferos del golfo de León, así como las asociaciones de silicoflagelados del Mediterráneo Occidental.

3. Los flujos de los tres grupos de microplancton experimentaron fuertes ciclos anuales determinados por la dinámica oceánica y atmosférica. Como norma general, los flujos máximos de los tres grupos ocurrieron durante la transición invierno-primavera, coincidiendo con el bloom de primavera. Por su parte, los flujos mínimos coincidieron con el periodo de estratificación de la columna de agua, i.e., ocurrieron durante el verano.

4. En referencia a la variabilidad interanual, no se ha observado una clara relación entre el estado de la NAO y los flujos de ninguno de los tres grupos de microplancton tratados en este trabajo. Sin embargo, las condiciones ambientales anómalas generadas por el evento ENSO 1997-98 tuvieron repercusiones en los flujos de los tres grupos durante la primavera de 1998. Por otro lado, la ola de calor de 2003 parece ser la causa de los bajos flujos de diatomeas y silicoflagelados registrados en el golfo de León durante la primavera de 2004.

\section{CONCLUSIONES ESPECÍFICAS}

Las conclusiones derivadas de los objetivos específicos que se plantearon al empezar el estudio se desglosan en los siguientes apartados:

\subsection{Sucesión anual de las asociaciones de diatomeas en el Mediterráneo Noroccidental.}

1. La asociación anual de los flujos de diatomeas en el golfo de León se compone de aproximadamente 126 taxones.

2. La buena correlación de los flujos de diatomeas con las imágenes de satélite de concentración de clorofila- $a$ sugiere que las diatomeas son uno de los grupos de fitoplancton más abundantes del golfo de León, especialmente durante el bloom de primavera. 
3. El año medio calculado a partir del registro de 12 años de la estación de Planier ha permitido describir los patrones generales de distribución anual de los flujos de las diatomeas en el golfo de León.

4. Las diatomeas son especialmente abundantes durante la transición invierno-primavera, periodo caracterizado por una fuerte mezcla en la columna de agua, alta concentración de nutrientes y una radiación solar relativamente baja. Después del bloom de primavera, el descenso gradual de la turbulencia y concentración de nutrientes y el aumento de la radiación solar motivan el desarrollo de una sucesión. Un buen ejemplo de esta sucesión es la secuencia Skeletonema-Chaetoceros-Rhizosolenia.

\subsection{Variaciones estacionales e interanuales de los flujos de diatomeas y cocolitos en el}

\section{Mediterráneo Noroccidental.}

1. Las diatomeas son el principal productor de sílice biogénica en el golfo de León mientras que los cocolitos y los foraminíferos planctónicos son los principales componentes de la fracción de carbonato biogénico.

2. Los flujos de diatomeas y cocolitos reflejaron las variaciones atmosféricas y de la columna de agua. Sus flujos máximos ocurrieron durante la transición invierno-primavera y los mínimos durante el verano. El análisis factorial de las muestras de diatomeas dio como resultado tres factores que representaron las principales condiciones oceanográficas del registro: factor "mesotrofía”, factor "bloom de primavera” y factor “estratificaciónoligotrofía”.

3. Los flujos de diatomeas más elevados en nuestro registro ocurrieron durante años de intensos vientos durante el invierno y vientos relativamente débiles durante el inicio de la primavera, mientras que los flujos de cocolitos parecen estar favorecidos por vientos débiles durante el invierno y/o fuertes vientos al comienzo de la primavera.

4. Los flujos de diatomeas y cocolitos no muestran una clara relación con el estado de la NAO. No obstante, el evento ENSO de 1997-98 y la ola de calor de 2003 pudieron ser la causa de los bajos flujos de esqueletos de fitoplancton registrados durante las primaveras de 1998 y 2004 respectivamente.

5. La estrecha relación entre los máximos anuales de los flujos de material (litogénico, carbono orgánico, ópalo y carbonato), los flujos de esqueletos de fitoplancton y la concentración de clorofila- $a$ sugieren que la productividad primaria es el desencadenante de la sedimentación masiva del material particulado en suspensión en el golfo de León durante la transición inverno-primavera.

\subsection{Variaciones estacionales, interanuales y distribución geográfica de los flujos de silicoflagelados en el Mediterráneo Occidental.}

1. Los flujos máximos de silicoflagelados ocurrieron generalmente durante la transición invierno-primavera, coincidiendo con el bloom de primavera. 
2. Este grupo de fitoplancton parece ser especialmente sensible a los aportes fluviales ya que muestra los flujos más elevados del estudio en aquellas estaciones influenciadas por el aporte fluvial.

3. Fueron identificadas un total de tres especies: D. fibula, D. speculum y O. octonaria. Dictyocha fibula es la especie de silicoflagelado más abundante en el Mediterráneo Occidental, presentando una abundancia superior al $80 \%$ en todas las estaciones estudiadas. La distribución de $D$. speculum y O. octonaria parecen estar controladas por la temperatura. Mientras que $D$. speculum está restringido a la cuenca Noroccidental donde la temperatura superficial de la columna de agua alcanza los $12^{\circ} \mathrm{C}$ en invierno, la presencia de $O$. octonaria se limita al mar de Alborán, donde las temperaturas mínimas anuales nunca descienden de los $15^{\circ} \mathrm{C}$.

4. Los datos de flujos de silicoflagelados procedentes de los dos registros de 12 años del golfo de León no muestran una clara relación con el estado de la NAO, sin embargo, las condiciones anómalas generadas por el evento ENSO 1997-98 y la ola de calor de 2003 parecen ser la causa de los bajos flujos de silicoflagelados registrados durante las primaveras de 1998 y 2004.

\subsection{Variaciones estacionales e interanuales de los flujos de foraminíferos planctónicos en el Mediterráneo Noroccidental.}

1. Los flujos máximos de foraminíferos planctónicos ocurrieron durante la transición invierno-primavera, coincidiendo con el bloom de primavera, mientras que el periodo de mínima productividad ocurrió durante el verano. Esto sugiere que la productividad de los foraminíferos en el golfo de León está principalmente controlada por la disponibilidad de nutrientes.

2. El flujo medio registrado en la estación de Lacaze-Duthiers fue el doble que en la estación de Planier debido al aporte fluvial y a la circulación general.

3. Al igual que el resto de grupos de microplancton estudiados, los flujos de los foraminíferos planctónicos no mostraron una relación directa con la NAO pero si con el evento ENSO de 1997-98 que provocó un descenso en los flujos de foraminíferos en las dos estaciones del golfo de León durante la primavera de 1998.

4. Se identificaron importantes diferencias entre las asociaciones registradas por las trampas de sedimento y en los core-tops del golfo de León. Mientras que las asociaciones registradas en las trampas están dominadas por G. bulloides, en las muestras de sedimento superficial domina habitualmente $N$. pachyderma. Estas diferencias se deben principalmente a la diferente escala de tiempo que representan las muestras, a los procesos sedimentarios y a la bioturbación. 



\section{GENERAL CONCLUSIONS}

The analysis of the fluxes of the diatoms, silicoflagellates and planktonic foraminifera registered in sediment traps in the Western Mediterranean resulted in the following main conclusions:

1. Thetechnique developed to process the sediment trap samples for themicropaleontological analysis allowed an optimum preservation of calcareous and siliceous microplankton, which guarantees high quality results.

2. The good temporal and spatial resolution of the sediment trap records presented in this work made possible the characterization of the diatom and planktonic foraminifer assemblages of the Gulf of Lions and the silicoflagellate assemblages of the Western Mediterranean.

3. The fluxes of these three microplankton groups underwent consistent annual cycles determined by the atmospheric and oceanic dynamics. As a general trend, maximum fluxes of these three groups occurred during the winter-spring transition, at the same time of the spring bloom. Conversely, minimum fluxes were recorded during the stratification period, i.e. the summer.

4. Regarding the interannual variability, no relationship was found between the NAO and the fluxes of the three microplankton groups studied in this work. Nevertheless, the anomalous environmental conditions elicited by the 1997-98 El Niño Event had consequences on the fluxes of the three microplankton groups. On the other hand, the 2003 heat wave seems to be the cause of the low diatom and silicoflagellate fluxes recorded in the Gulf of Lions during spring 2004.

\section{SPECIFIC CONCLUSIONS}

The conclusions derived from the specific objectives exposed at the start of this study can be divided in the following sections:

\subsection{Annual succession of the diatom assemblages in the northwestern Mediterranean}

1. The annual assemblage of the diatom fluxes in the Gulf of Lions consists of approximately 126 taxa.

2. The good correlation between the diatom fluxes and the satellite chlorophyll-a images suggests that diatoms are one of the most abundant phytoplankton groups in the Gulf of Lions, especially during the spring bloom.

3. The average year compiled from the 12-year-long sediment trap record of the Planier site permitted the description of the general annual distribution patterns of the diatom fluxes in the Gulf of Lions.

4. Diatoms are especially abundant during the winter-spring transition, a period characterized by a strong water mixing, high nutrient concentration and relative low solar radiation. The gradual decrease of the turbulence and nutrient concentration and the increase of 
the solar radiation after the spring bloom trigger the ecological succession. A good example of this succession is the Skeletonema-Chaetoceros-Rhizosolenia sequence.

\subsection{Seasonal to interannual variability of diatom and coccolith fluxes in the northwestern Mediterranean.}

1. Diatoms were the most important contributor to the opal productivity in the Gulf of Lions while coccoliths, together with planktonic foraminifera, mainly integrated the biogenic calcareous fraction.

2. Diatom and coccolith fluxes mirrored the atmospheric and water column dynamics. Their fluxes showed maxima during the winter-spring transition, while their minima occurred during summer. The main diatom species were grouped in three factors that reflect the main conditions of the water column throughout the record: mesotrophy, spring bloom and stratification-oligotrophy.

3. The development of the strongest spring diatom blooms in the record occurred during those years with intense and cold winds during winter and low wind stress during the beginning of the spring period. In contrast, coccolith downward fluxes seem to be favored by weak winter mixing and/or intense wind stress at the beginning of spring.

4. Diatom and coccolith fluxes did not show a straightforward relationship with the NAO winter index. However, the strong 1997-1998 ENSO event and the 2003 summer heat wave seem to have been the cause of the low phytoplankton skeleton fluxes during the spring season of the following year.

5. The tight coupling between the annual maximum of the total mass flux (lithogenic, organic carbon, opal and carbonate), the phytoplankton skeleton fluxes and the chlorophyll-a concentration suggest that the primary productivity triggers the sedimentation of the suspended particulate material in the Gulf of Lions during the winter-spring transition.

\subsection{Seasonal to interanual variability and geographic distribution of silicoflagellate fluxes in the Western Mediterranean.}

1. Maximum silicoflagellate fluxes often occur during the winter-spring transition, coinciding with the spring bloom.

2. Silicoflagellates seem to be especially sensitive to river input, showing maximum fluxes at the stations affected by river plumes.

3. A total of three species were identified:D. fibula,D. speculum and O. octonaria. Dictyocha fibula is the most abundant silicoflagellate species in the Western Mediterranean, accounting for more than $80 \%$ of the silicoflagellate assemblage in the five studied sites.

4. The distribution of $D$. speculum and $O$. octonaria seems to be controlled by temperature. While $D$. speculum is restricted to the northwestern basin, where annual temperatures 
drop to $12{ }^{\circ} \mathrm{C}$ during winter, O. octonaria is limited to the Alboran Sea stations, where annual minimum temperatures are never colder than $15^{\circ} \mathrm{C}$.

5. The Silicoflagellate flux data from the two 12-year records of the Gulf of Lions does not show a straightforward relationship with the NAO winter index, however, the strong 1997- 1998 ENSO event and the 2003 summer heat wave seem to have been the cause of the low silicoflagellate fluxes of the 1998 and 2004 springs.

\subsection{Seasonal and interannual variability of planktonic foraminifera in the Northwestern}

\section{Mediterranean.}

1. Maximum total foraminifer fluxes occur during the winter-spring transition in both stations, coinciding with the spring phytoplankton bloom, while minimum fluxes were always registered during summer, which suggests that total foraminifer fluxes are controlled mainly by food availability.

2. The mean foraminifer flux was the double at Lacaze-Duthiers than in Planier station owned to the fertilizing effect of the Rhône river plume and the general oceanographic circulation.

3. As the rest of the studied microplankton groups, the fluxes of planktonic foraminifera did not show a clear relationship with the NAO although they seemed to respond to the 1997-98 ENSO event that elicited the low foraminifera fluxes in both stations of the Gulf of Lions during spring 1998.

4. Notable discrepancies between the planktonic foraminifer assemblages found in the sediment-trap samples and in the core-top array have been observed. While both sediment-trap records were dominated by $G$. bulloides, superficial sediment samples generally were dominated by $N$. pachyderma. These differences have been ascribed to the different time scale of the samples, sedimentation processes and bioturbation. 

I am ending this communication with the feeling that I was not able to fathom this profundity of organismic creation. To have opened it should be my excuse for time and energy spent. May fresh and soulful eyes delve into nature and collect which it conceals - not purposeless - in darkness and smallness.

Christian Gotfried Ehrenberg, 1830 

Apéndice

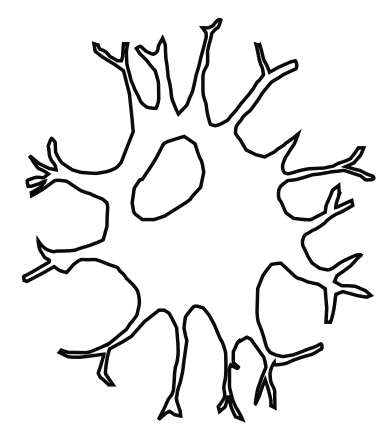





\title{
Análisis de un nuevo registro micropaleontológico en el margen meridional del archipiélago de las Svalbard (océano Ártico): resultados preliminares e implicaciones paleoceanográficas
}

\author{
Analysis of a new micropalaeontological record from the southern margin of the Svalbard Archipelago (Arctic \\ Ocean): preliminary results and palaeoceanographic implications
}

\begin{abstract}
Elena Colmenero Hidalgo (1), Andrés S. Rigual Hernández (1), Renata G. Lucchi (2), Mª Ángeles Bárcena (1), Francisco J. Sierro (1), José-Abel Flores ${ }^{(1)}$, Anne de Vernal (4) y Angelo Camerlenghi ${ }^{(3,2)}$
\end{abstract}

\author{
(1) Departamento de Geología, Facultad de Ciencias, Universidad de Salamanca, 37008 Salamanca, España. elecolme@usal.es; arigual@usal.es; \\ mbarcena@usal.es; sierro@usal.es; flores@usal.es. \\ (2) GRC Geociències Marines, Facultat de Geología, Universitat de Barcelona, 08028 Barcelona, España. rglucchi@ub.edu; acamerlenghi@ub.edu \\ (3) ICREA, Istitució Catalana de Recerca i Estudis Avançats. \\ (4) GEOTOP-UQAM, Université du Québec à Montreal, Montreal, Canadá. devernal.anne@uqam.ca
}

\section{ABSTRACT}

Preliminary results of micropalaeontological analyses carried on samples from a sediment core recovered in summer 2007 in the Storfjorden area (SW Svalbard margin, Arctic Ocean) reveal changes in the concentrations of coccolithophores, diatoms and dinocysts. The larger shifts seem to be linked to the increase in the strength of the Atlantic-sourced, warm Western Spitsbergen Current and the retreat of the Barents Sea Ice Sheet at the onset of the Last Deglaciation and during the Holocene.

Key words: Coccolithophores, diatoms, dinocysts, S Svalbard, Western Spitsbergen Current, deglaciation, Holocene

Geogaceta, 46 (2009), 91-94

ISSN: $0213683 X$

\section{Introducción}

El proyecto SVAIS tiene como objetivo principal comprender la evolución de los márgenes continentales influidos por procesos de glaciarismo y su relación con los cambios en la dinámica de los casquetes de hielo inducida por variaciones climáticas. Para ello, en agosto de 2007 se realizó una campaña oceanográfica de geofísica y recuperación de testigos oceánicos en un sistema deposicional marino que, durante el último periodo glacial, estuvo dominado por la acción de una corriente de hielo. Los datos obtenidos servirán para definir su arquitectura sedimentaria y morfología, además de obtener un registro de la evolución de las condiciones glaciales en la zona (Camerlenghi et al., 2007).

El área del Storfjorden, al sur del archipiélago de Svalbard (Noruega), fue seleccionada para este propósito por haber sido una de las principales vías de salida del hielo acumulado en el casquete desarrollado sobre lo que hoy es el mar de Barents. Los frentes de estas "corrientes de hielo" sufrieron constantes avances y retrocesos durante la última deglaciación que parecen haber estado estrechamente relacionados con las variaciones en la intensidad de la Corriente del Oeste de Spitsbergen (WSC, relativamente cálida) (Martrat et al., 2003; Rasmussen et al., 2007) (Fig. 1). Por lo tanto, el registro sedimentario del margen continental en esta zona ha de contener evidencias que permitan reconstruir la evolución del casquete de hielo del mar de Barents y la influencia de las corrientes oceánicas.

Con este fin, se eligió estudiar los indicadores micropaleontológicos contenidos en los sedimentos de la zona. Los análisis de microfósiles proporcionan datos biostratigráficos y permiten la correlación entre testigos, además de proporcionar un registro paleoceanográfico de la zona e incrementar el conocimiento que se tiene de la distribución de los diversos grupos de microorganismos en altas latitudes, zonas de las que se dispone de muy pocos datos. Los grupos estudiados en este trabajo - cocolitóforos, diatomeas y quistes de dinoflagelados de pared orgánica (dinoquistes)- forman parte del fitoplancton. En los tres casos, la concentración total y la distribución de los distintos taxones depende de factores ambientales tales como la temperatura, salinidad, cubierta de hielo, luz, contenido en nutrientes, etc de las masas de agua en las que viven, por lo que las variaciones en las asociaciones fósiles representan cambios en las características de las corrientes oceánicas ocurridos en el pasado.

\section{Marco oceanográfico y geológico}

El Storfjorden es un ancho fiordo localizado entre las islas de Spitsbergen (al W) y Barentsøya y Edgeøya (al E), que se abre y se hace más profundo hacia el SW, en donde conecta con el borde de la plataforma continental. En su boca se ha desarrollado un abanico submarino de dimensiones considerables, en cuya zona más profunda y distal se recuperó el testigo SVAIS04 (Fig. 1).

El área del Storfjorden está influida hoy en día por la circulación superficial 


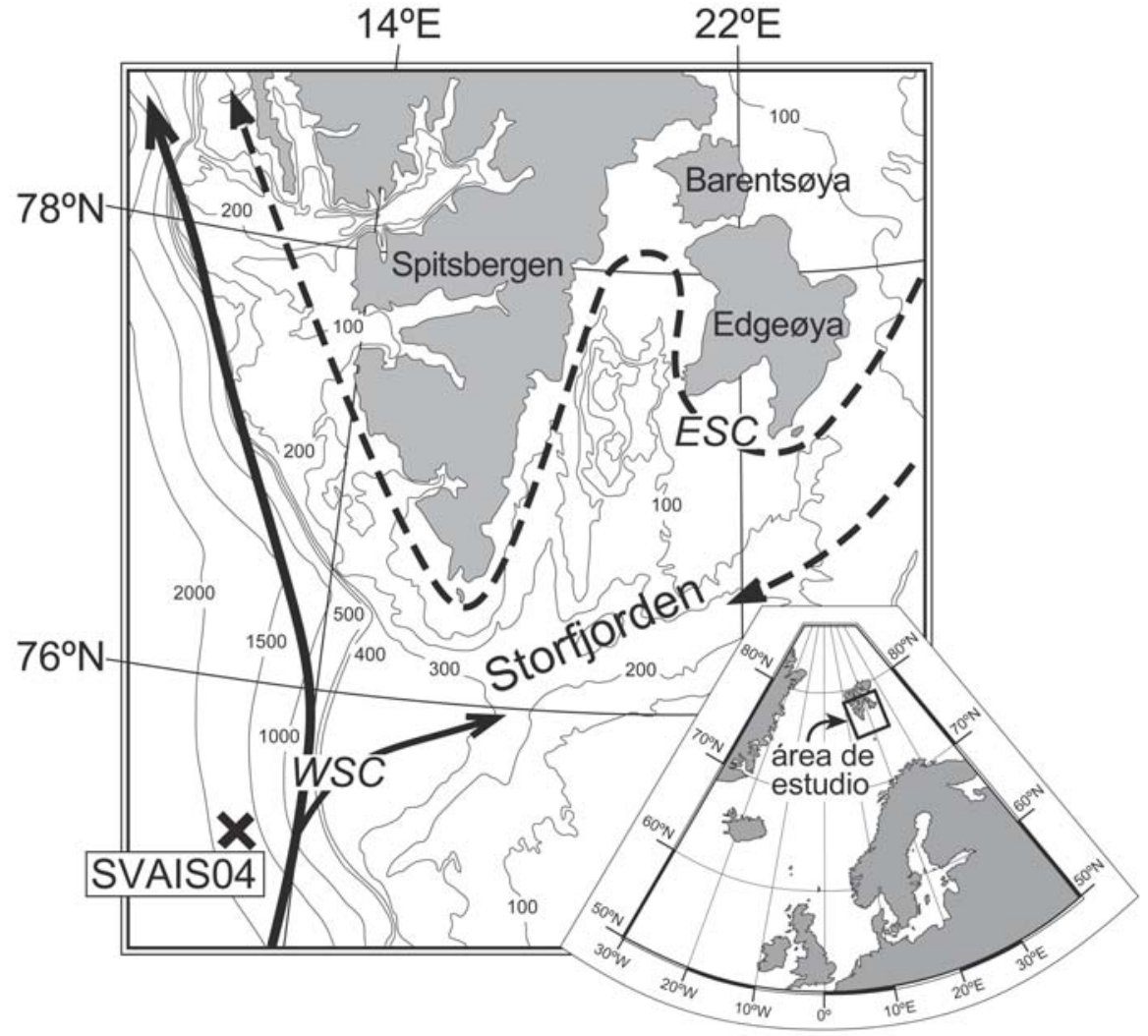

Fig.- 1.- Área de estudio y principales corrientes superficiales (WSC: Corriente del oeste de Spitsbergen; ESC: Corriente del este de Spitsbergen). La localización del testigo SVAIS04 está marcada con una X. Profundidades en metros.

Fig.- 1.- Studied area and main surface currents (WSC: West Spitsbergen Current; ESC: East Spitsbergen Current). The location of core SVAIS04 is marked with an X. Depths in metres.

de dos masas de agua bien diferenciadas. Por un lado, la WSC (aguas atlánticas), de temperaturas y salinidades moderadas, fluye de sur a norte hacia el océano Ártico a lo largo del talud continental. Por el otro, la Corriente del Este de Spitsbergen (ESC, aguas árticas), de bajas temperaturas y salinidades, recorre todo el margen oriental y meridional del archipiélago desde el océano Ártico hasta las costas occidentales de la isla de Spitsbergen. Las grandes diferencias entre ambas corrientes hacen que se defina un frente de mezcla (el frente Ártico). El área dominada por la WSC puede llegar a estar libre de hielos incluso durante el invierno, mientras que, simultáneamente, el dominio de la ESC es bloqueado por la banquisa.

\section{Materiales y métodos}

El testigo de pistón SVAIS04 $\left(74^{\circ}\right.$ $57,425^{\prime} \mathrm{N}, 13^{\circ}$ 53,972' E) fue recuperado por el buque español BIO Hespérides a una profundidad de columna de agua de 1839 m (Fig. 1). Con una longitud total de $303 \mathrm{~cm}$, consta de una capa superior de fangos bioturbados, una segunda capa de fangos ligeramente laminados, un ter- cer tramo sin estructuras y con fragmentos de rocas transportadas por icebergs, $\mathrm{y}$ una capa inferior de fangos y arenas laminados (Fig. 2).

El análisis micropaleontológico se llevó a cabo mediante la preparación de 31 muestras para cocolitóforos y diatomeas y 60 para dinoquistes. El espaciado entre muestra y muestra fue de 10 $\mathrm{cm}$ para los 2 primeros grupos, y una alternancia de 4 y $6 \mathrm{~cm}$ para el tercer grupo. Las láminas para el examen de las asociaciones de cocolitóforos se prepararon conforme a la técnica de decantación de Flores y Sierro (1997), que permite obtener una distribución homogénea del sedimento y, por lo tanto, posibilita estimar concentraciones y flujos de partículas. Para diatomeas, se siguió una técnica de decantación similar precedida de varios pasos de ataque del sedimento con ácido clorhídrico y peróxido de oxígeno, seguidos de lavados y decantaciones. La preparación de láminas para el estudio de dinoquistes consistió en un tamizado de sedimento seco seguido de ataques con ácidos fluorhídrico y clorhídrico, una fase de lavados, un nuevo tamizado del material restante, y finalmente una concentra- ción del material restante para proceder al preparado de la lámina.

Las tres series de muestras fueron estudiadas de manera cuantitativa y cualitativa con microscopios ópticos (400x/luz natural para dinoquistes, $1000 \mathrm{x} / \mathrm{luz}$ natural para diatomeas y 1250x/nícoles cruzados para cocolitóforos). En cocolitóforos, aunque se procuró observar más de 500 individuos por lámina, en algunas de ellas las bajísimas abundancias obligaron a realizar recuentos más pequeños y, en determinados casos, las muestras se declararon azoicas tras la observación, con resultados negativos, de más de 30 campos visuales. En el estudio de diatomeas, se tomó como límite para declarar la muestra como azoica la ausencia de valvas en por lo menos 2 transeptos. Para el recuento de dinoquistes se estableció un mínimo de 300 individuos aunque en alguna muestra no se pudo alcanzar esa cifra a pesar de contar más de 1000 esporas de Lycopodium spp.

\section{Resultados y discusión}

\section{Preservación}

En el grupo de los cocolitóforos, el grado de preservación de los individuos observados es bueno, ya que no se aprecia disolución a gran escala que impida la identificación en taxones. Se ha observado disolución en el área central de cocolitos de Coccolithus pelagicus, confirmada con observaciones de microscopio electrónico. Sin embargo, como parece afectar únicamente al área central y no influye en las dimensiones de los cocolitos, su identificación es posible.

Las diatomeas y los dinoquistes no presentan problemas de disolución apreciables.

\section{Concentraciones}

El recuento de individuos ha permitido calcular la concentración total (abundancia absoluta) de cada grupo y observar sus oscilaciones a lo largo del testigo (Fig. 2). Los cocolitóforos presentan abundancias máximas a techo $\left(\sim 2,3 \times 10^{9}\right.$ cocolitos/g), aunque decrecen rápidamente hasta los $5 \times 10^{8}$ cocolitos/g a los $30 \mathrm{~cm}$. Vuelven a aumentar hasta cerca de los $10^{9}$ cocolitos/g a los $40 \mathrm{~cm}$, y se mantienen en este valor hasta los $85 \mathrm{~cm}$, cuando vuelven a decrecer hasta desaparecer hacia los $150 \mathrm{~cm}$. Aparecen de nuevo en los intervalos $170-210 \mathrm{~cm}$ y $240 \mathrm{~cm}$ muro, pero su número es muy bajo.

Por su parte, las diatomeas presentan una distribución caracterizada por dos máximos cercanos a las $2 \times 10^{6}$ valvas/g centrados en 10 y $100 \mathrm{~cm}$, mientras que 


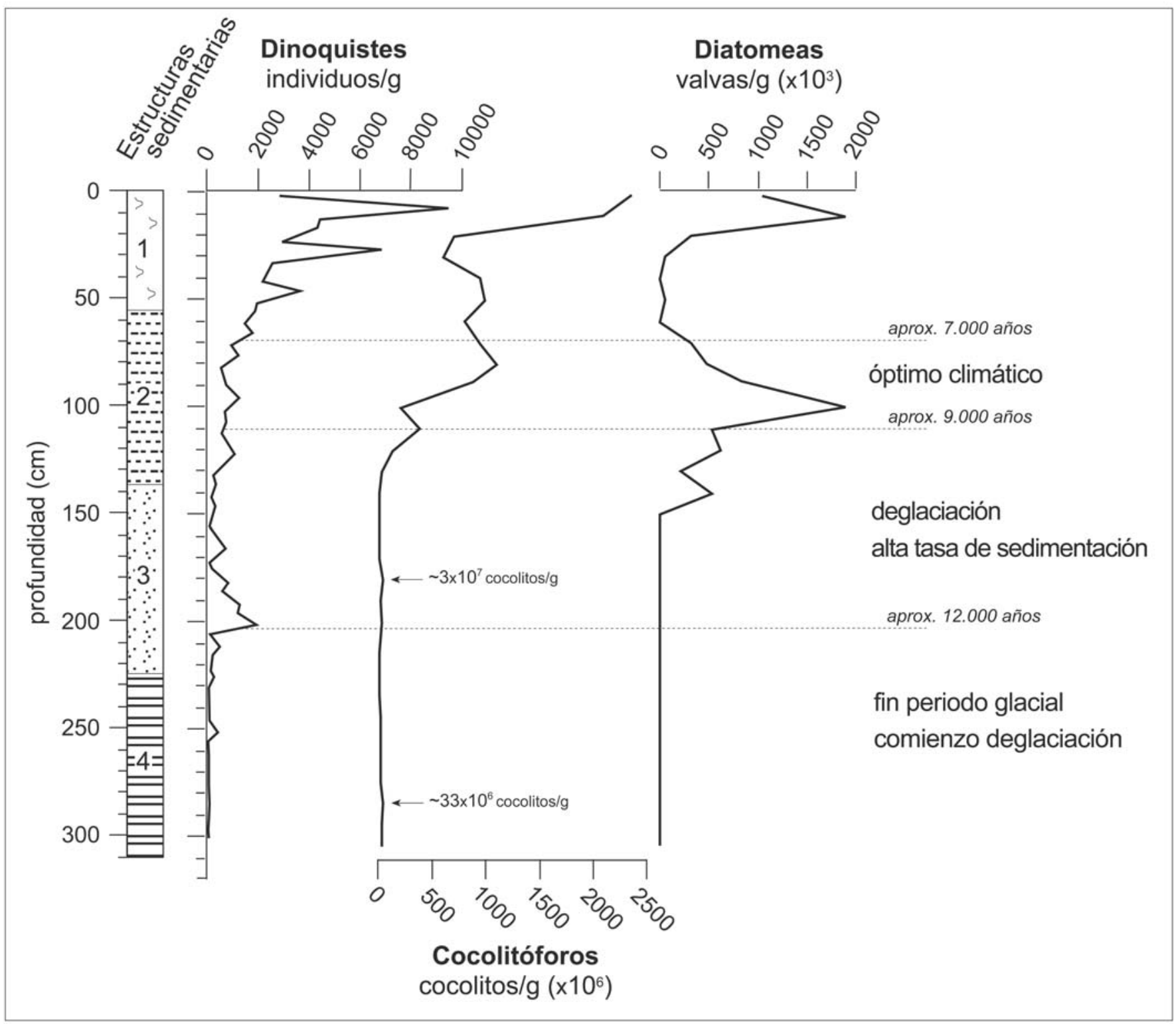

Fig. 2.- Tramos del testigo SVAIS04 en función de las facies sedimentarias, y concentraciones (abundancias absolutas) de dinoquistes, cocolitóforos y diatomeas. Se indica la edad aproximada de los horizontes más significativos. Tramos: (1) fangos bioturbados; (2) fangos ligeramente laminados; (3) sedimentos sin estructuras y con fragmentos de roca dispersos; y (4) fangos y arenas laminados.

Fig. 2.- Lithologic units of core SVAIS04 according to the sedimentary facies, and concentrations (absolute abundances) of dinocysts, coccolithophores and diatoms. The approximate age of the most significant horizons is indicated. Units: (1) bioturbated fine sediments; (2) crudely laminated fine sediments; (3) structureless sediments with sparse rock fragments; and (4) laminated fine sediments with sandy layers.

en el resto de muestras las abundancias son mucho más bajas, siempre alrededor de las 5 x $10^{5}$ valvas/g, e incluso son muy escasas en el intervalo entre 20 y $60 \mathrm{~cm}$. Desaparecen por completo a partir de los $150 \mathrm{~cm}$ hasta el muro del testigo.

Por último, los dinoquistes muestran un pico de concentración máxima a techo del testigo ( $\sim 10^{5}$ quistes/g), seguido de otro pico de $7 \times 10^{4}$ quistes/g a los 30 $\mathrm{cm}$, y de otro de $3,6 \times 10^{4}$ quistes/g a los $50 \mathrm{~cm}$. La concentración no supera los $2 \times 10^{4}$ quistes/g entre los 50 y los 130 $\mathrm{cm}$, y es muy baja entre los 130 y 160 $\mathrm{cm}$. Vuelve a aumentar hasta $\sim 2 \times 10^{4}$ quistes/g a los $200 \mathrm{~cm}$, tras lo cual dis- minuyen de nuevo a valores casi nulos hasta el muro del testigo.

Aproximación a la edad de los materiales

La comparación de los registros de diatomeas y cocolitóforos -especialmente de sus máximos- con los de testigos recuperados en el mar de Noruega datados con ${ }^{14} \mathrm{C}$ (Koç et al., 1993; Andruleit y Baumann, 1998) permite proponer una edad deglaciación-Holoceno para los 200 cm superiores del testigo (Fig. 2). Los picos de diatomeas y cocolitóforos registrados entre los $70 \mathrm{y}$ los $110 \mathrm{~cm}$ del SVAIS04 son similares a los observados en estos otros testigos entre los $9.000 \mathrm{y}$
7.000 años; este intervalo temporal coincide con la edad del óptimo climático en el área (Marchal et al., 2002). Por otro lado, los pequeños picos de dinoquistes y cocolitóforos entre los 180 y $200 \mathrm{~cm}$ pueden ser indicativos del comienzo de la deglaciación, ya que señales similares han sido datadas en 12.000 años (Baumann y Matthiessen, 1992). La escasa abundancia de dinoflagelados y la desaparición de los otros grupos de microfósiles en el tramo 180-140 cm podría ser indicativa de que, a pesar de estar en condiciones de mar abierto, se produjo una fuerte dilución de los materiales biogénicos por el aumento de la tasa de 
sedimentación durante las primeras fases de la deglaciación, aunque no se puede descartar la existencia de un intervalo de disolución de sílice y de carbonato.

Interpretación paleoceanográfica preliminar

En base a este modelo de edad preliminar, las variaciones en las concentraciones de estos tres grupos de microfósiles parecen estar registrando los cambios oceanográficos y climáticos ocurridos durante los últimos 15.000 años aproximadamente. El final del periodo glacial y las fases más tempranas de la deglaciación estarían recogidas en el metro basal del testigo, caracterizándose por un alto aporte de terrígenos, y en donde los avances y retrocesos del frente del casquete de hielo estarían registrados mediante la alternancia de distintas litologías. La práctica ausencia de microfósiles en este intervalo podría estar causada por la combinación de dilución y de existencia de un ambiente muy severo, en el que la WSC apenas dejaría sentir su influencia (Rasmussen et al., 2007).

A partir de los 12.000 años el aumento de las temperaturas (Marchal et al., 2002; Martrat et al., 2003), posiblemente causado por la mayor intensidad de la WSC (Rasmussen et al., 2007), crea unas condiciones favorables para la vida de dinoflagelados y, en menor medida, de cocolitóforos. Sin embargo, el deshielo del casquete cercano durante este periodo pudo traer consigo el aumento de partículas terrígenas y rocas transportadas por icebergs, causando probablemente la dilución de la señal micropaleontológica. Por otro lado, la turbidez generada por este incremento de partículas en las aguas superficiales pudo perjudicar el desarrollo de los organismos fotosintéticos.

El final de la fase principal de la deglaciación a los 10.000 años trajo consigo el descenso de las partículas terrígenas. Por otro lado, la mayor fuerza y la somerización de la WSC (Rasmussen et al., 2007) pudo activar el frente ártico y crear una zona de mezcla entre la WSC y la ESC, incrementándose los nutrientes. Todos estos factores contribuyeron a crear las condiciones necesarias para el desarrollo de diatomeas y cocolitóforos. Estos grupos se reprodujeron en gran número a partir de los 9.000 años, cuando se registraron temperaturas más cálidas que en la actualidad (Koç et al., 1993; Marchal et al., 2002; Rasmussen et al., 2007) durante un periodo de 2.000-3.000 años (óptimo climático).

El cambio de las condiciones ambientales tras el óptimo climático -reflejado en descensos de las concentraciones de diatomeas y cocolitóforos- es observado también en registros de paleotemperaturas de la zona (Marchal et al., 2002; Rasmussen et al., 2007).

\section{Conclusiones}

Los sedimentos recuperados contienen microfósiles en buen estado de preservación, que permiten la realización de estudios paleoecológicos y paleoceanográficos, y que parecen haber registrado aproximadamente los últimos 15.000 años.

La sedimentación de los tramos inferiores del testigo tuvo lugar durante las últimas etapas de la glaciación y las primeras fases de la deglaciación, y se caracterizó por un mayor aporte de material terrígeno. Tras la retirada del casquete del mar de Barents, la subida de las temperaturas propició el mayor desarrollo de los distintos grupos de organismos que, en el caso de cocolitóforos y diatomeas, se mantuvo en niveles altos durante el óptimo climático y descendió a mediados del Holoceno, mientras que el aumento de dinoflagelados fue gradual a lo largo de todo el Holoceno.

\section{Agradecimientos}

La consecución de esta investigación ha sido posible gracias a la financiación del proyecto SVAIS (POL2006-07390/ CGL) en el marco de las actividades españolas del Año Polar Internacional, y a la concesión de una beca predoctoral FPU a Andrés S. Rigual por el MEC. Los autores desean expresar su agradecimiento a los científicos de la Campaña SVAIS, así como a la tripulación técnica y militar del BIO Hespérides, y a J.I. Martín Cruz (USal) por su ayuda en la preparación de muestras. Los comentarios del Dr. F. Serrano (U. Málaga) han contribuido sustancialmente a la mejora de este manuscrito. Este estudio se enmarca dentro de las actividades de los proyectos Consolider-Ingenio GRACCIE (CSD2007-00067) y CGL2008-05560, del Ministerio de Ciencia y Tecnología, y del Grupo de Excelencia GR34 de la Junta de Castilla y León.

\section{Referencias}

Andruleit, H.A. y Baumann, K.-H. (1998). Marine Micropaleontology, 35, 179-201.

Baumann, K.-H. y Matthiessen, J. (1992). Marine Micropaleontology, 20, 129146.

Camerlenghi, A. y tripulación científica de la Campaña SVAIS (2007). Cruise Report, 62 p.

Flores, J.-A. y Sierro, F.J. (1997). Micropaleontology, 43, 321-324.

Koç, N., Jansen, E. y Haflidason, H. (1993). Quaternary Science Reviews, 12, 115-140.

Marchal, O., Cacho, I., Stocker, T.F., Grimalt, J.O., Calvo, E., Martrat, B., Shackleton, N., Vautravers, M., Cortijo, E., van Kreveld, S., Andersson, C., Koç, N., Chapman, M., Sbaffi, L., Duplessy, J.-C., Sarnthein, M., Turon, J.-L., Duprat, J. y Jansen, E. (2002). Quaternary Science Reviews, 21, 455-483.

Martrat, B., Grimalt, J.O., Villanueva, J., van Kreveld, S. y Sarnthein, M. (2003). Organic Geochemistry, 34, 1057-1070.

Rasmussen, T.L., Thomsen, E., Slubowska, M.A., Jessen, S., Solheim, A. y Koç, N. (2007). Quaternary Research, 67, 100-114. 


\section{Bibliografía}

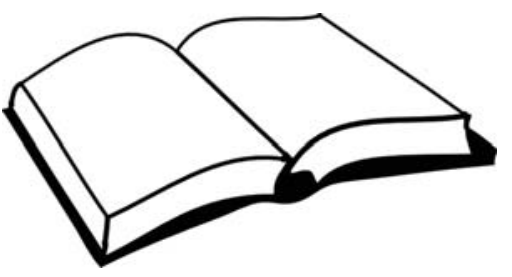





\section{Bibliografía}

Abrantes, F., Gil, I., Lopes, C. y Castro, M., 2005. Quantitative diatom analyses - a faster cleaning procedure. Deep-Sea Research I 52, 189-198.

Acker, J.G. y Leptoukh, G., 2007. Online Analysis Enhances Use of NASA Earth Science Data. Eos, Transactions. AGU 88, 14-17.

Aloïsi, J.C., Auffret, G.A., Auffret, J.P., Barusseau, J.P., Hommeril, P., Larsonneur, C. y Monaco, A., 1977. Essai de modélisation de la sédimentation actuelle sur les plateaux continentaux français. Bulletin de la Societe Geologique de France 7, 183-195.

Alvarez, I., deCastro, M., Gomez-Gesteira, M. y Prego, R., 2006. Hydrographic behavior of the Galician Rias Baixas (NW Spain) under the spring intrusion of the Miño River. Journal of Marine systems 60, 144-152.

Alldredge, A.L. y Gotschalk, C.C., 1990. The relative contribution of marine snow of different origins to biological processes in coastal waters. Continental Shelf Research 10, 41-58.

Anderson, O.R., Spindler, M., Bé, A.W.H. y Hemleben, C., 1979. Trophic activity of planktonic foraminifera. Journal of Marine Biological Association, United Kingdom 59, 791-799.

Andruleit,H., 1996. A filtrationtechnique forquantitativestudies of coccoliths. Micropaleontology 42, 403-406.

Appeltans, W., Bouchet, P., Boxshall, G.A., Fauchald, K., Gordon, D.P., Hoeksema, B.W., Poore, G.C.B., van Soest, R.W.M., Stöhr, S., Walter, T.C. y Costello, M.J., 2010. The World Register of Marine Species.

Asahi, H. y Takahashi, K., 2007. A 9-year time-series of planktonic foraminifer fluxes and environmental change in the Bering sea and the central subarctic Pacific Ocean, 19901999. Progress In Oceanography 72, 343-363.

Astraldi, M., Bianchi, C.N., Gasparini, G.P. y Morri, C., 1995. Climatic fluctuations, current variability and marine species distribution: a case study in the Ligurian Sea (north-west Mediterranean). Oceanologica Acta 18, 139-149.

Astraldi, M. y Gasparini, G.P., 1992. The seasonal characteristics of the circulation in the north Mediterranean basin and their relationship with the atmospheric-climatic conditions. Journal of Geophysical Research 97, 9531-9540.

Astraldi, M., Gasparini, G.P., Vetrano, S. y Vignudelli, S., 2002. Hydrographic characteristics and interanual variability of water masses in the central Mediterranean: a sensivity test for long-term changes in the Mediterranean Sea. Deep-Sea Research I 49, 661-680.

Backman, J. y Shackleton, N.J., 1983. Quantitative biochronology of Pliocene and early Pleistocene calcareous nannofossils from the Atlantic, Indian and Pacific oceans. Marine Micropaleontology 8, 141-170. 
Balch, W.M., 2004. Re-evaluation of the physiological ecology of coccolithophores, en: Thierstein, H.R., Young, J.R. (Eds.), Coccolithophores. From Molecular Processes to Global Impact. Springer-Verlag, Berlin, pp. 165-190.

Bao, R., Stigter, H. y Weering, T.C.E., 2000. Diatom fluxes in surface sediments of the Goban Spur continental margin, NE Atlantic Ocean. Journal of Micropaleontology 19, 123131.

Bárcena, M.A. y Abrantes, F., 1998. Evidence of a high-productivity area off the coast of Málaga from studies of diatoms in surface sediments. Marine Micropaleontology 35, 91-103.

Bárcena, M.A., Cacho, I., Abrantes, F., Sierro, F.J., Grimalt, J. y Flores, J.A., 2001. Paleoproductivity variations related to climatic conditions in the Alboran Sea (Western Mediterranean) during the last glacial-interglacial transition: the diatom record. . Palaeogeog. Palaeoclimatol. Palaeoecol. 167, 337-357.

Bárcena, M.A., Flores, J.A., Sierro, F.J., Pérez-Folgado, M., Fabres, J. y Calafat, A., 2004. Planktonic response to main oceanographic changes in the Alboran Sea (Western Mediterranean) as documented in sediment traps and surface sediments. Marine Micropaleontology 53, 375-398.

Barlow, R.G., Mantoura, R.F.C., Cummings, D.G. y Fileman, T.W., 1997. Pigment chemotaxonomic distributions of phytoplankton during summer in the western Mediterranean. Deep Sea Research Part II: Topical Studies in Oceanography 44, 833850 .

Baumann, K.-H., Andruleit, H., Böckel, B., Geisen, M. y Kinkel, H., 2005. The significance of extant coccolithophores as indicators of ocean water masses, surface water temperature, and palaeoproductivity: a review. Paläontologische Zeitschrift 79, 93-112.

Bé, A.W.H., 1960. Ecology of Recent Planktonic Foraminifera: Part 2: Bathymetric and Seasonal Distributions in the Sargasso Sea off Bermuda. Micropaleontology 6, 373-392.

Bé, A.W.H., 1969. Planktonic Foraminifera, Distribution of selected groups of marine invertebrates in waters south of 35" S latitude. American Geographic Society, New York, pp. 9-12.

Bé, A.W.H., 1977. An ecological, zoogeographic and taxonomic review of recent planktonic foraminifera, en: Ramsay, A.T.S. (Ed.), Oceanic Micropaleontology. Academic Press, London, pp. 1-100.

Bé, A.W.H., Caron, D.A. y Anderson, O.R., 1981. Effects of feeding frequency on life processes of the planktonic foraminifer Globigerinoides sacculifer in laboratory culture. Journal of the Marine Biological Association of the United Kingdom 61, 257-277.

Bé, A.W.H. y Ericson, D.B., 1963. Aspects of calcification in planktonic foraminifera (Sarcodina). Annals of the New York Academy of Sciences 109, 65-81.

Bé, A.W.H. y Hutson, W.H., 1977. Ecology of planktonic foraminifera and biogeographic patterns of life and fossil assemblages in the Indian Ocean. Micropaleontology 23, 369414. 
Bé, A.W.H. y Tolderlund, D.S., 1971. Distribution and ecology of living planktonic foraminifera in surface waters of the Atlantic and Indian Oceans, en: Funnell, B.M., Riedel, W.R. (Eds.), Micropaleontology of oceans. Cambridge University Press, London, pp. 105149.

Beaufort, L. y Dollfus, D., 2004. Automatic recognition of coccoliths by dynamical neural networks. Marine Micropaleontology 51, 57-73.

Bemis, B.E., Spero, H.J., Lea, D.W. y Bijma, J., 2000. Temperature influence on the carbon isotopic composition of Globigerina bulloides and Orbulina universa (planktonic foraminifera). Marine Micropaleontology 38, 213-228.

Berger, W.H., 1969. Ecologic patterns of living planktonic Foraminifera. Deep Sea Research and Oceanographic Abstracts 16, 1-24.

Berger, W.H., 1970. Planktonic Foraminifera: differential production and expatriation off Baja California. Limnology and Oceanography 15, 183-204.

Berger, W.H., 1971a. Planktonic foraminifera: Sediment production in an oceanic front. Journal of Foraminiferal Research 1, 95-118.

Berger, W.H., 1971b. Sedimentation of planktonic foraminifera. Marine Geology 11, 325358.

Berger, W.H., Smetacek, V.S. y Wefer, G., 1989. Ocean productivity and paleoproductivity, an overview, en: Berger, W.H., Smetacek, V.S., Wefer, G. (Eds.), Productivity of the Ocean: Present and Past. Wiley, pp. 1-34.

Berggreen, U., Hansen, B. y Kiorboe, T., 1988. Food size spectra, ingestion and growth of the copepod Acartia tonsa during development: implications for determination of copepods production. Marine Biology 99, 341-352.

Béthoux, J.P., 1979. Budgets of the Mediterranean Sea. Their dependence on the local climate and on the characteristics of the atlantic waters. Oceanologica Acta 2, 157-163.

Béthoux, J.P., Durrieu de Madron, X., Nyffeler, F. y Tailliez, D., 2002. Deep water in the western Mediterranean: peculiar 1999 and 2000 characteristics, shelf formation hypothesis, variability since 1970 and geochemical inferences. Journal of Marine Systems 33-34, 117-131.

Béthoux, J.P., Morin, P., Chaumery, C., Connan, O., Gentili, B. y Ruiz-Pino, D., 1998. Nutrients in the Mediterranean Sea, mass balance and statistical analysis of concentrations with respect to environmental change. Marine Chemistry 63, 155-169.

Béthoux, J.P., Prieur, L. y Nyffeler, F., 1982. The water circulation in the north-western Mediterranean Sea: its relation with wind and atmospheric pressure, en: Nihoul, J.C.J. (Ed.), Hydrodynamics of the Semi-Enclosed Seas. Elsevier Science, New York, pp. 129-149.

Béthoux, P., Pieur, L. y Bong, J.H., 1988. Le Courant Ligure au large de Nice. Oceanographie pelagique Mediterranéenne, en: Minas, H.J., Nival, P. (Eds.), Oceanologica Acta, pp. 59-67. 
Bijma, J., Erez, J. y Hemleben, C., 1990a. Lunar and semi-lunar reproductive cycles in some spinose planktonic foraminifers. Journal of Foraminiferal Research 20, 117-127.

Bijma, J., Faber, W.W. y Hemleben, C., 1990b. Temperature and salinity limits for growth and survival of some planktonic foraminifers in laboratory cultures. The Journal of Foraminiferal Research 20, 95-116.

Bijma, J., Hemleben, C., Oberhänsli, H. y Spindler, M., 1992. The effects of increased fertility on tropical spinose planktonic foraminifers in laboratory cultures. Journal of Foraminiferal Research 22, 242-256.

Boltovskoy, E., 1973. Daily vertical migration and absolute abundance of living planktonic foraminifera: Journal of Foraminiferal Research. 3, 89-94.

Bormans, M., Garret, C. y Thompson, K.R., 1986. Seasonal variability of the surface infow through the Strait of Gibraltar. Oceanologica Acta 9, 403-414.

Brand, L.E., 1994. Physiological ecology of marine coccolithophores, en: Winter, A., Siesser, W.G. (Eds.), Coccolithophores. Univ. Press, Cambridge, pp. 39-49.

Bukry, D., 1983. Upper Cenozoic silicoflagellates from offshore Ecuador. Deep Sea Drilling Project Site 504. Initial Reports DSDP 69, 321-342.

Bukry, D. y Monechi, S., 1985. Late Cenozoic silicoflagellates from the Northwest Pacific, Deep Sea Drilling Project Leg 86: Paleotemperature trends and texture classification, en: Heath, G.R., Burckle, L.H., et al. (Ed.), Initial Reports of Deep Sea Drilling Project, pp. 367-397.

Bustillos-Guzmán, J., Claustre, H. y Marty, J.C., 1995. Specific phytoplankton signatures and their relationship to hydrographic conditions in the coastal northwestern Mediterranean Sea. Marine Ecology Progress Series 124, 247-258.

Cacho, I., Grimalt, J.O., Pelejero, C., Canals, M., Sierro, F.J., Flores, J.A. y Shackleton, N., 1999. Dansgaard-Oeschger and Heinrich events imprints in Alboran Sea paleotemperatures. Paleoceanography 14, 689- 705.

Canals, M., Puig, P., de Madron, X.D., Heussner, S., Palanques, A. y Fabres, J., 2006. Flushing submarine canyons. Nature 444, 354-357.

Caroppo, C., Fiocca, A., Sammarco, P. y Magazzu, G., 1999. Seasonal variations of nutrients and phytoplankton in the coastal SW Adriatic Sea (1995-1997). Botanica Marina 42, 389-400.

Castellón, A., Font, J., Górriz, E.G. y Manrriquez, M., 1991. Estudio hidrográfico de corrientes marinas en la zona externa de la plataforma y talud continentales frente a Barcelona, Contract Report EMSSA, p. 208.

Castellví, J., 1971. Contribución a la biología de Skeletonema costatum (Grev.) Cleve. Investigación Pesquera 35, 365-520.

Ciesielski, P.F. y Case, S.M., 1989. Neogene paleoceanography of the Norwegian Sea based upon silicoflagellate assemblage changes in ODP Leg 104 sedimentary sequences. Proc. ODP, Sci. Results 104, 527-541. 
Ciesielski, P.F. y Weaver, E., 1974a. Early Pliocene temperature changes in the Antarctic seas. Geology 2, 511-515.

Ciesielski, P.F. y Weaver, F.M., 1974b. Early Pliocene temperature changes in the Antarctic Seas. Geology 2, 511-515.

Cifelli, R., 1974. Planktonic foraminifera from the Mediterranean and adjacent Atlantic waters (Cruise 49 of the ATLANTIS II, 1969). Journal of Foraminiferal Research 4, 171-183.

Colmenero-Hidalgo, E., 2004. Respuesta de las asociaciones de cocolitofóridos a los cambios climáticos del Cuaternario Final. Tesis doctoral. Departamento de Geología, Universidad de Salamanca, Salamanca.

Colmenero-Hidalgo, E., Flores, J.A., Sierro, F.J., Bárcena, M.A., Löwemark, L., Schönfeld, J. y Grimalt, J.O., 2004. Ocean surface water response to short-term climate changes revealed by coccolithophores from the Gulf of Cadiz (NE Atlantic) and Alboran Sea (W Mediterranean). Holocene 9, 237-241.

Cramp, A. y O’Sullivan, G., 1999. Neogene sapropels in the Mediterranean: a review. Marine Geology 153, 11-28.

Crawford, R., 2006. Diatoms: creators of glass castles. Science First Hand 10.

D’Ortenzio, F. y Ribera d'Alcalá, M., 2009. On the trophic regimes of the Mediterranean Sea: a satellite analysis. Biogeosciences 6, 139-148.

Darling, K.F., Kucera, M., Kroon, D. y Wade, C.M., 2006. A resolution for the coiling direction paradox in Neogloboquadrina pachyderma. Paleoceanography 21, p. PA2011.

Darling, K.F., Kucera, M., Wade, C.M., von Langen, P. y Pak, D., 2003. Seasonal distribution of genetic types of planktonic foraminifer morphospecies in the Santa Barbara Channel and its paleoceanographic implications. Paleoceanography 18, doi:10.1029/ 2001PA000723..

Darling, K.F. y Wade, C.M., 2008. The genetic diversity of planktic foraminifera and the global distribution of ribosomal RNA genotypes. Marine Micropaleontology 67, 216-238.

Del Amo, Y., Le Pape, O., Tréguer, P., Quéguiner, B., Ménesguen, A. y Aminot, A., 1997. Impacts of high-nitrate freshwater inputs on macrotidal ecosystems. I. Seasonal evolution of nutrient limitation for the diatom-dominated phytoplankton of the Bay of Brest (France). Marine Ecology Progress Series 161, 213-224.

Delgado, M. y Fortuño, J.M., 1991. Atlas de fitoplancton del Mar Mediterráneo. Scientia marina $55,1-133$.

Demarco, H., 1985. Applications de la télédetection infrarouge et visible en océanographie, Aix-Marseille 2. Université de Soutenance.

Deuser, W.G., 1996. Temporal variability of particle flux in the deep Sargasso Sea, en: Ittekkot, V., Schäfer, P., Honjo, S., Depetris, P.J. (Eds.), Particle flux in the ocean. John Wiley \& Sons Ltd.

Deuser, W.G., Brewer, P.G., Jickells, T.D. y Commeau, R.F., 1983. Biological Control of the Removal of Abiogenic Particles from the Surface Ocean. Science 219, 388-391. 
Deuser, W.G., Ross, E.H., Hemleben, C. y Spindler, M., 1981. Seasonal changes in species composition, numbers, mass, size, and isotopic composition of planktonic foraminifera settling into the deep sargasso sea. Palaeogeography, Palaeoclimatology, Palaeoecology 33, 103-127.

Díaz, F., Raimbault, P. y Conan, P., 2000. Small-scale study of primary productivity during spring in a Mediterranean coastal area (Gulf of Lions). Continental Shelf Research 20, 975-996.

Domack, E.W. y Mayewsky, P.A., 1999. Bi-polar ocean linktages: evidence from late Holocene Antartic Marine and Greenland ice-cores records. Holocene 9, 237-241.

Drakopoulos, P.G. y Lascaratos, A., 1999. Modelling the Mediterranean Sea: climatological forcing. Journal of Marine Systems 20, 157-173.

Drinkwater, K., Belgrano, A., Borja, A., Conversi, A., Edwards, M., Greene, C., Ottersen, G., Pershing, A. y Walker, H., 2003. The response of marine ecosystems to climate variability associated with the North Atlantic Oscillation, en: Hurrell, J.W., Kushnir, Y., Ottersen, G., Visbeck, M. (Eds.), The North Atlantic Oscillation: climatic significance and environmental impact. American Geophysical Union., Washington.

Dueñas-Bohórquez, A., da Rocha, R.E., Kuroyanagi, A., Bijma, J. y Reichart, G.-J., 2009. Effect of salinity and seawater calcite saturation state on $\mathrm{Mg}$ and $\mathrm{Sr}$ incorporation in cultured planktonic foraminifera. Marine Micropaleontology 73, 178-189.

Duplessy, J.C., Bé, A.W.H. y Blanc, P.L., 1981. Oxygen and carbon isotopic composition and biogeographic distribution of planktonic foraminifera in the Indian Ocean. Palaeogeography, Palaeoclimatology, Palaeoecology 33, 9-46.

Durrieu de Madron, X., Heussner, S., Canals, M., Calafat, A., Puig, P., Palanques, A., Estournel, C., Ulses, C., Danovaro, R. y Dell'Anno, A., 2007. Les plongées d'eau denses dans le Golfe du Lion et ses implications.

Durrieu de Madron, X., Nyffeler, F. y Godet, C.H., 1990. Hydrographic structure and nepheloid spatial distribution in the Gulf of Lions continental margin. Continental Shelf Research 10, 915-929.

Durrieu de Madron, X., Radakovitch, O., Heussner, S., Loye-Pilot, M.D. y Monaco, A., 1999. Role of the climatological and current variability on shelf-slope exchanges of particulate matter: Evidence from the Rhône continental margin (NW Mediterranean). Deep Sea Research Part I: Oceanographic Research Papers 46, 1513-1538.

Durrieu de Madron, X., Zervakis, V., Theocharis, A. y Georgopoulos, D., 2005. Comments to "Cascades of dense water around the world ocean. Progress In Oceanography 64, 8390.

Egge, J.K. y Jacobsen, A., 1997. Influence of silicate on particulate carbon production in phytoplankton. Marine Ecology Progress Series 147, 219-230. 
Erez, J., Almogi-Labin, A. y Avraham, S., 1991. On the life history of planktonic foraminifera: lunar reproduction cycle in Globigerinoides sacculifer (Brady). Paleoceanography 6, 295-306.

Escutia , C., Bárcena, M.A., Lucchi, R.G., Romero, O., Ballegeer, A.M., Gonzalez, J.J. y Harwood, D.M., 2009. Circum-Antarctic warming events between 4 and 3.5 Ma recorded in marine sediments from the Prydz Bay (ODP Leg 188) and the Antarctic Peninsula (ODP Leg 178) margins. Global and Planetary Change 69, 170-184.

Estournel, C., Durrieu de Madron, X., Marsaleix, P., Auclair, F., Julliand, C. y Vehil, R., 2003. Observation and modeling of the winter coastal oceanic circulation in the Gulf of Lion under wind conditions influenced by the continental orography (FETCH experiment). J. Geophys. Res. 108, 8059.

Estournel, C., Kondrachoff, V., Marsaleix, P. y Vehil, R., 1997. The plume of the Rhône: numerical simulation and remote sensing. Continental Shelf Research 17, 899-924.

Estrada, M., 1996. Primary production in the northwestern Mediterranean. Scientia Marina 60, 55-64.

Fabres, J., Calafat, A., Sanchez-Vidal, A., Canals, M. y Heussner, S., 2002. Composition and spatio-temporal variability of particle fluxes in the Western Alboran Gyre, Mediterranean Sea. Journal of Marine Systems 33-34, 431-456.

Fairbanks, R.G. y Wiebe, P.H., 1980. Foraminifera and Chlorophyll Maximum: Vertical distribution, seasonal succesion, and paleoceanographic significance. Science 209, 1524-1526.

Fatela, F. y Taborda, R., 2003. Confidence limits of species proportions in microfossil assemblages. Marine Micropaleontology 45, 169-174.

Fernex, F.E., Braconnot, J.C., Dallot, S., Boisson, M. y Mediterranean), Is ammonification rate in marine sediment related to plankton composition and abundance? A time-series study in Villefranche Bay (NW Mediterranean). 1996. Estuarine Coastal Shelf Science. 43, 359-371.

Flores, J.A. y Sierro, F.J., 1997. A revised technique for the calculation of calcareous nannofossil accumulation rates. Micropaleontology 43, 321-324.

Fogg, G.E., 1991. Tansley Review No. 30. The Phytoplanktonic Ways of Life. New Phytologist $118,191-232$

Fohrmann, H., Backhaus, J.O., Blaume, F. y Rumohr, J., 1998. Sediments in Bottom-Arrested Gravity Plumes: Numerical Case Studies. Journal of Physical Oceanography 28, 22502274.

Font, J., Salat, J. y Tintore, J., 1988. Permanent features of the circulation in the Catalan Sea. Oceanologica Acta 9, 51-57.

Fraedrich, K., 1994. An ENSO impact on Europe? A review. Tellus 46 A, 541-552.

Fraedrich, K. y Müller, K., 1992. Climate anomalies in Europe associated with ENSO extremes. International Journal of Climatolology 12, 25-31. 
García-Gorriz, E. y Carr, M.-E., 2001. Physical control of phytoplankton distributions in the Alboran Sea: a numerical and satellite approach. . Journal of Geophysical Research 106, 16795-16805.

Gaudin, M., Berné, S., Jouanneau, J.M., Palanques, A., Puig, P., Mulder, T., Cirac, P., Rabineau, M. y Imbert, P., 2006. Massive sand beds attributed to deposition by dense water cascades in the Bourcart canyon head, Gulf of Lions (northwestern Mediterranean Sea). Marine Geology 234, 111-128.

Gemeinhardt, K., 1934. Die Silicofl agellaten des südatlantischen ozeans. Wiss. Ergeb. Dtsch. Atl. Exped. Forchungs- und Vermenssungscchiff 'Meteor'. 1925-1927 12, 274-312.

Gómez, F. y Gorsky, G., 2003. Annual microplankton cycles in Villefranche Bay, Ligurian Sea, NW Mediterranean Journal of Plankton Research 25, 323-339.

Gorsky, G. y Fenaux, R., 1998. The role of Appendicularia in marine food webs, en: Bone, Q. (Ed.), The Biology of Pelagic Tunicates. Oxford University Press, Oxford, pp. 161171.

Gregory, J.M., Dixon, K.W., Stouffer, R.J., Weaver, A.J., Driesschaert, E., Eby, M., Fichefet, T., Hasumi, H., Hu, A., Jungclaus, J.H., Kamenkovich, I.V., Levermann, A., Montoya, M., Murakami, S., Nawrath, S., Oka, A., Sokolov, A.P. y Thorpe, R.B., 2004. A model intercomparison of changes in the Atlantic thermohaline circulation in response to increasing atmospheric CO2 concentration. Geophysical Research Letters 32, L12703.

Guiry, M.D. y Guiry, G.M., 2010. AlgaeBase. National University of Ireland, Galway.

Gust, G., Michaels, A.F., Johnson, R., Deuser, W.G. y Bowles, W., 1994. Mooring line motions and sediment trap hydrodynamics: in situ comparison of three common deployment designs. Deep-Sea Research I 41, 831-857.

Gutiérrez-Rodríguez, A., Latasa, M., Estrada, M., Vidal, M. y Marrasé, C., 2010. Carbon fluxes through major phytoplankton groups during the spring bloom and post-bloom in the Northwestern Mediterranean Sea. Deep Sea Research Part I: Oceanographic Research Papers 57, 486-500.

Hallegraeff, G.M., 1986. Taxonomy and morphology of the marine plankton diatoms Thalassionema and Thalassiotrix. Diatom Research 1, 57-80.

Hansen, J., Ruedy, R., Sato, M. y Lo, K., 2002. Global warming continues. Science 292, 275.

Harbison, G.R. y Gilmer, R.W., 1986. Effects on animal behavior on sediment trap collection: implication for the calculation of aragonite fluxes. Deep-Sea Research 33.

Hargraves, P.E., 1979. Studies on marine plankton diatoms IV. Morphology of Chaetoceros resting spores. Nova Hedwigia Beiheft 64, 99-120.

Hasle, G.R., 1969. An analysis of the phytoplankton of the Pacific Southern Ocean: abundance, composition, and distribution during the Brategg Expedition, 1947-1948, en: Skrifter, H. (Ed.), Scientific Results of Marine Biological Research. Universitetsforlaget, Oslo.

Hasle, G.R., 2001. The marine, planktonic diatom Family Thalassionemataceae: morphology, taxonomy and distribution. Diatom Research 16, 1-82. 
Hasle, G.R. y Sylvertsen, E.E., 1997. Marine Diatoms, en: Tomas, C.R. (Ed.), Identifying Marine Phytoplankton. Academic Press, St. Petersburg, Florida.

Heburn, G.W. y La Violette, P.E., 1990. Variations in the structure of the anticyclonic gyres found in the Alboran Sea. Journal of Geophysical Research 95, 1599-1613.

Hedges, J.I. y Keil, R.G., 1995. Sedimentary organic matter preservation: an assessment and speculative synthesis. Marine Chemistry 49, 81-115.

Hemleben, C. y Spindler, M., 1983. Recent advances in research on living planktonic foraminifera, en: Meulenkamp, J.E. (Ed.), Reconstruction of Marine Paleoenvironments, pp. pp. 141-170.

Hemleben, C., Spindler, M. y Anderson, O.R., 1989. Modern planktonic foraminifera. SpringerVerlag, New York.

Hemleben, C., Spindler, M., Breitinger, I. y Deuser, W.G., 1985. Field and laboratory studies on the ontogeny and ecology of some globorotaliid species from the Sargasso Sea off Bermuda The Journal of Foraminiferal Research 15, 254-272.

Henriksen, P., Knipschildt, F., Moestrup, Ø. y Thomsen, H.A., 1993. Autoecology, life history and toxicology of the silicoflagellate Dictyocha speculum (Silicoflagellata, Dictyochophyceae). Phycologia 32, 29-39.

Hernández-Almeida, I., Bárcena, M.A., Flores, J.A., Sierro, F.J., Sánchez-Vidal, A. y Calafat, A., 2010. Microplankton response to environmental conditions in the Alboran Sea (Western Mediterranean): one year sediment trap record. Marine Micropaleontology.

Hernández-Almeida, I., Bárcena, M.A., Flores, J.A., Sierro, F.J., Sanchez-Vidal, A. y Calafat, A., Microplankton response to environmental conditions in the Alboran Sea (Western Mediterranean): One year sediment trap record. Marine Micropaleontology 78, 14-24.

Heussner, S., Durrieu de Madron, X., Calafat, A., Canals, M., Carbonne, J., Desault, N. y Saragoni, G., 2006. Spatial and temporal variability of downward particle fluxes on a continental slope : Lessons from an 8-yr experiment in the Gulf of Lions (NW Mediterranean). Marine Geology 234, 63-92.

Heussner, S., Ratti, C. y Carbonne, J., 1990. The PPS 3 time series sediment traps and the trap sample processing techniques used during the ECOMARGE experiment Continental Shelf Research 10, 943-958.

Hodell, D.A., Brenner, M., Curtis, J.H. y Guilderson, T., 2001. Solar Forcing of Drought Frequency in the Maya Lowlands. Science 292, 1367-1370.

Hollibaugh, J.T., Seibert, D.L.R. y Thomas, W.H., 1981. Observations on the survival and germination of resting spores of three Chaetoceros (Bacillariophyceae) species. Journal of Phycology 17, 1-9.

Hurrell, J.W., 1995. Decadal trends in the North Atlantic Oscillation: Regional Temperatures and Precipitation. Science 269, 676-679.

Hurrell, J.W., 1996. The influence of variations in extratropical wintertime teleconnections on Northern Hemisphere temperature. Geophysical Research Letters 23, 665-668. 
Hurrell, J.W., Kushnir, Y., Ottersen, G. y Visbeck, M., 2003. An overview of the North Atlantic Oscillation, en: Hurrell, J.W., Kushnir, Y., Ottersen, G., Visbeck, M. (Eds.), The North Atlantic Oscillation: Climate Significance and Environmental Impact.

Hurrell, J.W., Kushnir, Y. y Visbeck, M., 2001. The North Atlanctic Oscillation. Science 291, 603-605.

Irigoien, X., Harris, R.P., Head, R.D. y Harbour, D., 2000. North Atlantic Oscillation and spring bloom phytoplankton composition in the English Channel. Journal of Plankton Research 22, 2367-2371.

Ivanov, V.V., Shapiro, G.I., Huthnance, J.M., Aleynik, D.L. y Golovin, P.N., 2004a. Cascades of dense water around the world ocean. Progress In Oceanography 60, 47-98.

Ivanov, V.V., Shapiro, G.I., Huthnance, J.M., Aleynik, D.L. y Golovin, P.N., 2004b. Cascades of dense water around the world ocean. Progr. Oceanogr. 60, 47-98.

Jickells, T.D., 1998. Nutrient biogeochemistry of the coastal zone. Science 281, 217-222.

Jickells, T.D., Newton, P.P., King, P., Lampitt, R.S. y Boutle, C., 1996. A comparison of sediment trap records of particle fluxes from 19 to $48^{\circ} \mathrm{N}$ in the northeast Atlantic and their relation to surface water productivity. Deep Sea Research Part I: Oceanographic Research Papers 43, 971-986.

Jochem, F. y Babenerd, B., 1989. Naked Dictyocha speculum - a new type of phytoplankton bloom in the Western Baltic. Marine Biology 103, 373-379.

Jones, P.D., Osborn, T.J. y Briffa, K.R., 2001. The evolution of climate over the last millennium. Science 292, 662-667.

Kallel, N., Paterne, M., Duplessy, J.C., Vergnaud-Grazzini, C., Pujol, C., Labeyrie, L., Arnold, M., Fontugne, M. y Pierre, C., 1997. Enhanced rainfall in the Mediterranean region during the last sapropel event. Oceanologica Acta 20.

Karl, D.M., Dore, J.E., Lukas, R., Michaels, A.F., Bates, N.R. y Knap, A., 2001. Building the Long-Term Picture: The U.S. JGOFS Time-Series Programs Oceanography 14.

Kemp, A.E.S., Pike, J., Pearce, R.B. y Lange, C.B., 2000. The "Fall dump" -- a new perspective on the role of a "shade flora" in the annual cycle of diatom production and export flux. Deep Sea Research Part II: Topical Studies in Oceanography 47, 2129-2154.

Kennett, J., 1968. G. truncatulinoides as a paleo-oceanographic index. Science 159, 14611463.

Kincaid, E., Thunell, R.C., Le, J., Lange, C.B., Weinheimer, A.L. y Reid, F.M.H., 2000. Planktonic foraminiferal fluxes in the Santa Barbara Basin: response to seasonal and interannual hydrographic changes. Deep Sea Research Part II: Topical Studies in Oceanography 47, 1157-1176.

Knappertsbusch, M., 1993. Geographic distribution of living and Holocene coccolithophores in the Mediterranean Sea. Marine Micropaleontology 21, 219- 247. 
Koning, E., van Iperen, J.M., van Raaphorst, W., Helder, W., Brummer, G.J.A. y van Weering, T.C.E., 2001. Selective preservation of upwelling-indicating diatoms in sediments off Somalia, NW Indian Ocean. Deep Sea Research Part I: Oceanographic Research Papers 48, 2473-2495.

La Violette, P.E., Tintore, J. y Font, J., 1990a. The surface circulation of the Balearic Sea. Journal of Geophysical Research 95, 1559-1568.

La Violette, P.E., Tintoré, J. y Font, J.C., 1559-1568., 1990b. The surface circulation of the Balearic Sea. Journal of Geophysical Research 95, 1559-1568.

Lacombe, H., Tchernia, P.E.S., D.J. y (Ed.): . Strousberg: Hutchinson \& Ross, p.-. 1972. Caractères hydrologiques et circulation des eaux en Méditerranée, en: Stanley, D.J. (Ed.), The Mediterranean Sea: A Natural Sedimentation Laboratory. Dowden, Hutchinson and Ross, Stroudsburg, Pennsylvania, p. 765.

Lange, B.C. y Boltovskoy, D., 1995. Trampas de sedimento, en: Alveal, K., Ferrario, M.E., Oliveira, E.C., Sar, E. (Eds.), Manual de Métodos Fisiológicos, Universidad de Concepción, Chile. , pp. 93-118.

Lange, C.B., Weinheimer, A.K., Reid, F.M., Tappa, E. y Thunell, R.C., 2000. Response of siliceous microplankton from the Santa Barbara Basin to the 1997-1998 El Niño Event. California Cooperative Ocean Fisheries Investigation (CalCOFI) Report. 4118641193.

Lange, C.B., Weinheimer, A.L. y Reid, F.M.H., 1997. Sedimentation patterns of diatoms, radiolarians and silicoflagellates in Santa Barbara Basin, California. CalCOF1 Rep. 38, 161-170.

Lapouyade, A. y Durrieu De Madron, X., 2001. Seasonal variability of the advective transport of particulate matter and organic carbon in the Gulf of Lion (NW Mediterranean). Oceanologica Acta 24, 295-312.

Le Pape, O., Del Amo, Y., Menesguen, A., Aminot, A., Quéguiner, B. y Tréguer, P., 1996. Resistance of a coastal ecosystem to increasing eutrophic conditions: the Bay of Brest (France), a semi-enclosed zone of Western Europe. Continental Shelf Research 16, 1885-1907.

Leblanc, K., Quéguiner, B., García, N., Rimmelin, P. y Raimbault, P., 2003. Silicon cycle in the NW Mediterranean Sea: seasonal study of a coastal oligotrophic site. Oceanologica Acta 26, 339-355.

Leblanc, K., Quéguiner, B., Raimbault, P. y Garcia, N., 2005. Efficiency of the silicate pump at a coastal oligotrophic site in the Mediterranean Sea. Biogeosciences 2, 219-229.

Lee, C., Wakeham, S.G. y Hedges, J.I., 1988. The measurement of oceanic particle flux - are swimmers a problem? Oceanography 1 . 
Lefevre, D., Minas, H.J., Minas, M., Robinson, C., Williams, P.J.L.B. y Woodward, E.M.S., 1997. Review of gross community production, primary production, net community production and dark community respiration in the Gulf of Lions. Deep-Sea Research II 44, 801-819.

Leventer, A., Domack, S.E., Ishman, S., Brachfeld, S., McClennen, C. y Manley, P.L., 1996. Productivity cycles of 200-300 years in the Antarctic Peninsula region; understanding linkages among the Sun, atmosphere, oceans, sea ice, and biota. Geological Society American Bulletin 108, 1626-1644.

Levitus, S. y Boyer, T., 1994. World Ocean Atlas: Temperature. NOAA Atlas NESDIS 4, . U.S. Department of Commerce, Washington, D.C.

Lewis, W.M., 1984. The diatom sex clock and its evolutionary significance. American Naturalist $123,73-80$.

Liu, H., Probert, I., Uitz, J., Claustre, H., Aris-Brosou, S., Frada, M., Not, F. y de Vargas, C., 2009. Extreme diversity in noncalcifying haptophytes explains a major pigment paradox in open oceans. PNAS 106.

Liu, K.K., Atkinson, L., Chen, C.T.A., Gao, S., Hall, J., Macdonald, R.W., Talaue McManus, L. y Quiñones, R., 2000. Exploring continental margin carbon fluxes on a global scale. EOS Trans. AGU 81, 641-644.

Loeillet, C. y Leveau, M., 1985. Influence des apports Rhôdaniens sur la structure du syst6me particulaire dans le golfe du Lion. Comptes Rendus de l'Académie des Sciences, Paris II, 397-402.

Lofi, J., Rabineau, M., Gorini, C., Berne, S., Clauzon, G., De Clarens, P., Tadeu Dos Reis, A., Mountain, G.S., Ryan, W.B.F., Steckler, M.S. y Fouchet, C., 2003. Plio-Quaternary prograding clinoform wedges of the western Gulf of Lion continental margin (NW Mediterranean) after the Messinian Salinity Crisis. Marine Geology 198, 289-317.

Lohmann, G.P., 1992. Increasing seasonal upwelling in the subtropical South Atlantic over the past 700,000 yrs: Evidence from deep-living planktonic foraminifera. Marine Micropaleontology 19, 1-12.

Lončarić, N., 2005. Planktic foraminiferal response to changing SE Atlantic oceanography. Vrije Universiteit Amsterdam.

Loncaric, N., van Iperen, J., Kroon, D. y Brummer, G.-J.A., 2007. Seasonal export and sediment preservation of diatomaceous, foraminiferal and organic matter mass fluxes in a trophic gradient across the SE Atlantic. Progress In Oceanography 73, 27-59.

Lopes, S., Mix, A.C. y Abrantes, F., 2006. Diatoms in the Northeast Pacific surface sediments as paleoceanographic proxies. Marine Micropaleontology 60, 45-65.

Ludwig, W., Dumont, E., Meybeck, M. y Heussner, S., 2009. River discharges of water and nutrients to the Mediterranean and Black Sea: Major drivers for ecosystem changes during past and future decades? Progress In Oceanography 80, 199-217. 
Mandra, Y.T. y Mandra, H., 1970. Antarctic Tertiary marine climate based on silicoflagellates. Antarct. J. U.S. 5, 178-180.

Mann, M.E., Bradley, R.S. y Hughes, M.K., 1999. Northern hemisphere temperatures during the past millennium: Inferences, uncertainties, and limitations. Geophys. Res. Lett. 26, 759-762.

Margalef, R., 1963. El ecosistema pelágico de un área costera del Mediterráneo occidental. Memorias de la real academia de artes y ciencieas de Barcelona 35, 1-48.

Margalef, R., 1974. Ecología, Barcelona.

Margalef, R., 1978. Life-forms of phytoplankton as survival alternatives in an unstable environment. Oceanologica Acta 1, 493-509.

Margalef, R., 1997. Turbulence and marine life. Scientia marina 61, 109-123.

Martín, J., 2007. http://www.icm.csic.es/geo/gma/geo0es.html.

Martinez, E., Antoine, D., D’Ortenzio, F.G. y Bernard, 2009. Climate-Driven Basin-Scale Decadal Oscillations of Oceanic Phytoplankton. Science 326, 1253-1256.

Martini, E., 1977. Systematics, distribution and stratigraphical application of silicoflagellates, en: Ramsey, A.T.S.E. (Ed.), Oceanic Micropaleontology. Vol. 2. Academic Press, London, pp. 1327-1343.

Marty, J.C., Chiavérini, J., Pizay, M.D. y Avril, B., 2002. Seasonal and interannual dynamics of nutrients and phytoplankton pigments in the western Mediterranean Sea at the DYFAMED time-series station (1991-1999). Deep-Sea Research II 49, 1965-1985.

Marty, J.C., Nicolas, E., Miquel, J.C. y Fowler, S.W., 1994. Particulate fluxes of organic compounds and their relationship to zooplankton fecal pellets in the northwestern Mediterranean Sea. Marine Chemistry 46, 387-405.

Masqué, P., Fabrés, J., Canals, M., Sánchez-Cabeza, J.A., Sánchez-Vidal, A., Cacho, I., Calafat, A.M. y Bruach, J.M., 2003. Accumulation rates of major constituents of hemipelagic sediments in the deep Alboran Sea: a centennial perspective of sedimentary dynamics. Marine Geology 193, 207-233.

McPhaden, M.J., 1999a. El Niño: The child prodigy of 1997-98. Nature 398, 559-562.

McPhaden, M.J., 1999b. Genesis and evolution of the 1997-98 El Niño. Science 283, 950954.

McQuoid, M.R. y Hobson, L.A., 1996. Diatom resting stages. Journal of Phycology 32, 889902.

Melki, T., Kallel, N., Jorissen, F.J., Guichard, F., Dennielou, B., Berné, S., Labeyrie, L. y Fontugne, M., 2009. Abrupt climate change, sea surface salinity and paleoproductivity in the western Mediterranean Sea (Gulf of Lion) during the last 28 kyr. Palaeogeography, Palaeoclimatology, Palaeoecology 279, 96-113.

Mercado, J., Cortés, D., Garcia, A. y Ramírez, T., 2007. Seasonal and inter-annual changes in the planktonic communities of the northwest Alboran Sea (Mediterranean Sea). Progress In Oceanography 74, 273-293. 
Mercado, J., Ramírez, T., Cortés, D., Sebastián, M. y Vargas, M., 2005. Temporal changes of the phytoplankton communities in an upwelling area of the Alboran Sea. Scientia Marina 69, 451-465.

Meteorological Office, 1962. Weather in the Mediterranean Sea. Her Majesty’s Office, London, U.K.

Michaels, A.F., Silver, M.W., Gowing, M.M. y Knauer, G.A., 1990. Cryptic zooplankton "swimmers" in upper ocean sediment traps. Deep-Sea Research 37.

Millero, F.J., Morse, J. y Chen, C.-T., 1979. The carbonate system in the western Mediterranean sea. Deep Sea Research Part A. Oceanographic Research Papers 26, 1395-1404.

Millot, C., 1990. The Gulf of Lions' hydrodynamics. Cont. Shelf Res 10, 885-894.

Millot, C., 1991. Mesoscale and seasonal variabilities of the circulation in the western Mediterranean. Dynamics of Atmospheres and Oceans 15, 179-214.

Millot, C., 1999. Circulation in the Western Mediterranean Sea. Journal of Marine Systems 20, 423-442.

Minas, H., Coste, B., Le Corre, P., Minas, M. y Raimbault, P., 1991. Biological and geochemical signatures associated with the water circulation through the Strait of Gibraltar and in the western Alboran Sea. Journal of Geophysical Research 96, 8755-8771.

Miquel, J.C., Fowler, S.W., La Rosa, J. y Buat-Menard, P., 1994. Dynamics of the downward flux of particles and carbon in the open northwestern Mediterranean Sea. Deep Sea Research Part I: Oceanographic Research Papers 41, 243-261.

Moestrup, O. y Thomsen, H.A., 1990. Dictyocha speculum (Silicoflagellata, Dictyochophyceae), studies on armoured and unarmoured stages. Biol. Skr. 37, 1-56.

Monaco, A., Courp, T., Heussner, S., Carbonne, J., Fowler, S.W. y Deniaux, B., 1990. Seasonality and composition of particulate fluxes during ECOMARGE I, western Gulf of Lions. Continental Shelf Research 10, 959-987.

Monaco, A., Durrieu de Madron, X., Radakovitch, O., Heussner, S. y Carbonne, J., 1999. Origin and variability of downward biogeochemical fluxes on the Rhone continental margin (NW mediterranean). Deep Sea Research Part I: Oceanographic Research Papers 46, $1483-1511$.

Moore, J.K. y Villareal, T.A., 1996. Size-ascent rate in positively buoyant marine diatoms. Limnology and Oceanography 41.

Mysterud, A., Stenseth, N.C., Yoccoz, N.G., Ottersen, G. y Langvatn, R., 2003. The response of the terrestrial ecosystems to climate variability associated with the North Atlantic Oscillation, en: Hurrell, J.W., Kushnir, Y., Ottersen, G., Visbeck, M. (Eds.), The North Atlantic Oscillation: climatic significance and environmental impact. American Geophysical Union, Washington, pp. 235-262. 
Nelson, D.M., Tréguer, P., Brzezinski, M.A., Leynaert, A. y Quéguiner, B., 1995. Production and dissolution of biogenic silica in the ocean: Revised global estimates, comparison with regional data and relationship to biogenic sedimentation. Global Biogeochemichal Cycles 9, 359-372.

Nival, P., 1965. Sur le cycle de Dictyocha fibula dans les eaux de surface de la rade de Villefranche-sur-Mer. Cah. Biol. Mar. 6, 67-82.

Norris, R.E., 1967. Algal consortiums in marine plankton., en: Krishnamurthy, V. (Ed.), Seminar Sea Salt and Plants. Central Salt and Marine Chemistry Res., Bhavnagar, India, pp. 178189.

O’Neill-Baringer, M. y Price, J.M., 1999. A review of the physical oceanography of the Mediterranean outflow. Marine Geology 155, 63-82.

Officer, C.B. y Ryther, J.H., 1980. The possible importance of silicon in marine eutrophication. Marine Ecology Progress Series 3, 83-91.

Olita, A., Sorgente, R., Natale, S., Gabersek, S., Ribotti, A., Bonanno, A. y Patti, B., 2007. Effects of the 2003 European heatwave on the Central Mediterranean Sea: surface fluxes and the dynamical response. Ocean Science 3, 279-289.

Onodera, J., 2006. Ecological study of siliceous phytoplankton in the Northwestern Pacific and paleoceanographic reconstruction in the Eocene Artic Ocean. Department of Earth and Planetary Sciences. Graduate School of Sciences. Kyushu University. .

Onodera, J. y Takahashi, K., 2005. Silicoflagellate fluxes and environmental variations in the northwestern North Pacific during December 1997-May 2000. Deep-Sea Research I 52, 371-388.

Ottens, J.J., 1992. Planktic foraminifera as indicators of ocean environments in the Northeast Atlantic, Amsterdam, p. 189.

Palanques, A., Durrieu de Madron, X., Puig, P., Fabres, J., Guillén, J., Calafat, A., Canals, M., Heussner, S. y Bonnin, J., 2006. Suspended sediment fluxes and transport processes in the Gulf of Lions submarine canyons. The role of storms and dense water cascading. Marine Geology 234, 43-61.

Parrilla, G. y Kinder, T., 1987. The physical oceanography of the Alborán sea. Boletín del Instituto Español de Oceanografía 4, 133-165.

Perch-Nielsen, K., 1985. Silicoflagellates, en: Bolli, H.M., Saunders, J.B., Perch-Nielsen, K. (Eds.), Plankton Stratigraphy, pp. 811-846.

Pérez-Cruz, L., 2006. Climate and ocean variability during the middle and late Holocene recorded in laminated sediments from Alfonso Basin, Gulf of California, Mexico. Quaternary Research 65, 401-410.

Perkins, H., Kinder, T. y La Violette, P., 1990. The Atlantic inflow in the Western Alboran Sea. Journal of Physical Oceanography 20, 242-263.

Philander, S.G., 1990. El Niño, la Niña and the Southern Oscillation. Accademic Press, San Siego. 
Pierre, C., 1999. The oxigen and carbon isotope distribution in the Mediterranean water masses. Marine Geology 153, 41-55.

Pinardi, N. y Masetti, E., 2000. Variability of the large scale general circulation of the Mediterranean Sea from observations and modelling: a review. Palaeogeography, Palaeoclimatology, Palaeoecology 158, 153-173.

Puig, P. y Palanques, A., 1998. Temporal variability and composition of settling particle fluxes on the Barcelona continental margin (Northwestern Mediterranean). Journal of Marine Research 56, 639-654.

Pujol, C. y Vergnaud Grazzini, C., 1995. Distribution patterns of live planktic foraminifers as related to regional hydrography and productive systems of the Mediterranean Sea. Marine Micropaleontology 25, 187-217.

Ragueneau, O., Tréguer, P., Leynaert, A., Anderson, R.F., Brzezinski, M.A., Demaster, D.J., Dugdale, R.C., Dymond, J., Fisher, G., François, R., Heinze, C., Maier-Reimer, E., Martin-Jézéquel, V., Nelson, D.M. y Quéguiner, B., 2000. A review of the Si cycle in the modern ocean: recent progress and missing gaps in the application of biogenic opal as a paleoproductivity proxy. Global and Planetary Change 26, 317-365.

Reynolds, L.A. y Thunell, R.C., 1985. Seasonal succesion of planktonic foraminifera in the subpolar North Pacific. Journal of Foraminiferal Research 15, 282-301.

Reynolds, R.W., Rayner, N.A., Smith, T.M., Stokes, D.C. y Wang, W., 2002. An improved in situ and satellite SST analysis for climate. Journal of Climate 15, 1609-1625.

Ribera D’Alcalà, M., Conversano, F., Corato, F., Licandro, P., Mangoni, O., Marino, D., Mazzocchi, M.G., Modigh, M., Montresor, M., Nardella, M., Saggiomo, V., Sarno, D. y Zingone, A., 2004. Seasonal patterns in plankton communities in a pluriannual time series at a coastal Mediterranean site (Gulf of Naples): an attempt to discern recurrence and trends. Scientia marina $68,65-83$.

Rigual-Hernández, A.S., Bárcena, M.A., Sierro, F.J., Flores, J.A., Hernández-Almeida, I., Sanchez-Vidal, A., Palanques, A. y Heussner, S., 2010. Seasonal to interannual variability and geographic distribution of the silicoflagellate fluxes in the Western Mediterranean. Marine Micropaleontology 77, 46-57.

Rohling, E.J., 1994. Review and new aspects concerning the formation of eastern Mediterranean sapropels. Marine Geology 122, 1-28.

Romero, O., Lange, C.B., Fischer, G., Treppke, U.F. y Wefer, G., 1999. Variability in export production documented by downward fl uxes and species composition of marine planktonic diatoms: observations from the tropical and equatorial Atlantic, en: Fischer, G., Wefer, G. (Eds.), The Use of Proxies in Paleoceanography - Examples from the South Atlantic. Springer-Verlag Berlin Heidelberg, pp. 365-392.

Romero, O.E., Hebbeln, D. y Wefer, G., 2001. Temporal and spatial variability in export production in the SE Pacific Ocean: evidence from siliceous plankton fluxes and surface sediment assemblages. Deep-Sea Research I 48, 2673-2697. 
Rost, B. y Riebesell, U., 2004. Coccolithophores and the biological pump: responses to environmental changes, en: Thierstein, H.R., Young, J.R. (Eds.), Coccolithophores: from molecular processes to global impact. Springer, Berlin pp. 99-125.

Round, F.E., Crawford, R.M. y Mann, D.G., 1990. The Diatoms, Cambridge.

Salat, J. y Font, J., 1987. Water mass structure near and offshore the Catalan coast during the winter of 1982 and 1983. Annales Geophysicae 5, 49-54.

Sánchez-Goñi, M.F., Cacho, I., Turon, J.L., Guiot, J., Sierro, F.J., J.P., P., Grimalt, J.O. y Schackleton, N., 2002. Synchroneity between marine and terrestrial responses to millennial scale climatic variability during the last glacial period in the Mediterranean region. Climate Dynamics 19, 95-105.

Sanchez-Vidal, A. , A. Calafat, M. Canals y J. Fabres, 2004. Particle fluxes in the AlmeriaOran Front: control by coastal upwelling and sea surface circulation. Journal of Marine Systems 52, 89-106.

Sautter, L.R. y Sancetta, C., 1992. Seasonal associations of phytoplankton and planktic foraminifera in an upwelling region and their contribution to the seafloor. Marine Micropaleontology 18, 263-278.

Sautter, L.R. y Thunell, R.C., 1991. Planktonic foraminiferal response to upwelling and seasonal hydrographic conditions: sediment trap results from San Pedro Basin, Southern California Bight Journal of Foraminiferal Research 21, 347-363.

Schiebel, R., Bijma, J. y Hemleben, C., 1997. Population dynamics of the planktic foraminifer Globigerina bulloides from the eastern North Atlantic. Deep-Sea Research I 44, 1701 1713.

Schilman, B., Bar-Matthews, M., Almogi-Labin, A. y Luz, B., 2001. Global climate instability reflected by Eastern Mediterranean marine records during the late Holocene. Palaeogeography, Palaeoclimatology, Palaeoecology 176, 157-176.

Schneider, A., Wallace, D.W.R. y Körtzinger, A., 2007. Alkalinity of the Mediterranean Sea. Geophysical Research Letters 34, L15608.

Schott, F., Visbeck, M. y Send, U., 1994. Open ocean deep convection, Mediterranean and Greenland Seas, en: Malanotte-Rizzoli, P., Robinson, A. (Eds.), Ocean Processes in Climate Dynamics: Global and Mediterranean Examples. Kluwer, pp. 203-225.

Schrader, H., Pisias, N. y Cheng, G., 1986. Seasonal variation of silicoflagellates in phytoplankton and varved sediments in the Gulf of California. Marine Micropaleontology 10, $207-$ 233.

Schrader, H.J. y Gersonde, R., 1978. Diatoms and silicoflagellates. Utrecht Micropaleontological Bulletins.

Shanks, A.L. y Trent, J.D., 1980. Marine snow: sinking rates and potential role in vertical flux. Deep Sea Research Part A. Oceanographic Research Papers 27, 137-143. 
Siegel, D.A., Granata, T.C., Michaels, A.F. y Dickey, T.D., 1990. Mesoscale eddy diffusion, particle sinking, and the interpretation of sediment trap data. Journal of Geophysical Research 95, 5305-5311.

Sierro, F.J., Andersen, N., Bassetti, M.A., Berné, S., Canals, M., Curtis, J.H., Dennielou, B., Flores, J.A., Frigola, J., Gonzalez-Mora, B., Grimalt, J.O., Hodell, D.A., Jouet, G., Pérez-Folgado, M. y Schneider, R., 2009. Phase relationship between sea level and abrupt climate change. Quaternary Science Reviews 28, 2867-2881.

Simonsen, R., 1974. The diatom plankton of the Indian Ocean Expedition of RV Meteor 19641965. Meteor Forschung-Ergebnisse. Reihe D Biol. 19, 1-66.

Simpson, A.G. y Roger, A.J., 2004. The real 'kingdoms' of eukaryotes. Current Biology 14, 693-696.

Siokou-Frangou, I., Christaki, U., Mazzocchi, M.G., Montresor, M., Ribera d'Alcalá, M., Vaqué, D. y Zingone, A., 2010. Plankton in the open Mediterranean Sea: a review. Biogeosciences 7, 1543-1586.

Smayda, T.J., 1990. Novel and nuisance phytopankton blooms in the sea: evidence for a global epidemic, en: Granéli, E. (Ed.), Toxic Marine Phytoplankton. Elsevier, pp. 29-40.

Smayda, T.J. y Mitchell-Innes, B., 1974. Dark survival of autotrophic planktonic marine diatoms. Marine Biology 25, 195-202.

Smetacek, V., 1985. Role of sinking in diatom life-history cycles: ecological, evolutionary and geological significance. Marine Biology 84, 239-251.

Smetacek, V., 1999a. Bacteria and silica cycling. Nature 397, 475-476.

Smetacek, V., 1999b. Diatoms and the ocean carbon cycle. Protist 150, 25-32.

Smetacek, V., 2000. The giant diatom dump. Nature 406, 574-575.

Sournia, A., 1982. Is there a shade flora in the marine plankton? Journal of Plankton Research 4, 391-399.

Spindler, M., Hemleben, C., Bayer, U., Bé, A.W.H. y Anderson, O.R., 1979. Lunar periodicity of reproduction in the planktonic foraminifer Hastigerina pelagica. Marine Ecology Progress Series 1, 61-64.

Stanev, E.V. y Friedrich, H.J., 1991. On the assimilation of climatological data by means of numerical circulation models, examplified for the Mediterranean Sea. Oceanologica Acta 14, 97-114.

Stephenson, D.B., Wanner, H., Brönnimann, S. y Luterbacher, J., 2003. The History of Scientific Research on the North Atlantic Oscillation, en: Hurrell, J.W., Kushnir, Y., Ottersen, G., Visbeck, M. (Eds.), The North Atlantic Oscillation: Climate Significance and Environmental Impact. Geophysical Monograph Series. 
Straile, D., Livingstone, D., Weyhenmeyer, G. y George, D., 2003. The response of freshwater ecosystems to climate variability associated with the North Atlantic Oscillation, en: Hurrell, J.W., Kushnir, Y., Ottersen, G., Visbeck, M. (Eds.), The North Atlantic Oscillation: climatic significance and environmental impact. American Geophysical Union, Washington, pp. 263-279.

Strasburguer, E., 1994. Tratado de Botánica, 7 ed. Omega, Barcelona.

Strzepek, R.F. y Harrison, P.J., 2004. Photosynthetic architecture differs in coastal and oceanic diatoms. Nature 431, 689-692.

Suto, I., 2007. Taxonomy and biostratigraphy of the fossil resting spore of the marine diatom genus Chaetoceros and non-Chaetoceros group, 2nd Neogene polar Diatom Workshop, Lincoln University-Nebraska.

Takahashi, K., Fujitani, N., Yanada, M. y Maita, Y., 2000. Long-term biogenic particle fluxes in the Bering Sea and the central subarctic Pacific Ocean, 1990-1995. Deep Sea Research Part I: Oceanographic Research Papers 47, 1723-1759.

Takahashi, K., Honjo, S. y Tabata, S., 1989. Siliceous phytoplankton flux: interannual variability and response to hydrographic changes in the northeastern Pacific, en: Peterson, D.H. (Ed.), Aspects of Climate Variability in the Pacific and Western Americas, pp. 151160.

Tappan, H., 1980. Silicoflagellates, en: Freeman, S.F., CA (Ed.), The Paleobiology of Plant Protists, pp. 535-566.

Thiede, J., 1978. A Glacial Mediterranean. Nature 276, 680-683.

Thompson, D.W.J. y Wallace, J.M., 2000. Annular modes in the extratropical circulation , Part I: Month to month variability. Journal of Climate 13, 1018-1036.

Throndsen, J., 1997. The planktonic marine flagellates, en: C. R. Tomas (Ed.), Identifying Marine Phytoplankton. Academic Press, San Diego.

Thunell, R.C., 1978. Distribution of recent planktonic foraminifera in surface sediments of the Mediterranean Sea. Marine Micropaleontology 3, 147-173.

Thunell, R.C. y Reynolds, L.A., 1984. Sedimentation of Planktonic Foraminifera: Seasonal Changes in Species Flux in the Panama Basin. Micropaleontology 30, 243-262.

Thurman, H.V. y Burton, E.A., 2001. Introductory Oceanography. Prentice Hall.

Tintoré, J., Gomis, D., Alonso, S. y Parrilla, G., 1991. Mesoscale dynamics and vertical motion in the Alboran Sea. Journal of Physical Oceanography 21, 811-823.

Tintoré, J., LaViolette, P., Blade, I. y Cruzado, A., 1988. A study of an intense density front in the Eastern Alboran Sea: the Almería-Orán front. Journal of Physical Oceanography 18, 1384-1397.

Tintoré, J., Wang, D.P. y La Violette, P.E., 1990. Eddies and thermohaline intrusions of the shelf/slope front off the Northeast Spanish coast. Journal of Geophysical Reseach 95, 1627-1633. 
Tomas, C.R., 1997. Identifying Marine Phytoplankton, New York.

Townsend, D.W., Cammen, L.M., Holligan, P.M., Campbell, D.E. y Pettigrew, N.R., 1994. Causes and consequences of variability in the timing of spring phytoplankton blooms. Deep Sea Research Part I: Oceanographic Research Papers 41, 747-765.

Travers, A. y Travers, M., 1968. Les silicoflagellés du Golfe de Marseille. Mar. Biol. 1, 285288.

Travers, M., 1971. Diversité du microplancton du Golfe de Marseille en 1964. Marine Biology $8,308-343$.

Tréguer, P., Nelson, D.M., Van Bennekom, A.J., Demaster, D.J., Quéguiner, B. y Leynaert, A., 1995. The silica budget of the World Ocean: a re-estimate. . Science 268, 375-379.

Treppke, U.F., Lange, C.B. y Wefer, G., 1996. Vertical fuxes of diatoms and silicofagellates in the eastern equatorial Atlantic, and their contribution to the sedimentary record. Marine Micropaleontology 28, 73-96.

Ulses, C., Estournel, C., Durrieu de Madron, X. y Palanques, A., 2008a. Suspended sediment transport in the Gulf of Lions (NW Mediterranean): Impact of extreme storms and floods. Continental Shelf Research 28, 2048-2070.

Ulses, C., Estournel, C., Puig, P., Durrieu de Madron, X. y Marsaleix, P., 2008b. Dense shelf water cascading in the northwestern Mediterranean during the cold winter 2005: Quantification of the export through the Gulf of Lion and the Catalan margin. Geophysical Research Letters 35.

Usbeck, R., Schlitzer, R., Fischer, G. y Wefer, G., 2003. Particle fluxes in the ocean: comparison of sediment trap data with results from inverse modelling. Journal of marine systems 39, 167-183.

Van Bennekom, A.J., Berger, G.W., Van der Gaast, S.J. y de Vries, R.T.P., 1988. Primary productivity and the silica cycle in the Southern Ocean (Atlantic sector). Palaeogeography, Palaeoclimatology, Palaeoecology 67, 19-30.

Van Valkenburg, S.D., 1971a. Observations on the fine structure of Dictyocha fibula Ehrenberg. I. The skeleton. Journal of Phycology 7, 113-118.

Van Valkenburg, S.D., 1971b. Observations on the fine structure of Dictyocha fibula Ehrenberg. II. The protoplast. Journal of Phycology 7, 118-132.

Vénec-Peyré, M.T., 1990. Contribution of foraminifera to the study of recent sedimentation in the Gulf of Lions (western Mediterranean Sea). Continental Shelf Research 10, 869883.

Vergnaud-Grazzini, C., Caralp, M., J.C., F., Gonthier, E., Grousset, F., Pujol, C. y Saliège, J.F., 1989. Mediterranean Outflow through the Strait of Gibraltar since 1800 years B.P. Oceanologica Acta 12, 305-324. 
Vidussi, F., Marty, J.C. y Chiavérini, J., 2000. Phytoplankton pigment variations during the transition from spring bloom to oligotrophy in the Northwestern Mediterranean Sea. Deep-Sea Research I 47, 423-445.

Vignudelli, S., Cipollini, P., Astraldi, M., Gasparini, G.P. y Manzella, G., 2000. Integrated use of altimeter and in situ data for understanding the water exchanges between the Tyrrhenian and Ligurian Seas. Journal of Geophysical Research 105, 19649-19663.

Vignudelli, S., Gasparini, G.P., Astraldi, M. y Schiano, M.E., 1999. A possible influence of the North Atlantic Oscillation on the circulation of the Western Mediterranean Sea. Geophysical Research Letters 26, 623-626.

Villareal, T.A., Altabet, M.A. y Culver-Rymsza, K., 1993. Nitrogen transport by vertically migrating diatom mats in the North Pacific Ocean. Nature 363, 709-712.

Viúdez, A., Pinot, J.M. y Haney, R.L., 1998. On the upper layer circulation in the Alboran Sea. Journal of Geophysical Research 103, 21653-21666.

Waniek, J.J., Prien, R. y Koeve, W., 2000. Trajectories of sinking particles and the catchment areas above sediment traps in the northeast Atlantic. Journal of Marine Research 58, 983-1006.

Waniek, J.J., Schulz-Bull, D.E., Kuss, J. y Blanz, T., 2005. Long time series of deep water particle flux in three biogeochemical provinces of the northeast Atlantic. Journal of Marine Systems 56, 391-415.

Wanner, H., Rickli, R., Salvisberg, E., Schmutz, C. y Schuepp, M., 1997. Global Climate Change and its Influence on Alpine Climate: Concepts and Observations. Theoretical and Applied Climatology 58, 53-76.

Wassmann, P., Egge, J.K., Reigstad, M. y Aksnes, D., 1996. Influence of dissolved silicate on vertical flux of particulate biogenic matter. Marine Pollution Bulletin 33, 10-21.

Webster, P.J. y Palmer, T.N., 1997. The past and the future of El Nino. Nature 390, 562-564.

Werner, D., 1977. Introduction with a note on taxonomy, en: Werner, D. (Ed.), The biology of diatoms. University of California Press, Berkeley and New York, pp. 1-17.

Whitehead, J.M. y Bohaty, S.M., 2003. Pliocene summer sea surface temperature reconstruction using silicoflagellates from Southern Ocean ODP Site 1165. Paleoceanography 18, 1075 .

Williams, D.F., Bé, A.W.H. y Fairbanks, R.G., 1981. Seasonal stable isotopic variations in living planktonic foraminifera from bermuda plankton tows. Palaeogeography, Palaeoclimatology, Palaeoecology 33, 71-102.

Winter, A. y Siesser, W.G., 1994. Coccolithophores. Cambridge University Press.

Wüst, G., 1961. On the vertical circulation of the Mediterranean Sea. Journal of Geophysical Research 66, 3261-3271.

Young, J.R., 1994. Functions of coccoliths, en:Winter, A., Siesser, W.G.(Eds.), Coccolithophores. Cambridge University Press, Cambridge, pp. 63-82. 


\section{GLOSARIO}

Capa nefeloide: Se trata de una capa rica en materia particulada por encima del fondo oceánico. Su grosor depende de la velocidad de la corriente de fondo y es el resultado del balance entre el asentamiento gravitacional de las partículas y la turbulencia de la corriente.

Deep Chlorophyll Maximum (DCM): Máximo subsuperficial de concentración de clorofila.

Global radiation (radiación global): Suma de la radiación solar directa y difusa recibida por unidad de superficie.

Mooring: Es el conjunto de aparatos conectados por un cable anclado temporalmente al fondo del mar. Entre estos aparatos cabe destacar las trampas de sedimento y los correntímetros.

Nutriclina: rango de profundidades en el que el gradiente de concentración de nutrientes es máximo.

Progradación: Proceso por el que el continente gana terreno al mar por deposición de materiales en la región costera.

Sapropeles: Depósitos ricos en Carbono orgánico (carbono orgánico total superior al 2\% en peso) que pueden contener pirita en cantidades relativamente altas y altas concentraciones de elementos como el Azufre y Bario.

Sverdrup: Unidad de caudal o flujo. Un Sv. corresponde a $10^{6} \mathrm{~m}^{3} / \mathrm{s}$.

Termoclina: rango de profundidades por debajo de la superficie del agua en donde el gradiente de temperatura es máximo.

Upwelling (surgencia): Proceso por el cual aguas frías y normalmente ricas en nutrientes ascienden desde niveles inferiores de la columna hacia la superficie.

Viento catabático: El viento catabático (del griego katabatikos: "bajando colinas") se origina en un enfriamiento, radiativamente o a través de movimientos verticales, de aire en el punto más alto de una montaña, glaciar o cerro. Como la densidad del aire se incrementa con el descenso de la temperatura, el aire fluirá hacia abajo, calentándose por proceso adiabático al ir descendiendo pero sigue permaneciendo relativamente frío. 



\section{ACRÓNIMOS Y ABREVIATURAS}

A continuación, se enumeran alfabéticamente una recopilación de los acrónimos y las abreviaturas más utilizadas en esta tesis doctoral.

AW - Atlantic Waters

DSWC - Dense Shelf Water Cascading

EAG - Eastern Alboran Gyre

ENSO - El Niño Southern Oscillation

EMDW - Eastern Mediterranean Deep Water

GoL - Gulf of Lions

LIW - Levantine Intermediate Waters

mab - meters above bottom

MAW - Modified Atlantic Waters

MEM - Maximum Entropy Method

NAO - North Atlantic Oscillation

NC - Northern Current

PCA - Principal Component Analysis

psu - practical salinity unit

SST - Sea Surface Temperature

TDW - Tyrrhenian Dense Water

WAG - Western Alboran Gyre

WIW - Winter Intermediate Waters

WMDW - Western Mediterranean Deep Water

MOW - Modified Outflow Water

Sea-WIFS - Sea-viewing Wide Field-of-view Sensor

Sv - Sverdrup $\left(10^{6} \mathrm{~m}^{3} / \mathrm{s}\right)$ (unidad de caudal)

ZCIT - Zona de Convergencia Intertropical 
